Florida International University FIU Digital Commons

10-30-2015

\title{
In Search of Safety, Negotiating Everyday Forms of Risk: Sex Work, Criminalization, and HIV/AIDS in the Slums of Kampala
}

Serena Cruz

Florida International University, serena_cruz@yahoo.com

DOI: $10.25148 /$ etd.FIDC000213

Follow this and additional works at: https://digitalcommons.fiu.edu/etd

Part of the African History Commons, African Studies Commons, Community-Based Research Commons, Community Health and Preventive Medicine Commons, Comparative Politics Commons, Feminist, Gender, and Sexuality Studies Commons, Gender and Sexuality Commons,

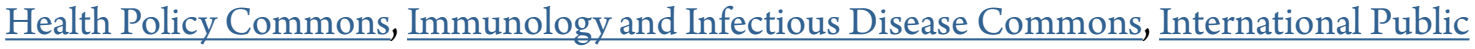
Health Commons, International Relations Commons, Medicine and Health Commons, Other Public Health Commons, Public Policy Commons, Quantitative, Qualitative, Comparative, and Historical Methodologies Commons, $\underline{\text { Social and Cultural Anthropology Commons, Social Policy }}$ $\underline{\text { Commons, Social Work Commons, and the Women's Health Commons }}$

\section{Recommended Citation}

Cruz, Serena, "In Search of Safety, Negotiating Everyday Forms of Risk: Sex Work, Criminalization, and HIV/AIDS in the Slums of Kampala" (2015). FIU Electronic Theses and Dissertations. 2293.

https://digitalcommons.fiu.edu/etd/2293 


\section{FLORIDA INTERNATIONAL UNIVERSITY}

Miami, Florida

IN SEARCH OF SAFETY, NEGOTIATING EVERYDAY FORMS OF RISK:

SEX WORK, CRIMINALIZATION, AND HIV/AIDS IN THE SLUMS OF KAMPALA

A dissertation submitted in partial fulfillment of the

requirements for the degree of

DOCTOR OF PHILOSOPHY

in

INTERNATIONAL RELATIONS

by

Serena Cruz

2015 
To: Dean John F. Stack, Jr.

Steven J. Green School of International and Public Affairs

This dissertation, written by Serena Cruz, and entitled In Search of Safety, Negotiating Everyday Forms of Risk: Sex Work, Criminalization, and HIV/AIDS in the Slums of Kampala, having been approved in respect to style and intellectual content, is referred to you for judgment.

We have read this dissertation and recommend that it be approved.

$\begin{array}{r}\hline \text { Richard S. Olson } \\ \hline \text { Susanne Zwingel } \\ \hline \text { Jean Muteba Rahier } \\ \hline \text { Aurora G. Morcillo } \\ \hline \text { John F. Clark, Major Professor }\end{array}$

Date of Defense: October 30, 2015

The dissertation of Serena Cruz is approved.

Dean John F. Stack, Jr. Steven J. Green School of International and Public Affairs

Dean Lakshmi N. Reddi University Graduate School

Florida International University, 2015 
(C) Copyright 2015 by Serena Cruz

All rights reserved. 


\section{DEDICATION}

I dedicate this dissertation to the women of Rubaga, the men of Makindye, and

the three and half men in my life_-Jim, John, Robert (and Lucien)—my holy trinity that saved my writing so my work could be found. 


\section{ACKNOWLEDGMENTS}

I am truly and forever grateful for Dr. John F. Clark, who stepped forward to become my supervisor, and ultimately a mentor and dear friend. His guidance allowed me to transition from student to peer and his unwavering support throughout the process of collecting data and writing this dissertation allowed me to believe completion was possible. I wish to acknowledge and thank Dr. Jean M. Rahier, Dr. Aurora Morcillo, Dr. Richard Olson, and Dr. Susanne Zwingel, who complete my committee. Their support and guidance throughout the research and writing process of this dissertation has been invaluable. Robert N. Tyrrell, thank you for loving me, partnering with me, and committing to me, and this project, when at times it all seemed beyond my reach. Susan Mori Silva, Daniela Bododea, and Olivia Glinski, you three came to my rescue by providing nurturing care for my son Lucien. By doing so, you eased my worries and allowed me to carve out the necessary room of my own, so I could realize the end of this dissertation. James Jefferson Rice, my Dissertation Coach, who urged me along from the sidelines, I am truly humbled and forever honored by your gift of support and never ending and steadfast belief in my success, even from the beginning. Thank you, always, for guiding, cheering-on, and at times caging my mad dog tendencies, as I strived to connect with my true academic heart.

They say it takes a village to raise children. I now believe the same is true for doctoral dissertations. I want to thank my parents, Joe and Alma Cruz, my sister Adrienne Cruz, and my dearest Aunt Carmen and Uncle Walter, for all their years of listening and patience for my almost eternal student-status. Richard Gioioso, Amy Ritterbusch, Monalisa Gangopadhyay, Diana Ter-Ghazaryan, Sara Rice, Alycia Lee De 
Kraa, Jacob Doherty, Erin Moore, Brooke Bocast, Melissa Minor, Melina Platas Izama, Janneke Verheijen, Donny Martens, Ariel Sanchez Meertens, Sandra Quintero, Tiffany Zientz Heckler, Sophie Brion, Meredith Beattie, Kerstin Carlson, Katie Gleason, Kimberly Marie Brown, Aine Campbell, Florence Muhanguzi Kyoheirwe, Wilfred Kabunga, Stella Nyanzi, Kristen Cheney, Helen Hintjens, Ivan Briscoe and many others gave their support along the way. I thank you all for offering countless hours of listening, informal advising, and/or outright therapy.

I want to thank Marie Stopes Uganda, particularly Julia Mayersohn, for giving me the chance to test my ideas and deepen my findings. I am grateful for the support of Soa Aids Nederland, especially Mark Vermeulen and Marieke Ridder-Wiskerke, who helped to keep my ideas practical and connected to the daily lives of women and men living with HIV/AIDS in Kampala. To Mariska van Beijnum and Rosan Smits, thank you not only for holding a place for me in the Conflict Research Unit of Clingendael, but also for giving me the time and space I needed to be both a research fellow and an academic. I am also thankful for the care, kindness, and protection of my Ugandan family, Mr. and Mrs. Kazinda, who helped keep me safe, clean, and healthy in Makindye. I give special thanks to Beyonce, Hajarah, and Diana, for standing beside me even when it was uncertain if I would be able to continue. I am especially grateful for the assistance of Daisy, Rose, Sarah, Gloria, and George, who made it possible for my research to endure. Finally, the words on these pages have no meaning, no reality, and no substance without every woman and man, who chose to connect with me during the arduous fourteen months of primary data collection in Kampala, thank you, forevermore. 
Institutional support came in the form of guidance, affiliation, and funding. I am especially thankful for the help of Maria C. Wilkinson-Diaz from the Department of Politics and International Relations, who came to my aid as I approached my D-5 submission. I also want to thank Sanya Checo in the Financial Aid Department, who kept me afloat by making sure my research funds came through while I was in Kampala. I give special thanks to Brandie Thomas, the UGS ETD Coordinator, who patiently guided me through the final editorial and electronic submission process. I am eternally grateful for the guidance and assistance of the United States Embassy in Kampala, especially Mr. Daniel Travis, who provided security information and instructions at a critical time in the data collection. I am thankful for the Department of Women and Gender Studies at Makerere University, particularly Dr. Consolata Kabonesa, Dr. Grace Bantebya Kyomuhendo, and Dr. Florence Muhanguzi for their gracious and generous support of my affiliation with Makerere University. Funding for this research was granted by Florida International University in the form of the Doctoral Evidence Acquisition Fellowship and the Shepard Broad Fellowship. Any opinions expressed in this dissertation are those of the author and do not represent the views of the funding institutions. 


\begin{abstract}
OF THE DISSERTATION
IN SEARCH OF SAFETY, NEGOTIATING EVERDAY FORMS OF RISKS: SEX WORK, CRIMINALIZATION, AND HIV/AIDS IN THE SLUMS OF KAMPALA

by
\end{abstract}

Serena Cruz

Florida International University, 2015

Miami, Florida

Professor John F. Clark, Major Professor

This dissertation offers an in-depth descriptive account of how women manage daily risks associated with sex work, criminalization, and HIV/AIDS. Primary data collection took place within two slums in Kampala, Uganda over the course of fourteen months. The emphasis was on ethnographic methodologies involving participant observation and informal and unstructured interviewing. Insights from this research process then informed document analysis of international and national policies concerning HIV/AIDS prevention and treatment strategies in the context of Uganda.

The dissertation finds social networks and social capital provide the basis for community formation in the sex trade. It holds that these interpersonal processes are necessary components for how women manage daily risks associated with sex work and criminalization. However, the dissertation also finds that women's social connections can undermine the strategies they need to manage their HIV/AIDS prevention and treatment.

Consequently, the dissertation concludes that social connections undermine current HIV/AIDS policies because clinical HIV/AIDS interventions have been found to prioritize individual behavioral change practices that impair the complex interpersonal 
activities developed by women to stay alive. In response, this dissertation asserts that social networks are fundamental to the formation of sex work communities and to the survival of women in the sex trade and should be considered in future HIV policies and programs intending to intervene in the HIV epidemic of female commercial sex workers in Kampala, Uganda. 


\section{TABLE OF CONTENTS}

CHAPTER

PAGE

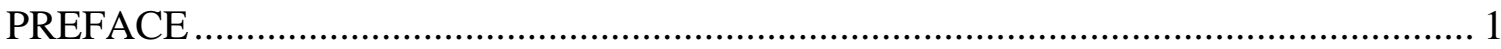

Breaking the Silence of Experience: An Introduction of What Happened .............. 1

People, Policy, and Purpose................................................................................ 3

I. GOING TO WORK IN THE SLUMS - SEX WORK, HIV, AND RISK................. 5

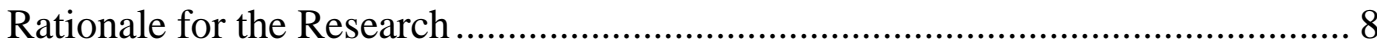

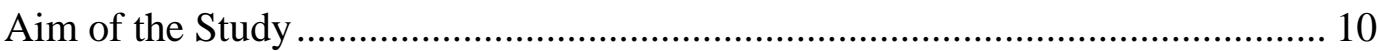

Design of the Study .................................................................................. 12

Research Locations, Assistance, and Challenges ............................................. 15

Outline of the Dissertation ................................................................................... 19

II. SEX WORK, CRIMINALIZATION, AND HIV/AIDS IN KAMPALA ................. 23

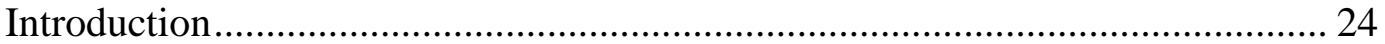

From the Comforts of Home to Letting them Die: The literature on Sex

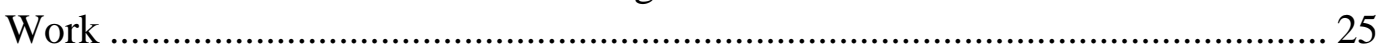

Category one: Sex work and colonial expansion.......................................26

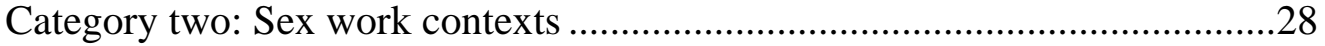

Category three: Sex work risks ..................................................................32

Category four: Sex work and HIV interventions ..........................................36

The Rewards of Candor: Uganda's HIV History and the Discourse of AIDS

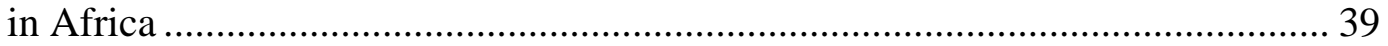

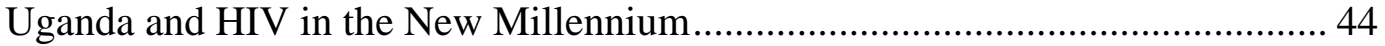

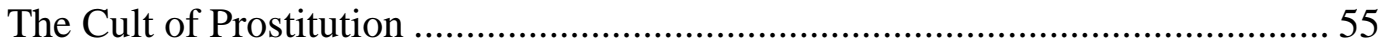

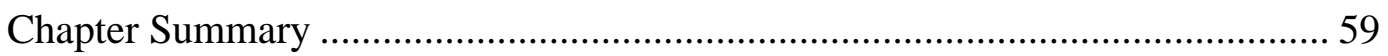

III. THE LINKS BETWEEN READING AND WRITING: A CASE FOR

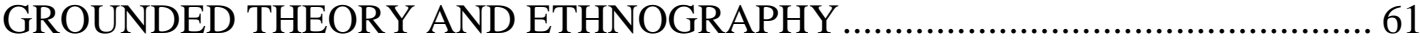

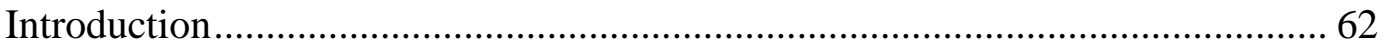

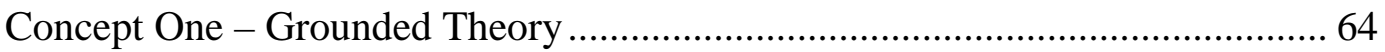

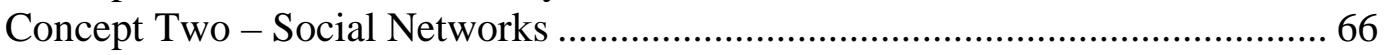

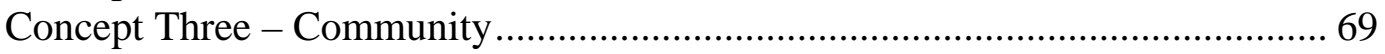

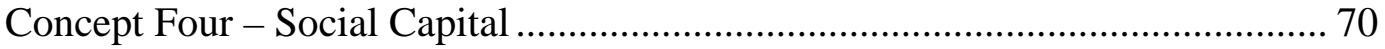

Concept Five - Ethnography .......................................................................... 72

Ethnography and the Hard to Reach: Before, during, and writing the research ............................................................................................. 72

Ethnographic templates of vulnerability: Illness and the Everyday ................74

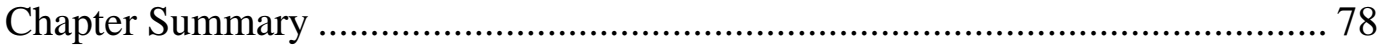




\section{THE COMFORTS OF COMMUNITY: FINDINGS FROM A BROTHEL}

COMPOUND IN RUBAGA ……………………................................................ 82

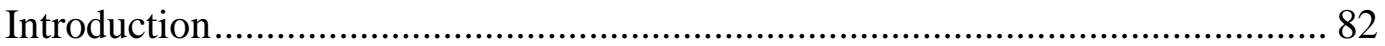

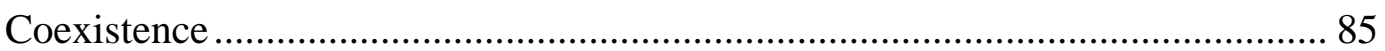

If These Walls Could Talk.....................................................................86

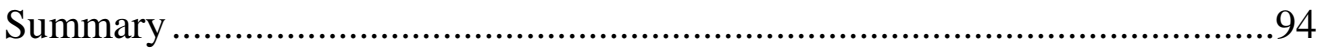

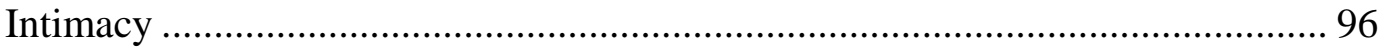

Queen Bees and Wannabes......................................................................99

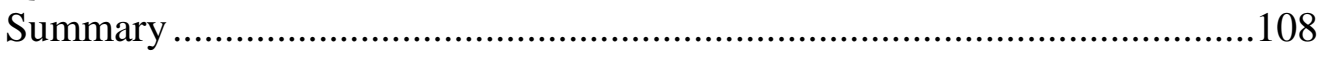

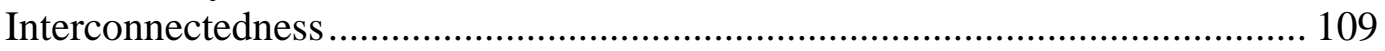

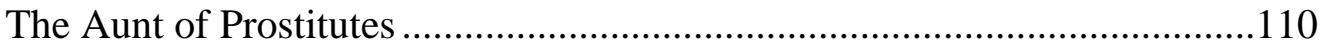

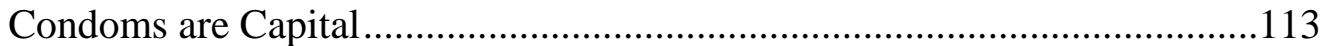

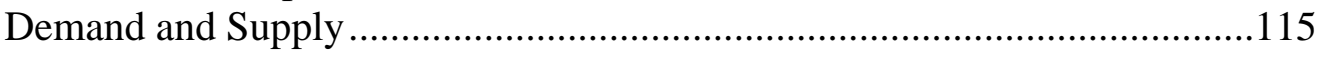

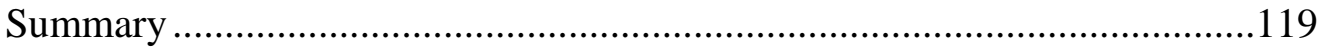

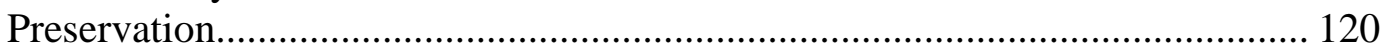

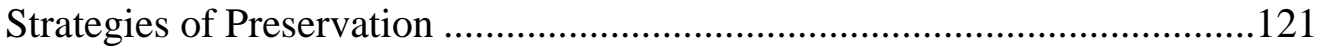

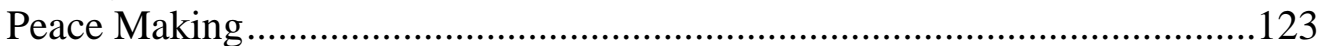

Lost and Found ...................................................................................125

Scarcity and the Paradox of Friendship ...................................................127

Secrecy, Silence, and Shame ............................................................128

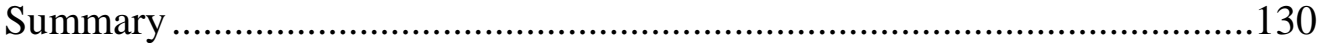

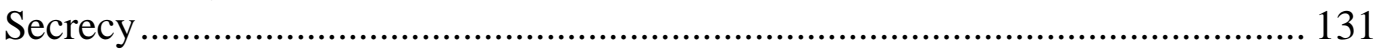

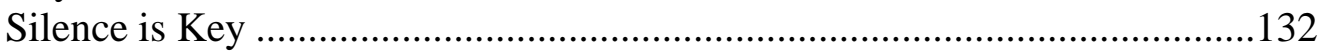

Pragmatics of Privacy .......................................................................136

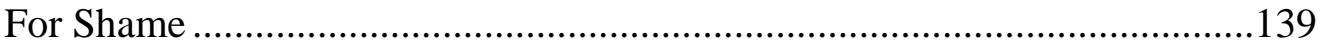

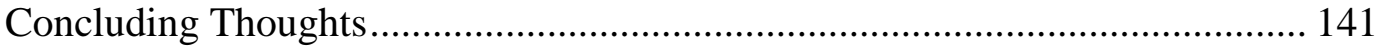

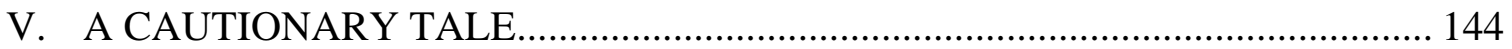

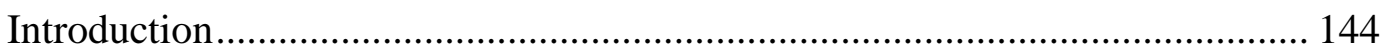

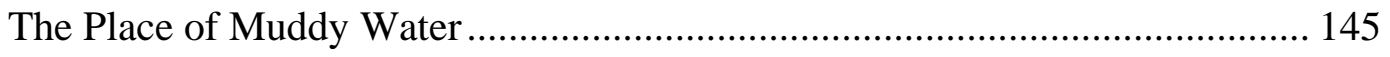

I have my cameras - Christian ........................................................................ 147

That is the very place where I was working - Rico........................................... 149

The others leave their concerns to us - Landlord ............................................. 151

My coming is because I always see you here - Sebastian................................. 155

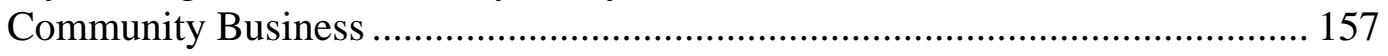

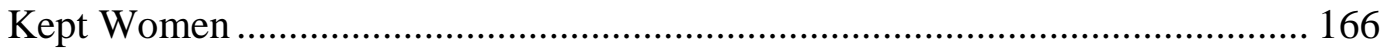

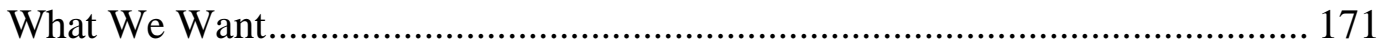




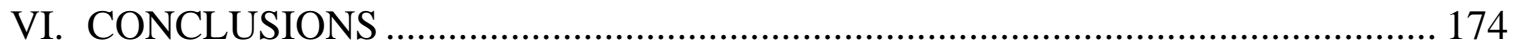

Reflections on Managing Each Day ................................................................. 174

Virtue, Decency, and Domesticity: The Necessary Trinity for Women in

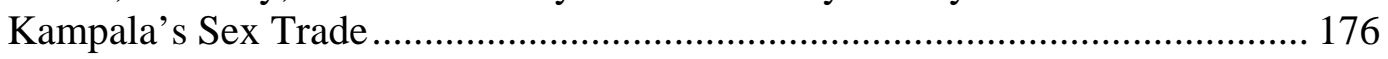

Volatile Circumstances and Compromising Social Networks........................... 179

A Haven for Hopes ................................................................................. 183

The Making of New AIDS Policies: Prescriptions for Intervention.................. 187

Meeting the Needs of Sex Work Communities ................................................ 190

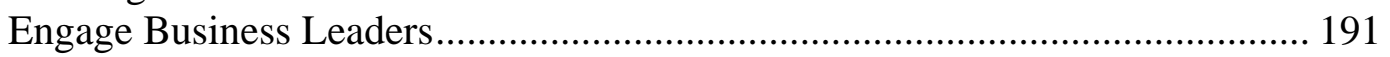

Incorporate the Police ................................................................................... 193

Community Approaches to Preventing and Treating HIV/AIDS ....................... 194

Second Chances and Further Research ........................................................... 202

Endings and New Beginnings ................................................................. 206

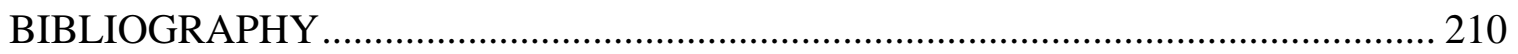

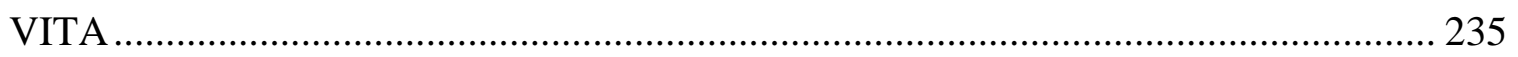




\section{LIST OF FIGURES}

FIGURE

PAGE

Figure 1.1 - Email message from Dr. Helen Epstein .................................................. 5

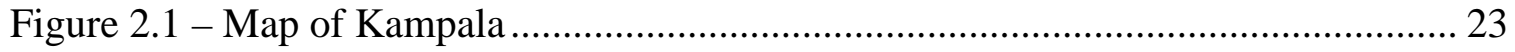

Figure 4.1 - Picture of outside Babito brothel .......................................................... 82

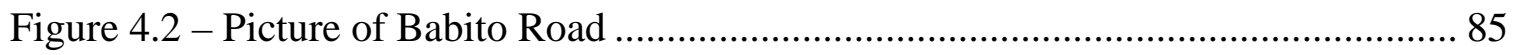

Figure 4.3 - Picture of inside Babito brothel.......................................................... 96

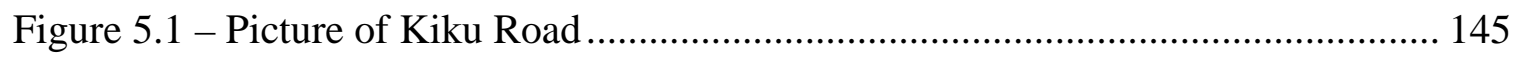

Figure 5.2 - Picture of inside Mr. Z's brothel ....................................................... 149

Figure 5.3 - Picture of the entrance to Landlord's bar and brothel ............................. 151

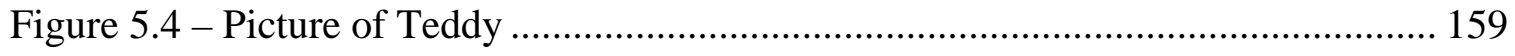

Figure 5.5 - Picture of room 95 in Landlord's brothel ........................................... 166

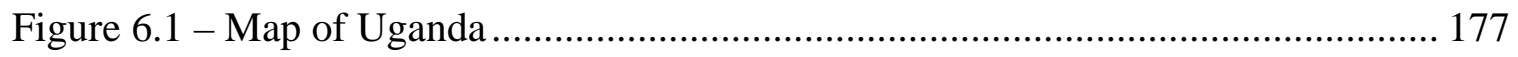




\section{ACRONYMS}

ABC Abstinence, being faithful, using condoms

ABC+ $+\quad$ Abstinence, being faithful, using condoms + linking to other prevention and care interventions

ABCD Abstinence, being faithful, using condoms, death

AIDS Acquired immune deficiency syndrome

ART Antiretroviral treatment

ARV

Antiretroviral therapy

CD4 T-lymphocyte cell bearing CD4 receptor

CHANGE Center for Health and Gender Equity

DFID Department for International Development

DRC Democratic Republic of Congo

FCSW $\quad$ Female commercial sex workers

HBV Hepatitis B virus

HIV Human immunodeficiency virus

HSSIP Health sector strategic investment plan

IMF International Monetary Fund

IR International relations

KLA Kampala

MARPI Most at-risk populations initiative

MARPs Most at-risk populations

MSU Marie Stopes Uganda

NGO Non-governmental organization 


\begin{tabular}{|c|c|}
\hline NHSBS & Uganda's National Sero and Behaviour Survey [sic] \\
\hline NPS & National prevention strategy \\
\hline NSP & National strategic plan \\
\hline PEP & Post-Exposure Prophylaxis \\
\hline PEPFAR & United States President's Emergency Plan for AIDS Relief \\
\hline PLHIV & People living with HIV \\
\hline PMTCT & Prevention of mother-to-child transmission of HIV \\
\hline PSI & Population Services International \\
\hline SNA & Social network analysis \\
\hline STI & Sexually transmitted infection \\
\hline TB & Tuberculosis \\
\hline UGX & Ugandan Shillings \\
\hline UK & United Kingdom \\
\hline UNAIDS & Joint United Nations Programme on HIV/AIDS [sic] \\
\hline UNFPA & United Nations Population Fund \\
\hline US & Untied States \\
\hline US\$ & United States Dollar \\
\hline WHO & World Health Organization \\
\hline WIPO & World Intellectual Property Organization \\
\hline WISH & $\begin{array}{l}\text { Sex worker-led NGO entitled "Women's Individual efforts for Sex } \\
\text { Workers Human Rights” in Kampala, Uganda (not real name) }\end{array}$ \\
\hline
\end{tabular}




\section{PREFACE}

"It seemed as if the academic world had imposed a conspiracy of silence regarding the personal experiences of field workers...I decided to fill this gap...in undertaking this task it seemed important to be as honest about myself as I possibly could be" (Whyte 1993: 358-359)

\section{Breaking the Silence of Experience: An Introduction of What Happened ${ }^{1}$}

The data collection for this dissertation informally began in the city of Amsterdam sometime in October 2009. Staying in Amsterdam readily affords accessibility to events concerning the topic of commercial sex work. As a result, my research project was able to capitalize on a networking function related to sex work and criminalization. There I met the executive director of a sex worker-led NGO in Kampala, Uganda, called WISH.

Mickey, a charismatic and passionate panel speaker for the event, quickly agreed to share her Skype contact information and email address when we spoke during the reception. The impetus for connecting with Mickey came about while listening to her describe the difficulties facing sex workers in Kampala. Mickey shared that sex workers in Kampala are suffering and their suffering is at the hands of police and clients. As a result of this abuse, Mickey believed sex workers were getting sick with AIDS. Her analysis of their vulnerability was compelling and it offered a fresh lens through which to explore international policy to curtail the spread of AIDS—-policies, such as the United States President's Emergency Plan for AIDS Relief (PEPFAR). At the time PEPFAR had inculcated a policy practice of defunding organizations and/or projects explicitly linked to sex work (Center for Health and Gender Equity (CHANGE) 2008). Known by critics

\footnotetext{
${ }^{1}$ Through out this entire dissertation the majority of names for people and organizations have been changed to protect privacy. An informant key was developed and has been securitized through computer password protections and storage systems.
} 
as the "prostitution pledge", the policy approach was described as a means of preventing the sale of women and girls into the sex trade-a way to end sex trafficking (PEPFAR 2007). Unfortunately, the language in the policy statement was just murky enough to cause a funding panic, whereby many small and/or local NGOs working with "high risk" populations were being systematically stripped of funds or denied funding for HIV prevention projects (Pisani 2008). Mickey was in Amsterdam as a guest of the local Women's Fund. Her goal was not only to raise awareness about the plight of sex workers in Kampala, but also to attract resources to counter this critical funding shortfall.

I believe my interest in Mickey’s stories about her work with WISH, could be interpreted by her as a means of facilitating support. Over the course of one year Mickey and I stayed in contact through Skype and email. Our exchanges and discussions concerned project developments taking place at the NGO, as well as my funding efforts to visit the organization and the sex workers being helped. Eventually, I managed to raise funds to visit Kampala for November $2010 .^{2}$

Through a series of mutual contacts I secured accommodations in a small village just south of Kampala. Days were spent volunteering for Mickey’s organization. Duties included editing manuals and reports, writing a sex worker safety tool kit, and, observing staff “outreaches” ${ }^{3}$ taking place in sex work communities throughout Kampala. In

\footnotetext{
${ }^{2}$ Between December 2009 and February 2012 the Netherlands Ministry of Foreign Affairs hired me as an external gender consultant. The work involved regular travel between Amsterdam, Rwanda, and DR Congo, in order to conduct ethnographically inspired policy research concerning donor responses to gender-based sexual violence in Eastern DRC. As a result of this project, I was able to raise resources, as well as organize my schedule in the region, to allow me the time and the money for my pursuing predissertation data collection fieldwork in November 2010.

3 "Outreaches" are how the NGO staff referred to carrying out what is known in public health services as "community-outreaches". These visits included traveling to different neighborhoods in Kampala to deliver condoms, speak with women and men in the sex trade, gather personal contact information from these
} 
exchange for my help, Mickey committed to assisting my access to relevant information for my dissertation proposal. ${ }^{4}$

In order to develop a dissertation proposal it was important that I immerse myself, as much as possible, into the daily routines of the NGO. Doing so allowed me to cultivate ties with staff. These relationships offered a chance to attend outreaches at night. The combination of day and night visitations within the sex work areas provided a means of comparing and contrasting how women behaved in relation to the presence of men. My observations, in turn, began a series of internal questions concerning women's daily routines, their relationships with men and other women, and the resources they devise to counter explicit threats to their individual safety and security (gossip, coercive practices, jealousies, in-fighting, theft, police violence, abuse, and/or rape within their respective communities). I departed Uganda, with these thoughts in mind and eventually developed a successfully funded proposal that allowed me to move to Kampala on 2 June 2012.

\section{People, Policy, and Purpose}

Ultimately, this dissertation is about policy. Specifically it is about the policy of HIV/AIDS relief in the East African context. Rather than beginning with an exploration of how HIV/AIDS policies impact people, this dissertation first describes how daily survival for women selling sex in Kampala has implications for policy designed to prevent and treat HIV/AIDS. At its core the research of this dissertation is concerned

\footnotetext{
women and men (i.e. names and cell phone numbers), and provide vouchers for free or discounted services (i.e. family planning and/or HIV testing and treatment) services at either a local AIDS clinic or Marie Stopes Uganda (MSU).

${ }^{4}$ Prior to advancing for candidacy I successfully passed, with distinction, comprehensive examination questions explicitly concerned with ethnography (history, cultural turn, self-reflexivity, subject positions, and utility), feminist ethnography, and feminist dilemmas in theory and fieldwork.
} 
with the challenges of what happens to HIV/AIDS polices when they are introduced on the ground and taken up by hard-to-reach populations.

Primary data was collected for over fourteen months from two slums in Kampala Uganda. In the vein of pursuing grounded theoretical research (Brown 2012; Bryant and Charmaz 2013; Charmaz 2014; Glaser and Strauss 1967), and practicing the larger tradition of ethnographies concerned with everyday practices and vulnerability (Bourgois et. al. 1997; Cheney 2007; Farmer 2006; Hunter 2002 and 2010; Parker 2000; ScheperHughes 1992, 1996, 2004; van den Borne 2005; Verheijen 2014), the objective of my data collection was to understand how the minutiae of women's daily survival stands in the way of a particular logic inherent in HIV/AIDS prevention and treatment strategies. Together this literature informs the basis for the findings in this dissertation. A basis that comes from months of sitting, watching, and talking inside brothels, bedrooms, lodges, guesthouse corridors, and bars. From inside these places I documented how HIV/AIDS policies come to die, become reimagined, and/or get manipulated in order to fit the purposes of interpersonal connection and communal fealty in the slum. 


\section{CHAPTER I}

\section{GOING TO WORK IN THE SLUMS - SEX WORK, HIV, AND RISK}

\section{Figure 1.1 - Email message from Dr. Helen Epstein}

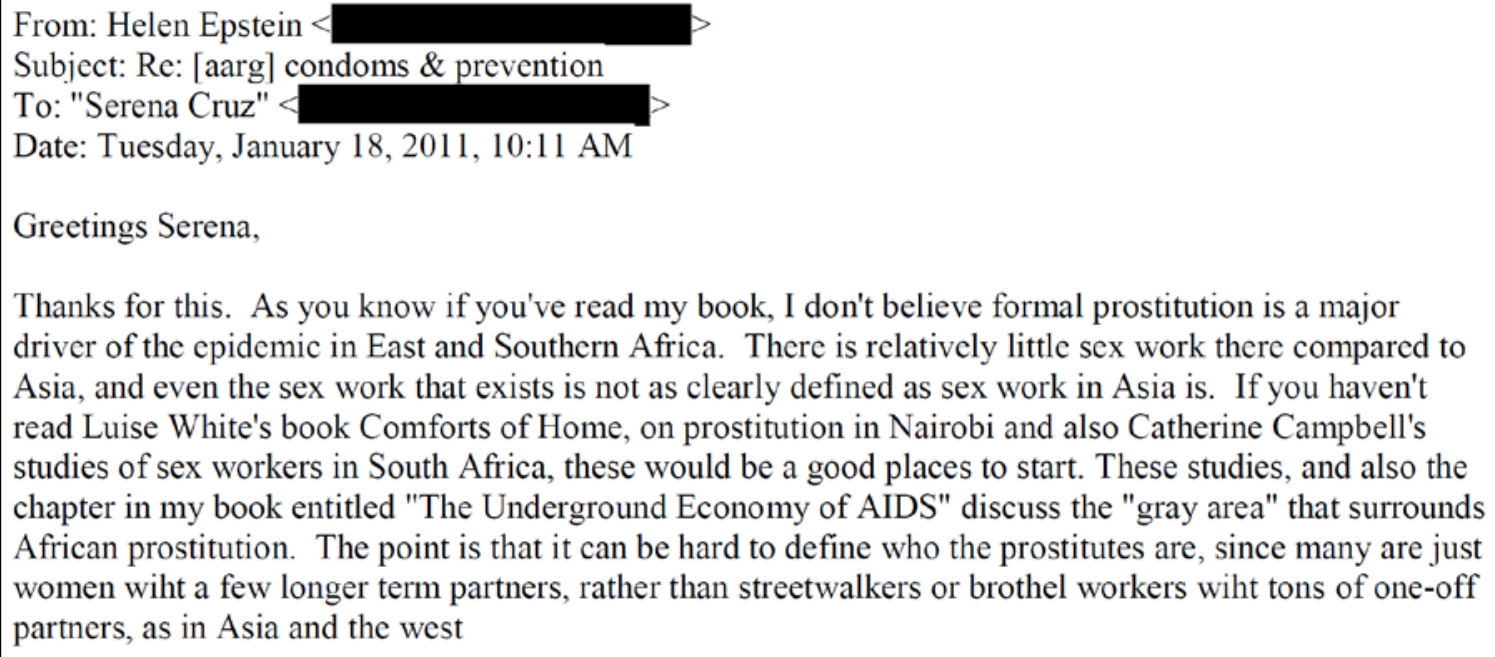

There are some formal prostitutes in Kampala, who mainly service transient men; but even UNAIDS admits that the majority (I would say the VAST majority) of HIV transmission in East Africa has nothing to do with formal sex work. During the late 1990s, the World Bank had a giant "STI" project that was meant to target "high risk groups" like prostitutes, etc with condoms and sti treatment. It was very enlightened, no abstinence at all etc. But HIV incidence either stayed the same or rose during this time. You can get the reports online. It was manged by someone named

Having said this, there are prostitutes in KLA (as everywhere) and the government has policies for them. You should chat to at the Uganda AIDS Commission; he can help you out. You should also interview them. When I did (in 2003) they all had comdoms and said they were easy to get; someone in the Ministry of Health even wanted to hold a celebration because their condom use rates were so high. The "ABC" policy, which came in the following year, did not affect their access, as far as I could tell--except perhaps briefly during hte shortages, which were a disaster; but the $\mathrm{ABC}$ programs were mainly designed to give more $\$$ to programs run by Bush's evangelical friends.

Cheers, Helen [sic]

Eighteen months before moving to Kampala I received the above email from Dr. Helen Epstein, author of the book The Invisible Cure (2007). Now just over four years later I know much of what Dr. Epstein shared in her message is incomplete. Perhaps I sensed something was amiss even when I first read Dr. Epstein’s email. Yet it would take, in total, more than 16 months of grounded ethnographic fieldwork, spanning three 
years to possess enough knowledge to identify the gaps in her message. In filling Epstein’s gaps I offer knowledge, amassed from women’s everyday practices, presented in "story-like” form. ${ }^{5}$ That is I narrate how women, who explicitly engage in commercial sex work, navigate vulnerable circumstances. To accomplish this task I am fortunate to be entrusted with women’s personal histories and to document their daily events through observation and participation in their everyday socializing.

While I set-out to collect data from two distinct communities, the answers to my central research question — that is both my findings and my writing —are anchored by my ethnographic experience in the first location, a brothel setting in Rubaga Division. Risk runs deeply throughout my second research site, a slum-based sex work community in Makindye Division. ${ }^{6}$ But my ability to gain and maintain access to this second location was severely encumbered, restricted, and at times prevented with outright hostility by men associated with the area's brothel ownership and management. As a result the data from the second location I collected, when analyzed, is limited. My findings from the second community reveal only how men experience risk—specifically the ways men seek control over their peers and important sex-work related material resources in order to minimize threats to their income generation, social capital, networks, and ultimately respect. While the data at this second site does not speak directly to my central research

\footnotetext{
${ }^{5}$ While this dissertation discusses sex work and the term "female commercial sex workers" (FCSWs), my preference is to describe and discuss these individuals as women. When possible I will defer to them as women and only use the terms "sex worker" or "female commercial sex worker" when necessary, as a result of literature and/or a critical discussion of documents being reviewed.

${ }^{6}$ In chapter five I provide a detailed description of the research site in Makindye Division.
} 
question, it does have implications for future research and policies. I reflect upon this indirect evidence in chapter five of the dissertation.

When I set out to answer the central question driving this dissertation it was important to explore two overarching lines of inquiry: (1) the first concerns understanding how women selling sex in Kampala slums manage risks associated with sex work, criminalization, and HIV/AIDS, and (2) the second considers the implications of women's risk management practices for policy approaches to prevent and treat HIV/AIDS in the East African context. Both tasks came about in response to three realities shaping the international discussion about AIDS in Africa. The first is the ongoing commitment of the United States government to continue funding a multi-billion dollar emergency response to HIV/AIDS in Africa (PEPFAR 2007). The second is the ongoing use of Uganda as an exemplar case on the continent of Africa for successfully battling HIV/AIDS (Boone and Batsell 2001; Epstein 2007; Kuhanen 2008; Pisani 2008; Singh, et al. 2003; Thornton 2008). The last is the poorly documented statistics concerning the high percentage of women in Kampala that are practicing "high-risk" commercial sex and who are HIV positive (Vandepitte et al. 2011.)

The third point involves the publication of a study (Vandepitte et al. 2011) calling attention to an HIV statistic not included in the HIV/AIDS success narrative of Uganda, one that has been explicitly neglected in the US response to AIDS in Africa (Center for Health and Gender Equity 2004; Dietrich 2007; PEPFAR Watch 2011). The combined research, history, and policy regarding Uganda's HIV epidemic, provided the impetus I needed to explore how women manage daily risks associated with sex work, criminalization, and HIV/AIDS in the slums of Kampala. To address the concerns of my 
research I believed it was important to begin with the research on HIV rates for women engaging in sex work from within Kampala’s slums.

\section{Rationale for the Research}

Vandepitte et al. reported in their 2011 study that one in three women in Kampala practicing "high risk" sex in the form of commercial sex work is HIV positive (Vandepitte et al. 2011: 316). The study targeted a sample population of 1000 women. Eligible participants, over the age of 18, had disclosed practicing commercial sex work, which was defined as receiving money, goods, or other favors in exchange for sex (Vandepitte et al.: 317), and/or maintained employment in Kampala's entertainment sector (bars, discos, and/or pool-halls). Women were enrolled in the study through the Good Health for Women Project. Recruitment took place in two areas of Kampala, Rubaga and Makindye Divisions, with the help of peer-educators who had been trained by staff from the project (Vandepitte et al.: 317). Women participating in the study provided urine for analysis and were given rapid HIV tests, malaria smears, syphilis tests, and vaginal examinations in which tissue samples were collected (Vandepitte et al.: 316). These activities took place in a health center located in Makindye Division. In addition to laboratory tests, women engaged in semi-structured interviews. During the interviews, women were asked to provide information concerning their "socio-demographic and economic status, sexual risk behavior, alcohol and illicit drug use, intra-vaginal practices, reproductive health, and STI symptoms” (Vandepitte et al.: 317).

Of the 1000 women screened and interviewed between February 2008 and April 2009 the HIV prevalence was 37\% (Vandepitte et al.: 318). Of those found HIV positive there was a strong association with specific socio-demographic factors, specifically: 
"women 35 or older, lower levels or no education, being widowed, recruiting clients on the street, not knowing HIV status, never having been tested for HIV, and alcohol use” (Vandepitte et al.: 320-321). Juxtaposing the HIV statistic found in the study alongside national figures for Uganda's epidemic, it seems "the prevalence of HIV is very high [as] compared with the national prevalence $(6.4 \%)^{7}$ and with the prevalence among the general population of women from Kampala (12\%) [sic]" (Vandepitte et al.: 322). This study, as well as previous research, identifies a need for specific HIV prevention interventions with vulnerable populations such as sex workers (Atwiine et al. 2000; Bukenya et al. 2013; Vandepitte et al. 2011) and calls attention to how "established general care health services may not cater adequately for their specific needs and accessibility may be hampered due to perceived stigma and misconceptions" (Vandepitte et al. 2011: 322).

These statistics, as well as the study's (Vandepitte et al. 2011) call for improvements in care in Uganda's national HIV/AIDS policy strategies make compelling reasons for further research. At the outset of my research project it seemed that the population sampled in the Vandepitte et al. (2011) study was only identified as a means of responding to the lack of epidemiological data concerning Kampala's female commercial sex work population. In this way, the Vandepitte et al. (2011) study provides little information about women’s actual risk management practices beyond documenting HIV prevalence and discussing specific socio-demographic patterns related to prevalence.

\footnotetext{
${ }^{7}$ As of the publication of Vandepitte (et. al.) (2011), the national statistic held. However in 2012 new figures were released showing the national average had increased to 7.2\% (Republic of Uganda: National Strategic Plan for HIV/AIDS 2011/12-2014/15, 2012).
} 
As a result, gathering this information about daily risk management is the primary task for the analysis of this dissertation.

\section{Aim of the Study}

The data presented in this dissertation aims to describe how women survive each day under the rubric of Uganda's national HIV policy, a national policy intended for people living with HIV (PLHIV). ${ }^{8}$ The objective of the policy is to prevent the spread of HIV as well as provide treatment for those infected with low cost and/or free ARVs. Uganda's national HIV policy is based on evidence about the disease taken from the general population (Mulder et al. 1994; Mulder et al. 1995; Kamali et al. 2000; Mbulaiteye et al. 2002; Shafer et al. 2008). Considering the contrast between the country's HIV policy and the basis of the Vandepitte et al. (2011), my study approaches daily risk management (in terms of economic, political, and social safety) from the perspective of women living at the margins of Ugandan society.

The perspective of this dissertation prioritizes a particularly "hard-to-reach population” receiving scant attention from outside Uganda (Bukenya et al. 2013; Gysels et al. 2002; Mbonye et al. 2012; Mbonye et al. 2013; Scorgie et al. 2013; Sentumbwe 2010; Ssemwanga et al. 2012; Tamale 2011 and 2011; Twinomugisha 2012; Zalwango et al. 2010). Implicitly, dismissing this population as unimportant limits consideration towards understanding the interconnectivity of their HIV risks with the risks prevailing among Uganda’s general population (Epstein 2007; Epstein and Morris 2011; Morris et al. 1996). The dismissal, in part, is because women engaging in commercial sex work in

\footnotetext{
${ }^{8}$ I am specifically focusing on the following policies: Republic of Uganda National Strategic Plan 2011/12 - 2014/15, 2012 and Republic of Uganda Global AIDS Response Progress Report 2012.
} 
Kampala slums are a particularly hard-to-reach population. Prior to undertaking my research, little had been known and/or understood about how these women experience HIV risks and how the conditions and people in their environments mediate these risks.

Thus by choosing to delve into the sociability of women's risk management, it was important that I review an extensive body of literature. To begin, I considered studies pertaining to risks associated with sex work. From there, I included research about risks specific to sex work and the overlap between risk of HIV/AIDS in the context of SubSaharan Africa (Bukenya et al. 2013; Campbell 2000; Campbell 2003; Gysels et al. 2002; Jewkes et al. 2003; Quarraisha et al. 1995; Kyonkunzire 2006; Munoz et al. 2010; Mbonye et al. 2012; Mbonye et al. 2013; Plus News Global 2011; Scorgie et al. 2013; Sentumbwe 2010; Ssemwanga et al. 2012; Ssemwanga et al. 2012; Tamale 2009 and 2011; Twinomugisha 2012; Zalwango et al. 2010). After my analysis of the literature, I identified the need for flexible and iterative theoretical and methodological tools (Bryant and Charmaz 2013; Charmaz 2014). It was important that I use techniques that could accommodate rapid changes in the environment and with the individuals participating in the study. As I sought methods to best explore my subject, I soon realized most studies pursued information about women's daily risks with sex work, criminalization, and HIV/AIDS without considering women's experiences in connection to their larger social networks or without engaging in longer-term observation and participation in women's everyday practices (Bukenya et al. 2013; Gysels et al. 2002; Mbonye et al. 2012; Mbonye et al. 2013; Scorgie et al. 2013; Sentumbwe 2010; Ssemwanga et al. 2012; Ssemwanga et al. 2012; Tamale 2009 and 2011; Twinomugisha 2012; Vandepitte et al. 2011; Zalwango et al. 2010). 


\section{Design of the Study}

In contrast to the literature I surveyed, my study focuses on the way women's interpersonal experiences shape how they mitigate hazards connected with their environments and their illnesses. To do so, it was important for me to first address ways research about HIV and sex work often fails to incorporate the social dimensions of risk in terms of root causes and resolutions.

The literature on risk is extensive. However, this dissertation prioritizes the meanings of risk that emerged from the findings. This means understanding risk in terms of its everyday meaning - the immediate and intimate ways risk shapes daily life. Briefly, data from my research found risk to be a social process. Risk develops between people and often directly in response to ways women and men attempt to survive in the slum. In this way, my research found risk to be omnipresent and multifaceted in both research locations. As a result women and men engage in social behaviors as a means of addressing as many risks at possible, at one time. In doing so, they often have to choose between competing risks. Their choices often reflect a social process I refer to as the “sociability of risk”, which I discuss more fully in chapters four and five.

Prior to the data collection several studies were consulted in order to help provide a basis of understanding risk in relation to HIV and sex work. These include Bourgois et al. 1997; Cusick 2006; Gysels et al. 2002; Harcourt and Donovan 2005; Karim et al. 1995; Kohler et al. 2007; Nagot et al. 2002; Pyett and Warr 1997 and 1999; Rekart 2005; Rhodes 2002; Robinson and Yeh 2007; Shannon et al. 2007; Vandepitte et al. 2011; Wechsberg et al. 2005; Wolfers 2001; Wojcicki and Malala 2001. These studies primarily operationalize risk in relation to violence, violation, and vulnerability, with particular 
focus on "factors exogenous to the individual that interact to increase vulnerability to HIV infection referring to spaces—both physical and social—in which risk is produced and reproduced” (Shannon et al. 2007: 912).

In thinking about the sociability of risk, I began by considering the failing of what Verheijen calls the "transactional sex model" (Verheijen 2011: 116). According to Verheijen, the model assumes women's risks can be mediated by improvements to their financial security. Meaning, women will make safer choices about sex once there is less pressure on their livelihoods (Verheijen 2011). The assumption here, as Verheijen rightly asserts, is that women's sexual choices are simply reflections of their social inequality, specifically, the gendered nature of their disempowerment and poverty (Verheijen 2011: 1). Verheijen brings attention to how the model is continuously used as a viable explanation for the ongoing spread of HIV throughout Sub-Saharan Africa, while simultaneously maintaining a discourse of women as powerless and subject to poordecision making (Verheijen 2011: 116). In response, Verheijen calls for a broadening of the model to "acknowledge women's agency and include less direct gains such as community membership and social safety networks” (Verheijen 2011: 116). In this vein, I believed it was important to develop a research design capable of capturing how women understood, experienced, and expressed risks among peers in their social networks and from within community.

Second, it was important to build upon ethnographic evidence concerning HIV risk and interpersonal power dynamics among 'high risk' individuals, who occupy marginal spaces in urban landscapes (Bourgois et al. 1997). This meant I would pursue an ethnographic design contending with what Bourgois et al. (1997) calls contextualized 
power relations of behavior, specifically relations that affect one's vulnerability to HIV (Bourgois et al. 1997: 155). To do this I needed to immerse myself into brothel life, to be fully attuned to the everyday conditions in the slums. Yet before I could enter, if not dwell to some extent inside the brothel, it was necessary for me to develop a contextualized understanding of research methods that incorporates both women's power relations and individual practices (Bourgois et al. 1997: 155). To fortify my attempts to account for individual behavior, while still managing to document the network and communal dimensions of risks, I explored what Bourgois et al. (1997) theorize "are the everyday practices...the pragmatics of income-generating strategies and the symbolic hierarchies of respect and identity [that] shape risky behavior” (Bourgois et al. 1997: 155). To widen my research lens, it was important to conceptualize risky behavior in conjunction with women's daily practices. By monitoring women's everyday practices I believed the data would generate information from individual women, while simultaneously being filtered through the constraints of community.

Lastly, I came to believe in the importance of having a research design able to accommodate monitoring women's everyday practices as they are shaped by the demands of social networks, community, and social capital. Doing so involved documenting women's practices amidst happenstance moments of interconnectivity. Moments, I believe, that provide the basis for risk and the factors that contribute to women's HIV prevention. Thus, I found in order to gather information concerned with the sociability of risk required a research design capable of identifying and contemplating how women mitigate danger out of their habitual and routinized daily lives. By taking this approach, my design reflects the insights offered by Latkin et al. (2010), which reminds us that after 
20 years of research concerning how to prevent the spread of HIV there is still far too little attention paid to the structural and social influences on people's behavior, and as a result of this dearth of evidence, there continues to be very few structural oriented efforts to address the epidemic.

In accord with this critique, my work brings attention to the need for research designs that go beyond clinical randomization and impact assessments. Instead, my work counters the predominance in HIV studies to measure and test impact in favor of community based expressions of knowledge and indigenous solutions to risk. By reengaging with structural factors, as Latkin et al. (2010) advise, my research keeps central how women manage survival through their social networks, in the context of their community, and out of the reciprocity associated with generating much needed social capital.

\section{Research Locations, Assistance, and Challenges}

When I set out to explore sociability of women's risks it helped to pursue and maintain four related activities: (1) selecting and then preserving research locations; (2) developing and retaining relationships with participants; (3) organizing and overseeing research assistants; and (4) managing limited resources. The initial period of my data collection involved volunteering for a local Ugandan sex worker led NGO called Women's Individual efforts for Sex Workers Human Rights (WISH). ${ }^{9}$ As a volunteer, I found it easiest to gather information through a snowball technique. Thus snowballing became a crucial tactic of the data collection process. Snowballing generated connections

\footnotetext{
${ }^{9}$ See Preface.
} 
for the data collection that led to identifying and accessing research locations and participants, which in turn encouraged a sense of familiarity between me and the women and men in both research communities. My arrangement with WISH only lasted three months as a result of deteriorating relations among the NGO leadership and staff. However, the time I spent volunteering for the organization did create a basis for the methodology of the study. At the conclusion of my arrangement with WISH one of the three original founding directors, Nakato, chose to also leave the organization and join me in the research for the dissertation. In chapter five I reflect on working with Nakato, but here I discuss our time together in relation to how it facilitated identifying my two research communities.

When Nakato and I began working together it was important to find two locations for the data collection. Our search was motivated by three criteria. The first reason related to the feasibility of reaching each location. Our second reason involved the security and safety of the locations. And finally, but most importantly, I believed it was important for both sites to align with literature on HIV/AIDS and 'high risk' sexual practices among female commercial sex workers in Kampala (Vandepitte et al. 2011). Combined, these three reasons led Nakato and I to settle on two locations. Site one is a brothel compound in Rubaga Division, which I later refer to in the findings chapter as "Babito". The second location is actually a community made-up of several brothels, which crisscross a small strip of land in Makindye Division. Later in the dissertation I refer to this community as "Kiku”. While our selection was predicated on feasibility, security, and validity, I believe the last reason is the most compelling for the data collection. This is because underpinning the selection of these two sites is previous research, which found: "two 
divisions of southern Kampala (Rubaga and Makindye) with clusters of bars, night clubs, local beer breweries, eating places, lodges, and guesthouses known to provide rooms for sex-work or selected street spots often frequented by sex workers in search of clients” (Vandepitte et al. 2011: 316). When I considered the data about both Divisions, it seemed the information from the Vandepitte et al. study provided an important basis for staying in these communities.

Although Nakato was instrumental in identifying both research communities, it proved challenging to maintain the relationship. I address this more explicitly in chapter five. In general, over the course the data collection it was difficult to find and maintain reliable and skillful research assistance. In the beginning there was Nakato, but also several other individuals provided assistance. In total there were three women who served as research assistants—Nakato, Roz, and Helen, but only Helen began as an informant. We met during my data collection in the community I call Kiku. During my last three months of data collection (June, July, and August) Helen began to assist me. I discuss our collaboration, which involved working with a large International NGO, more specifically in chapter six. Lastly, aside from these women, I also came to rely on the skills of one man, George Mpanga ${ }^{10}$ George became my primary transcriber. His assistance spanned the last three months of the data collection until the completion of this dissertation.

When I reflect on the process of data collection for the study I believe it is important to disclose the challenges I faced during the fieldwork. Although my preparations for ethnographic research included extensive reading about a myriad of

\footnotetext{
${ }^{10}$ I have kept George's real name as he requested I do so in the dissertation in hopes it would bring him more clients that need research support.
} 
difficulties in fieldwork, it did seem especially challenging to find individuals willing to spend each day in the slums with commercial sex workers. Yet there were other hurdles. All together I believe there were five ongoing difficulties throughout the period of my fieldwork: (1) assistance; (2) language; (3) funding; (4) safety and security; and, (5) accessibility. Here I offer a brief commentary about each.

First, the challenge of assistance is connected to the initial reason I needed research support, which is also connected to my second challenge-my need to communicate in Luganda. Lacking in fluency I resorted to hiring assistants/translators. Each of my assistants was asked to accompany me to my field sites, as well as provide translation and transcription. As shared above, there were several individuals who provided assistance with differing results. Their compensation, which included several resources, but most especially money, put pressure on my financial resources, which was my third challenge. Pressures on my financial resources eventually had implications for my safety, security, and ultimately accessibility in Kiku, which contributed to challenges four and five. Although these five challenges emerged and remained during the 14 months of primary data collection, the overall methodology was flexible. This is because theoretically my approach is grounded. By grounded I mean inspired by grounded theory and ethnographic methodology. I explore these terms and their impact on my research in chapter three. But here I reference them in relation to how I was able to recover from the ongoing challenges to the data collection. In this way the theoretical and methodological approach I took up to complete this project allowed my design to absorb these "hits" by incorporating them into the findings, analysis, and conclusion of the dissertation. 


\section{Outline of the Dissertation}

This first chapter has introduced the topic of my dissertation, explained the rationale for the project, discussed the aim of the research, disclosed the limitations in the data collection, and now, reveals the outline of the dissertation. Introducing the topic, rationale, and aim of the project required a preliminary discussion of the literature concerning HIV/AIDS, sex work, and Uganda. Alongside this brief discussion of literature, the current chapter referenced three overarching critiques called upon to support the design of the study. The chapter builds upon these insights by incorporating data about the prevalence and geography of HIV risk for women engaging in commercial sex work in Kampala. From there I explain the site selection for where the research took place. Connected to this discussion I conclude the chapter with a self-reflexive ${ }^{11}$ account of the challenges associated with research assistance, language, funding, safety and security, and accessibility.

The next chapter resumes my discussion of the risks associated with sex work in the Ugandan context. It delves into greater detail about these subjects in order to present the background of the research project and the problems it addresses. I begin with the literature describing the nature, conditions, experiences, and interventions associated with commercial sex work in the case of Uganda. From there, I provide an overview of Uganda’s HIV history. Taken as a point of departure, the historical discussion moves to analyzing current mainstream global policy approaches for combatting AIDS, particularly within Sub-Saharan Africa. From these overarching frameworks, the chapter shifts

\footnotetext{
11. My use of the term "self-reflexive" is meant to indicate to the reader my affiliation with a particular approach to theory and writing, which I discuss in greater depth in chapter three.
} 
downward to the particular national policy and strategies deployed in the case of Uganda's HIV epidemic. With Uganda's national policy introduced, the discussion narrows to focus on the country's penal code, which addresses commercial sex work via criminalization. From this literature the chapter finally concludes with a brief summary that reflects upon theoretical debates at the center of chapter three.

Chapter three delves into the theoretical literature at the heart of this dissertation. It begins with a discussion of grounded theory, as it centers the rationale for how the data collection unfolded. Next, the chapter discusses three primary concepts (social networks, community, and social capital), which facilitate the interpretation of the data presented in my findings. Finally, chapter three reviews insights gleaned from important ethnographies concerning illness and disease, as well as the process of ethnographic writing and self-reflection. By discussing the theoretical and methodological position taken up in the research (in conjunction with "writing and self") chapter three offers the necessary critical insights for the reader to grasp and "keep-with" the complex and dynamic circumstances described in my findings.

On the heels of my theoretical discussion, I render my findings into two chapters. I begin sharing the findings with chapter four, which is based on data I collected from Babito brothel. In this chapter I offer a description of how women contend, manipulate, and/or ignore HIV risks, as they face off with daily survival. Specifically, I narrate how sex work is a communal occupation requiring a network approach to negotiating everyday forms of risk. I then describe how risk is produced and negotiated out of interconnected processes of reciprocity associated with social capital, which can be life extending or extinguishing. By showing the sociability involved in risk management the 
findings reveal how women's everyday practices in the sex trade have implications for how HIV polices are understood, practiced, reinterpreted and/or ignored on the ground.

Next is chapter five, A Cautionary Tale. The basis of this fifth chapter is a firsthand account of what I experienced entering the private and commercial domains of the men who dominate the sex trade in my second site, Kiku community. In this chapter I present a description of how men contend and manipulate one anther all the while often ignoring their HIV risks. I illustrate men engaging in these behaviors as a means of seeking control over important resources (capital) in an effort to gain the respect of their peers and elders. At the center of this tale is a juxtaposition; one that is about the impediments of gathering data among individuals, who are driven to endure risk so as to secure their social capital and networks in the community. By showing the interconnectedness of men's attempts to survive in relation to the needs of their community, the data I present indirectly speaks to the ways in which women are silenced and disconnected from efforts to address HIV. In this way, the chapter is able to underscore the plight of women and any efforts to counter the spread of AIDS in that community.

Finally, chapter six brings the dissertation to an end. It begins with a brief reflection on the objectives of the research, the background and problem of the project, and what the findings say about risk and social networks, social capital, and community formation in relation to both research locations. Next, the chapter considers the policy implications of my findings and offers considerations for intervention about the ways future programs can incorporate the lessons learned in this dissertation. Finally, the dissertation finishes by redressing these implications with recommendations for further 
research. I do this by considering new ways to explore sex work related risks, which are linked to the findings in chapter four and five. Then, in the last few pages of the dissertation, I discuss new ideas for my own work, which I believe can continue to better refine interventions seeking to address how women manage daily risks associated with sex work, criminalization, and HIV/AIDS in the slums. 


\section{CHAPTER II}

\section{SEX WORK, CRIMINALIZATION, AND HIV/AIDS IN KAMPALA}

Figure 2.1 - Map of Kampala

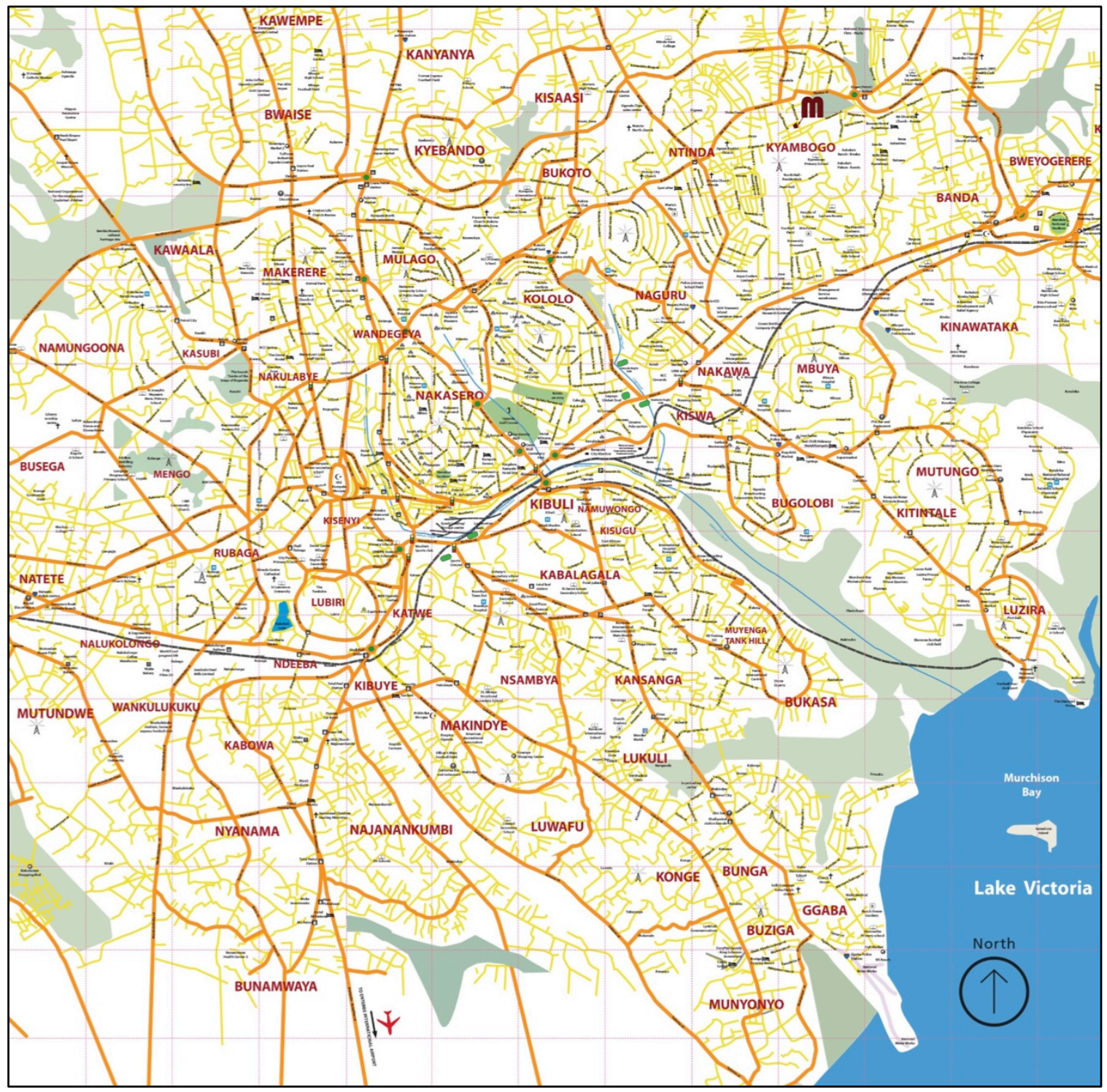




\section{Introduction}

"But the Kingdom of Uganda is a fairy-tale. You climb up a railway instead of a beanstalk, and at the end there is a wonderful new world [original italics] - Winston Churchill 'My African Journey, 1908'” (Ofcansky 1996: vi)

Presently Uganda's people are caught in a web of overlapping policies to address the nation’s HIV epidemic. This chapter offers a brief overview of Uganda's HIV history, both the emergence of the virus and subsequent efforts to curb its spread. By offering this history, the chapter provides a basis for understanding the central problem of the dissertation, which concerns the daily risks women face in relation to sex work, criminalization, and HIV/AIDS in the slums of Kampala. I delve into these subjects five different ways in order to present the background for the research project.

First, I begin with a review of the literature concerning commercial sex work in Sub-Saharan African countries (e.g., conditions, locations, experiences of women, HIV/AIDS risks, and interventions), and then the particular literature relevant for the context of Uganda. Next, I briefly recount the manner in which Uganda's central HIV policies came into being. I do this by discussing how the country's national HIV interventions developed in parallel with what has become a larger global discourse to prevent and treat AIDS in Africa. Third, with these links established the chapter then examines Uganda's current HIV agenda. Recent national HIV strategies are compared with the particular issue of "prostitution" and its criminalization. ${ }^{12}$ In comparing the country’s attempts to address HIV with how Uganda's Penal Code defines prostitution, the chapter's fourth section brings attention to legislated processes undermining the

\footnotetext{
12. I use the term sex work to describe the commercial exchange of having sex for money. When the words prostitution or prostitutes are used it is to convey how others view the practice of sex for money.
} 
nation's efforts to combat its HIV epidemic. With this background in place, the chapter's final section introduces the critical theoretical insights explicitly concerned with how women survive the risks associated with sex work in the slums by way of their social networks, community, and social capital.

\section{From the Comforts of Home to Letting them Die: The literature on Sex Work}

To better understand how women manage daily risks associated with sex work, criminalization, and HIV/AIDS, while being at the periphery of Uganda's national HIV policy, it is necessary for one to consult the greater literature on sex work in sub-Saharan Africa ${ }^{13}$, and more specifically, those studies that explore the sex trade in the context of Uganda. ${ }^{14}$ While the sex trade literature in this region is extensive, my literature review has a more narrow focus. The existing literature reveals four ways to catalogue research in relation to sex work, risk, and HIV/AIDS. I organize these four categories as follows: (1) sex work as part of a historical process of colonial expansion; (2) sex work contexts, such as locations, typologies, and conditions; (3) sex work related risks; and finally, (4) sex work-specific HIV interventions. What follows in this sub-section is a discussion of these four trajectories in the literature. I begin by acknowledging the ways the literature

\footnotetext{
13. Review of the literature was primarily drawn from studies undertaken in East Africa. However, several important and continuously cited studies, which took place in Nigeria, South Africa, and Burkina Faso, were deemed highly relevant for the literature review and preparation for this study.

14. A review of the literature concerning the sex trade in Africa, and Uganda specifically, has revealed that most studies are concerned with commercial sex work that is carried out by biological females, who selfidentify as women. The literature continually uses the terms 'sex work' and/or 'sex worker'. In the vein of this literature, and because this dissertation is not preoccupied with the roots or historical-political differences and meanings of prostitute/prostitution vs. sex worker/sex work, I use the terms 'sex work' and 'sex worker', unless these terms are explicitly linked to a local discussion in the case of findings. When findings are being analyzed local terms will be used to discuss a person engaging in sex work, as well as the practice of sex work itself, in the local terminology and with a contextual explanation of the local term. An example of this is the Luganda word "neko", which I define and discuss on page 27.
} 
helped my research in terms of question formulation, design, and preparation for data collection, but I also mark where the literature deviates from my own interests. I then reflect upon this literature, in terms of how my work builds upon its foundations, while contrasting how my research offers a wider methodological and multi-dimensional understanding for risk management in the context of sex work. From there I discuss how my work emphasizes a broader analytical scope in terms of identifying what constitutes risk and how it can be managed. And finally, I describe how my work affords greater attention to exploring the intersection of individuals, environments, and structures in relation to improving our understanding of the ways women mitigate their daily risks.

\section{Category one: Sex work and colonial expansion}

While few sources offer more than a cursory discussion of prostitution during the colonial period of Uganda (Kyomuhendo and McInotosh 2006; Tamale 2011), Luise White's (1990) discussion of prostitution in colonial and post-colonial Nairobi offers three important aspects of the sex trade that facilitate a deeper understanding of it in the region of East Africa and in Uganda, specifically. To begin, White candidly addresses how her, "research which began as a way to study women's work became a way to study the workings of a colonial society from its most intimate moments- the interaction of the work of daughters, the makeshift arrangements of male migrants, and the long-term strategies of rural lineages and urban employers” (White 1990: ix). White introduces the complexities of sex work and places the practices of "prostitution" within the larger dynamics of family and community. In this way, her work supports explorations, such as mine, that prioritize inter-relational dynamics. 
Second, White explains the etymology of particular terms used to distinguish the types of sex work that took place in colonial Nairobi, and how "the forms of prostitution have their own characteristics, behavior, rate of accumulation, and organization and labor time” (White 1990:13). White’s distinctions, within and among practices associated with sex work, lend themselves to interpreting similar habits within my own research locations. White explains, "The watembezi form is streetwalking...[and with] the malaya form...a woman stayed inside her room and waited for men to come to her" (original italics) (White 1990: 13, 14, and 15). White defines malaya, "taken from the proper dictionary Swahili word for prostitute" (White 1990:15), and watembezi, "from the Swahili verb, kutemba, 'to walk'” (original italics) (White 1990: 13). These terms provide a helpful means of understanding what emerged in my findings, in terms of how and when "malaya" was used versus the word "neko" from a local Luganda term “'Nekolera Mmaali" meaning "'I make money in my way". In Kampala, where the dominant local language is Luganda, "malaya" retains its Swahili meaning, but was found in my observations and exchanges with women and men in the sex trade to be pejorative; an insulting way to reference a woman's promiscuity and "whorish” behavior. Also, White's discussion of sex work, particularly the privileges and protections afforded to "malayas" in colonial Nairobi, offers another important insight I link to the term "neko" in my findings.

Finally, a third aspect of White's work that proves highly relevant to my own work, is her analysis of the unique position women held in maintaining their families' economic survival. In this way, sex work is interpreted as being part of women's larger reproductive contributions to the household, with "prostitution placed alongside 'bride 
wealth’” (White 1990: 39). White's work elucidates the valuation of women's labor and how sex work offers independence, as well as significance in relation to the larger welfare of women's families. For White the focus was on "The issue of a non-capitalist [sic] sector of East African society...[and] the particular ability of women, through prostitution, to enable that sector to replenish itself and to profit from the revenues obtained...” (White 1990: 38-39). Similar patterns emerged in my own research. Women explained how their entry into sex work and their longer-term goals provide a means for them to perform labor for their families. In this way, White provides an alternative lens in which to interpret women's sex work in relation to familial ties and personal empowerment. In being able to generate cash from sex work, I found women in Babito discussing how their earnings pay for children's school fees and/or buy land for aging parents, ailing relatives, and/or offer a means to save for their own retirement. Thus, White's insights strengthen how to interpret women's intentions and actions in relation to the ways and means they develop in order to manage resources in the face of daily risks.

\section{Category two: Sex work contexts}

Prior to 14 months of primary data collection I believed the type of sex work in Kampala was mostly determined by location. As a result I gave little consideration to the flux between different locations and the implications this complexity has on risk management. Believing these categories were fixed, as well as knowing data collection necessitates isolating, qualifying, defining, and assigning meaning and significance to particular populations, I determined it was important to work with women struggling with risks associated with life in Kampala slums. The rationale for selecting slums involved three factors: (1) pre-dissertation fieldwork, in combination with analysis of previous 
studies, indicated a dearth of data concerning HIV risk management practices among women in Kampala slums, which results from difficulties in gathering information about women's health behaviors and conditions, their overall risks, and their unwillingness to engage with outsiders (PlusNews Global Uganda 2011; Sentumbwe 2010; Twinomugisha 2012; Vandepitte et al. 2011; Zalwango 2010); (2) connections I made at WISH, which increased my accessibility, proximity, and feasibility in accessing several slum locations; and, (3) literature confirming that women working in slums experience the most vulnerable conditions in terms of risks associated with sex work, criminalization, and HIV/AIDS (Atwiine et al. 2000).

These three reasons explain why slums were chosen for my research. ${ }^{15}$ Yet when placed alongside previous studies, my work offers a means of distinguishing the minutia of everyday practices (Bourgois et al. 1997). In this way, the lens I use is far more narrow and looks upward from the ground, in order to capture how daily habits have meaning for how and where sex work takes place (e.g., inside rooms or outdoors in corridors, bar or brothel, or lodge or street based (Mbonye et al. 2012; Scorgie et al. 2013).

A nuanced, upward looking, and grounded lens places my research just outside most literature concerned with sex work typologies in the case of Uganda. Often the literature about sex work practices begins by interpreting commercial sex work in relation to policy interests, which are generated apart from where sex work primarily takes place. For example, Sentumbwe (2010), in response to Uganda's National Sero and Behaviour

\footnotetext{
15. My research explores risk conditions and management strategies among women engaging in commercial sex work from inside two slum-based communities in Kampala. Yet in the context of Kampala there are many ways in which sex work and/or transactional sex practices are constituted. See Moore (2014) and Bocast (2014).
} 
Survey (NHSBS), is concerned with the "sexual transmission attributes of the virus whereby commercial sex contributes about $21 \%$ of new infections to Uganda's epidemic [sic]...and who are in most cases the reservoirs and source of infection to the general public" [sic] (Sentumbwe 2010: 1-2). Yet as a result of these priorities, Sentumbwe's research is limited by a preoccupation with sex work in relation to "place":

In Kampala today, one can readily identify three categories of sex workers ...namely:

1. In-door sex workers located in the various slum areas of Kampala.

2. Bar-based and bar maid sex workers located in various bars in the city center and the various suburbs of Kampala such as Kabalagala Kansanga, Bwayise, Nakulabye, and Wandegeya. ${ }^{16}$

3. Street/red light sex workers located along Nile Avenue, Kampala Road and other main streets, and streets leading to various discotheques such as Angenour, Silk, and those in city suburbs (Sentumbwe 2010: 7-8).

Based on Sentumbwe's descriptions, sex work and/or sex work and HIV risk in Kampala, are only identifiable three ways (indoor, bar-based, or street-based), which overemphasize the locations for sex work. While location is important to understanding the risks associated with sex work, so are the social and interpersonal drivers of risks. In this way Sentumbwe's research, like others from the dominant literature on sex work in Kampala, conflate location with "type" of sex work (Bukenya et al. 2013; Ssemwanga et al. 2012a; Ssemwanga et al. 2012b; Mbonye 2013). Sex work in these sources is synonymous with "'hot spots, bars, night clubs, local beer breweries, eating places, lodges and guest houses, or selected street spots” (Mbonye et al. 2012). Repeatedly listing locations as a means of qualifying types of sex work reveals a penchant for

\footnotetext{
16. Sentumbwe has misspelled Bwayise. The correct spelling is Bwaise. However, among sex worker communities and/or those who engage directly with sex workers in Kampala, it is important to distinguish where in Bwaise, which is a very large slum situated north and northwest of central Kampala City. In this case, the area of Bwaise, known for sex work, is called: Bwaise Kimumbasa ("Ki" is pronounced "ch" in Luganda, so when pronounced, the name of the area sounds like "chee-moom-ba-sa”).
} 
"place". While important, the emphasis lacks critical reflection about what drives decision making in relation to place. By prioritizing place, the literature assumes geography is the primary means of distinguishing sex work practices, and therefore making place the only legitimate variable in terms of constructing sex work typologies.

Contrary to these mainstream assumptions, evidence from my research reinterprets place in relation to the sociability of risk and risk management practices. Emphasizing risk, in lieu of place, gives rise to at least three alternative means of categorizing sex work practices: (1) interchangeability of location (e.g., bar, guesthouse, lodge, or street); (2) economics of location (e.g., slum vs. entertainment and/or "hot spot”); and, (3) politics of management in relation to practice (e.g., male managers from brothels/guest-houses/lodges vs. male street-based brokers and/or independent women).

These alternative categories reflect how a woman's choices, in relation to place, often require her to negotiate her position within an established social network, where interpersonal processes shape communal fealty in relation to a particular location. This often necessitates that she expend social capital in order to succeed in that setting. In this way the data in my dissertation finds that what mediates risk has less to do with the "places of sex work," as described in the dominant literature (Bukenya et al. 2013; Gysels et al. 2002; Mbonye 2013; Sentumbwe 2010; Ssemwanga et al. 2012a; Ssemwanga et al. 2012b; Tamale 2011; Vandepitte et al. 2011; Zalwango et al. 2010), and more to do with everyday practices that intersect with women's social networks, communal fealty, and social capital. 


\section{Category three: Sex work risks}

Literature describing risks associated with sex work is extensive, interdisciplinary, and spans multiple contexts (e.g., social, economic, political, etc.). However research specific to Uganda is limited and often dichotomized. Most often research concerning sex work, HIV, and risk is epistemologically differentiated as either positivist or non-positivist AIDS research (Joffe 1997). ${ }^{17}$ The results are that a majority of literature, concerning commercial sex work and HIV risk in Uganda, operationalizes a positivist data collection process. Generally, studies do not gather information from where women practice commercial sex work. Instead they enlist participants from clinical sites, and execute a research design that maintains self-reporting techniques in lieu of participant observation from the ground. As a result, the literature often lists methods involving: “repeat in-depth life history and work practice interviews” (Mbonye et al. 2013: 1); “structured questionnaires” (Ssemwanga et al. 2012: 358); “interview guides containing mainly open-ended questions and some prompts” (Scorgie et al. 2013: 452); "structured face-to-face interviews...conducted at the clinic by nurse-counselors who received supplementary training on the present research” (Bukenya et al. 2013); and/or, “interviews conducted with women after they have sought incentivized services at public and private healthcare facilities” (Marlow et al. 2014).

In comparison, only one study (Gysels et al. 2002) emerged from the literature review that had generated insights about risks with, "an approach concerning non-

\footnotetext{
17. Positivism is understood as Sandra Harding describes: "the positive benefit of science could be restricted to its method, thus making it unnecessary for scientists and the institution of science to be overtly concerned with social, political, and economic origins, consequences, or constituting values of science...of being value-neutral, objective, and impartial... and with having the proper vantage point the relations of the natural and social world can appear” (Harding 1991: 57).
} 
positivist, non-predictive models that are social and representational” (Joffe 1997: 75). The Gysels et al. (2002) study pursued a research process spanning, "over two years in which detailed life histories of 34 women were collected...through recording open, indepth interviews, collecting sexual and income and expenditure diaries, visits to the women’s native villages, and participant observation” (Gysels et al. 2002: 179). While self-reporting techniques were utilized, the research emphasized exploring risk and sex work in the context of everyday practices (Bourgois et al. 1997). To explore these practices, Gysels et al. (2002) equally prioritized participant observation and socialization in relation to women's daily lives, as well as their life histories and ancestral ties. In this way the study maintains "placing different practices in their specific cultural contexts as being vital to understanding...women’s protection needs” (Gysels 2002: 180). My own thinking about sex work, HIV/AIDS, and risk has been strongly influenced by the Gysels et al. (2002) study. Their research offers the most astute considerations for further interpersonal data collection processes, such as mine. The Gysels et al. (2002) study lends itself to helping one contextualize sex work, HIV/AIDS, and risk. But more importantly, their research brought forth a greater understanding about the complexity of survival strategies among women selling sex in Uganda (Gysels et al. 2002: 179).

The discussions by Gysels et al. (2002) about survival supports the way women develop a constellation of risk management strategies. Similarly my own research found like Gysels et al. (2002) that even when: “...women have similar backgrounds... violence, rape and oppressive relationships with men...poverty, broken homes, early pregnancy, non-completion of schooling and various other constraints...they have divergent experiences in their utilization of opportunities and in the level of success they 
achieve....and as a result they have developed different....and varied ways of dealing with sexual risks” (Gysels et al. 2002: 190). In this way the Gysels et al. (2002) study is unique in how it discusses the nuanced ways women cope with risk, and these strategies are often mediated by a woman's capacity to navigate opportunities benefitting her survival.

By discussing risk management as a complex process, Gysels et al. (2002) uncovered three distinct risk conditions that were pertinent to the sex work practices in their research sites:

1. The women who work in the back-street bars have no capital of their own and are almost entirely dependent on selling sex for their livelihood. Because they live from hand to mouth and because they lack entrepreneurial skills they are unable to break out of the situation.

2. The waitresses in the bars along the main road engage in a more institutionalized kind of commercial sex, often mediated by middlemen. Although they are dependent on commercial sex for earning a living, they also appear to enjoy sexual networking.

3. The more successful entrepreneurs who earn their money from their own bars as well as from commercial sex tend to be more in control of sexual relationships due to their financial independence (Gysels et al. 2002: 190).

Within these descriptions, the first category is most similar to what I experienced. Yet there were irreducible and explicit inter-group and intra-group differences among the women in my first research location, Babito brothel. Most women I observed in Babito were likely to be financially insecure apart from the cash they earned from sex work, at high-risk for HIV and other STIs, vulnerable to violence either perpetuated by police, and/or their colleagues in the brothel, and often without access to comprehensive and sensitive medical care for their sex work related health needs.

While the risks Gysels et al. (2002) describe were also present in both of my research communities, the most important similarity between my and the Gysels et al. 
(2002) study relates to risks associated with condom use. Gysels et al. (2002) summarize this behavior showing how “...participants generally claimed to use condoms with casual partners [clients] but not with regular partners [boyfriends]” (Gysels et al. 2002: 190). This behavior has implications for HIV policies, which encourage women and men to minimize the number of partners and/or to use condoms. This is because, as Gysels et al. (2002) suggest, risk has less to do with the number of partners than the type of partner, who could be a regular lover who also has many regular partners (Gysels et al. 2002: 190). Rather than delving into the inter-relational implications of condom use with women's partners, Gysels et al. (2002) study sheds light on the particular risk associated with this practice of multiple long-term partnerships. By bringing attention to reasons why women may or may not use a condom, the study by Gysels et al. (2002) validates this similar finding in my own data, but as it relates to the male dominated social network in my second community, Kiku (see chapters five and six).

Because of the different focuses and approaches between my research and that of Gysels et al. (2002), I am able to interpret this risk behavior through the interpersonal practices that dictate women's anti-risk measures. In this way, my research explores the sociability of women's risk beyond condom usage. Although condom use is one of many critical risk management strategies, this dissertation argues that risk and risk management are better understood in relation to how women negotiate opportunities for survival that emerge from their social networks, communal featly, and social capital. Understanding risk in relation to these factors better explains why a woman may choose to forgo a condom in order to maintain important ties in her social network. I found this important in terms of how women maintain community fealty to increase much needed social 
capital. In this way a woman's efforts to strengthen her social ties creates a pattern of risk and risk management far more complex than simply using condoms.

\section{Category four: Sex work and HIV interventions}

Catherine Campbell's (2000 and 2003) research investigates the hurdles of a particular HIV intervention targeting female commercial sex workers in a squatter camp adjacent to a South African gold mine. Over a span of seven years Campbell collected and disseminated findings relevant to the ways HIV interventions impede and/or clash with 'the routine organization of sex workers' everyday working and living conditions, as well as the strategies they use to construct positive social identities" (Campbell 2000: 479). The findings she presents proved helpful during my data collection and also during the writing of this dissertation. This is because Campbell's work accommodates the challenges that researchers and the programs face when working within highly volatile environments, such as sex work communities.

During the formulation of my research question and proposal, Campbell's (2000) study helped situate the importance of what she describes as "the range of coping strategies and social support networks that women construct to deal with their day-to-day life challenges” (Campbell 2000: 479). In her first study Campbell (2000) interprets sex worker's social networks as a means of "serving as potentially strong resources for community-based sexual health promotion programs” (Campbell 2000: 479). Campbell's discussion of sex workers' social support, through social networks, provided a lens through which my data collection could focus on different activities and/or roles taken-up by women (e.g., cash saving circles, collective security, and/or health information). 
Moreover, Campbell's first study strengthened the rationale underpinning a component of my research design, which involved working alongside a local sex worker-led NGO. ${ }^{18}$

My assumption, then, was that by working with a local NGO, I would gain access to female sex worker communities and increase my personal safety, while also being able to directly observe the presumptions implicit in an HIV intervention that aligned with the prescriptions in Campbell’s study: "successful community-led projects succeed or fail to the extent that they succeed in mobilizing already existing psycho-social resources and community networks that are most likely to support their health promotion goals" (original italics) (Campbell 2000: 481). I designed my fieldwork in response to the presumption that by studying the possibilities and limitations of a local NGO's HIV interventions I could discern the ways women comprehend, adhere, amend, and/or disregard messages related to HIV prevention, treatment, and care.

In my case, hopes of working with the organization went unfulfilled when the project ultimately failed (see chapter one). When this strategy was no longer an option, my data collection was forced to shift direction and became heavily informed by an unaffiliated participant observation technique that offered opportunities for unstructured interpersonal engagements with members of two different sex work communities. Once this shift took place, the findings I presumed important from Campbell's first study (2000) tended to give way to reflections generated in her monograph, Letting them Die: Why HIV/AIDS Prevention Programs Fail (2003).

18. See Preface 
Looking backward through the lens of the revisions made to my original research design (see chapters five and six), the greatest lesson I take from Campbell’s (2003) work is, "in the context of studying daily risks associated with HIV/AIDS and sex work, any project concerned with local credibility is easily impacted by events in a community that is managed and/or frequently engages 'gangsters'” (Campbell 2003). Campbell (2003), as well as my own findings, discusses how a "complex series of incidents can highlight the ways in which a program [in this case my research] often becomes embroiled in local community dynamics in unintentional and unpredictable ways” (Campbell 2003: 103).

After fourteen months of primary data collection that became heavily dependent on participant observation and unstructured interpersonal engagements, I now have personal insight into Campbell's second study (2003). Her research in this second case offers an additional lens in which to understand the implications of social networks. Campbell's (2003) description of networks holds them: "as socially situated and located at the interface of a range of constituencies with competing actions and interests" (Campbell 2003: 8). This definition has helped me to further interpret how HIV information about prevention, treatment, and care (as well as being able to directly engage with these networks) is filtered by the expectations of women's social contexts. Campbell's (2003) emphasis is on the constraints of disseminating HIV information. My emphasis is on the constraints related to researching women's interpretations of HIV information; specifically, how these interpretations proved relevant for their risk management. To do this required that I contend with general phenomenon that Campbell describes as: "Projects that can unintentionally become embroiled in unpredictable and dangerous situations...in a community characterized by excessive physical violence and 
alcohol use as well as crippling poverty, where events may often move very swiftly in unexpected directions and with unintended consequences” (2003: 103-104).

While Campbell's studies (2000 and 2003) follow the trajectory of a specific HIV intervention project, her work is essential for other research projects, such as mine. It is valuable first, in terms of how to reflect on the importance of socialization and networks in the context of sex work. Second, her work provides a means of understanding the dangers, fluctuations, and unknowable dynamics that emerge during projects preoccupied with individual and communal vulnerability, survival, and instability. In this way my research, while involving two communities in Kampala City, extends the work of Campbell (2000 and 2003) and other research endeavors concerned with social networks, community, and social capital as these concepts deepen the understanding of the sociability of risk.

\section{The Rewards of Candor: Uganda's HIV History and the Discourse of AIDS in Africa}

Reflecting upon a larger discourse of AIDS in Africa as it relates to Uganda's HIV history requires exploring two sets of literature. The first is from multinational, intergovernmental, and US policy, documents concerned with the broader issue of AIDS in Africa. The second series of documents address HIV conditions in Uganda spanning almost 28 years. When I compare these texts, it appears only a handful of scholars reflect on the particular history of HIV in Uganda (Hooper 1987; Kuhanen 2008 and 2010; Parkhurst 2002, 2008, and 2012; Seeley 2014; Thornton 2008). Meanwhile, other sources only tangentially include Uganda's history into a larger discussion about the "true" causes of Africa's AIDS epidemic and/or the "accurate” policy approaches and protocols 
to prevent and treat AIDS in Africa (Epstein 2007; Garrett 1994; Lanegran and Hyden 1993; PEPFAR 2008; Pepin 2011; Pisani 2008; UNAIDS HIV Prevention Toolkit 2008). Rather than separate Uganda’s HIV history from the literature preoccupied with roots, causes, and best interventions to counter AIDS in Africa, the priority in this subsection is to relay how the Ugandan government's approach to managing the country's HIV epidemic came into being as part of a process of policy reciprocity within a much larger discussion of AIDS in Africa (Hooper 1987; Lanegran and Hyden 1993; Packhurst 2012; Sing et al. 2003; Thornton 2008). My review of the literature on AIDS in Africa, and, specifically where it overlaps with Uganda's HIV history, reveals how policy developments to address AIDS in Africa simultaneously brought greater attention to Uganda's HIV initiatives. This is because while AIDS appeared to spread across subSaharan Africa, Uganda achieved world recognition as a case study in how to accomplish a reduction in the number of HIV infections. Singh et al. (2003) note, "Policy makers around the world looked to Uganda as a role model in the fight against HIV/AIDS, because of its success in reducing HIV rates during the late 1980s and early 1990s" (Singh et al. 2003: 4). This success brought attention as well as funds into Uganda. The benefits of these rewards also contributed to an increasing presence of foreign-based international and intergovernmental agencies (Kuhanen 2008). With this attention Uganda’s approach to HIV prevention received larger demands from international donors as well as greater expectations for how the country was to manage its HIV epidemic. With this attention came, “...international bodies [that] not only monitor, report, and educate, but demand their say in how the epidemic should be managed” (Kuhanen 2008: 301). 
While the early 1990s commenced with the international popularization of Uganda's HIV prevention successes, earlier reports describe the devastation wrought by the virus. From these early accounts it is possible to understand how Uganda came to be seen as unique, not only for pursuing an open social policy approach to combating HIV, but also for achieving an overall drop in HIV prevalence (Kuhanen 2008; Parkhurst 2012). One of the earliest accounts of Uganda's epidemic comes from Ed Hooper's article AIDS in Uganda (1987). Hooper describes a small village decimated by what locals were calling "slim":

The death rate acquires a new perspective when one recalls the dictum that for every AIDS victim there are another fifty carriers. If this applies to Uganda as it apparently applies to Western countries, then half the population of a town like Gwanda, that is virtually its entire sexually active population, is already infected (Hooper 1987: 471).

Hooper's description is nuanced by his accompanying analysis of how HIV is being transmitted: "Because heterosexual sex is the main method of spreading the disease in Uganda...this clearly presents the Ugandan government with a massive problem because it is the normal pattern of behavior, not the exceptional, which is at the root of the spread of AIDS" [my italics] (Hooper 1987: 476). The "normal pattern" of behavior Hooper references was taking place in a country just coming out of a long civil war and with continued fighting in the north. For Hooper, Uganda was a place where, "The minimum monthly wage was enough to purchase [then] just four bottles of beer or six kilograms of meat and where most people live by means of the black economy, including prostitution in its various forms and guises" (Hooper 1987: 476). Yet Hooper's description remains relevant. Indeed his experiences of Uganda, circa 1987, continue to exist unchanged by the country's national HIV policy, in communities with few 
economic resources other than commercial sex work. While the findings in this dissertation explore the everyday circumstances reminiscent of Hooper's description, here the discussion centers on the government's attempts to reduce the number of sexual partners in their efforts to develop Uganda’s national HIV response.

As Uganda emerged from conflict the newly formed government was committed to incorporating an HIV response into its larger agenda of state rebuilding (Kuhanen 2008; Thornton 2008). The Ministry of Health sought to combat the growing threat of HIV by focusing on public health campaigns that brought attention not only to the risks of sex, but also the need for citizens to have fewer sexual partners (Hooper 1987). The latter effort had a particular slogan known as "zero grazing”, which refers to "sticking to one partner” (Hooper 1987: 476). Along with the Ministry of Health campaigns, leadership against the spread of HIV came from the top. Speeches from President Museveni emphasized the country's willingness to execute an AIDS policy that supported open communication and increased awareness through education efforts (Kuhanen 2008). Yet it is precisely the tactics of "openness" that critical histories of Uganda's HIV epidemic claim attracted the international community to this particular African narrative of success (Parkhurst 2002 and 2012).

Critical analyses of Uganda’s HIV success story are slowly mounting, especially, in the face of recent reports documenting an increase in the nation's HIV prevalence rates (PlusNews 2011). Important insights from these critical perspectives raise two points. First, that Uganda's "success story" is based on selective pieces of information, which have been continuously circulated by an international policy discourse of "how to combat AIDS in Africa” (Parkhurst 2002: 80). Second, alternative histories of Uganda's HIV 
epidemic emphasize how Uganda’s success was amplified by the Bush Administration's efforts to develop and promote its plans for PEPFAR. These plans included an approach to HIV reduction known as the 'ABC' model, which the Bush White House claims were inspired by Uganda's own efforts to curb the spread of HIV (Parkhurst 2012: 19). Together these points prove important because they are indicative of how Uganda's HIV history came to be entangled with a larger discourse of AIDS in Africa (Biakolo et al. 2003).

The discourse of AIDS in Africa has been described as “agenda setting dominated by the international community and, in particular, those agencies which control funds for AIDS research and education” [sic] (Lanegran and Hyden 1993: 253). For critics of the discourse, the agenda setting they describe resulted in Sub-Saharan Africa becoming the global focal point for the AIDS pandemic (O’Manique 2004). And within this "AIDS in Africa” discourse Uganda's strategies discursively emerged as a model approach for the whole of the region (Parkhurst 2002). The country's national HIV policy was extolled for what Thornton describes as an: "extraordinary response by government and civil society to meet the crisis and to support appropriate changes in sexual behavior" (Thornton 2008: 84). A response that historians believe focused heavily on promoting the ABCD approach (abstinence, being faithful, using condoms, and death) (Thornton 2008: 84). In turn, Uganda seemed to the international community, and eventually the Bush Administration, to symbolize an indigenous answer for an entire continent's AIDS pandemic. With this "home grown" response to HIV in place it was possible for Western governments, particularly the United States, to set about incorporating a reimagined and politically expedient approach to Africa's AIDS crisis (Thornton 2008). With these expectations 
thrust upon Uganda's national strategy, the country headed into the new millennium, sixteen years after Hooper's account of the village of Gwanda, with the responsibility of maintaining a modified version of its ABC approach in order to reduce the country's HIV infection rates.

\section{Uganda and HIV in the New Millennium}

Four years after US President George W. Bush announced the unilateral United States policy response to Africa's AIDS crisis in 2003, Helen Epstein offered an answer to the problem of AIDS in Africa (Epstein 2007). The answer is laid out in the conclusion to her book the Invisible Cure, where Epstein recounts the "benevolent" form of colonialism with which British ruled Uganda. Her description claims: "the colonial experience was more benign...discussions of sex and AIDS may have been easier...in the 1980s these discussions helped Ugandan health officials... and in turn enabled them to design pragmatic campaigns... and as a result most Ugandans understood that people with AIDS were just 'normal'” [my italics] (Epstein 2007: 255). For Epstein the answer is found in the way English rule "allowed" Ugandans to maintain a culture of opencommunication, which eventually led to “real talk” about their HIV crisis. But Epstein’s history of Uganda's HIV epidemic is preoccupied with what is relevant for "most" Ugandans, who she claims have managed to “curb behaviors” (Epstein 2007). As a result, Epstein's history ignores a critical fact, which is that an important sector of Uganda's population — female commercial sex workers — has been ignored. The health, safety, and daily needs of these women remain understudied, and therefore, unknown. And while Epstein may have an answer for solving Uganda’s general epidemic, it fails to address the small but highly powerful residual pool of infection among women in the sex trade. In 
this way, the focus here is to move us closer to understanding how women in Kampala's sex trade manage the hazards of HIV/AIDS.

Along the way to gaining a deeper understanding of women's risks it helps to consider Uganda's current policies, which are divided among four primary national reports concerning the county’s HIV epidemic: (1) Republic of Uganda National AIDS Policy 2010; (2) Republic of Uganda National Strategic Plan (NSP) 2011-2015; (3) Republic of Uganda National Prevention Strategy (NPS) 2011-2015; and, (4) Republic of Uganda Health Sector Strategic Investment Plan (HSSIP) 2010/11. In addition to each of these national policy reports, data collection also included the Republic of Uganda HIV/AIDS Country Progress Report (2013) and Chapter 120 Ugandan Penal Code Act.

In the cases of the National Strategic Plan 2011/12-2014/15 (Revised), the National Prevention Strategy 2011-2015, the Health Sector Strategic Investment Plan 2010/11-2014/15, and the Global Progress Report (2014), these documents directly address the issue of HIV in Uganda, now. For the moment these documents provide the most current national figures for Uganda’s HIV epidemic. Aside from the National AIDS Policy Report, ${ }^{19}$ the second, third, and fourth reports offer prescriptions for addressing HIV for most Ugandans; and, finally the National Progress Report reflects on these prescriptions in the context of the Global AIDS Response Progress Reports and Universal Access indicators. ${ }^{20}$ As official policy statements from Uganda's government, these

\footnotetext{
19. It was not possible to receive and/or find a copy of the Republic of Uganda National AIDS Policy 2010.

20. The Global AIDS Response Progress Report and the Universal Access indicators are measurements developed by several global health bodies (UNAIDS, Global Fund, and WHO) to monitor countries in their fight against HIV/AIDS.
} 
reports demonstrate the country's understanding, rationale, and commitment to preventing and treating HIV in Uganda.

Combing through reports provides a means of gauging Uganda's national response for preventing and treating HIV. There are two documents that stand out: the Country Progress Report (2014) and the National Strategic Plan 2011/12-2014/15. Both reports demonstrate a linkage between Uganda's national strategy and the country's institutional capacity to maintain the role of global model-state in addressing HIV, and therefore, AIDS in Africa. Yet in making this link, both examples continuously emphasize a vision and means for combating HIV in Uganda that eclipses how commercial sex workers mitigate HIV related risks in the slums. Instead, the Country Progress Report (2014) and the National Strategic Plan 2011/12-2014/15 both persist in offering policy conclusions that are disconnected from the life and death realities of everyday sexual practices on the ground—experiences that call for a deeper discussion.

Beginning with the Country Progress Report (2014), the document best summarizes Uganda's national strategy in responding to ten global targets in preventing and treating HIV in the country; all deemed necessary actions by international bodies such as the World Health Organization (WHO), the Joint United Nations Programme on HIV/AIDS [sic] (UNAIDS), the Global Fund to Fight AIDS, Tuberculosis, and Malaria (Global Fund) and PEPFAR (see preface). The ten targets are to: (1) reduce sexual transmission of HIV by 50\% by 2015; (2) reduce transmission of HIV among people who inject drugs by 50\% by 2015; (3) eliminate new HIV infections among children by 2015 and substantially reduce AIDS-related maternal deaths; (4) reach 15 million people living with HIV with life-saving antiretroviral treatment by 2015; (5) reduce tuberculosis deaths 
in people living with HIV by 50\% by 2015; (6) close the global AIDS resource gap by 2015 and reach annual global investment of US\$22-24 billion in low-and middle-income countries; (7) eliminate gender inequalities; (8) eliminate stigma and discrimination; (9) N/A; ${ }^{21}$ and, (10) strengthen HIV integration (Republic of Uganda: HIV and AIDS Uganda Country Progress Report 2014: xii-xiv). While the Global Progress Report (2014) reads to be in compliance with global measurement protocols, particularly those attached to international funding, only target one gives special attention to commercial sex work.

Within target one, the mention of commercial sex work is done gratuitously and only in conjunction with an overall call to reduce the country's HIV transmission. This minimal attention is indicative of what Twingomugisha describes as, "a policy approach that is limiting and offers no participation for female sex workers in terms of developing HIV related policy frameworks” (Twingomugisha 2012: 1). In this way the approach taken up in the report can also be interpreted as disjointed. The progress report claims “over 3,000 sex workers...received a comprehensive prevention and care package for STI/HIV services through the MARPI Clinic in Mulago Hospital and other sites in Kampala” (Republic of Uganda HIV/AIDS Country Progress Report 2013: viii). Yet further down on page xi of the report, under the heading "sex workers", is point 1.7, which reads, "Percentage of sex workers reached with HIV prevention programs". Here the report claims "no data" for this particular activity and community, as of December 2013 (Republic of Uganda HIV/AIDS Country Progress Report 2013) and then goes on

21. A title and description for target nine is not listed in the report. 
to claim all data related to the commercial sex work populations comes from the Crane Survey report of 2008/2009. ${ }^{22}$ Even more troubling are the unresolved gaps in the data. If the data collected is indeed from the Crane Survey, then the Country Progress Report (2014) is relying on information that was gathered almost seven years prior.

While it seems the Global Progress Report (2014) is responding to indicators set in place by an international monitoring system, there are more worrisome aspects. The report has no current data specific to the HIV prevalence among commercial sex workers, a community designated as a "high risk" and in need of continuous HIV surveillance (UNAIDS HIV Prevention Tool Kit 2008). The absence of sex work-specific HIV prevalence data is confounding, yet not surprising. In the findings I address the lack of comprehensive sex work oriented monitoring and care practices. There my analysis describes how women attempt to balance their HIV needs with the demands of their social networks and social capital. But for now, it is important to compare the Global Progress Report (2014) with Uganda’s revised HIV national strategic plan (2011). Making this comparison demonstrates how both documents reflect an unquestioning continuation of Uganda's “call to duty” to maintain its status as an exemplary state on the frontlines of combating AIDS in Africa.

Putting aside the Global Progress Report (2014), we come to the second policy document, The National Strategic Plan 2011/12-2014/15. This plan is the most illustrative of Uganda's national HIV strategy. Document analysis of the national strategy (2011) reveals an agenda for an HIV-free Uganda. The Plan articulates a vision of

22. The Crane Survey Report (2010) is an independent report published by Makerere University Department of Public Health and sponsored by PEPFAR, the US Centers for Disease Control, and the Uganda Ministry of Health. 
Uganda with "a population free of HIV and its effects...[with] a goal to achieve universal access targets for HIV\&AIDS prevention, care, treatment, and social support and protection by 2015” (Republic of Uganda National Strategic Plan 2011/12-2014/15 (Revised) 2011: xiv). To arrive at an HIV free future the policy is guided by the following principles:

1. Personal responsibility: Every person in Uganda has a responsibility to protect himself/herself and others from HIV infection, to know their HIV status and to seek appropriate care and support;

2. Non-discrimination: That no person shall be discriminated from accessing HIV/AIDS services;

3. Adherence to the multi-sectoral [sic] response, and effective partnership at all levels;

4. Meaningful involvement of People Living with HIV;

5. Human rights based approach to programming

6. Gender sensitive [sic]

7. Evidence based planning and implementation

8. Adherence to the "Three Ones Principle"

9. Adherence to national and obligations by all stakeholders;

10. Effective mainstreaming of HIV/AIDS in all sectors and Plans

11. Country ownership and Accountability for results (Republic of Uganda National Strategic Plans 2011-2015: 21).

As a basis for policy, these principles describe a Ugandan government capable of enacting what O’Manique calls “a particular 'Western’ understanding of AIDS deriving from biomedicine, and its articulation within a neoliberal and androcentric human rights discourse...” (O’Manique 2004: 50). O’Manique’s argument is salient for its ability to locate a deep paradox in the policies proposed. For instance, point six explicitly calls for a "gender sensitive" approach. Yet gender is unequivocally understood as "women", who I show in my findings chapters four and five, still bare the greatest responsibility for maintaining local socio-cultural norms around sexuality, decency, and virtue. In this way the points being made in the policy underscore the high prioritization of women, while 
cloaking them in what neoliberal scholar Cheng describes as a paradoxical conservative and moral agenda towards issues of identity and personal freedoms—such as sexuality, gender, family, reproduction, etc. (Cheng 2013). Following, this paradox can be extended by way of the policy's emphasis on "personal responsibility" (point one). This more than any other point is a prominent display of an important feature within neoliberalism.

Neoliberal theory paradoxically entwines the notion of "personal responsibility" with the idea of "personal freedom". In doing so the individual is constituted as a rational actor, one that is extoled in opposition to the state and/or institutions with a historical mandate to protect the commons and greater society (Cheng 2013). As a result, the glorification of individual risk and responsibility within neoliberal theory, places an unrealistic burden of self-care and personal obligation on the most vulnerable members of society, which in this case are female commercial sex workers. Moreover, the supremacy of individualism undermines collective and communal practices, which my research shows are extremely relevant in the daily lives of these women in terms of how they manage risk. Yet so long as HIV healthcare practices are entwined with a neoliberal framework, the needs as well as ongoing practices of women in sex work communities remain outside the purview of policies and interventions.

This is precisely what happens with the National Strategic Plan (2011). The policy draws upon biomedical and neoliberal frameworks in delineating how to execute its goals. Specifically, the report claims, "strategic actions under [the] HIV prevention thematic service area include those that address biomedical, behavioral and structural factors related to the spread of the virus...” (Republic of Uganda National Strategic Plan 2011/12-2014/15 (Revised) 2011:19). Yet when the policy mentions behavioral and 
structural factors, in addition to biomedicine, the document illustrates a competing understanding of the epidemic and possible ways to prevent and treat the virus. In turn these competing ideas reveal the politics of policy-formation, which in this case seems to mean ranking priorities in terms of their capacity to reflect narrow ideas about personal responsibility in relation to risk (O’Manique 2004).

We see this ranking in the way knowledge about AIDS is cultivated, disseminated, and managed. First order knowledge is based on an understanding that essentializes the virus. HIV is a virus that can be explored through virological and immunological science, and effectively managed bio-medically. Next order knowledge is developed through sexual norms and practices that are culturally scripted and therefore more complex and difficult to predict and/or generalize. As a result, policies struggle to generate longer-term interventions that align with these normative sexual values and behaviors. Finally, last order knowledge about the virus is driven by global socioeconomic interests, which engulf countries like Uganda, when donor states (such as the United States) promote political and economic interests through aid and intervention. An example of this ranking system is revealed with a careful reading of the National Strategic Plan 2011/12-2014/15. The plan states: "the Revised NSP is situating the national response within the overarching broader National Development Plan” (Republic of Uganda National Strategic Plan 2011/12-2014/15 (Revised) 2011: 20).

By embedding its National Strategic Plan for HIV within the larger policy ambitions for Uganda's development, the country's commitments to address its HIV epidemic are explicitly conflated with an overarching national development agenda. What results is a vision for Uganda that is bound-up in ideas of "a transformed Society 
from a Peasant to a modern and prosperous Country" (Republic of Uganda National Strategic Plan 2011/12-2014/15 (Revised) 2011: 20). Yet this march towards modernity is envisioned only through the country's ability to accomplish what the report calls the nation's “overarching objective...to achieve universal access targets for HIV/AIDS prevention, care, treatment and social support and protection by 2015” (Republic of Uganda National Strategic Plan 2011/12-2014/15 (Revised) 2011: 20). To arrive at its development, via universal access to HIV/AIDS, the country's HIV policy must achieve three goals: "[1] Build and maintain an effective national HIV/AIDS response system; [2] Reduce the incidence of HIV by 40\%; [3] Enhance livelihood and economic development of affected communities and households” (Republic of Uganda National Strategic Plan 2011/12-2014/15 (Revised) 2011: 20). In this way, the design of Uganda's national HIV strategy is only exacerbating the economic, social, and criminal retrenchment of the most marginal members of Ugandan society (Ezeonu 2008).

It is important to understand the roots of my case study, which highlights the long-standing history of neoliberal policies that have brought structural adjustment to African states. Conditions of economic, social, and political instability are part in parcel of a process Ezeonu describes as "massive retrenchment of workers...and the pauperization of those who survive the retrenchment” (Ezeonu 2008: 123). Among those who survive, it seems "they often desperately seek alternative employment...men... migrate farther away from their families...[and] they patronize commercial sex workers, many of whom are HIV positive...” (Ezeonu 2008: 123). Conversely, while men engage in the purchase of sex, the neo-liberalization of Sub-Saharan African economies has pushed retrenched female workers into more vulnerable economic situations, many of 
who then resort to commercial sex work (Ezeonu 2008). Under this rubric of economic transformation, health care, specifically access and costs, has been re-envisioned (Ezeonu 2008).

Austerity for African countries has resulted in a disproportionate share of the costs associated with healthcare to be shifted away from the state and passed along to individuals. This resulted from massive budget cuts that were deemed necessary in order for African governments to attract foreign investment and credit from international donor agencies, like the World Bank and IMF. Today patients must contend with a series of difficulties in terms of accessing medical care. Services now typically require "user fees" and require that patients wait long periods of time as a result of fewer trained medical staff (Ezeonu 2008).

In chapter four I look more closely at the implications of user-fees, which are especially impactful for women's ability to manage their HIV/AIDS. I illustrate how accessing HIV care is a risk in itself for the women in my case study. By documenting these costs, my work highlights how user fees are both prohibitive for the most economically vulnerable, but also highly moralizing in how they demonstrates a patient's capacity to care for herself. Care in this way becomes symbolic of a re-imagined Ugandan; an economically self-sufficient person capable of engaging, through payment, in modern practices associated health and hygiene (Fredby and Nilsson 2013; Scherz 2014; Doherty forthcoming).

Thus the financial incentivizing within The National Strategic Plan (2011) reflects a particular development agenda, which at its core, is a contradiction in efforts. One need only a cursory reading before quickly identifying the paradoxes of how the National 
Strategic Plan (2011) seeks to take particular action to address Uganda’s HIV epidemic. An example can be found under the mandate for "strategic objectives and strategic activities for HIV prevention service area” (Republic of Uganda National Strategic Plan 2011/12-2014/15 (Revised) 2011: 24). The mandate calls for ten deliberate steps to be taken in order to bring about an HIV-free Uganda. These strategic actions include:

1. Scale up PMTCT

2. Scale up access and update for ART services among those in need

3. Scale up Safe Male Circumcision

4. Increase correct and consistent condom use during risky sexual encounters

5. Sustain $100 \%$ blood transfusion safety and adherence to universal precautions

6. Promote medical infection control

7. Promote $100 \%$ access to Post-Exposure Prophylaxis (PEP)

8. Promote safer sexual behavior among key/target population

9. Strengthen Behavior change communication programs to address sociocultural, gender, and other underlying drivers in communication endeavors;

10. Promote ABC+ for HIV prevention [sic] (Republic of Uganda National Strategic Plan 2011/12-2014/15 (Revised) 2011: 24).

Below, I provide an in-depth discussion of the inherent contradictions between Uganda's national strategies and daily life among for female commercial sex workers. But herein it is important to note that not one of the ten strategic actions above explicitly addresses "high risk" populations. At best, strategy action point number four makes reference to "risky sexual encounters" and point eight mentions "key/target populations". However, these two strategies are examples among a list of blanket actions that fail to clearly define what it means to engage in risky sex or who qualifies as a member of the key/target population. Rather than clearly define and/or deal unequivocally with "high risk" practices and/or populations, the policy instead expounds in a generic manner on the ways to prevent, treat, and provide care for “all” Ugandans. 
Overall, the National Strategic Plan 2011/12-2014/15 claims to target all Ugandans, as does the summary of the country's ongoing efforts listed in the Global Progress Report (2014). These two examples and the other national HIV documents listed above, demonstrate Uganda's political will to address the country's HIV epidemic as both a hollow and incomplete gesture. As strategies representative of national policy, each document reveals how national measures inadvertently construct a discourse of Uganda's HIV epidemic. Closer reading of these reports exposes an underlying idea concerning who is susceptible or infectious, as well as who is deserving of information and assistance, where HIV prevention and treatment are concerned. Hence, these HIV policies only reflect a deeper, institutionalized construction of what are acceptable (legal) and unacceptable (illegal) behaviors. In this way, Uganda's national HIV strategies are positioned against the backdrop of the country's Penal Code, which strictly forbids “prostitution”.

\section{The Cult of Prostitution}

Uganda’s Penal Code makes explicit what constitutes “prostitution” and how this practice is punishable. Yet the criminalization of sex work has been shown to impede Uganda’s national HIV response (Atwiine et al. 2000; Bukenya et al. 2013; Gysels et al. 2002; Harcourt and Donovan 2005; Jitta and Okello 2010; Marlow et al. 2014; Mbonye et al. 2012; Mbonye et al. 2013; Parikh 2004; Scorgie et al. 2012; Sentumbwe 2010; Ssemwanga et al. 2012; Ssemwanga 2012; Tamale 2003; Tamale 2011; Twinomugisha 2012; Zalwango et al. 2010). As Twingomugisha argues, “criminalization of sex work has deleterious implications for the realization of HIV prevention, treatment and care...driving underground the practices of sex workers and making it difficult for health 
workers to engage them in meaningful ways” (Twingomugisha 2012: 1). Conversely, Tamale calls attention to the ways criminalization of sex work is defended: "proponents of criminalizing prostitution argue it poses a health hazard to society through the spread of sexually transmitted diseases, such as HIV/AIDS...” (Tamale 2011: 146). When set against the backdrop of the country's national HIV strategies, the Penal Code inadvertently places practices and people outside the framework of national efforts to fight the country's HIV epidemic. As a result, individual and community reactions to the penal code have unintended implications for how Uganda’s national HIV strategies are received, understood, and taken-up and/or rejected on the ground.

My findings address the unanticipated implications of Uganda's penal code on the country's HIV policies. I do this by documenting how these strategies are interpreted, understood, adhered and/or rejected by individuals and communities engaging in the sex trade. Yet here it is important to note an avoidable contradiction in the way laws and polices are understood. When national HIV policies are deployed under the rubric of the country's penal code, a dynamic ensues complicating how straightforward national HIV strategies reach individuals engaging in activities deemed criminal (i.e. Penal code sections 136 through 139 of Chapter 120 Uganda Penal Code). A close reading of the penal code illustrates this contradiction. To begin, section 136 discusses "Persons living on earnings of prostitution"; section; 137 outlines what constitutes "Brothels"; section 138 provides a "Definition of prostitute and prostitution"; and, section 139 outlines the "Prohibition of prostitution” (Chapter 120 Uganda Penal Code, WIPO, 2014). These definitions reveal what Tamale calls, "the primary purpose of criminal law" (Tamale 2011: 9). 
The primary purpose of Uganda's prohibition against sex work is the preoccupation with ending an everyday practice (Bourgois et al. 1997); one interpreted to be harming the general public, to which the law makes clear its authority in demanding punishment for causing this harm (Tamale 2011). Yet, not only do the legal terms define what constitutes harm, and therefore punishment, but Uganda’s Penal Code inadvertently confers a pejorative identity upon particular individuals engaging in communal activities related to what is clearly necessary for daily survival (Gysels et al. 2002; Mbonye et al. 2013; Tamale 2011; Twingomugisha 2012). Constituting and assigning this identity inadvertently takes place at the outset of sections 136 (1) and (2), which begin with a delineation of activities concerned with the economy of sex work. Section 136 (1) claims, "Every person who knowingly lives wholly or in part on the earnings of prostitution and every person who in any place solicits or importunes for immoral purposes commits an offence...” (Chapter 120 Ugandan Penal Code Act: 67).

Not only does Uganda's penal code offer a means of delineating the economic practices associated with "prostitution", the code also addresses the networked, communal, and reciprocal aspects of the trade. Section 136 (2) goes on to describe these social dimensions for both the person engaging in the sale as well as for those who profit by association:

Where a person is proved to live with or to be habitually in the company of a prostitute or is proved to have exercised control, direction or influence over the movements of a prostitute in such a manner as to show that he or she is aiding, abetting or compelling his or her prostitution with any other person, or generally, that person shall, unless he or she shall satisfy the court to the contrary, be deemed to be knowingly living on the earnings of prostitution (Chapter 120 Ugandan Penal Code Act: 67) 
Within section 136 (1) and (2) the dimensions of prostitution are outlined and clearly determined in relation to social aspects of the practice. Section 137 goes on to discuss the conditions and places of work, specifically, what constitutes a brothel, "a house, room or a set of rooms or place of any kind for purposes of prostitution” (Chapter 120 Ugandan Penal Code Act: 67). However, the term "prostitute" is only clearly defined once in the code (section 138): "In this Code, 'prostitute' means a person who, in public or elsewhere, regularly or habitually holds himself or herself out as available for sexual intercourse or other sexual gratification for monetary or other material gain, and ‘prostitution’ shall be construed accordingly” (Chapter 120 Ugandan Penal Code Act: $68)$.

Finally, only in the last section of the Penal Code does the State offer the terms of punishment: "any person who practices or engages in prostitution commits an offence and is liable to imprisonment for seven years” (Section 139, Chapter 120 Ugandan Penal Code Act 120: 67). In this way the law clearly outlines, and inadvertently emphasizes, a series of activities that are networked, communal, and social-capital producing. As the code delineates these social affects in order to determine who is prostituting and/or benefitting by association, the law has an inverse effect on the country's strategies to stem its HIV epidemic (Scorgie et al. 2013). This is clearly illustrated in the data I collected about how the practices listed in Uganda's Penal Code are exactly those behaviors where HIV risk and the possibility of HIV risk management are most necessary.

By analyzing the Penal Code, in conjunction with Uganda’s national HIV policy, it is possible to recognize the contradiction in the country's efforts to curb, prevent, 
and/or treat HIV. This is because Uganda's Penal Code inversely enacts a process of prohibition whereby HIV prevention, treatment, and care are concerned. This is especially true for individuals and behaviors associated with the sex trade. In this way the Penal Code acts upon the discourse of Uganda's HIV policy by way of linking, what Comaroff calls "Western ideas of medical knowledge...with ways to address nonnormative sexuality through a language of retribution” (Comaroff 2007: 197, 199). Demanding punishment for behaviors that transgress sexual and gendered norms, the Penal Code in turn limits the capacity of the country's HIV strategies. And in turn, necessitates that women find alternative means for how to manage daily risks associated with sex work, criminalization, and HIV/AIDS in Kampala slums.

\section{Chapter Summary}

This second chapter provided the background for the dissertation. It began with a review of literature on HIV, risk, and sex work, in relation to colonial legacies, sex work contexts and types, sex work risks, and insights gleaned from sex work HIV interventions. Next the chapter recounted a brief review of Uganda's HIV history. This account helped to situate the history of Uganda's national HIV policy, especially, how the policy developed in parallel to a larger and internationally driven discourse on AIDS in Africa. From there the chapter advanced the link between the country's national HIV strategies and Uganda's Penal Code, specifically, where prostitution is defined and understood in relation to practices and harm and punishments, as a means of curbing the spread of disease. With this background in place the chapter now concludes with a brief summary, as well as with an introductory explanation of the coming chapter. 
At the heart of chapter three is the theoretical and methodological dimensions of the research project. This next chapter delves into the literature on grounded theory; assesses the literature concerning the concepts social networks, community, and social capital; and finally, considers important ethnographic work specific to everyday practices and vulnerability, with particular sensitivity to moments of self-reflection related to the larger project of 'writing ethnography' (Crang and Cook 2007). Together these concepts and methodological processes underpin the critical insights that helped me to explore how women manage daily risks associated with sex work, criminalization, and HIV/AIDS in the slums of Kampala. 


\section{CHAPTER III}

\section{THE LINKS BETWEEN READING AND WRITING: A CASE FOR GROUNDED THEORY AND ETHNOGRAPHY}

"I use a specific methodology called Grounded Theory...the basic premise...is to start with as few preconceived ideas and assumptions as possible so that you can build a theory based on the data that emerges from the research process" (Brown 2010: 128)

"Social network analysis is especially suitable for understanding the AIDS epidemic...whereas many infectious diseases are spread through casual contact and contagion, HIV transmission results from risk-behaviors that involve close and often intimate contact...as a result the transmission of $H I V$ is structured by the social relationships within which these contacts are embedded" (Heckathorn et al. 1999: 159).

"...The core idea of social capital theory is that...the ways our lives are made more productive by social ties...it has both an individual and a collective aspect...can thus be simultaneously a 'private good' and a 'public good'...comes in many different shapes and sizes with many different uses...[and] can be directed toward malevolent, anti-social purposes, just like any other form of capital” (Putnam 2000: 20-21).

"How we think of community will affect how we think about the concept...including the resources that may exist within communities to address common problems...(Norton et al. 2002:196)

What is the value of ethnography... the ethnographer knows the personal history of the community...she is their genealogist and because of her privilege she can readily call to mind the fragile web of human relations that binds people together into a collectivity" (Scheper-Hughes 1992: 2829)

“...In understanding what ethnography is, or more exactly, what doing ethnography is...it is establishing rapport, selecting informants, transcribing texts, taking genealogies, mapping fields, keeping a diary and so on...it is [a] kind of intellectual effort...a venture in 'thick description'...written not in conventionalized graphs of sound but in transient examples of shaped behavior” (Geertz 1973: 6, 10). 


\section{Introduction}

This chapter forms the conceptual bedrock of this dissertation. It is the bridge between the social, historical, and political contexts described in the previous chapter, as well as the data described and analyzed in my coming findings chapters. The objective of chapter three is to bring together several concepts (i.e. grounded theory, social networks, community, social capital, and ethnography) in order to clarify how each term lends itself to exploring the implications of particular social phenomenon; phenomenon deeply connected to the choices women make about how to manage their risks. This chapter also calls upon these concepts for their capacity to place women's risk management practices beside the core principles of HIV/AIDS interventions motivating Uganda's policy response to the virus in the context of the larger global discourse of AIDS in Africa.

I begin by introducing and explaining grounded theory. As an approach, grounded theory describes the spirit of my data collection, which is best understood as an iterative process (Charmaz 2014: 89). Next the chapter briefly introduces three concepts: "social networks," “community,” and "social capital”. The explanatory capacity of each term is discussed only in so far as the meaning and history of the concept facilitated the data analysis in my findings. ${ }^{23}$ Following is a discussion of literature on ethnography, which prioritizes HIV/AIDS and/or disease in relation to everyday practices and interpersonal vulnerability. An in-depth reading of this ethnographic literature reveals the interlocking

\footnotetext{
23. Each term comprises an area of research, but for the purposes of this dissertation these three concepts are primarily discussed in relation to literature concerning HIV/AIDS.
} 
nature of theory and method, most explicitly when coupled with a particular form of writing and self-reflection ${ }^{24}$.

The melding of theory and method, with self-reflexive writing, when explained, underscores what Fetterman describes as the: "importance of understanding the epistemological basis from a phenomenologically oriented paradigm” (Fetterman 1998). By approaching data collection as well as writing from a self-reflexive perspective, the social problems described in this dissertation personalize the challenges of women's daily lives, particularly as they bare consideration with Uganda's current policy approach to its HIV/AIDS epidemic. In doing so my dissertation melds the personal and political in order to consider the social implications of these women's risks, and to suggest better suited ways for policies, and therefore programs, to address the dynamics of vulnerability shaping women's everyday practices in the slum. Finally, as the chapter concludes I offer a both an overall summary as well as an introduction to the findings. In this second section of chapter three, the conclusion prepares the reader for understanding and interpreting the data, while simultaneously initiating a transition from discussing evidence as "static and [in the] overly simple way field research is usually configured" (McCarthy Brown 2001: xi) towards a style of ethnographic writing most concerned with reaching "the last layer...the continuous, dynamic, reciprocal interpretation [that] gets us

\footnotetext{
24. Ethnographic writing is a particular preoccupation of ethnography. Ethnographies are literary exercises as much as scientific endeavors set out to capture impressions of embedded practices associated with community, culture, and/or socialization. In order to fully give voice to the research experience, as well as represent the information I was entrusted with by the women and men in each research community, it is important to utilize a style of ethnographic writing that attempts transparency (i.e. situates me and the participants in terms of my "self", as a "subject", engaging in a research process about "others", who are "agents" in their own risk and risk management behaviors).
} 
closer to what really happens...when an ethnographer is doing research in multicultural urban centers...” (McCarthy Brown: 2001: xi).

\section{Concept One - Grounded Theory}

In 1967 Glaser and Strauss introduce the concept of grounded theory in their text The Discovery of Grounded Theory: Theoretical Strategies for Qualitative Research. The authors define the term as "the discovery of theory from data systematically obtained from social research" (1967: 2). Their claim is that with grounded theory the emphasis is on "the practical application of grounded social theory with (at least) four highly interrelated properties” (original parentheses) (1967: 237). These four components involve:

...First...that theory must closely fit the substantive area in which it will be used...second, theory be readily understandable by laymen within this area...third, theory be sufficiently general to be applicable to a multitude of diverse daily situations within the substantive area...fourth, theory must allow the user partial control over time (original italics) (Glaser and Strauss 1967: 237).

Combined, their work $(1967,1978,1992,1998,2001$, and 2005) served to refine the meaning, intention, and utility of grounded theory. As a result the concept evolved over time. Yet, at its core grounded theory continues to be "a systematic, inductive, and comparative approach for constructing theory” (Charmaz 2014: 1). The approach encourages researchers to continuously engage with their data, while allowing data and theory to integrate as each informs the other (Bryant and Charmaz 2014). ${ }^{25}$ Time gave rise to interpretations, and grounded theory became understood more specifically in

\footnotetext{
25. For a more thorough review of grounded theory methodology see Grounded Theory (Bryant and Charmaz 2014).
} 
relation to methodology. Subsequently, the methods of grounded theory serve as a basic process for research that includes:

- Simultaneous involvement in data collection and analysis

- Constructing analytic codes and categories from data, not from preconceived logically deduced hypotheses

- Using the constant comparison method, which involves making comparisons during each stage of analysis

- Advancing theory development during each step of data collection and analysis

- Memo-writing to elaborate categories, specify their properties, define relationships between categories, and identify gaps

- Sampling aimed toward theory construction (theoretical sampling), not for population representativeness

- Conducting the literature review after developing an independent analysis [sic] (Charmaz 2014: 7-8).

Characterizing grounded theory, these key points came about in response to debates shaping the discipline of sociology in the United States. It seems the approach has a history that overlaps with greater changes in social theory, especially those involving quantitative and qualitative approaches (Charmaz 2014). Grounded theory was proposed as an alternative to "positivistic conceptions of scientific method and knowledge...[that] stressed objectivity, generality, replication of research...falsification of competing hypotheses and theories... and the assumption of an unbiased and passive observer who collected facts but did not participate in creating them...” (Charmaz 2014: 2). Grounded theory was seen as a way to bring about a compromise between "two contrasting and competing traditions in sociology: Columbia University positivism and Chicago school pragmatism and field research” (2014: 8-9). Emerging from ethnography, grounded theory scholars were seeking a more adroit means of pursuing qualitative analysis (Timmermans and Tavory 2007). Reflecting upon these roots helps to provide a means of crafting an epistemological way to pursue research deviating from positivist 
prescriptions and deductions. Thus grounded theory offers an important means of characterizing the data collection process undertaken in the dissertation.

The research process for this dissertation diverged from positivism, and in doing so, managed to devise theory from the ground, where data collection remained rooted in ethnography. This is because grounded theory provided a means of bridging "within IR...standards for methodological rigor that can make a difference...” (Ackerly, Stern, and True 2006: 6). The rigor I intended allowed my work to pursue research in-line with other feminist scholars of international relations (Ackerly 2000; Enloe 1983, 2000, 2000, 2004; Moon 1997; Peterson 1999 and 2003; Prugl 2015; Sjoberg 2006; Tickner 2001; Weber 1999; Whitworth 1994; Young 1990 and 1997; Zalweski 2013). These feminist researchers have long questioned the theoretical approaches (models and methods) IR has drawn upon from "economics and the natural sciences to explain the behavior of states in the international system” (2006: 25). Rather than attempt IR scholarship predicated on the assumptions of positivist social science, my work supports pursuing research in-sync with how other "IR feminists have used sociological analyses that start with individuals and the hierarchal social relations in which their lives are situated” (2006: 25). Aligned with this foundation the research of this dissertation builds upon scholarly inquiries concerned with everyday practices and vulnerability, as they can be interpreted through the lens of social networks; as they play out within the confines of community; and, as they are shaped by the reciprocal nature of social capital.

\section{Concept Two - Social Networks}

J.A. Barnes (1954) introduced the term "social network" during his analysis of class dynamics in the Norwegian Fishing Village of Bremnes. Barnes describes a process 
whereby "each person is...in touch with a number of other people, some of whom are directly in touch with each other and some of whom are not...[and] finds it convenient to talk of a social field of this kind as a network" (original italics) (Barnes 1954: 43). Barnes' sole focus, in the use of social networks, was to understand the social class structure of Bremnes. Yet, in his efforts to explore class his work spawned an important insight: "from merely one point of view [one can observe]...a network of relations between pairs of persons according each other approximately equal status” (1954: 45).

While Barnes sought to develop a theoretical means of conceptualizing social class relations between individuals, and as a result generated the concept "social network", his insight would be advanced. The phrase "social network" has evolved in association with an idea. According to Scott the "phrase has become a hallmark of a distinctive style of sociological work—social network analysis [SNA]...appealing to those of a mathematical cast of mind...” (1988: 109). Today the vast majority of SNA is carried out with the assistance of software capable of calculating the dimensions of social interaction, first described by Barnes (1954).

En route to computations SNA has been applied with interdisciplinary tact to address the particular social problem of HIV transmission, risk, and intimacy. The literature concerning HIV transmission has applied SNA to explore, reveal, or contest dominant narratives concerning individual risk behavior (Bourgois et al. 1997; Heckathorn et al. 1999; Helleringer 2007; Kohler et al. 2007; Latkin et al. 2010; Maguire 1983; Mitchell 1969; Scott 1988 and 1991; Smith and Nichols 2008; Wellman and Berkowitz 1988; Wallace 1991; Wolfe 1978 and 2011). Consequently, SNA has offered a means of challenging "the tenets of methodological individualism" (Bourgois et al. 1997: 
155 ) in pursuance of deeply understanding the inter-relational dynamics that individuals exhibit in connection with HIV and risk. Studies applying SNA understand the minutiae of what Bourgois calls the "interpersonal power hierarchies, hidden income-generating strategies, and repeated mutual betrayals” (1997: 158). And it is precisely these, the interrelational applications of SNA that offer a means of interpreting daily risk without necessitating a mathematical model.

In lieu of a mathematical model, this dissertation retains the principles of SNA, while constituting risk through sociability. Here risk is understood in relation interpersonal practices that individuals develop in order to maintain their social networks. Therefore my research identifies social networks as only one part of greater pattern of the sociability of risk. An individual's social network represents an aspect of this pattern. Networks develop out of any relation; in this case a woman's network can include other women in the sex trade, brothel managers, pimps, clients, boyfriends, police officers, HIV clinic staff, etc. These relationships can be formed and found in multiple settingsbars, lodges, clinics, and/or the street. The location lends itself to how a network expands and develops (Latkin et al. 2010). The development of a network therefore draws on the social capital individuals offer one another in the form of information and/or material support. And while networks provide support, they also disperse risk. A network provides a means for risky events, which may initially impact one person, to move through the web of social ties impacting other members (see chapter four). But just as networks become primary ways for risk to move through individuals' lives, interdependence also makes it possible for risk to be managed collectively, while offering a means of solidifying communal relations (Heckathorn et al. 1999). 


\section{Concept Three - Community}

The term community is incredibly broad, as is the literature about the concept. As a result, I restrict my use of the term to the common sense way it was found in the data. Based on my data "community" is defined by the ways individuals experience a sense of interdependence and how this in turn results in ongoing mutual obligations. Understanding community this way allows for it to be seen as an expression of interconnectivity. Interconnection, which I found exists between members of the same sex work community, illustrates another facet of risk—sociability. Social networks help disseminate risk, as well as provide a means of mitigating problems. This is because risk offers individuals a way to forge bonds out of ongoing practices associated with their survival. I found this to be true in both communities, where the process of community formation came about through incidental moments women and men spent time together. However, before I could articulate my own definition it was important to search the literature on HIV and community.

The concept “community”, in connection with AIDS, spans the fields of social movements, community empowerment, community development, and community capacity (Lippman et al. 2013). Use of the term in these areas is often done in conjunction with behavioral change interventions (e.g., WHO Toolkit for Targeted HIV/AIDS Prevention and Care in Sex Work Settings, 2005). These fields constitute community apart from any one person’s social network (Lippman et al. 2013). When considering my own findings, I found that while all people working and living in the slum can be defined as members of the community, not all of these individuals are 
included in a social network patterned by actions specific to commercial sex. In response, I shifted my analysis to practices.

Once I came to understand "community” in relation to certain practices, I found it easier to do as Whyte (1993) suggests, which is to view practices as a way to determine what constitutes a group of individuals. Whyte's own work in an "Italian slum" in Boston's North End showed, "how actions which were performed explicitly for the sake of friendship were revealed as being part of a system of mutual obligations" (Whyte 1993: 257). Like Whyte (1993) mutual obligations became a way to capture how the women and men from both of my research sites sustained their social ties. The obligations that developed from their social networks resulted from ongoing practices devoted to how they were helping each other counter vulnerability. This is something that took place even when survival sometimes competed with mobilizing these practices to increase respect from their colleagues and peers in the sex trade. Thus, the ongoing need of women and men in each community to attend to obligations, which helps thwart risk, can also be understood in relation to the norms of reciprocity associated with how women and men generate social capital in the slum.

\section{Concept Four - Social Capital}

Social capital, specifically as understood or defined by Putnam (1993 and 2003), offers a theoretical lens in which to interpret how women manage daily risks. The term rounds out the understanding of risk taken up in this dissertation, which concerns its sociability. I began with social networks, then incorporated community, and here I finally integrate the term "social capital" in order to complete the conceptual framework of this dissertation. The data presented in the findings describes how women attempt to address 
mutual obligations, which arise from interactions embedded in their social networks. As a result of these interactions, a basis for community coalesces around everyday practices. All the while these practices signify a deeper process at work. Mutual obligations arise from reciprocity - the give and take needed for women and men to stay afloat in a dangerous environment. Understood this way, social capital is what drives networks and cements the foundations of community.

Putnam (1993 and 2003) deconstructs reciprocity by breaking down the term into two parts: (1) specific reciprocity and (2) generalized reciprocity (2003: 20-21). In the first instance, specific reciprocity is understood as being generated one-to-one as in "I'll do this for you if you do that for me". Yet, generalized reciprocity is described as, "I'll do this for you without expecting anything specific back from you, in the confident expectation that someone else will do something for me down the road” (2003: 21). While Putnam is focused on the efficiencies of reciprocity in relation to trustful vs. distrustful societies, for the purposes of my research, his definitions provide a useful way of interpreting how everyday practices bind people together in their efforts to manage the hazards of sex work, criminalization, and HIV/AIDS.

Taken together, social networks, community, and social capital explain a complex process of survival shaping the ways women and men manage daily risks. Analysis of my data reveals the existence of particular patterns of behavior that are better understood through the lens of these three concepts. While it has been helpful to define each term above, via three distinct sub-sections, these distinctions are arbitrary and unlike the natural course in which each term percolates from the enmeshed description of both research locations. Ultimately, the description and analysis throughout the two chapters 
to come (four and five) continuously strive to reflect upon each concept (social network, community, and social capital) in relation to how they make sense of two very complex and shifting environments.

\section{Concept Five - Ethnography}

Ethnography and the Hard-to-Reach: Before, during, and writing the research

In order to support the reflexivity of my writing I deemed it important to consult a particular sub-set of ethnographic literature. Doing so has allowed me to incorporate the insights from scholars who are primarily concerned with situating the researcher and researched; with confronting the politics of representation; and, most especially with making sense of everyday practices and vulnerability. As a result, my efforts to explore women's daily risks were facilitated by an ethnographic literature that prioritizes selfreflexivity in the research and writing process.

My use of ethnography is inspired by what Marcus (1997) describes as a “tradition encompassing both fieldwork and the writing it engenders” (Marcus 1997: 231). Taking up this tradition has involved what Wedeen (2010) describes, "as a technique associated with a specific set of activities, such as learning a local language or dialect; participating in the daily life of the community through ordinary conversations and interaction; observing events; examining gossip, jokes, and other informal speech acts for their underlying assumptions; and recording data in field notes” (Wedeen 2010: 257). Yet, I also found it was important to recognize how these activities are complicated by the relationship between the researched and researcher. Wedeen (2010) is careful to note this complication as a condition within ethnographic practice: "the term participant observation is often used as shorthand for the double nature of these activities, in which a 
researcher is both an actor and a spectator" (Wedeen: 257). After 14 months of primary data collection, I believe the complexity of being both actor and spectator is precisely why my research with "hard-to-reach" individuals and settings necessitates an ethnographic approach before and during the research and throughout the writing of this dissertation.

While I pursued the activities Wedeen (2010) describes under the complex and double-natured rubric of participant observation, my data collection became an ongoing effort in survival for both the project and me. At the juncture of this tension, the technique of ethnography became my lifeline as the research sunk deeper into a context of deprivation similarly studied by Bourgois et al. 1997 and 2003; Farmer 1992 and 2006; Hunter 2010; and Scheper Hughes 1992 and 2004. Amidst each of my research settings, “doing ethnography” became a means of eventually enacting what Hunter calls: "story telling about everyday lives and emotions of those most marginalized in society" (Hunter 2010: 3). Like the work of Hunter (2010), this dissertation contributes and builds-upon theoretical and epistemological foundations of ethnographies concerned with illicit everyday practices, power relations, illness, and vulnerability (Bourgois et al. 1997; Bourgois 2003; Farmer 1992 and 2006; Hunter 2010; Scheper-Hughes 1992, 1996, 2004). Yet, the help I needed was most often found in the pages of four particular ethnographic sources. As a result I believe these four studies offered me the correct blend of theory, method, and writing best suited for how I could explore women's risk management in the face of sex work, criminalization, and HIVAIDS within the slums of Kampala. 
Ethnographic templates of vulnerability: Illness and the Everyday

Over twenty years ago Paul Farmer (1992 and 2006) published the monograph AIDS \& Accusations: Haiti and the Geography of Blame. In this study Farmer offered a compelling rendering of Haiti's HIV epidemic (including its roots, causes, and conditions) with insights about the ways "AIDS is deeply embedded in social and economic structures long in place” (2006: xi). In the book Farmer argues, "that violence, poverty, and inequality are the fault lines along which HIV spreads” (2006: xi). Farmer presents a way of pursuing research about “affliction” that combines history, economics, and power. In doing so he pushes us to think about how these overlapping realities invade the collective conscious, which in turn renders new socio-historical and communally based understandings about disease, suffering, and violence (Farmer 2006). The vulnerability Farmer describes is structurally positioned and observable from out of people's everyday experiences. As a result, research like mine is supported in its efforts to reveal how HIV is both an interpersonal condition and a reflection of the impersonal and material effects of policies. In this way I am theorizing, as well as writing, about daily practices, as being both local and global manifestations of political, economic, and social structures; particularly, those most intertwined with how policies seek to resolve the crisis of AIDS.

Relying on people’s everyday lives to reveal structural manifestation of the AIDS pandemic has been furthered as well as refined. Mark Hunter's (2010) book Love in the Time of AIDS: Inequality, Gender, and Rights in South Africa endeavors to narrate the intimate details of AIDS in KwaZulu-Natal. Hunter sets out by contrasting the political economy of an informal settlement with the intimacies of daily life among its residents. 
Hunter is making visible "the fleshy, messy, and indeterminate stuff of everyday life" (Hunter: 4). He does this by showing the ways inequality becomes embodied by society's most vulnerable members. In this context, Hunter reveals the subtle ways inequality helps to establish locally understood power relations, which create opportunities for subjugation whereby "victims become victimizers" (Hunter 2010). These oppressive interpersonal relations are something I found in both research communities. Through Hunter's work I have been able to deconstruct the ways a collective group of individuals, such as female commercial sex workers, can become divided by localized ways of competing and belonging. In my findings I describe how the immense pressure to solidify their social networks through favors and/or mutual obligations perpetuates a hierarchal system of acceptance among women and men in both sex work communities. The results of which create victimizers among a class of individuals, who as both Farmer and Hunter show, are already victims of structural violence and social neglect (Farmer 2006 and Hunter 2010). Addressing the vulnerability of daily life, Hunter along with Bourgois and Scheper-Hughes (2004), grapple with daily living in relation to disease and death in the context of community and interpersonal processes. By doing so, their work stretches the bands of ethnography, making it possible to utilize participant observation as a means of studying the social and structural dimensions of oppression that accompany social marginalization (Bourgois et al. 1997).

Social marginalization is a central tenet of Bourgois’ work (1996, 1997, 1998 and 2003). His reliance on "ethnographic immersion" is well suited for his exploration of what he calls "chronic social suffering” (Bourgois 2003: xxii). In this way, Bourgois' research provides important insights about interpersonal practices that have implications 
for risk and respect (Bourgois 2003). By utilizing "the power of ethnography”, Bourgois (1996 and 2003) believes it is possible to move in closely, to be on the ground, in order to intimately account for vulnerability and localized understandings of suffering (Bourgois et al.: 2003 156). With these tenets in mind, my work sought similar means of engaging with the women and men in both of my research communities. My efforts reflect a deep belief that organic immersion leads to valuable knowledge about interpersonal connections and reciprocity. I found this to be true especially in my first community, where women's risk management practices slowly emerged over the course of 14 months. And even in my second community, to some degree, I was able to identify the ways in which men's networks revolve around risk inducing practices.

Bourgois (1998) adamantly attests to the benefits of ethnographic approaches, specifically in relation to public health research (Bourgois 1998: 2323). Yet the benefits of an ethnographic approach can be furthered by reflexively writing. Writing that addresses the complexities of participant observation in such a way as to "illuminate the general through a focus on the particular” (Callaway 1992: 31). In this way, research like mine is goes beyond accounting for difficult and unsettling social realities through participant observation. This is because my work strives to document and describe "everyday social suffering” in order to push for practical and applied ways of developing HIV interventions predicated on social contact and sustained interaction with vulnerable populations.

Sustained social contact among the vulnerable has been an essential component of the research taken up by Nancy Scheper-Hughes. Although Scheper-Hughes has disclosed a more explicit commitment to studying and writing about violence, her work 
provides a compelling way of positioning "everyday practices" within structural analyses of social, economic, and political marginalization and dislocation (Scheper-Hughes 1992). Critically interpreting people's ongoing behaviors is an important tenet in her book Death Without Weeping: The Violence of Everyday Life in Brazil (1992). Here Scheper-Hughes reveals an entrenched history of suffering in a region of northeastern Brazil, which she describes as a "...land of sugar and hunger, thirst and penance, messianism and madness [sic]" (Scheper-Hughes 1992: 20). Writing about a shanty town in Alto do Cruzeiro, and its residents, Scheper-Hughes is able to present, as well as reflect upon, “the everyday tactics of 'getting by' and 'making do'...” (Scheper-Hughes: 21). She carefully describes and theoretically positions how people's everyday practices can inadvertently contribute to a series of fatal circumstances: "early child death...in a set of conditions that place infants at high risk, accompanied by a normalization of this state of affairs in both the private and public life...[creates] an environment in which death is understood as the most ordinary and most expected outcome for the children of poor families” (Scheper-Hughes: 20).

Scheper-Hughes depictions of "making do" and "getting by," in a context of poverty and infant death, are couched in a strong commitment to grappling with what she describes as a departure from traditional or classic ethnography (Scheper-Hughes: 23). In this way Scheper-Hughes presents an "ethnography of vulnerability" cognizant that it is impossible to "rid ourselves of the cultural self we bring into the field" (Scheper-Hughes: 28). Here she is revealing the tensions of fieldwork that are concerned with the ongoing ways both the researched and the researcher coexist, while also contributing to a larger corpus of theory about vulnerability, which assists in the development of research such as 
mine. This is because like Scheper-Hughes, my work is set inside an environment where daily practices, born out of a need to survive, often inadvertently bring greater risk.

Yet in order for me to identify this process of risk making, I had to find ways of managing my own understandings of safety, security, health, and ultimately survival. By doing so I became vulnerable, that is open and sensitive to the vulnerability around me, and therefore better able to capture and record the risk of the women and men in each community. Risks, which I found, often signify individuals' attempts to manage daily life, while effecting unintended consequences. In this vein, and with the insights from Farmer, Hunter, Bourgois, and Scheper-Hughes, my intentions within this dissertation are to demonstrate how the power of empathy and compassion in the process of data collection, helped to ground my efforts to explore the everyday practices and vulnerability of two very different communities; places I consider hard-to-reach in terms of the settings as well as the individuals. Overall, these four ethnographic studies provide a basis for the ways I contend with describing and analyzing the risks women face in their efforts to manage sex work, criminalization, and HIV in the slums of Kampala.

\section{Chapter Summary}

Chapter three introduced and expounded upon several concepts (grounded theory, social networks, community, social capital, and ethnography) for the purposes of bridging the background, history, and policy discussions in the previous chapter with the description and analysis in the findings to come. In the spirit of grounded theory, the research process in this dissertation has been ethnographic and especially non-positivist. In seeking to move beyond the bounds of the "objective" exercise of clinic data that positivism prescribes, the chapter has suggested how the meaning and use of the concepts 
"social networks," "community," and "social capital" are integral for the purposes of this dissertation. In the first instance, social network theory is useful for exploring and accounting for inter-relational dynamics, as they have implications for individual's social connections. As we shall see below, the nature of the social networks in which individuals are embedded create conditions that allow them to cope with the risks associated with sex work.

As a basis for chronicling inter-relational dynamics and social connectedness, my use of social network theory underpins my understanding of community. The concept of community is discussed as a means of interpreting how conditions of coexistence arise among individuals. Coexistence is then deconstructed through the notion of mutual obligation, which forms a theoretical means of explaining what constitutes community. Obligations are discussed in order to establish how social capital, explicitly reciprocity, is a process that partly shapes everyday practices connected to survival among vulnerable and hard-to-reach individuals.

Once explained and linked, the chapter cautions that each concept (social networks, community, and social capital) is drawn upon in a self-reflexive manner during the findings. The tenor and pace of the self-reflection is described in alignment with the process of gathering information and sharing insights ethnographically. Discussing ethnographic data collection and reflexive writing, was addressed first by unpacking ethnography and its ensuing activities (e.g., participant observation). Next the inherent dichotomy of being both 'actor' and 'spectator' is explored through four ethnographies of vulnerable communities coping with risks not unlike those faced by myself. By approaching the topic of risks faced by sex workers in Kampala with the ethnographic 
tools forged out of compassion and awareness of that helps my efforts to document and describe their vulnerability, the works of Farmer, Hunter, Bourgois, and Scheper-Hughes provide an important basis for the research project in this dissertation. Finally, the chapter reflects upon how these four ethnographic studies ground as well as position the way my research understands and critically interprets "everyday practices” and "conditions of vulnerability” in relation to women's HIV risk.

Moving forward, the next chapter concerns the experiences and findings that emerged between when I arrived in Kampala on 2 June 2012 and when I departed on 2 August 2013. Writing self-reflexively I reveal the messiness of the ethnographic research. In this way the dissertation takes up the work of disclosure presented by Sanchez Meertens (2013) who, writing about Sri Lanka’s Civil War, speaks to the difficulties of messy projects. Meertens cautions that research must resist attempting to know root causes and, instead, focus on how specific actors interpret conditions so as to fulfill personal desires and ambitions (Sanches Meertens 2013: 18). What lies ahead is a description of two very different communities, which I first introduced in chapter one. In these two dissimilar places I came to learn how inhabitants interpret conditions, as well as engage in interpersonal negotiations in order to fulfill needs and wants they believe will help them to thwart personal risk. The first of these findings chapters begins with my experiences in the community I call Babito. This chapter offers a description of the social complexities of women's risk management. I do this by introducing the setting along with the women who entrusted me with their personal histories, daily habits, and private hopes and fears. Following is my second findings chapter, which is based on the events that 
took place in Kiku, the second community in my research. The chapter is driven by men’s experiences with social networking, reciprocity, and community formation.

In this way, I have come to deeply believe that by researching women's risk management as well as identifying men's risk practices, I am able to understand and compare the ways in which risk is divergent in terms of location, and yet similarly negotiated interpersonally. As a result of these experiences it is even more possible to understand the sociability of risk. Finally, I take time to explain my presence, role, and interests in the research. By doing so, I explain the tensions that arose as I balanced being both “actor and spectator". As I describe my efforts to overcome these constraints, the findings reveal a personalized approach to learning about the competing ways women and men behave in response to volatile conditions that influence their choices. Finally, in choosing to meld data collecting with personal circumstance, this dissertation offers my own rendition of "ethnography that is woman centered" (Scheper-Hughes 1992: 25). Taking up this "feminist project”, ${ }^{26}$ I hope to bring about better solutions for responding to how sociability shapes risk by way of the mutual obligations embedded in communities grappling with vulnerability associated with sex work, criminalization, and HIV/AIDS in the slums of Kampala.

\footnotetext{
${ }^{26}$ Here I am referencing Scheper-Hughes' self-reflections, “As a woman and a feminist...I am drawn to the experiences of women, and their lives...” (Scheper-Hughes 1992: 25). In addition to her use of feminist, my reference to feminism aligns with the way, "all power relations are essential to feminist perspectives and to the feminist research process, [and to which], feminist methodologies are highly relevant for the study of global politics” (original italics) (Ackerly, Stern, and True 2006: 1). In this case, my work is preoccupied with the power relations between women, between men, and between women and men. In doing this, I am applying a feminist lens that seeks to reveal the power embedded in these gendered relationships. I believe, and show in my findings, how these dynamics have implications for the way global AIDS policies come into being and fall away into oblivion on the ground through the interpersonal processes that shame women and complicate men's daily lives in sex work communities.
} 


\section{CHAPTER IV}

\section{THE COMFORTS OF COMMUNITY: FINDINGS FROM A BROTHEL COMPOUND IN RUBAGA}

Figure 4.1 - Picture of outside Babito brothel

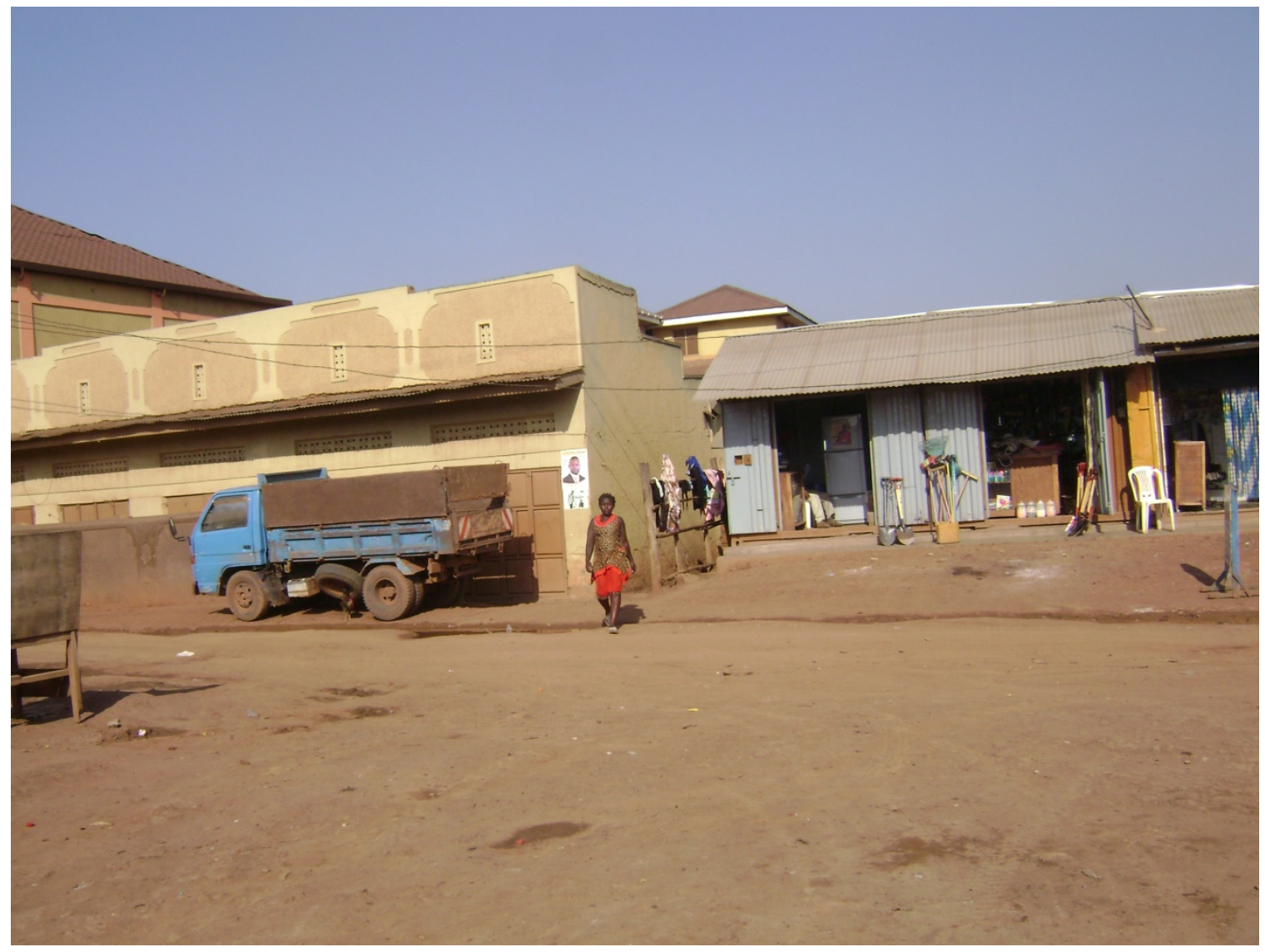

\section{Introduction}

Life in the brothel certainly leaves women vulnerable and uncertain about their survival. Yet the residents have a myriad of ways to grapple with their susceptibility to risk. I came to understand the complexities of these habits by carefully listening to their personal histories and juxtaposing these stories with observations and instances of women's social interaction. When I gained access to women's inner circles and private spheres, I found specific risk-management practices. These included sharing information, 
maintaining relationships, and securing material support; perpetuating social control in the form of stigma, isolation, and castigation; brokering and betraying trust; and, collectively enduring gains as well as losses. Taken together these practices form the basis of women's survival strategies.

I organize these practices into five themes: (1) coexistence, (2) intimacy, (3) interconnectedness, (4) preservation, and (5) secrecy. Each theme offers a means of exploring a multifaceted body of evidence culled from an environment wherein risks are ongoing and volatile. While these themes increase the intelligibility of women's risk conditions and their practices of risk management, they do not represent a definitive solution to the problem of insecurity. There is almost no way to totally capture the precariousness of their existence and the alienation they endure in order to survive. Yet even as women's lives are molded by these dynamics, there continue to be ways in which they succeed in coping with risk. Therefore, I believe it is important to share an impression of these practices, as well as the interpersonal entanglements in which women become caught up when choosing to practice sex work in a Kampala slum.

Of all the practices I documented, the most basic to the formation of women's social ties, that is their networks, involves the incidental time they spend together. These happenstance moments provide women an opportunity to build and practice coexistence. This first theme describes the links between the brothel setting and women's daily routines. Women's unplanned time together spurs their social networks, builds their social capital, and contributes to the formation of their community. But their sociability is framed against an environmental context that is dangerous and isolating as much as it is 
congenial and sheltered. When women find security in their coexistence, they have a basis for intimacy.

Intimacy is my second theme. It captures women's meaningful exchanges. Women keep each other's company or disavow and slander fellow residents in pursuit of safety. These practices give rise to stigma and segregation. But at the center of women's alienation, as well as their connection, is hierarchy. Women's power and authority is divided. These divisions allow some women to implement and maintain a particular social order, which benefits their survival while leaving less socially connected women to flounder. Both positions reflect an important process I call interconnectedness. This third theme builds upon women's intimacy. Women's intimate practices manifest into collective action with uneven results. This is because women's interconnectedness brings prosperity as much as social division. Fueling women's interconnectedness is a need for preservation.

Women's efforts to avoid criminalization reveal their most explicit practices of preservation. This fourth theme captures the durability of community survival, which is most vulnerable in the face of police brutality and judicial coercion-two social forces that combined punish women. Preservation is central to how women escape these criminalizing measures. Yet preservation is also linked with how residents lose their freedom and property. The turbulence caused by policing gives rise to hardship, but also to opportunities for women to redistribute resources and strengthen their community. Strong community bonds keep women safe but also silent. Secrecy is the final theme. Secrecy is a practice women sustain to secure resources for HIV care (e.g., condoms, medications, treatment). But maintaining silence undermines women’s sociability and 
ties in the community, while increasing risks to their health. This final theme exhibits the dangerous lengths women will go to protect their resources. For many women survival is about balancing competing secrets even when keeping silent results in physical illness and social isolation.

Ultimately the findings in this chapter focus on the everyday practices of women's social support. In the case of Babito brothel, risk management is conditioned by women's collaboration and their mechanisms for social control. The themes described above, taken together, ground the position taken up in this dissertation. At the core of my work is a belief in the power of women's experiences to better inform future policy approaches primarily concerned with how women manage daily risks associated with sex work, criminalization, and HIV/AIDS in the slums of Kampala, Uganda.

\section{Coexistence}

\section{Figure 4.2 - Picture of Babito Road}

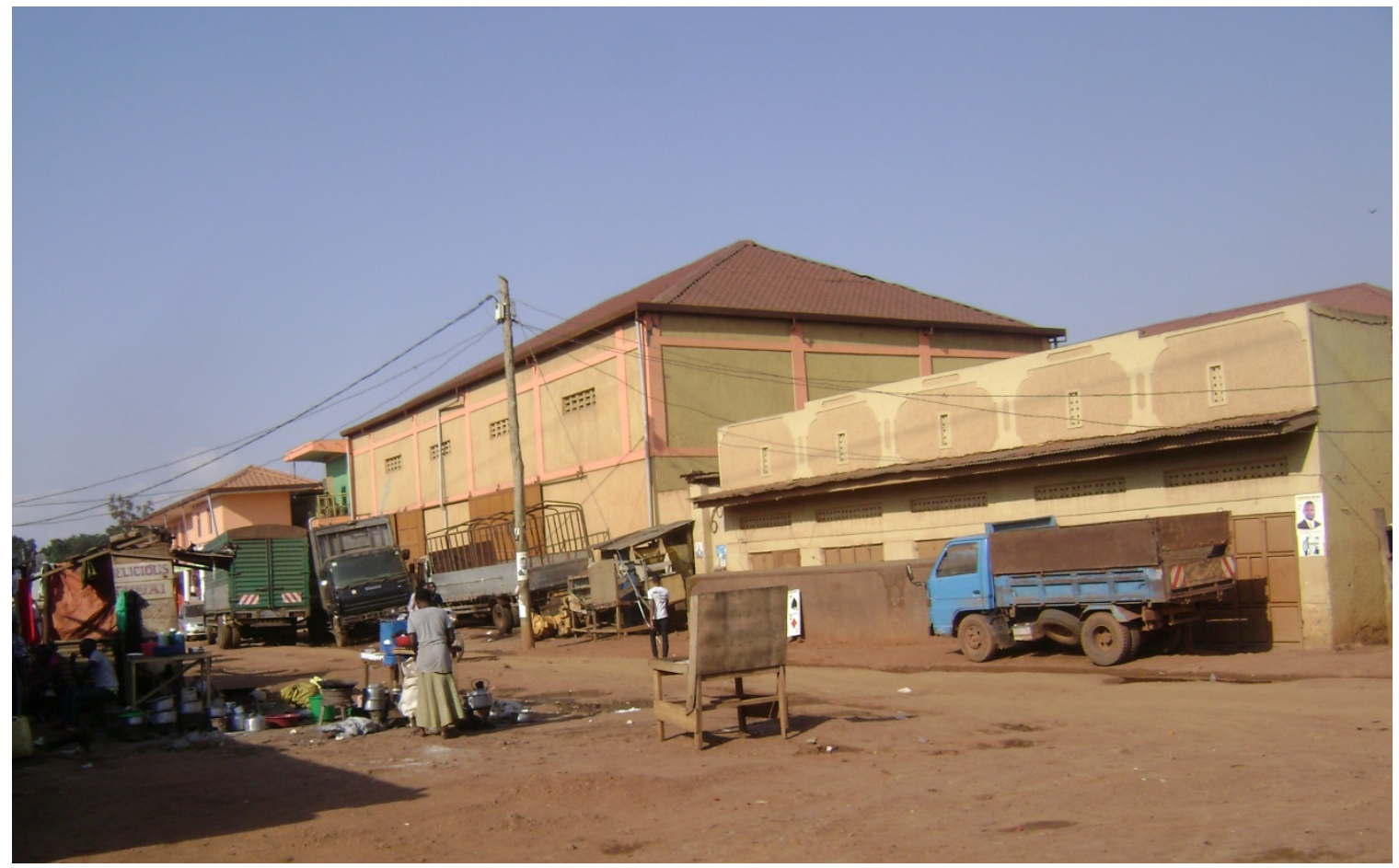




\section{If These Walls Could Talk}

"Rain disorganizes us when it pours so hard filling up all the places, which forces us to move and return when it dries up..." (Anna, 18 October 2012)

If the walls of the brothel could talk, the stories they most likely tell begin with the place itself. The large compound, called Babito, is located along a muddy finger path branching off from Musaka Road, just before exiting Kampala en route to Mbarara. Babito has two open areas and three sections of rooms. The layout of the building is deeply entwined with women's daily practices. Women who rent in the front of the compound belong to the "Clinic". Available "Clinic" rooms contain a bed consisting of a wooden frame and a foam mattress encased in fabric. Beds are typically large enough to hold two adults and are elevated from the ground high enough to allow for storage underneath. In the rooms women keep condoms, beauty supplies, bags, shoes, and clothes are either strewn on the floor, hanging from wooden pegs, protruding from large empty cardboard UNFPA condom boxes, or piled into plastic tubs. Fortunately for women in the “Clinic,” the cement floors in their rooms minimize vermin (roaches, ants, mice and rats) that can damage the women's belongings.

Women describe the "Clinic" as quiet and separated from the raucous events taking place in the second, newest section of the brothel, called the "Bus. The "Bus" is a freestanding building set back from the brothel's main entrance/exit, and it appears much newer than the rest of the compound. Both the outer and inner walls are painted a light butter yellow, and a long hallway extends from the entrance. Rooms line the right side of the hallway and three separate corridors branch off to the left. The brothel management keeps a list of rules hanging above the building’s entrance, as well as on the opposite wall 
of the hallway. These handwritten guidelines dictate, in Luganda, expectations for resident's personal conduct:

Tubaaniriza mu bulamu bwaffe obujja (N'amateeka gawandikiddwa) ne mu nnyumba

Tulina okugondera Amateeka n'eBiragiro

Obukyafu tebukkirizibwa

Okufuweeta emmindi mu kisenge tekukkirizibwa

Okuyomba n'okulwana tekukkirizibwa

Bw'oyonoona omufaliso ogula mupya

Okubba n'okuggulawo ebisenge by'abalala tekukkirizibwa

Omugenyi alina okweyanjula

We welcome you to our new house

We have to abide by rules and regulations

Dirtiness is not allowed

Smoking pipes in rooms is forbidden

Quarreling and fighting is forbidden

When you destroy a mattress you buy a new one

Stealing and opening other people's rooms is prohibited

You have to identify visitors yourself

The rules inside the "Bus" reflect a preoccupation with specific inter-personal and bodily conduct. While these rules place an emphasis on regulating women's use of space, they also reveal an important discursive practice concerned with decency and virtue. I reflect upon these practices in the following sub-section, intimacy, and again in my conclusion. Whereas here I draw attention to the connection these rules have to women's habits and social preferences. The rules tell us much about what is assumed women do (smoke pipes, quarrel) and what they are (unclean, thieves, destructive). These guidelines attempt to instruct residents to observe certain habits. By emphasizing what women should no longer do, the rules in the "Bus" inadvertently affect important dimensions of women's sociability in the brothel. 
Women's social tendencies are extensions of deeply held beliefs concerning lifestyle and routines. These ideas become enmeshed with women's conduct, which is reinterpreted in relation to where women reside in the brothel. In this way residency is symbolic of women's power and their capacity to consume and distribute resources. It serves as a marker of women's propensity to distinguish the personal practices of their peers, and demarcates territory in a way that results in a particular social order. Yet, against the backdrop of this social order, there are instances when women find themselves occupying the same open areas. These coincidental moments of coexistence form the building blocks of women's connectivity, and therefore, their social networks.

Just before the "Bus" there is an open space where women often sit on wooden benches and stools leaning against the building's outer walls. Women gather daily in this area to take their meals and enjoy time for leisure. In terms of meals, I found lunchtime to be the most popular meal of the day. My observations and conversations reveal that most women take lunch between 11:00 a.m. and 2:00 p.m. Women rarely possess a charcoal burning stove, and without the means to cook their own food, women turn to vendors from the community outside the brothel walls. Vendors are typically younger women who cook and sell large quantities of "matoke" (boiled and mashed plantains), "g-nut sauce” (groundnut sauce), green peas, beans, "posho” (white boiled corn meal that often has no taste and is used with fingers to eat other items such as peas, beans, and/or matoke), fish, and "palow" (fried rice and beef), and prepare fresh passion fruit juice. Most women receive their prepared food at the entrance to their room. However, some women prefer to eat outside. These women take their meals on wooden stools and benches at the base of the "Bus". 
Mealtimes are a more benign activity. Whether these picnickers purposefully plan to eat together or if their meals result from the pragmatics of ordering food, when they share meals these women upend, disengage, and/or overlook the competition, harassment, and even violence often coloring their interactions during nightly working hours. In these moments women seem capable of simply eating and being at ease. Their coexistence is a moment of communion that inverts professional demands requiring they perform an artifice of rarity to attract individual clients. Instead of competing, women's meals reset relations developed during each day. This daily practice allows women to ignore, shrug off, or disconnect with outbursts and/or harm committed against each other at night. By taking food simultaneously many women demonstrate a capacity to diffuse tension-filled practices. The good will from meals creates opportunities for harmony, because eating together minimizes discord and generates attachment through laughter, advice giving, and opportunities for women to support each other interpersonally.

When women manage to take lunch together the happenstance of their encounters deepens existing social relations and reaffirms their social networks, as well as offers chances for women to deepen their social capital. This happens again, when eventually lunchtime gives way to a second moment in the day where women's coexistence transitions from eating to leisure. Around 3-4 p.m. the open area at the base of the "Bus" transitions from outdoor cafeteria to a space where women perform daily routines playfully (braiding hair or painting nails; inspecting, comparing, and/or swapping clothing; taking up card games; "making noise" (gossip); doing chores, like bringing down laundry; sponge bathing; coming and going from the compound; and/or listening to music over mobile phones and dancing, singing, and/or swaying together). Women's 
lighthearted exchanges extend their social position and status. In turn these encounters actualize women's social capital. Many women hold these moments of casual and enjoyable engagement with little expectation for deeper connection. Yet the intimacy and reciprocity created during times of leisure provide a means for women to cultivate and consummate social processes of bonding and befriending. In this way coexistence in the brothel, while predicated upon necessity, offers women opportunities to lean-into the waiting hours before work by enjoying the company of fellow "nekos" (women in the “business”). Women's time together gives rise to deeper connections and greater chances for collaboration. By choosing to spend time in the same place women inadvertently strengthen their social networks; grow their social capital; and, nurture a fragile, but identifiable community.

Women's interpersonal ties often culminate in ringing laughter and boisterous conversation. Being inside the "Bus" I often heard the harmony of women's interactions echoing down the hall or bouncing between their rooms. Compared to the two other sections of the brothel, the rooms I visited in the "Bus" seem larger and built to accommodate more personal items. Tenants in the "Bus" experience far fewer environmental difficulties (flooding, heat, air pollution, mosquitoes, etc.). Fewer hazards make it easier for women to care for their belongings. Elevated and mostly constructed out of cement, the "Bus" remains cool most of the day. The building seems designed to minimize flooding and to regulate the indoor temperature. The "Bus" is by far the most secure and cleanest section of the brothel. Each room has a foam mattress covered in printed fabric resting atop a built-in double size bed frame made from cement and wood. Wooden pegs line the walls above the built-in bed. Although there is no running water, 
each room has a shower stall in the corner with enough space to keep a plastic bucket for washing. Above each door is a narrow screened opening letting in natural light and air. In comparison with the other sections of the brothel, the "Bus" seems built to accommodate a more realistic conception of what women need to manage daily life while practicing sex work (cool and dry rooms, shower stalls, screened openings for air circulation, etc.).

In contrast to the "Bus" the third section of the compound is by far the most remote and precarious set of rooms. Women call this last section of the brothel "Hell”. To reach these rooms residents must walk down a narrow passage over uneven rocks and puddles. "Hell" is essentially one long corridor. Rooms with grayish blue doors flank both sides of the areas long hallway, which ends into a large open cement paved square. This square is the second area in the brothel where women socialize on a daily basis. Here women convene to companionably pipe smoke and pray. Typically around 3:00 p.m. women begin to gather at the end "Hell". I often found women sitting on the cement floor, with their backs against perimeter compound walls, and grabbing at bunches of large dried dark green tobacco leaves. Women would then stuff these leaves inside long wooden pipes, which they eventually smoked. I am told that as smoke drifts upward women send prayers to ancestors and deities. But learning about women’s pipe smoking practice was difficult. What knowledge of the custom I gleaned came to me serendipitously.

Early in the data collection I began to mark a change in women's behavior around 3:00 p.m. each day. As that time approached, regardless of whether we were engaged in conversation, undertaking a group discussion, or holding an interpersonal interview, women stepped away and withdrew into the back of the brothel. At first I was unaware 
that the women were retreating to engage in their smoking ritual, so I followed. And there I found myself trespassing into a moment when many residents seek solace, privacy, and peace. I would need an accumulation of women's "off-hand" comments, their descriptions of one another in relation to habits and routines, and my occasional distant observation (seated at the entrance to "Hell" holding an interview and able to peer down the corridor), to see women quietly puffing, chattering, and/or chuckling together.

The quiet of women's pipe smoking reflects a stillness that settles over "Hell". The stillness enfolds women, who desire to practice this particular tradition, but realize they must do so with other residents out of necessity. This is because brothel rules prohibit residents from smoking in their rooms. As a result, women must share their pipe smoking time and space with other residents. Women's anecdotal information, combined with my observations, facilitates a means of piecing together how pipe smoking is a routinized daily practice.

Yet, unlike meals and leisure, pipe smoking is intentional and identifiable. Tobacco smoking is customary and deeply entwined with faith and ancestry. Women talk about the practice as a means of invoking aid for their livelihood and coexistence: "the women are smoking the pipe to pray to the Gods for help" (Roz, 10 April 2013). Prayers express women's heartfelt desires and sorrows. Rising smoke symbolizes women's entreaties for money, lovers, clients, children's school fees, as well as pleas to lift burdens, to keep safe from police, and to gain protection from other violations (clients, each other, curses). Smoke bespeaks women's beliefs that their ancestors and deities care for them, protect them, and if needed, guide them into making safer and more prosperous choices. In this way, pipe smoking is an individuated practice, whereby many women 
perform their beliefs by symbolically giving voice to personal desires, connecting with spirits, and fortifying ethnic ties.

Yet the practice in this instance gives women a chance to experience unity, which in turn relieves tension, calms unrest, and reinforces the bonds of community in the brothel. By jointly communing, residents demonstrate a willingness to practice a deeply personal habit with others. They also cultivate the basis for trusting each other. With trust women have greater reserves of social capital as well as deeper ties within their social networks. In this way, prayer, through pipe smoking, is a daily event capable of forging communal ties among women faced with prevailing inequity and exploitation that arises from social and environmental risks.

In terms of environmental risks, rooms in "Hell" exhibit a striking differencedeterioration. Here rooms have cement floors but are only wide enough to fit a twin size wooden bedframe, which is usually covered by a foam mattress encased in fabric. Decaying and cramped, rooms in "Hell" are also battered by environmental conditions, hastening the destruction of floors and walls, so they appear cracked and stained. "Hell" is an uncomfortable and often hazardous dwelling. Floods consume the area during the biannual monsoons. ${ }^{27}$ The heavy daily rain creates conditions in which women have few to none places where they can store and keep belongings safe from rising water. In the aftermath of flooding, puddles of water remain, providing a fertile breeding space for mosquitos. Water lines mark the outer and inner walls of rooms, leaving stains above women's beds. While women seem willing to struggle for some semblance of flood

\footnotetext{
27. Uganda experiences two monsoon seasons per year. The first takes place during the months of March, April, and May and the second during the months of September, October, and November.
} 
control, little is done to control air pollutants resulting from burning trash. The building adjacent to the brothel usually burns garbage in the late afternoon. ${ }^{28}$ Depending on wind direction thick smoke regularly curls throughout "Hell” blanketing the hallway in front of women's rooms. During this period of day women in "Hell” struggle to stay outdoors in the enveloping smoke.

Ultimately, each day residents of "Hell" must decide whether to leave their rooms. Women resolve to either seek refuge in the open area at the base of the "Bus" or stay indoors with no light. Many women renting in "Hell" seem to choose isolation and avoid the social space at the base of the "Bus". Their isolation is indicative of the frictions within the brothel. When women choose to be alone they are choosing darkness. In the dark, women in "Hell" attempt to avoid the tumultuous facets of women's interactions. By waiting in the opaque stillness, women hope to escape the ugly side of coexistence, which impedes connection and undermines intimacy. For women in "Hell" isolation is only a matter of time. As the day turns to dusk the only electrical fittings in the brothel, which line the walls of all three sections, begin to glow red. These red lights signal to women business time is upon them. And under the symbolic fixture of red bulbs, residents step out of their rooms and take up the pressures of nightly survival. ${ }^{29}$

$\underline{\text { Summary }}$

Residents of Babito brothel have learned to coexist within a space with few comforts. Women accept the necessity of sharing company during meals, leisure, and

\footnotetext{
28. Although garbage collection is managed by the Kampala Capital City Authority slums rarely benefit from public services and as a result garbage is burned in the open, electricity is syphoned from nearby, and/or sewage is open.

29. Red lights often indicate sex work districts and/or areas.
} 
pipe smoking. These explicit occasions signify women's capacity for generating connection. The happenstance of each daily routine allows women to formulate a basis for their social norms. It is precisely these norms, erected out of women's coexistence, that reflect their choices about survival. I believe it is critical to understand how women's social norms come into being and to whom these norms matter most. In the following sub-section, intimacy, I delve further into the ways particular norms, which are linked to residency in the brothel, have implications for women's abilities to develop their social networks. I describe how residency underlies women's willingness to purposefully engage one another and therefore foster intimacy.

Underpinning women's intimacy is the brothel's social hierarchy, which extends beyond coexistence as women forge social ties that either foster friendship or trigger animosity. These interpersonal conditions of rapport and enmity reflect the power of the brothel's hierarchy and the ways women perpetuate stigma, segregation, and disdain as well as how they experience trust and respect. Yet, women's sociability and their capacity to practice intimacy ultimately involves where they reside in Babito. In this way the location of a woman's room in Babito has implications for her capacity to build connections, as well as experience the benefits of social cohesion, when attempting to mitigate hardship. 


\section{Intimacy}

Figure 4.3 - Picture of inside Babito brothel

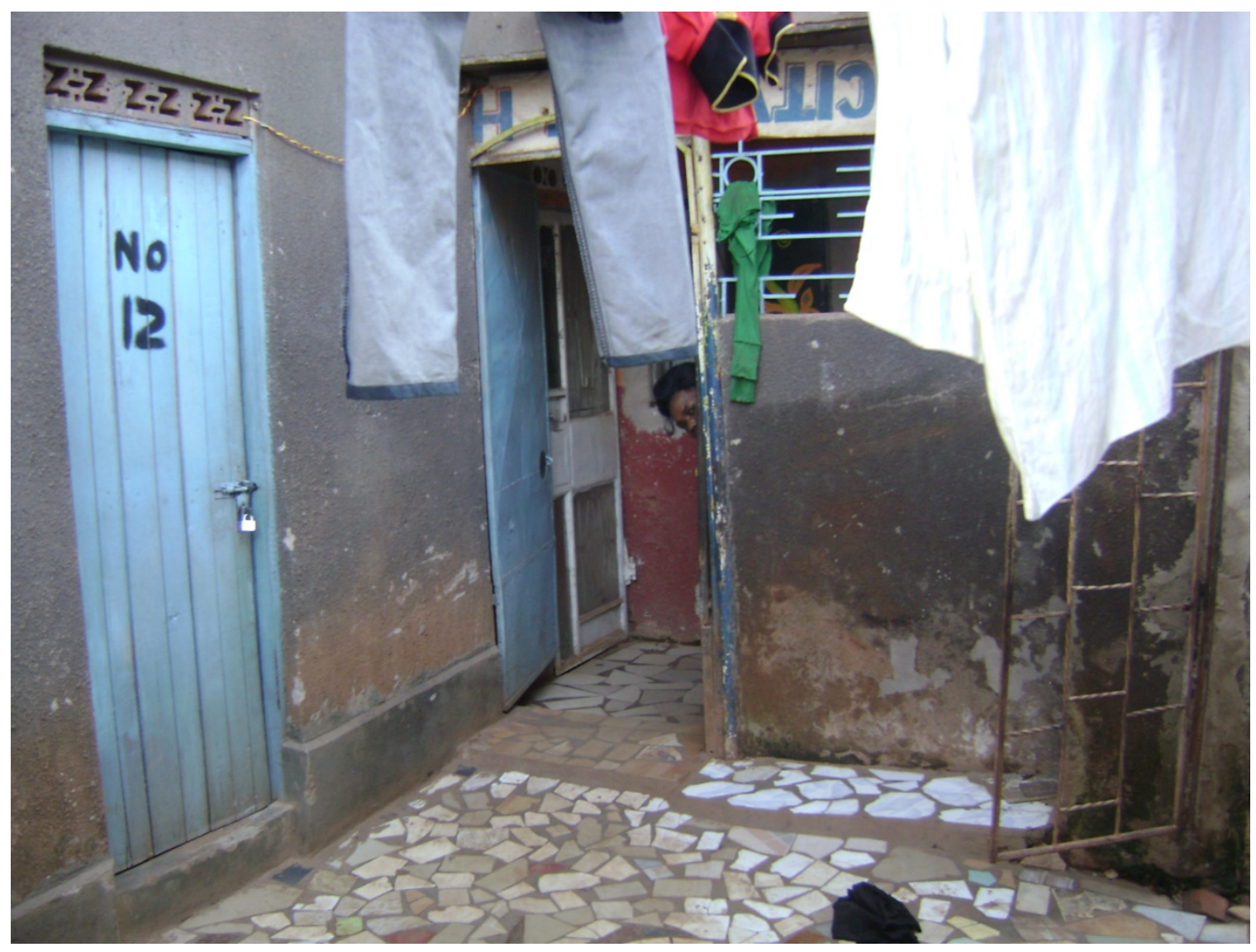

Intimacy involves familiarity, affection, and expressions and gestures of knowing and interpersonal sharing, which can be attributed to romantic, familial, or platonic relationships. For women in the brothel, intimacy is a practice for managing daily risks. The strength of women's social ties allows for greater risk resilience and a better means of managing the violence, criminality, and illnesses and destitution associated with sex work. Yet there are residents of the brothel lacking in strong social ties. These women with weaker brothel connections are more susceptible to the same environmental constraints, even though they have similar access to daily events (meals, play, and pipe smoking) as a means of discussing beneficial practices with their peers. But these women 
rarely socialize beyond their section of the brothel. Instead, eating, doing laundry, beautifying, and/or preparing for work is done with little to no eye contact, speaking, and/or being near other women. While all women in the brothel must navigate a setting with specific constraints, those who remain aloof and/or choose not to engage in the primary daily moments of coexistence become the subjects of slander, gossip, and mistrust. These residents come to be seen as different or deficient (physically or morally), and/or draw suspicion from other women. Driving this division is a hierarchy based on where women reside in the brothel, which is predicated on the assumption that not all sections of the brothel have the same caliber of residents.

Residency in Babito takes on greater meaning than just location. This is because brothel residents organize their social hierarchy according to room rental. Where a woman rents is emblematic of her lifestyle, routines, and habits. These factors signify her capacity to be entrusted, supported, and protected by other women. Women's willingness to practice intimacy is therefore encompassed by social norms associated with a hierarchical system of residency. Atop this hierarchy are the women, who have rented the longest and/or who reside in the "Bus"; below them are those women living in the "Clinic", who may also be long-term residents but choose to keep their original rooms; and, finally, those at the bottom of the hierarchy are women who are either very recent brothel residents and/or who have no choice but to rent a room in "Hell".

Hierarchy in the brothel has consequences, such as stigma, segregation, and disdain, yet it also sustains women's social cohesion. Women gain support for their social networks and social capital through the brothel's hierarchy. Where a woman resides is most often how she finds allies, women who become a lifeline when she needs help 
(cash, condoms, health information, and/or camaraderie). Women's individual practices are important markers reflecting how hierarchy in the brothel functions. I arrived at this understanding by assembling observations, women's comments of one another, and their life histories into a mosaic of brothel life. As a result, I was able to identify a pattern of women's practices that signify the presence of a hierarchy in the brothel; one which has implications for women's abilities to manage daily risks. Central to these patterns are routines and habits associated with particular notions of virtue and decency for Ugandan women (Bantebya Kyomuhendo and Keniston McIntosh, 2006).

What I found is that women recognize virtue and decency by way of material expenditures—purchases that accentuate their beauty and/or sexual availability (hair extensions, manicures and pedicures, shoes, accessories, jewelry, etc.), as well as implicit practices related to livelihood (rent, transportation, meals, refreshments, etc.). This is not an exhaustive list, but rather a way to illustrate the ways women atop the brothel hierarchy openly spend their cash. By doing so these women exhibit a particular aesthetic associated with important class distinctions in Uganda, specifically practices connected with notions of virtue and decency (Mamdani 1976; Bourdieu 1984; Bantebya Kyomuhendo and Keniston McIntosh, 2006).

Further on in this sub-section I present several cases of women in Babito, whose experiences underpin the complex and nuanced ways women's expenditures relate to their position in the brothel. For now I want to emphasize that at the heart of women's sociability in Babito exists a hierarchy. The presence of this hierarchy illustrates the complexity of women's ability to practice intimacy with their peers. Essentially, women's capacity to come together and trust one another minimizes risk, but it also 
creates disadvantages for those women who fail to exhibit the aesthetic qualities that cultivate trust from their colleagues. Without the intimacy and trust needed to belong to the inner social circles of Babito, women face significant obstacles when it comes to managing risks associated with sex work, criminalization, and ultimately their HIV/AIDS.

\section{Queen Bees and Wannabes ${ }^{30}$}

"God gave to you with two hands. For us we have to buy the skin, buy the hair. For us, we have to eat a full plate to be healthy. For you, you just eat bread and your Muzungu chicken and you are healthy" (Senga 6 November 2012).

Anna

Anna moved into the "Bus" on Wednesday 17 October 2012. I know because we held our first of several interviews the day after her move. Talking with Anna about her time in the rooms at the back of the brothel made it very clear, "these people here [in the "Bus"] despise the others, calling it 'hell'. Moving to the "Bus" is a financial achievement for Anna. At the time of my data collection a room for rent in the "Bus" cost approximately US\$4 per day, whereas rooms in the “Clinic" and "Hell” cost approximately US\$3. Anna’s capacity to afford an additional dollar per day for rent has great significance for her. Moving into the “Bus” demonstrates Anna’s financial capacity to participate in routines and habits associated with self-improvement. Relocating to the "Bus" implies Anna is willing and able to change in ways integral to materially expressing the norms held by the brothel's dominant cliques.

\footnotetext{
30. This title sub-section is referencing Rosalind Wiseman's (2002) book concerning the social behaviors of U.S. high school teen-age girls, who engage in cliquish behavior, as well as exhibit aggressive behavior towards girls deemed less popular and/or deserving of social respect and protection.
} 
Change is something Anna underwent gradually. During our first conversation I asked after the possibility of her "taking up new ways" now that she belonged to the "Bus". Anna expressed a conviction that she would not change, but she spoke openly about differences between her neighbors. "Most of them beautify themselves [in the "Bus] and light skinned women here [in the "Bus"] call those out there [in "Hell"] as kifuufu (trashy)”. It is possible to bridge the gap between lightness and kifuufu. Women can conquer their darkness by purchasing skin-bleaching creams. While Anna made it clear "women in the back do not purchase [bleaching creams]", by her second day in the "Bus" she bought her own blend of creams. During her purchase Anna explained, "That man usually comes to each one's door [in the "Bus”] and asks, 'will you buy cream?' During this exchange, the man went on to explain: "I have made this for dark skinned people".

Yet Anna did change, even when her intentions were to remain connected to her previous networks in "Hell". "Those from the past, even when I was still a child (less experienced sex worker) up to now, I cannot fail to share because most of them [women in "Hell"] are my friends". During this initial conversation Anna was willing to acknowledge her less experienced ways, as well as her affinity for women in "Hell”. But time revealed Anna's shift away from these connections as well as her openness. From our first interview to the end of July 2013, Anna became susceptible to "Bus"-based conduct; she grew distant with residents from other areas of the compound; and eventually, came to guard her HIV status with secrecy and silence out of a real fear of judgment. I delve into a deeper discussion of Anna, especially her fears and shame, in the final sub-section, secrecy; however, here her behavior underscores the pressures of sociability within the confines of the brothel's hierarchy. 


\section{Tina}

Tina began residing in the brothel compound of Rubaga Division in April 2012. Prior to life in the brothel Tina shared: "I had studied up to S4 and went to a course at Pope Paul catering. ${ }^{31}$ It is a certificate. Then I went out and began to work. While I was working I got my husband. When we got married, I stopped working”. Tina eventually reentered the labor force through sex work. By the time she arrived at the brothel Tina was already infected with HIV. She contracted the virus from her husband, who had succumbed to an AIDS related death the year before. Both of her children were delivered after Tina tested positive for HIV. Although Tina disclosed both children tested negative for the virus, by Buganda custom her children are being raised by her ex-husband's family. Tina's claims to her children, though emotionally strong, are culturally circumscribed, "In the Buganda culture when a husband dies, everyone goes to his family". ${ }^{32}$ What Tina claims to do is send money for her children's school fees. Saving money for school fees requires that Tina succeed first at meeting her minimal daily expenses.

Like Anna, Tina rents a room in the “Bus” and is required to pay US\$4 per day. She also benefits from being able to pay "cooks who bring us tea and food and I take morning, lunch, and evening meals, whatever I want”. While I cannot reliably account for Tina's earnings, or any other woman's, it is possible to interpret that Tina's attitude about sex work and her experience with earnings is very easygoing. For Tina work is a

\footnotetext{
31. Secondary four in Uganda is approximately the equivalent of 10th grade in the United States.

32. Among the Buganda in the event of a divorce it is customary for the children to remain with the husband's family and in the event of death of the husband and his wife, the children will also be given to his family.
} 
matter of "when one wishes. It depends on how much you have earned. Even your life and how you feel". The ease with which Tina seems to experience life in Babito illustrates her comfortable position in the brothel's hierarchy. The ties Tina has developed among the other women seem to give her a sense of freedom as well as safety. As a result Tina is better positioned in terms of managing her exposure to dangers related to violence, HIV information, and even her ability to earn and save money—all things I discuss in more depth further on in the dissertation.

When I met Tina in September 2012 she appeared cheerful. She was eager to be part of the research and spoke at length about her HIV positive status, her past, and her present. The present included a room in the "Bus", but over time, it would evolve into more recognizable practices linked to those with women atop the brothel hierarchy. Eventually Tina's lifestyle included an expanding wardrobe, blonde weave, a willingness to hire private transport for her HIV appointments, and unabashedly claiming to ask clients for at least US\$25. In terms of how much Tina charges clients, she, like all women I interviewed, provide figures ranging between US\$2 for a “short” (when a man quickly ejaculates inside a woman's vagina) to hosting a "friend" overnight for upwards of US\$50. Although I could not verify these figures outright, I did document the frequency of women's spending habits, particularly women congregating in the open area at the base of the "Bus". I discerned several prestigious spending habits, beginning with renting a room in the "Bus". It seems all women in the brothel recognize a room in the "Bus" takes resources in the form of cash and social connections. These resources reflect the importance of social networks. This is because women with strong social networks have greater access to safer environments, and therefore more prestigious, residency in Babito. 
Women with access to these rooms reaffirm their position in the brothel's hierarchy and are more likely to minimize the risks associated with sex work and criminalization.

\section{Defense}

Women describe the "Bus" as the most expensive residential section of the brothel. But before the "Bus” was built, Anna remembers, "They were the same houses even here [the place where the "Bus" now stands]. This was when the compound was more homogenous in design and expense. My notes about the "Bus" indicate that, when the building was finished, the longest-term residents were allowed first pick of rooms. Not all women residing in the "Bus" are long-term residents and several of my informants in the "Clinic" were among the women who received an invitation to move into the new building.

One informant in particular, Defense, is a resident of the "Clinic". ${ }^{33}$ Defense refused to move to the "Bus" because "the new building has noise [gossip]". But aside from gossip, she also wants to maintain the financial and social capital she has generated from her particular residency: "Yes, the rooms were there, but my customers know me in this place [the "Clinic'] and also they [rooms in the "Bus"] are at 10.000. Yet here they are 8.000. You save that 2.000 which is 60.000 in a month". ${ }^{34}$ From her perch in the “Clinic”, Defense is able to save money, avoid gossip, and maintain her own connections with clients and other women. Moreover, Defense believes it is important to differentiate

\footnotetext{
33. Defense’s name is actually a nickname, which reflects her role as the Security Leader of Babito.

${ }^{34}$ In this quotation I left the figures in Ugandan Shillings, but in 2012 UGX10.000 was approx. US\$5 and UGX8.000 was approx. US\$3. UGX is the symbol for Ugandan Shillings.
} 
herself from, "the new Nekos [in "Hell"] that came after Eid, ${ }^{35}$ who are still new and don't interact with the other Nekos [“original” residents]". For Defense, the needs and networks in the back are different. As a result it is unnecessary for her to be concerned with their affairs: "Those in the back ["Hell”] keep to themselves. They only have channels [networks] with those they are in the same group". While I return to Defense at greater length in the sub-section interconnectedness, here it is important to share her opinion of the "Bus" and "Hell" residents. Doing so I introduce the ways women atop the brothel hierarchy demonstrate their material, and therefore, social superiority.

\section{Rita}

Women from the "Bus" and/or long-term residents openly spend money in front of an audience. Open spending involves negotiating and purchasing accessories, such as clothes and shoes, services like pedicures and room cleaning, and treats like fresh milk. Women’s spending habits most often take place in the open area at the base of the "Bus". Yet, not all women who openly spend live in the "Bus" or "Clinic". Residents of "Hell" also manage to express their accomplishments materially, notably by displaying steady clients and handy cash. But their behaviors are seen as subversive. Many women atop the brothel hierarchy often describe the spending habits of "Hell” residents as indecent and vulgar. More experienced and/or longer-term residents are quick to cast "Hell" spenders as trashy, dark skinned, childlike beings with "no sense" about how to keep their money. ${ }^{36}$ Observations indicate that many women in "Hell" practice avoidance as a

\footnotetext{
35. Eid al-Adha 2012, otherwise known as Eid is the Feast of Sacrifice or Bakr-Eid. It is the second of two religious holidays in Islam. The women used this is a time marker for when they know the "Bus" was completed.

36. The issue of "keeping money" is important. I deal with it explicitly further on.
} 
measure to protect themselves from these comments. But there are a select few who refuse to retreat into the back. Women from "Hell” who resist intimidation and derision seem undeterred by brothel politics, resulting in greater access to information regarding saving money, personal safety, and physical health.

Rita is one woman who successfully navigates the brothel's hierarchy. In May 2013 Rita was new to the brothel. When we met she had only been a resident of "Hell" for one month. Born in 1996, and the mother of baby less than one year old, Rita had gone as far as tenth grade. Often we conversed directly, in English, and Rita seemed confident. She freely admitted that, "I don't like Babito, but life is hard. It is what they are [the older women in the brothel]". Rita's unique approach to living reveals itself in her uncanny way of describing hardship, as well as pleasure. "The pain is that resources are none for us women" is shared along with "I want to go for sex work in Dubai". These comments demonstrate Rita is aware of her circumstances, but refuses to cede her aspirations.

Rita’s aspirations are based on her successes in sex work, "Men like a new girl...my client will call me and I will be ready. I just stand on the street [in front of the compound]. I don't pull the men like those [referring to older residents]! Although she believes in her qualities as a sex worker, Rita strives to balance her professionalism with her values. As a Muslim, Rita attempts to harmonize the demands "of wearing trousers [covering her legs], covering arms, and not wearing short skirts” with her work, when “skirts are only for the club [disco]”. Rita's descriptions of work "Staying in Kabalgala to work in De Posh [a disco]" reflect her personal ambitions, "my goal as a new girl is to make more money than the rest". Rita appears fearless and proud to declare, "If we throw 
a big party to vote for Mrs. Babito I will be number one and then Selena, Eva, Alice ${ }^{37}$ who look nice [attractive, young, fresh, not tired]". Rita acts brash but she is also open and her openness allows her to circumvent the outright hostility from many women with greater authority in the brothel's hierarchy.

Rita demonstrates a penchant for ingratiating herself to women in the "Bus". She declares, "Tina is my best friend". Seen together, Rita and Tina laugh easily; describe stories of escapades at discos; name preferences (type of beers, favorite hair weaves, preferable clothes, shoes, and jewelry, etc.); and share information about herbs and other ways to "keep stamina [with clients]". Yet not all women believe friendship is possible, "That is the nature of Nekos; they are not open. You will see a person laughing with you and you think she is a friend, yet she is not your friend. And the one who is not laughing at you is your friend. So there is no deep friendship" (Jackie in the "Bus" on 17 October 2012).

Friendship, like love, is susceptible to description but does not yield a universal definition. Therefore, I found it important to observe women's actions as a means of documenting intimate practices. Rita's claim to Tina's friendship is an important risk management strategy. Through Tina Rita accesses social networks belonging to longerterm residents and/or women living in the "Bus". Rita’s connection to Tina, and therefore other women atop the brothel hierarchy, results in her learning ways to save money, avoid violence, and/or minimize sickness. This information moves through Rita entering her own channels in "Hell”. Rita's position, within in "Hell”, and overall in the brothel, is

37. Other residents of "Hell” 
elevated by the information she gathers and disperses. As Rita's networks expand, so does her capacity to call in favors, be heard, seen, and respected by more powerful women. Rita, unlike Anna, appropriates "Bus” based conduct to strengthen her position and ties within "Hell" and inspire other women from her section of the brothel to move more freely throughout the compound.

\section{Others}

Rita’s habits inspired at least two other women from "Hell”, Selena and Alice, to strive for different circumstances. Both women began spending time in the area at the base of "Bus". Whereas Selena, like Rita, remained in "Hell” Alice eventually moved into the "Bus". Alice, similarly to Anna, changed after her move from the back. She no longer wore the same clothes and shoes each day; she began openly spending cash to have her hair braided regularly; and, she spent less time in the company of her previous neighbors from "Hell”. Selena emulated Rita. She spent time moving freely between all three sections of the "Bus"; kept company with other women in the afternoons; openly discussed pipe smoking; and, candidly bartered sex for clothes, shoes, and jewelry. Selena adapted norms associated with elite women in the brothel to fit her own interests (clients and cash). Although Rita's information seemed to embolden Selena, ultimately it could not shield her from gossip. Selena’s behavior was seen as a perversion of norms set by women in control of the hierarchy. Longer-term residents and/or residents of the “Bus” rarely condemn one another for spending money openly. Yet, this practice reflects a tacit agreement about personal conduct directly connected to residency. This is because residency has implications for women's abilities to develop trust with their peers. For 
those women who manage a level of intimacy with other residents they have a greater chance of managing their risks.

\section{Summary}

The location of residency signifies relative power and privilege in the brothel. Women who have lived longest and/or who can afford to pay the highest rent price have accrued the most resources. Although there are women residing in "Hell" capable of linking with women atop the brothel hierarchy, such as Anna, Rita, and Alice, their ascent involves carefully negotiating a set of norms associated with a particular aesthetic of virtue and decency. Anna and Alice subsume these norms by taking up "Bus” based conduct involving skin, clothes, shoes, and hair. Alternatively, Rita navigates the hierarchy through friendships, while (ironically) claiming chastity as a Muslim. Maintaining access to elite circles is an important risk management strategy. Becoming a member of the brothel hierarchy serves to protect women against threats associated with sex work, criminalization, and HIV/AIDS. However, in order to maintain control over these resources elite women gossip, slander, shun, and/or withhold important information from those deemed less worthy—darker, trashy, newer women mostly residing in "Hell”. Faced with belonging or antipathy, women cope with the plasticity of the brothel environment either alone or together. Yet for women who do so with others, it is through their social networks that they manage to successfully negotiate the politics of daily life in the brothel. With strong social ties, these women illustrate the benefits of interconnectedness when it comes to addressing their insecurity with money, physical harm, and illness. 


\section{Interconnectedness}

By observing and participating in differing social aspects of brothel life, I was able to capture the milieu of struggle, strife, and success shaping women's lives. What I found is that risk colors most encounters and activities connected to sex work, and it forms a "one-ness" to almost all things involving daily life for many of the women in Babito. To face these dangers some women devote time to developing survival strategies. Underpinning how these women survive is a unifying process, born from choosing to address their individual risks collectively. I call this unity 'interconnectedness'. Against the backdrop of the brothel's environmental hazards and social hierarchy there are women who thrive by utilizing the social capital within their individual networks. These women invert the primary basis of their coexistence. No longer do they simply cope with risk, but instead these particular residents manage to prosper, as well as survive. The women who thrive optimize their social resources by erecting and maintaining specific forms of assistance, which either directly or indirectly benefit their welfare.

Most assistance is simple, with women sharing small resources within their networks (e.g., small amounts of cash, buckets, cellular phone air time, etc.). Yet for more than 10 months I documented a more lucrative and consistent form of support involving one particular leader of the brothel hierarchy called Senga (Auntie). Although Senga was not the landlord or the person who collected rents, between June 2012 and the end of March 2013 she was at the center of brothel politics. Her leadership involved “mobilizing women” into cash-saving circles. To do so, Senga relied upon women’s trust. To gain women's trust Senga coaxed them into believing she was capable of hearing and seeing their interpersonal struggles. Part of why women willingly gave Senga portions of 
their earnings was to minimize the burden of their financial insecurity. However, another reason is that Senga symbolized a mechanism for women to connect. Through cash savings circles women drew strength and support at a deeper and more intimate level. The pragmatics of Senga's approach afforded women a chance to experience trust, reliance, and predictability together. Savings transcended risk materially while bolstering women's interpersonal connectivity. No longer were women simply managing their grievances individually. Rather, the reciprocity being generated through Senga’s savings circles provided a prism of hope through which women could balance their own vulnerabilities with a sense of interconnectedness.

\section{The Aunt of Prostitutes}

Senga understood the power of her influence, both socially as well as financially. The longer I observed her interactions with other women, as well as listened (through translation) to women's comments about her, the more it seems Senga may have even established the brothel's social hierarchy. The influence she possessed was essential to women's risk management practices. Whether it is how women learned to save their money or how they came to understand the value of condoms (discussed later), at the center of these values is Senga's interpretation of women's respectability-that is their virtue and decency.

"However much one studied, it is hard for women here [in the brothel] to listen to you, if they don't know you. But if I call them, they respond 'Senga has said so'... they know that 'Senga has no problem', even if she is a fat woman or small. My real names are But my sisters always ask 'why are you known as 'Senga' in the whole of [brothel areas]?' My father recently died and all the men who work in the park came for the burial and spread it 'that one is the aunt of the prostitutes'. But I didn't have that name before. It was when I started mobilizing women for forming groups. Some could get sick but couldn't find money 
for treatment. So I told them to form groups. At that time these lodges were just constructed. 'Kandy Brothel' was the first one. I had got tired of moving in journeys [changing locations for sex work]. So I enjoyed here because I could go and see my children easily. I started the groups slowly because I could get loans with my sister from the bank and I repaid it. My friends asked 'how do you do it Senga?' and I told them that 'my big sister took me to the bank.' If I need [US\$120-200] I get it and pay as I work here so I took one by one to the bank. That is why I initiated the women. I told them 'our fellow women get sick'. Those who joined the groups were many and I couldn't take them all. So I thought that if someone could contribute [US\$4] every day, it becomes [US\$28] in a week. And if they are 10 people it becomes [US\$280]. So that could go to one person of the group in each week. I formed different groups of ten. I found that the children [less experienced women in the sex trade] were enjoying the groups. Because I was faithful [honest], they brought in many girls to me. One could say to me 'help me keep this [US\$280] for me. I don't want to keep it with me' she could bring another [US\$280], or withdraws [US\$80]. Sometimes I advise them to buy plots and many of them have started...shops. I am never envious of anyone like others do when someone has a nice dress. I always mediate them. I tell them that 'If someone looks nice in her dress, work hard and buy it too but don't hate them'. Just ask her 'how much did you buy that dress?' They always bring their wrangles to me 'someone threatened to bewitch me' and I ask them 'what is bewitching?' [Why bother doing this?]. Some even threaten me but I always tell such people, that 'you need the people even when the people will hate you and you won't like it when they do.' Some fall sick and sleep in very bad ways, old mattresses on the floor. I ask 'you have been working for long; where do you put the money?' Many may laugh but I don't talk behind backs. I just tell others to pick a book [start a savings circle] and collect money and take hospital and when you recover, I will summon you. I tell them that 'give me two or three thousand [Ugandan shillings] everyday and I register it in a book'. Most of them save more than that: [US\$2, US\$4]. After sometime I can tell them 'I have [US\$40 USD] for you', but they don't believe. That makes them save more to hit their target. So we started a group with first saving [US\$.40], later [US\$.80]. I now have two groups, one with [US\$280] and one with one million [Uganda Shillings which is approx. US\$400]. But they still make small groups for their simple needs that by the time I give one of them one million she can do something big with it. Those who start by getting [US\$280] have the promise to make a million the next week. I have never lost anyone's shilling. I sit with them and tell them 'this is a temporary job'. When I started, men could buy me at a high speed [many men] but I got tired [of many partners in one night]. Our tubes get blocked. Others are admitted [to the hospital] because of malaria. Others, especially those who booze are foolish. But I am now trying to curb alcoholism here. If I 
fail someone [fail to change her behavior-make her respectable, decent, virtuous], I approach the lodge owner, 'this woman doesn't know what brought her here; she over drinks and doesn't keep her money. She abuses others, pours urine onto others, and she doesn't keep her used condoms well. I request that you ban this woman or suspend her for some time'. Those are the things that have led the women to trust me."

(Senga, interpersonal interview on 6 November 2012).

Senga's story and her actions offer clues about the complex and fluctuating social conditions of the brothel. Almost five months after describing her methods of cultivating women's trust Senga "failed to return" to the brothel. On Easter Sunday 2013 Senga "left Babito" taking with her the equivalent of over US\$2000. Although it seemed women understood the risks of saving money with their fellow "nekos", the social incentives were highly desirable. This is why, even though the loss of money was a blow for many women, Senga's failure to return was far more devastating to their capacity for interconnectedness. In the aftermath of Senga's flight, some residents still had hope of her return. Tina believed, "Senga will return to the brothel when the problems with the police go away", and her belief illustrates the power information has on the brothel's hierarchy. Tina shared that Senga had spoken to Martha, who was one of the longest-term residents in the brothel. Although Martha agreed to participate in the data collection by signing a consent form, she never sat for an interview. And while I do not know the reasons for Martha's resistance, ironically her voice often echoes in the background of my audio recordings. Ultimately, Martha's presence was noted, and even though directly recording her stories proved allusive to the research process, she is an important member of Babito's hierarchy. As a result, women in the brothel often repeat Martha's "wolokoso" (gossip). 
Tina believed Martha's story about Senga, and whether or not Martha actually spoke with Senga, women passed along the information she shared. In this way, Martha's information was vitally important to the brothel community. Her "wolokoso" ameliorated the upheaval caused by Senga's desertion. By claiming to hear from Senga, Martha's information offered women a chance to stymie their hopelessness as a result of the theft. This is because gossip helps women restore their sense of interconnectedness. This happens when women can amass collective control over what happened through the ability to share information. Instead of resigning themselves to the crisis, women passed news about Senga along to each other: "People see her in town, purchasing things. She invested the money in her things. She can never come back here after eating the money [stealing the money]. I hear that she started a big hardware shop and her daughter attends to it". Ultimately, "wolokoso" about Senga offered women a means to communally endure the vulnerability they experienced by taking on the risk of sharing their savings with her. In this way, gossip became a powerful tactic for women to mutually grapple with grief, but it also foreshadows the darker side of "wolokoso". For it is with gossip that women also sharpen their divisiveness and social hierarchy.

\section{$\underline{\text { Condoms are Capital }}{ }^{38}$}

Part of Senga's social control was to establish a hierarchal system based on worthiness. Senga believed and perpetuated specific notions of acceptable conduct. Women she identified as decent, self-respecting, and trustworthy, were given access to cash savings. Those Senga believed "took up" drunkenness and foolishness, as described

\footnotetext{
38. In the next sub-section I deal explicitly with women's access to condoms. For now it is important to know access is irregular and unequal, which has implications for women's ability to develop social connections (network) and social capital, as well as hold a "respectable" position in the brothel community.
} 
in her quote above, as well as misused their condoms, deserved discipline and punishment. Although it was clear to many women, "Senga does not keep condoms for anyone" they deeply understood the connections she made between cash and condoms: "for her condom is capital”. Even though cash is important for women and they need it to survive, many realize they will earn more money if they avoid sexually transmitted infections.

In order to be safer, women know it is important to keep condoms: "Here condoms are not sold but given freely...Condoms mean much to my job. And even if I am shifting to another place, I may leave some things but can never forget my condoms”. This basic knowledge is layered into the sociability of brothel life whereby condoms symbolize far more than the prevention of illness. Women ascribe normative values to the possession and care of condoms, such that condom keeping is synonymous with women's morality, goodness, and worth. These beliefs commingle with other aspects of women's interconnectedness. Below I describe how these beliefs feed into a process of social marginalization that compounds women's difficulties accessing condoms.

Interconnectedness in the brothel is complicated by the importance of condoms. Women identified by their peers as being able to take "proper” care of their condoms are seen as trustworthy. Conversely women who fail to care for their condom supplies and/or who rarely have condoms are more likely to be socially spurned. With fewer social ties and/or no reliable "channels" (networks) in the brothel, socially marginalized women in turn are less likely to gain access to condoms. A cycle of deprivation emerges, whereby, women without entrée to condoms are found unworthy. Found morally lacking, these women fail to reliably keep condom supplies, while increasingly becoming associated 
with "wolokoso" such as: "those have live sex [sex without condoms]...they even drink alcohol and take too much [substances that affect their ability to stay aware] and one can just do anything to her...You find someone with sperms poured into her and some even poured on her belly". Consequently women who already have access to condoms experience incredible social pressure to maintain the notion: "We are different in character" [better, moral, responsible]". Condoms therefore are socially circumscribed with uneven access being both a consequence of social divisions in the brothel as well as symptomatic of an insecure condom supply and disbursement process.

\section{Demand and Supply}

Access to condoms and women's practices associated with keeping supplies safe vary among sections of the brothel. In the "Clinic" women store their boxes under beds, stuff boxes alongside clothing inside cardboard UNFPA boxes, or precariously balance boxes on wooden wall pegs. Residents of the "Bus" tuck their boxes inside small window-like screened openings above the door to their rooms, where boxes also barricade mosquitos. Yet, unlike residents of the "Clinic" and the "Bus", women residing in "Hell" are in short supply of condoms. What cache women in "Hell" acquire is difficult to keep as a result of flooding, but more importantly, their supply is highly dependent on the generosity of others.

During Senga's tenure women described reasons for not sharing condoms: "When they [NGOs] give those condoms [freely] we don't know when they are bringing [them] again. So there is no point of sharing the condoms when you know that time will come and you run out of condoms and no one will give you... So when we get [them], we keep to ourselves”. Infrequent resupply of condoms underscores social divisions in the brothel 
and reflects a paradox of interconnectedness. By refusing to share condoms women inadvertently increase the likelihood that HIV and other STIs enter the brothel community, since women without condoms risk unprotected sex with the same pool of clients and boyfriends. In this way women's risk management must contend with the pressures associated with hierarchy as well as condom insecurity.

Events in the brothel reveal the most common ways condoms enter the brothel are through the landlord, NGOs, or when women purchase their own supply at a nearby pharmacy. Of these three strategies the least inconsistent way for women to freely receive condoms is through NGOs. Observation and participation on both sides of the condom procurement process indicates NGOs rely on brothel contacts when making deliveries. Women’s gossip attributes many roles to Senga, including her capacity to procure condoms through personal connections with NGOs: "maybe the people who supply condoms take her number to call in case they run out of condoms”. Whether or not Senga actually brokered condoms for the brothel, her disappearance aggravated an already volatile resupply process. After Senga's departure women came to fear the notion of a new leader, believing "especially since the last one went away having stolen [Senga]...they think that even the next one will steal”. Lacking new definitive leadership, the women's networks became brittle with skepticism and riddled with opportunism from inside and outside the brothel. Condoms in particular were increasingly embroiled in brothel politics whereby a capricious inventory system within Babito further entrenched women's HIV risk.

Just as residents were grappling with losing both a leader and their savings, a resident named Frances surfaced. Frances perpetuated a more austere form of social 
hierarchy compared with Senga’s paternalistic efforts of supporting women. In Senga's absence, Frances began using condoms as a means of asserting her brand of leadership in the brothel. It was said that: "Frances is proud. Even if she is giving away condoms she cannot give you one if she doesn't want" (Flower 10 April 2013). Her method of social control reflects a deep desire for respect and recognition. Although women feared a new leader it was possible for Frances to assume this position to outsiders, which was increasingly likely as she courted condom supplies from local HIV prevention efforts.

By mid-spring 2013 program staff from a biomedical research facility in Kampala began frequenting Babito. Online research into the background of the organization reveals significant sources of funding [e.g., Bill and Melinda Gates Foundation, UK Medical Research Council, and the UK Department for International Development (DFID)] and a long-standing presence in Uganda. Their website states that their facilities provide clinical services for "disadvantaged women", while carrying out laboratory research on sexually infectious diseases. When I spoke with staff I learned the organization is interested in promoting condom use and sensitizing women about gender issues (although no examples were provided). It was revealed these activities were part of the organization’s “Anti-Risk Campaign Against HIV”, which included free condom supplies and site visits every two weeks. Babito had been incorporated into the organization's service area in February, when the representatives of the biomedical facility began to, "Meet with women in the brothel and gain an understanding of their struggles” (Dan on 19 April 2013).

I had an opportunity to hold a conversation with program staff during one of their site visits, as well as make observations of their programmatic efforts. I recorded 
information from a staff member named Dan, as well as observed him engaging with residents of Babito. On this particular visit, Dan’s longest conversation was with Frances, which Martha eventually joined. At the end of their discussion, Dan instructed his driver to retrieve two large UNFPA condom boxes, ${ }^{39}$ which Frances asked to be delivered to a padlocked "Clinic" room. The room already contained five other boxes. Condom supplies were either piled on a narrow bed or left to lean against the only available wall in the room. The space was cramped, making it difficult to open the door and walk inside. Air in the room was hot from high daytime temperatures and minimal circulation. Essentially the condoms were being stored in an unsuitable space; exposing them to environmental factors that could damage their integrity. ${ }^{40}$ Yet, these conditions seemingly went unnoticed by Dan, his driver, or Frances. While Frances organized the condom boxes, Dan moved throughout the brothel speaking to women and writing down their surnames (clan names) and phone numbers (if possible). When asked about why he needed this information Dan disclosed, "this is how we enroll and track women in the program". But aside from writing down women's names and contact details, Dan's only contribution on this occasion was to provide condoms to Frances, who he referred to as, "their leader". Unbeknownst to Dan, Frances would later distribute the condoms selectively and without necessarily providing supplies directly to the same women he had enrolled.

Access to condoms gives Frances authority. Although women "fail to accept her" as a new leader, many recognize the importance of belonging to Frances’ network. As a

\footnotetext{
39. Each large brown UNFPA box contains 50 white boxes and each white box contains 144 individual condom pieces. On this occasion Frances was given 14,400 condoms (i.e. two brown UNFPA boxes).

40. Condoms should be stored in a cool and dry place, and should not be stored in excess of 100 degrees or below 32 degrees F (found at http://www.lifestyles.com/sexualhealth/ CondomFacts.html).
} 
member of her network, women validate Frances' leadership in exchange for condoms. The reciprocity of these exchanges maintains the interconnectedness of the brothel community, which must endure for women to survive. Women understand that while condoms are fundamental for their survival, so are the mechanisms of their sociability. Even in the aftermath of Senga's deceit, women continued to recognize the importance of unity. However, unity seems to emerge only through the brothel's social hierarchy, which comes about when a leader and/or prominent women remain in control of resources. With this control women can select among their colleagues who is deserving of belonging within a social network capable of generating a sense of interconnectedness. In turn this creates a divergence in how women can manage the insecurity of daily life. Some women resign themselves to following the social norms set by these more assertive and/or wellconnected women, while others, like Frances, capitalize on vulnerability in order to prosper. Underlying these practices is a fragile acceptance that women are stronger together rather than alone even if it means relying on an imperfect and unequal system of reciprocity.

Summary

Unity and loyalty are what Senga's saving circles provided women. During Senga's tenure as leader some women found a means of disbursing risk more equitably. Yet Senga only seemed to include women deserving of her saving practices, while leaving others to languish without resources. Although divisive and judgmental, Senga's ways were instrumental in getting women to practice interconnectedness. The importance of Senga's process was far more impactful after her departure. The stark reality of her abandonment meant women had not only lost their money. Senga's vacancy also 
fractured the women's ability to trust one another, therefore, undermining a primary means of collective risk management. However, even though Senga's theft weakened women's trust, new ways emerged for women to collaborate. Gossip about Senga offered women a chance to grieve collectively. Eventually, though unevenly, women managed to collaborate in maintaining access to condoms through the "channels" (connections) Frances developed. Throughout these events interconnectedness helped women endure the instability within the brothel. With this practice maintained, women also protect their social networks in order to address external threats.

\section{Preservation}

"I would rather run to the end of the earth or die before being arrested" (Becky - field notes on 29 April 2013)

Within the brothel women contend with environmental hazards and social instability resulting from hierarchy and marginalization, as well as theft. But beyond the walls women confront what is often described as their greatest threat—police: ${ }^{41}$

"A risk is that the policemen raid us in the night and some even force us into sex then they promise to release you and they don't wear condoms. Even sometimes when they arrest you, they sleep on you forcefully. When an officer is on duty, he can open [your room] and take you. And there is no way you can deny because you don't know where he is taking you" (Group discussion 16 Oct 2012).

Arrests, raids, rape, and beatings, at the hands of police are frequent events, as are how women survive by fleeing, hiding, and paying bribes: "here the police chase us. There are times when the children [other women] even jump over iron sheets and including

\footnotetext{
41. It is important to underscore the illegality of sex work in Uganda (see chapter two). But also that Uganda's police forces are inconsistently paid as well as poorly trained, which results in high levels of graft (East African Bribery Index, 2011), abuse of power, and human rights violations against vulnerable communities, such as commercial sex workers, gay, lesbian, and transsexual individuals, and "boda-boda" and "mutatu" drivers.
} 
men. Sometimes they are cut. We are afraid of them [the police]. Whenever we see their car we just take off” (Anna 18 October 2012).

While women project a sense of deep loss when describing prior raids, fear always seems to color their stories of abuse. Fear is the result of deeply believing and knowing how inconsequential their suffering is to the greater society. Women confide the horrors of police brutality against a backdrop of inescapability, where their freedoms, rights, and/or dignity are disregarded by the legal system:

"The police come to the brothel in uniform and some in civilian clothes. Even 50 can come [in military trucks]...if they grab a neko they pull you, taking you to [the station]. They arrest you and put you into a cell. Even 20 people [including men can be inside one cell]...the cells are very small. You can spend a night or get [bail]. Depends on [the bribe]. No paying then you go to court by mini bus that has no windows. The court is on Musaka Road...20 minutes from Babito. You sit in chairs for sometime and then the judge arrives. When they call you, the judge says pay [US\$30], but if no one can pay they are charged. Then they go to Luzira Prison [maximum security]" (Conversation with Becky on 29 April 2013).

Women, therefore, knowingly work each night with the potential of being policed with little or no recourse if they are detained and coerced to pay bribes.

\section{$\underline{\text { Strategies of Preservation }}$}

In this context preservation is paramount. At the time of any raid "there are many women who come to work on the street [out front of the brothel]. These women are arrested because they have nowhere to hide. The women who stay at the brothel run into their rooms and hide locking themselves inside" (brothel attendant 19 April 2015). Yet not all residents of the brothel successfully manage to avoid arrest. Knowing there are fellow residents vulnerable to capture, senior members of the brothel hierarchy organize strategies to assist women in their social networks. Between June 2012 and April 2013 
one brothel resident held the name Defense, first introduced in the section about coexistence. Her nickname signified her designated role as leader for all matters concerning security. Defense claimed: "I interact with them [residents in her social network] day and night because if someone gets a problem at night, she looks for me. Even when I am here in the room, she comes and knocks on my door. She can even knock during the day, or even in the morning” (Defense interview on 22 October 2012). As security leader, Defense helped "fellow nekos" fend off prison: "if I hear that this one is arrested, I cannot sit here, I go and ask her what is needed, "do you have some money?" If she doesn't have, we collect it from us here and when we get you out, you pay back" (Defense interview on 22 October 2013). Yet, the assistance Defense describes is enmeshed within the brothel hierarchy, therefore, coloring her actions by the same notions of worthiness perpetuated by Senga. Defense believed in helping those she trusts and understands, unlike "those people do not have company with us because they are still new [residents of "Hell”]...we don't know them well”. Less willing to assist new residents, Defense maintained the order established by Senga, who purportedly could control the police: "If Police comes and says 'every woman should get out' no one comes out, but if I say so, they all open [their rooms]. It is because they know that Senga has no problem. If I think that the case needs to be settled at the Police, I say so. And if I think it isn't necessary, I tell you 'don't come out' [of your room]” (Senga 6 November 2012). Women belonging to the brothel hierarchy benefitted from Senga and Defense's relationships with police. Privileged residents could avoid arrest by arranging their work hours around raids, "We have informants within the police. They can warn one of us, such as Senga or [Defense]. And when they come to arrest, they find that we are not here. 
And if you miss the arrest, you can come back at 12 or 1 in the night and resume working” (group discussion on 17 October 2012). Within this dynamic, women had few alternatives to the security norms perpetuated by Defense, and ultimately Senga. Other than running and hiding, women were at the mercy of the mercurial nature of the brothel leadership until Senga, and eventually Defense, quit the brothel.

\section{Peace Making}

Women’s security efforts adapted to Senga and Defense’s departure from Babito. Tina describes accompanying the brothel landlord to coordinate with police and take measures to defend the compound: "The police told women have to be inside by midnight. Those who choose to stay outside will be arrested. The police are conducting these raids to chase out thieves. There are thieves among us and they must be pushed out [of the area]" (Tina field notes from 10 April 2013). Tina's interest in working with the police to corral women and apprehend thieves is indicative of her desire to take on a leadership role in the brothel. By joining meetings between the landlord and police, Tina elevates her position and recognition among other residents. She becomes a conduit for information flows among networks between the police, management, and women. In return for this knowledge Tina gains the means to assert power over others.

Unlike Frances, who wields power by way of controlling women's condom resupply, Tina's goal is information itself; information is her power. Allied with the brothel's owner, Tina is able to assemble women for meetings with management and police under the pretense of safety. Women's descriptions of these meetings chronicle an atmosphere whereby Tina's knowledge and support for police intervention lends authority to increased surveillance measures, such as photo identification booklets 
[women pay US\$2 for these mandatory cards]. Anna believes these efforts are to protect residents from outside threats (bandits) as well as assist sick or dying women: "They asked me for photos to put in the identity card. One of our friends was killed in a [nearby] lodge. ${ }^{42}$ So they told us that if these photos are put in our small books labeled 'Babito guest house'. They will be talking about where one is born so that when you die or get sick, it becomes easy for them to carry the body. But they won't include it that we are Nekos [prostitutes]”.

Along with identification, women are called upon to participate in a protection racket. The "investment” requires that women's "savings are collected every week and taken to police for security" (field notes 10 April 2013). Attending meetings, securing identification cards, and paying into a police bribery strategy demonstrates women's willingness to follow Tina's directives. With information, especially related to police, Tina demonstrates to other women that she is superior-morally, intelligently, spiritually—and deserving of respect. Tina's knowledge about policing, as well as the landlord's curfew, is reaffirmed when she hosts visitors from the police force.

On one observed occasion, Tina received police officers by greeting the women on her knees, ${ }^{43}$ demonstrating her adherence (and know how) of Buganda etiquette. She explains, "the two women [police officers] help the nekos of Babito by talking with them and in keeping the calm when the women fight amongst each other" (Tina 9 May 2013).

\footnotetext{
42. Anna revealed: "She was killed by suffocation. After killing her, he straightened her, covered her and locked the room with a lock. She was discovered after four days. They didn't know that she died; they thought that she was not in the room. They only knew from the smell. It seems like the killer was one of the men who come to buy us, or was sent for that purpose” (interpersonal interview March 2013).

43. In the Buganda culture it is a sign of respect for women and girls to be seated on their knees and to bow their heads to male relatives, elders, "important" men, and husbands (Bantebya Kyomuhendo and Keniston McIntosh 2006).
} 
Tina's display of etiquette and her access to information are instruments of preservation, both for herself as well as the larger brothel community. Forming alliances with police officers, supporting management decisions regarding women's street conduct, and slowly being validated by other women for her actions all anchor Tina's role as peace maker.

Lost and Found

Peace is tantamount to happiness. Many residents desire freedom from police aggression above all else. Women believe being free of police is as equally important as financial solvency and for some it is almost the same thing: "If a NEKO can get security, treatment [health care] and earns her money, she lives in peace. You see these women are very patient. If she fails to get money for two or three days, she is sure to earn on the fourth day. And they even say that, 'we were used to our poverty without [police] chasing us, but now the chasing has taken our peace"” (Flower 22 April 2013). The absence of police, therefore, brings greater security to women's daily life. Yet while police aggression and a failing criminal justice system leave many women without refuge, my research shows that these realities only spur practices of preservation far more detrimental to women's HIV risk management.

Police raids threaten women's personal safety, property, and freedom, as well as set in motion secondary risks with lasting repercussions for their HIV health. For some women being arrested is a matter of life or death: "If you are arrested when already having the virus, there is nowhere you will get the ARVs in the prison. It is said that when you miss the drugs once, your life is at stake. So if they arrest you, it quickens your death” (Group discussion 16 October 2012). In other instances women manage security sweeps more successfully. Lucky residents can reach their rooms and well-networked 
women can schedule their working hours around police activities. Yet for all the rest, police raids mean struggling in the dark to dodge and ditch security forces, which often block the main road.

In the aftermath of an attack the brothel's population is often reduced. Rooms are left vacant and many women's belongings go unguarded. Among the departed, some women rely on their "channels" (networks) to keep vigil over their property, as well as manage relations with management. Women capable of taking these measures are likely to keep their possessions safe and their rooms available upon return. Yet, residents without internal support become "lost" (missing, not around, gone) to the brothel. By failing to provide assurances of their return, lost women go unaccounted for by remaining residents and management. Consequently, the landlord assumes control of their rooms and belongings. And in a matter of days women lose not only the security of their income, perhaps even their freedom, but also their possessions.

When management repossesses a room, condoms are among the spoils found and redistributed. This fact was made very clear after a particularly intense period of police raiding. One afternoon during this time a man came through the brothel with white condom boxes, "he's here to distribute condoms for free". Residents sought out boxes and it was shared "the condoms belong to the women who fled...were jailed. And they [management] are redistributing" (Flower 10 April 2013). Boxes were covered in mold and water stained. The particular damage to each box suggests they were taken from "Hell”, where women are more likely to be apprehended by police. These newer residents have weaker social ties and fewer resources to exchange for their freedom. Lacking in 
social capital and less embedded in the community fabric of the brothel, women from "Hell” are especially susceptible to the deleterious effects of preservation.

\section{$\underline{\text { Scarcity and the Paradox of Friendship }}$}

Women's preservation, especially in matters concerning police and those who become "lost", is about maintaining harmony in the brothel. The communal practice of consolidating women's property is a necessary component of collective preservation. While this form of preservation is detrimental to some it benefits women who avoid arrest and continue working. Women who continue to work need condom supplies, and this becomes more possible after residents disappear. The condoms being reclaimed benefit individuals, personally, while the practice of redistribution also supports the bonds of community in the brothel, as a whole. Redistributing condoms maintains the tenuous sociability women need in order to bear the demands of survival. In order to survive women must delicately balance having enough on a daily basis. Whether it is food, water, sleep, clients, cash, friends, condoms, and/or time for leisure, everyday is about taking precautions against overcommitting resources in an environment of severe scarcity. Women's tendencies are to hold back, avoid over committing, and stealthily survive. Restraint is vitally important for women because it minimizes competition. Even among women atop the brothel's hierarchy, outwardly displaying "too much" (cash, clients, boyfriends, condoms) is strategic. Underlying many women's caution is the knowledge any day can bring "troubles” (arrest, sickness, abandonment from boyfriends and/or family) and only friends are truly capable of helping to resolve these issues. Ironically it is the very practice of friendship that distorts the practice of preservation in the brothel. 
Friendship in the brothel is complicated by scarcity. Observations and conversations with women indicate friendship is deeply connected with material security. Often instances of women’s reciprocity personify friendship, “if you get arrested, even if she is not your friend, she can bail you out and pay money. You can come and work and pay later. Is the person is your friend sometimes you even don't have to pay back. You can say 'because you have been in jail, don't pay me' or 'pay half of the money'” (group discussion 17 October 2012). Women are more likely to partake in friendship when it directly benefits their preservation: “Almost every girl here is Senga's friend. We made her our friend because she keeps our money" (group discussion 17 October 2012). Women's friendships, therefore, mirror conditions in the brothel. The more difficult it is for women to survive the more likely friendships can be impactful. Yet, women understand that during periods of more stability, there are fewer opportunities for exchange. In the absence of reciprocity women resist trusting others: "it is not possible to have a real friend in the Neko business. The friend you trust. And if you trust her, there is a limit. There is no real friend in the Neko business” (group discussion 17 October 2012). But without trust women become more susceptible to less immediate forms of risk, such as illness.

\section{Secrecy, Silence, and Shame}

Illness is perhaps the most insidious risk in the sex trade. Not all diseases overtake the body and/or mind immediately or thoroughly. Unlike malaria or Ebola, HIV works covertly, taking years to reconfigure the body's immune system. Over time the virus causes the body's natural immune system to begin failing. Failure results when fewer CD4 cells are utilized in defense of disease. With more and more CD4 cells colonized by 
the HIV virus, either by carrying the virus (reproduction) or being destroyed (bursting from viral load), their count dwindles. Throughout this colonization process the virus is incubating. Incubation is what makes HIV incredibly lethal. The virus can lay dormant for years and then suddenly become triggered. What awakens HIV is still unknown, yet throughout its dormancy contagion can be rampant. While the virus is spreading the body is slowly losing its capability to fend off illnesses (colds, STIs, malaria, TB) as healthy CD4 cells fall below the "stage three" threshold (500-1500 cells/mm3) resulting in AIDS (Acquired Immune Deficiency Syndrome) (National Institutes for Health AIDS Info webpage).

AIDS is a stage of the HIV virus necessitating treatment to prevent death. Faced with this danger, women often retreat from others. What connections women make, in relation to their HIV, is rare and often hampered by shame: "there are many people on medicine but they are discreet" (Jackie 20 March 2013). Ultimately, women's needs for secrecy as well as money are significant obstacles for their HIV treatment. When women are willing to discuss their status with others, the results are complicated by self-interest:

"By the time they took their blood samples they could get ten thousand shillings and the people [other women] were after only that ten thousand. If they told her that she was infected or not, they couldn't care. But they cared for was the money. That friend of mine whom I have told you about may also had HIV, but she refused to go for that test. Even today I have asked her 'has your blood been taken?' she said 'I just explained to them and they gave me these tablets'. I told her 'you should have taken a blood sample'. What I wanted was for her to know whether she is infected or not. When I insisted, she said, 'I just need to go to Gombe hospital'. Gombe is also a government hospital and everything is free. She comes from Gombe like me" (Flower 22 April 2013).

Eventually, through direct observation and intense participation, I found nothing is free when it comes to HIV treatment in Uganda. In the following and final sub-section 
of this chapter I share a first-hand account of Anna's HIV treatment. I believe sharing our experiences, especially after I became her medication companion, reveal why HIV infection is perhaps the most difficult risk for women to manage socially. Women's sociability mechanisms (networks, communities, and capital) can be their greatest resources or their ruination. Yet my research shows the power of stigma and shame, coupled with an intense biomedical focus on individual solutions to prevent and treat HIV, causes many women to manage the virus alone. Tragically, the data reveals women's efforts to avoid shame and stigma, through secrecy and silence, are practices of preservation that put them and the entire brothel community at greater risk of HIV.

\section{Summary}

Women's attempts at preservation involve competing practices. Efforts to avoid arrest by some place less socially secure women at risk of being detained. Yet when women disappear, those who remain benefit. Herein lies the paradox between women's individual welfare and the needs of many. When women willingly receive condom boxes from repossessed rooms, they are being responsible even if rapacious. But these actions intensify a handful of women's losses wrought by police violence. While many women understand being arrested involves a loss of freedom and property, it is simply not enough to take these risks alone.

Friendship becomes a way for women to resolve what happens after being arrested. And for women who can rely on others, they manage to strategically exercise this privilege. This is most especially true during periods of intense scarcity. But scarcity, like abundance, is inconstant. Because women recognize the utility of friendship they also recognize its danger. Women practice strategic dependence and resist blindly sharing 
their secrets. Unwilling to meaningfully confide in others, women are left to clandestinely manage their health. What ensue are women's secretive HIV treatment practices, which become far more detrimental to the welfare of brothel communities. Practicing HIV prevention and treatment in silence is the focus of the next and final sub-section, secrecy.

\section{Secrecy}

Of all the risks women encounter in the brothel, HIV is by far the subtlest. Whether or not women have access to condoms and/or participate in HIV outreach programs, their risks associated with HIV are mainly the result of secrecy. In order to better understand the significance of secrecy in women's practices I expanded my ethnographic methodology. I chose to "follow the risks of HIV treatment" out of the brothel. I focused on one of the most difficult aspects of women's risk managementaccess to HIV healthcare. As my participatory observations got underway I began to identify a series of corrosive anti-social practices. These practices extend from a central tenet in Uganda's HIV programming. At the core of these programmatic efforts is a strong prioritization of individual behavioral change. My informant Anna sought to emulate these behavioral changes. She reasoned doing this required keeping the biomedical protocols secret from other residents. Anna's secrecy became a matter of maintaining her daily habits regardless of the health implications. The results were

disastrous for Anna's social resources. Along the way she became physically weakened and emotionally isolated, and her social ties and social capital within the brothel dwindled.

Anna's experiences and decisions are central to the story I tell in this final subsection. To do this effectively, the narrative veers more closely towards a personal 
account of our experiences trying to secure her HIV treatment. The interpersonal nature of my involvement provided unfettered access to AIDS programming. As a result the research captured events revealing the intense pressures, constraints, and inconsistencies befalling Anna. Through Anna's story we understand the tensions women face in their attempts to manage two separate, but colliding, risk processes. The clash of risks involves the choices women make to either adhere to clinical treatment or to retain their connections and social support in the brothel. For Anna secrecy was the most likely way for her to manage these uncompromising demands. Yet, silence proves to be the greatest threat to her health.

Silence is Key

Of all the women I came to know during the data collection only Anna willingly included me in her HIV treatment experiences. My first opportunity to join Anna for her scheduled treatment came after we held our first interpersonal interview. During our discussion Anna understood the risk of sharing her personal details. Thankfully, she believed herself safe. As a result Anna shared the ways seeking HIV healthcare is fraught with secrecy and anxiety. Throughout our discussion Anna conveyed an overarching sense of shame for practicing sex work. To cope with this sentiment she diligently strives to keep her profession a secret:

Serena: Why don't you want [the AIDS Clinic] to know that you are a Neko?

Anna: Ifeel ashamed

Serena: Do you think they already know because of other things?

Anna: $\quad$ I have a friend here who also goes to Entebbe. She went there having some complications. One doctor inserted his hand in her [vagina] and asked her later 'what is your job?' She kept quiet but the doctor insisted asking. The girl said, 'I sell 
clothes'. The doctor said, 'stop that kind of work'. She came back and told me and it seemed the doctor knew her work. But nobody has ever inserted a hand in me [a pelvic (vaginal) exam]. So I think they cannot know.

Serena: Do you think the [AIDS clinic] counselor will look down on you, will give you stigma if you told?

Anna: $\quad$ I just fear as a person. It [sex work] is shaming.

Anna's fears are grounded. I began learning this firsthand three weeks after our initial conversation. Shortly after our first interview I traveled with Anna to an AIDS clinic in Entebbe. The journey took over two hours. Aside from walking we shuffled between three modes of transportation and spent large periods of time in traffic. When we finally reached the clinic gates it quickly became evident Anna's visit would take a long time. In total we spent seven hours in the clinic so that Anna could receive her medication. We sat for hours in in the main waiting room. Seated on a bench Anna and I waited while clinic staff shuffled from one corridor to another; stacked and restacked medical files; read aloud patient's names; and, lectured to an ill and captive audience.

Eventually staff called Anna's number. A nurse escorted us to a section of the clinic where Anna would receive counseling prior to being given medication. Anna's counseling session can be divided into two parts. Part one involved a presentation from her counselor, Stan, wherein I gave my ascent to become Anna's medication companion. The second part took place after Stan asked for a private audience with Anna. During session one Anna quietly sat listening to Stan's behavioral change message. Stan initially prescribed Nevirapine, a standard anti-retroviral treatment. ${ }^{44}$ He explained Anna must

\footnotetext{
44. From the medication warning pamphlet: "The most serious adverse reactions associated with nevirapine are hepatitis/hepatic failure, Stevens-Johnson syndrome (a form of toxic epidermal necrolysis, which is a life-threatening skin condition, in which cell death causes the epidermis to separate from the dermis), toxic epidermal necrolysis (also known as Lyell's syndrome, is a rare, life-threatening skin condition that is
} 
take the medication twice per day. Before finishing his explanation about the drug, Anna disclosed that her work schedule makes it difficult to take more than one pill per day. When Stan inquires about Anna's work, she lies saying she is employed at night in a restaurant. Stan then decides to prescribe a different medication, Lamivudine (EPIVIR ${ }^{45}$ ). Unbeknownst to Anna, who cannot read the medication warnings in English, the second choice drug has far greater side effects (see footnotes 44 and 45 ).

During this exchange, I suspected Stan intended the "behavioral messaging” for me, as his interest in Anna's profession was passing. This seemed salient when Anna's response about her profession mollified Stan, who no longer cared to learn any more than necessary. Overall, the experience and conversation in this scenario was futile. In Stan's attempts to recite a preapproved behavioral change communication he was either unable

usually caused by a reaction to drugs causing the top layer of skin to detach from the lower layers of the skin all over the body, leaving the body susceptible to severe infection with mortality rate ranges from 25$30 \%$, and death usually occurring as a result of sepsis and subsequent multi-organ system failure) and hypersensitivity reactions. Hepatitis/hepatic fever failure may be associated with signs of hypersensitivity which can include severe rash or rash accompanied by fever, general malaise, fatigue, muscle or joint aches, blisters, oral lesions, conjunctivitis, facial edema (swelling), eosinophilia, granulocytopenia, lymphadenopathy, or renal dysfunction (kidney dysfunction)" (Highlights of Prescribing Information: Nevirapine Tablets USP, Initial US Approval 1996 Rx). The label lists six more warnings and precautions and below these points are three more specific descriptions of "Adverse Reactions".

45. EPIVIR: "WARNING LACTIC ACIDOSIS, POSTTREATMENT EXACERBATIONS OF HEPATITIS B IN CO-INFECTED PATIENTS, DIFFERENT FORMULATIONS OF EPIVIR. Lactic Acidosis and Severe Hepatomegaly. Lactic acidosis and severe hepatomegaly with steatosis, including fatal cases, have been reported with the use of nucleoside analogues alone or in combination, including lamivudine and other anti-retrovirals. Suspend treatment if clinical or laboratory findings suggestive of lactic acidosis or pronounced hepatotoxicity occurs [see WARNINGS AND PRECAUTIONS]. Exacerbations of Hepatitis B. Severe acute exacerbations of hepatitis B have been reported in patients who are co-infected with hepatitis B virus (HBV) and human immunodeficiency virus (HIV-1) and have discontinued EPIVIR. Hepatic function should be monitored closely with both clinical and laboratory follow-up for at least several months in patients who discontinue EPIVIR and are co-infected with HIV-1 and HBV. If appropriate, initiation of anti-hepatitis B therapy may be warranted [see WARNINGS AND PRECAUTIONS]. Important differences among Lamivudine-containing products: EPIVIR tablets and oral solution (used to treat HIV-1 infection) contain a higher dose of the active ingredient (lamivudine) than EPIVIR-HBV tablets and oral solution (used to treat chronic HBV infection). Patients with HIV-1 infection should receive only dosage forms appropriate for treatment of HIV-1 [see WARNINGS AND PRECAUTIONS]" (found at Rx List of medications at http://www.rxlist.com/epivir-drug.htm\#BW). 
or unwilling to convey a message Anna could personalize. In turn Anna could withhold the truth about her profession, while inadvertently complying with a dangerous medical intervention. Anna's consent to the medication Stan prescribes is questionable especially considering her inability to understand the ramifications of her lie and choice. Yet at the heart of this neglect is an intervention that exposes a troubling flaw in the treatment protocol.

Before Anna can receive ARVs Stan explains, "She must have a medication companion. The mediation companion has to be with Anna on the day she begins therapies, but it is not necessary to come with her in the future" (field notes 8 November 2012). And because I happen to be with Anna that moment, Stan states, "So just for now you must agree to help her". Stan made this request after repeatedly translating between Luganda and English in order for Anna and I to understand his instructions. My suitability for the role of medication companion is highly questionable. Yet this directive is compounded by an underlying ethical conflict it puts upon the companion.

As Anna's companion, I am aware of her profession and because I can read the warning in the medication pamphlet, I understand the implications of her taking the stronger drug. But my commitment to Anna's secrecy keeps us both silent. For me, silence is wholly rewarding. As I keep quiet, Anna remains trusting. For Anna, silence is double-edged. Secrecy provides a medication regimen she believes will let her maintain daily life in the brothel. But silence also means her body will likely suffer. Anna's suffering obliges us to think about the ramifications of her silence. Anna's secrecy signifies both the harm committed when AIDS policies are blind to vulnerable 
populations, like commercial sex workers, and it also exposes the lengths women will go to preserve their social resources.

\section{Pragmatics of Privacy}

In the months after our first trip to the AIDS clinic, Anna's body broke out into a full rash. Her lips and gums began to bleed, she formed sores inside her mouth, and she became more susceptible to fevers. As Anna's body absorbed the stronger medication, she struggled to conceal her condition from other brothel residents. She began "painting her lips” (wearing lipstick), keeping a shawl about her shoulders during the day, and intensifying her body cream regimen. Anna's efforts reveal how much she wanted to hide her AIDS: "My lips are white and I am using dark lipstick to hide it. Having discolored lips are a sign that you have HIV. I do not want anyone to know about my status, especially these new Nekos” (Anna 3 March 2013). Disguising her lips, covering her upper body, and slathering lotion over her limbs is how Anna remains in control during a chaotic and unpredictable situation. Anna cannot risk the outright censure of the brothel hierarchy nor can she do anything other than follow Stan's instructions. With no recourse but to adhere to her medication protocols and attend her appointments, Anna is left alone to struggle.

Anna's isolation is about survival. The same impulse to protect herself drives Anna to refuse additional support from the AIDS clinic. For Anna the decision is simple. Forgoing free clinic supplies is how she avoids signaling her positive HIV status to other women and provoking their stigma:

Serena: Do you get free condoms there [the AIDS clinic]? 
Anna: $\quad$ They give us as many as one can carry. They also give free jerry cans, mosquito nets, and water guard. I refuse to take them.

Nakato: What is wrong with them?

Anna: $\quad$ The way they are made shows exactly their purpose [free supplies for people with HIV]. Because I don't want people to know [I have HIV], I cannot take it [the jerry can]. It has a big inlet here and a small one at the side. People know what they are for [AIDS]. Very few people take them. Like these condoms, if people see you with these condoms, they will know that MARPs or Mulago provides these. So that is the same thing with the jerry cans. They are labeled and one will look at them and say 'oh, this one is HIV positive. She got this jerry can from the hospital'. I don't want people to know.

Keeping her secret safe is paramount for Anna. Accepting clinic supplies undermines her ability to avoid contempt. Therefore, Anna must refuse materials to keep herself safe from social censure in the brothel. Yet the support being offered reflects an inherent contradiction in Anna's HIV treatment. Fundamentally Anna's treatment promotes a behavioral change model focusing on individual ways of coping. This results in a celebration of individualism at the expense of community survival. When personal responsibility is tantamount to programmatic success, operations become trivial. Anna and I found this out during our second visit to the AIDS clinic.

Prior to me accompanying Anna for another HIV treatment she decided to travel for sex work through Eastern Uganda and Western Kenya. Consequently, Anna missed her scheduled appointment in February. Even though Anna could not keep her scheduled treatment in Entebbe, she recounts that, "while I was away on that long trip I missed out on my medical appointment and I went to the hospital in Tororo and explained my situation to the doctors, who called [the AIDS clinic in Entebbe] to check-out my file and give me the medicine I required" (Anna 3 March 2013). Unfortunately, staff at the clinic 
in Entebbe dealt with Anna's truancy by insisting she: “write an apology letter explaining why she had to miss her [previous] medical appointment in order to receive her medications” (Anna 7 March 2013). In order for Anna to receive her medication the letter needed to convey sincere remorse. Fortunately, Anna is literate and quick. She drafted a letter in few minutes offering an empty apology sprinkled with untruths:

"I hereby request for your forgiveness for not returning to collect my medicine on the exact date of appointment. But I had a patient who was so close to me in Tororo. She was very sick. She is my auntie. I had gone to take care of her while she was in hospital. And I requested in humbleness for medicine and they added me. I know I was supposed to come to return on 14th February 2013. They called the hospital here and they checked my file and they saw the type of medicine I needed and my medical records and they gave me the medicine from Tororo hospital, which I have been taking for the past 2 weeks. In my plea that I had done a mistake, please forgive me. I will not do it again. Please forgive me Madam. Yours, Anna" (Letter from Anna on 7 March 2013).

Begging for forgiveness is a means to an end. For Anna the end is medication. With medication Anna believes herself safe. To arrive at that safety Anna is willing to appear humble. Never mind she continues practicing sex work, is being treated with an incompatible medication for her current CD4 count, and lacks social support. So long as the counselor receives an apology Anna will have satisfied a measure of accountability underpinning the instrumentalist notion of healthcare operating in the clinic. Clinic patterns of instrumentalism focusing on individual behavior change are the crux of Anna's struggle. In this environment Anna must present herself as competent, contrite, chaste, and responsible. Sadly, Anna's capacity to conform to these expected behaviors, in the context of the brothel, is unintelligible to the biomedical discourse grounding her treatment. As a result Anna is forced to keep two secrets - her profession (from the medical establishment) and her condition (from her colleagues). 


\section{For Shame}

Guarding the secret of sex work puts Anna's health at risk. Yet so long as Anna hides what she does from medical staff she cannot receive optimal treatment. Conversely, the medical treatment Anna does receive inspires little trust. Herein lies one of the greatest dilemmas for women practicing sex work. In a cultural context that derides people for selling sex, many women question the safety of exposing what they do in order to manage their HIV more responsibly. Compounding this fear is the shame women carry. Anna's shame compels her to avoid the truth as well as withdraw from her colleagues; therefore, exposing her to additional risk while removing a critical means of support.

Other than our conversations Anna rarely confides in other residents about her HIV status. Alone and ill Anna’s behavior is starkly different from her peers, especially Tina. Tina easily discloses her HIV status and speaks openly about her AIDS care in front of other women in Babito: "Me I can sit with you and talk to you straight forward that 'I am like this' [HIV positive]. If you suspect yourself, you can ask me to 'take you'. That is how the two told me, that to "take us". So far I have taken two for testing and they tested positive. They have started getting [care] in Mulago” (Tina 29 September 2012). Although Tina candidly shares her HIV status with other women in the brothel, she resists having company during her HIV appointments. Tina’s resistance is partially explained by the pressures women face to extract income anytime possible. Unlike Anna Tina sought compensation for her stories. Tina's failure to earn through the research process eventually created distance between us. Yet her behavior is indicative of the 
pragmatics of income generation. Tina's business-like approach to daily life, like many women in the brothel, complicates most exchanges, and HIV treatment is no different.

Apart from Anna's clinic visits the only HIV treatment, and therefore programming, to reach the brothel is capricious and utilizes material incentivizing schemes to enroll women (condoms, cash, refreshments, meals, HIV testing referrals in exchange for women's "signatures" (i.e. thumb prints), names, and phone numbers). Whether or not women actually become and/or remain healthy during these programs, many realize by simply participating they mitigate their immediate risks. In doing so women, such as Tina circumvent the stigma associated with HIV in the brothel, while retaining their privacy. Unfortunately, Anna was unable to find relief from her shame, which was compounded after writing her apology letter. For Anna having to cope with two conflicting contexts, results in a process of balancing risks. She is aware AIDS related diseases could kill her, but so can her inability to generate income and keep savings. Anna is willing to risk the latter alone without strong ties in the brothel, so long as she can maintain access to medical interventions. Given her choices, Anna moves through the clinic's system in clever supplication, neither entirely transparent nor wholly obedient. Rather she simply survives the risks of each environment day-by-day.

In this way, Anna straddles two risk environments. Both are life extending, but only one is socially permissible. As a result of this permissibility Anna believes she must conceal the practice of sex work in order to receive HIV treatment. Yet the medical care she receives has implications for the social support she must regularly cultivate in the brothel. In Anna's attempts to balance both, she suffers socially and physically. Through her struggles we learn the difficulties women experience trying to balance the demands of 
community and health. Unfortunately, Anna's story illustrates how the fickleness of healthcare provision is by far a greater risk to the social net she needs in order to survive daily life.

\section{Concluding Thoughts}

Women in Babito have found ways to manage risks together, albeit, imperfectly. At the core of their survival is a complex social hierarchy, which involves an intricate pattern of sociability. This pattern has been discussed in relation to a series of five social practices that reflect women's social connectivity—-their networks, capital, and community. The first theme coexistence, concerns incidental moments of connectivity whereby women manage to spend time together with little expectations of social reciprocity. Yet I show as a result of these happenstance moments, women's trust is built incrementally. Next I discuss trust as it relates to the second theme, intimacy. With intimacy, women become invested in their peers so that select members of the brothel community begin to purposefully support one another. These interpersonal investments take the form of small favors and instrumental ways of demonstrating acceptance of one another in the face of the brothel's social hierarchy. At the same time women's behaviors reflect how the hierarchy imposes social expectations in relation to where women reside in Babito.

For those women who manage to belong to the brothel's inner circle, they have greater access to resources (e.g., rooms, cash, condoms, etc.) and more chances of staving off risks by way of practicing interconnectedness, which is theme three. This third theme helps one to understand the formation and presence of women's precautionary safety measures (savings circles and bribing police). Relying on one another, these elite 
members of the brothel engage in community building through interconnectedness, and as a result they have greater access to condoms and better ways of evading police during raids.

Not all residents in Babito benefit from practices associated with coexistence, intimacy, or interconnectedness. Rather some residents of Babito lacking in social capital and strong social networks are often the first sacrificed for the greater good of the community. This is most often the case during police raids, when the preservation of Babito's network becomes paramount over the safety and security of more vulnerable members. During these violent episodes the losses incurred by residents with weaker social ties, those women who are more likely to be arrested and therefore lose possession of their resources, become the collective property of Babito’s remaining residents. This in turn helps maintain the supply of condoms as well as access to rooms for women otherwise willing to practice sex work in far riskier environments. In this way women's preservation, theme four, signifies the importance of their social networks in relation to minimizing risks, particularly, those related to external threats, such as police.

Preservation is also a motivating factor for why women choose to keep their HIV/AIDS secret. Secrecy, which is the final theme, is perhaps the most dangerous risk management strategy of all. While it protects one from stigma and social alienation at the hands of residents atop the brothel hierarchy, it also endangers women's lives both inside the brothel as well as inside the clinic. From inside the brothel secrecy pushes women to conceal their condition in desperate ways in order to appear physically healthy, whereas inside the clinic women's secrecy leaves them vulnerable to receiving less comprehensive care. Afraid to reveal their profession to medical staff, women endure 
medical practices that isolate, discriminate, and/or shame patients. Ultimately, in the face of these secret practices women come to believe they do not deserve the support, acknowledgement, and acceptance of their peers or medical advisors. As a result these women turn towards managing a virus that proceeds slowly and steadily towards a terminal end, all the while with diminishing social ties and therefore a lack of resources for surviving the risks associated with sex work, criminalization, and HIV/AIDS. 


\section{CHAPTER V}

\section{A CAUTIONARY TALE}

\section{Introduction}

HIV/AIDS prevention and treatment policies and programs in Uganda are incomplete so long as they fail to consider the social implications of risk among individuals engaging in the commercial sex trade. I have already shown the relational conditions associated with women's daily risk and the social complexities of their survival. My work reveals how the nature of women's networks can teach us about the benefits and dangers of trust. Yet, here my focus shifts a bit. While these additional reflections do not deal solely with trust per se, the concept proves instructive. Trust is a signifier of deep and impactful patterns of social acceptance and respect. In the slums trust is neither wholly secure nor entirely broken. Rather it is a delicate necessity that sustains life. I learned this, personally, in my second community, Kiku, first introduced in chapter one.

In Kiku I found just as trust is necessary for doing research, it must also exist during any attempt to inform community practices. I benefitted directly from the trust of many women in Babito, which allowed me to delve deeply into the heart of their brothel lives. Yet the same cannot be said about the second community. My data collection in Kiku faced significant barriers. As a result I failed to directly gather information pertinent to women's daily risk management practices. However, my very inability to gain direct evidence from this site can be used to develop valuable insights about working with “hard-to-reach” populations. 
Here the dissertation moves closer to my personal experiences than ever before. I describe the development of my own social networks, interpersonal capital, and ultimately my struggles to maintain ties with Kiku’s sex work community. As a result, my description bears a fuller discloser of my challenges. By doing so, I offer a tale of caution that speaks directly to the potential obstacles for future researchers as well as policies. In this way, I render a greater sense of fragility underpinning HIV/AIDS interventions that do not consider the ways interdependence, community allegiance, and respect shape the daily lives of individuals in the sex trade.

\section{The Place of Muddy Water}

\section{Figure 5.1 - Picture of Kiku Road}

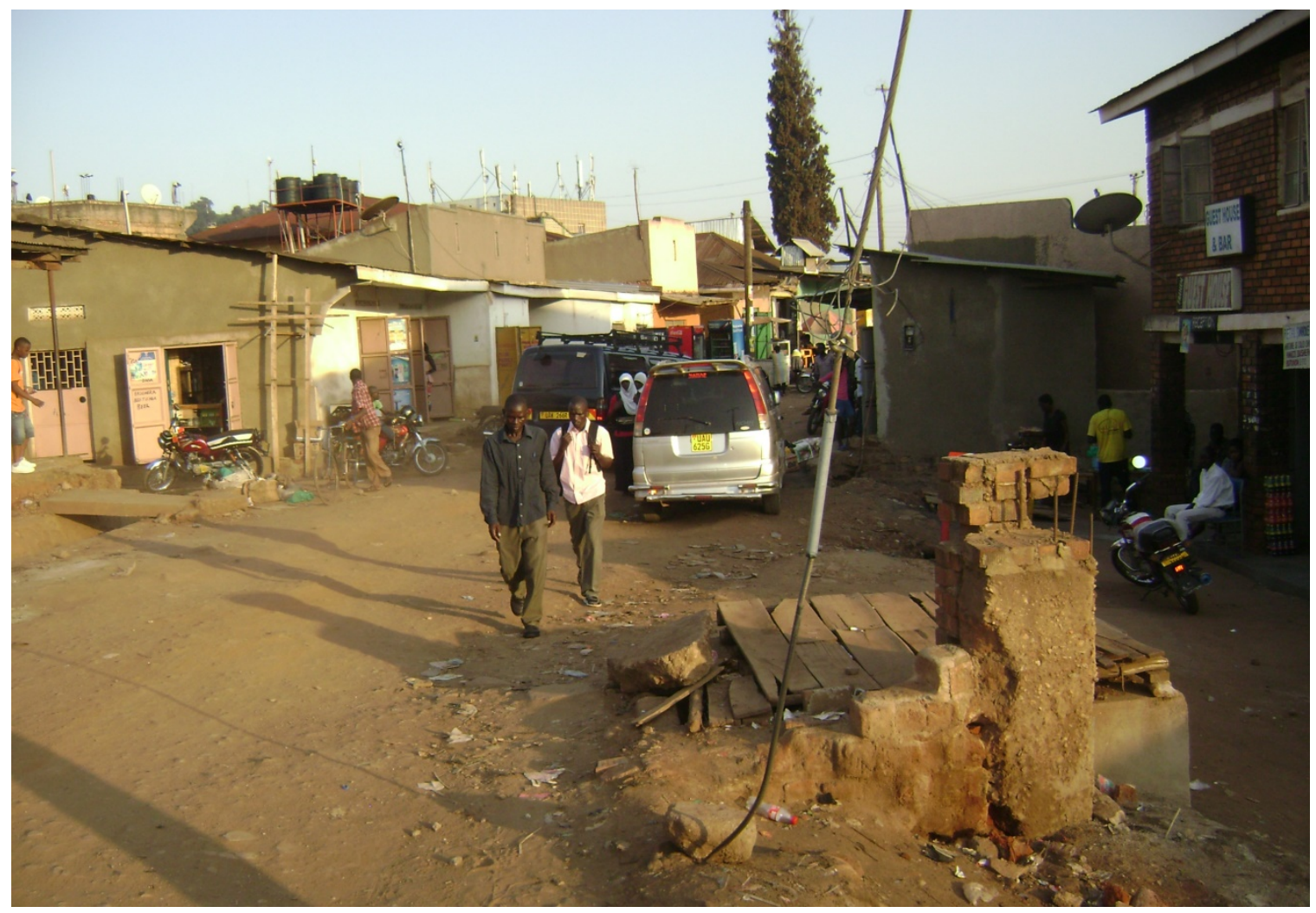

"This area is called Kiku, the place of muddy water. The name was here. But the situation changed when these ladies started working from here." (Rico, 5 March 2013). 
The first time I met Rico, in November 2010, he was the acting brothel manager for Mr. Z, a prominent landlord in the area. I was in Kampala for the month to explore the feasibility of my research. During this first trip I learned of Kiku, a prominent sex work location in Kampala. The times that I walked through the community, I learned a smattering of details. For starters the community branches off from Kabalagala Road and is no more than 100 meters wide. A dirt road bisects the area and small businesses closely abut one another on either side of the path. Many places are little more than one or two room wooden shacks, where residents come to gamble, buy medicine, eat local food and drinks, rent videos, and purchase cigarettes, alcohol, drugs, light consumer goods and/or cell phone cards and air time. Here in this small community I came to know of four distinct brothels sprinkled between the areas lean-tos—Danny's, Mr. Z's, Landlord's, and Guest Lodge.

When I returned to Kiku in June 2012 very little had changed. The community still thrived because of sex work and residents continued to frequent the same pharmacies, eateries, kiosks and bars, discos, and four brothels. It was this "sameness", in terms of the amount of human commercial activity and the large number of women selling sex, which contributed to why I wanted to study the community. I returned anchored by a budding professional association with a trusted local informant—Nakato. Although Nakato had left the area four years before, she had previously spent almost ten years practicing commercial sex work out of Mr. Z's brothel. It was through Nakato that my social networks grew in Kiku. By vouching for me, Nakato's support provided the much-needed social capital that increased my entrée into the community and allowed me 
to move through the area quite freely. This access gave me opportunities to spend time inside each of the four brothels, where I observed and recorded a dynamic process of mutual obligation that contributes to how men establish their social networks in the community. With obligations, men extend the reach of their social capital and, in turn, receive the respect of their peers. Yet central to men's activities is the control of women's time, money, and ultimately bodies. In this way, the women of Kiku's sex trade provide the essential means for men's success.

\section{I have my cameras - Christian}

Nakato's connections in Kiku run deep. Not only did she spend a significant portion of her professional time in the community, she also has relatives in the area. Nakato comes from a family of over 13 children. Her siblings and their children spread out through southern Uganda and it seems their reach includes Kiku. Here in the slum, Nakato's nephew, Danny, manages a brothel with three other men. Danny's brothel slopes down away from the heart of Kiku and is set farthest from the other three businesses. When away Danny enlists support from Christian, Barry, and Cisco. Taking turns, the four men keep the venture running 24 hours per day, seven days per week. Although they do not own the business, they are solely responsible for its provision and upkeep (condom supplies, cleaning, mattresses, security, etc.). The business itself operates out of a small space. Essentially these four men manage one room divided into three different sections by either plywood or cotton sheets. The latter are draped over thin twine, which has been strung between two of the four walls making up the room.

Whereas the first two divided sections have twin foam mattresses encased in fabric lying on the dirt floor, the third section is multi-functional. When Danny gave me a 
tour of the space I learned that section three is where he stores condoms. He apprised me that the large boxes of condoms find their way to him freely by way of his "channels" (local NGO networks). Aside from storage, section three also has an important feature, as Christian proudly revealed: "I have my cameras. In my room there is a camera. Not a real camera but there is a hole through which one can see inside with every customer. It is a must. I need to know what happens. I want to find out what may happen to a girl who meets the same person for a full month. I want to know what may happen out of it”. Thus, carved into the middle of the plywood divider is a small, almost invisible, hole. A "panopticon" of sorts, used for watching customers and women having sex. Christian believes it is necessary for them to keep vigil, as it ensures women behave (i.e., do not steal from customers). Yet his interest also signifies a level of interpersonal control over women's time, privacy, and relationships. In this way, Christian is carrying out an important practice among the men, a practice tied to the management of resources (women, condoms, and even privacy), which the men believe the hole in their wall ensures greater chances of protecting these "human assets."

The three “rooms" in Danny's brothel make up a dimly lit and very cramped space tucked into a maze of cement. The surrounding walls have peeling paint and stains from mud, water, and/or bodily fluids. The floors are open patches of dirt and retreating shattered tiles, which give some indication of how to enter and exit the building. When I would come and go from their small brothel, I had to first step over a thin stream of open sewage sandwiched between two cement buildings. From there I would walk through several dark hallways, often passing what seemed like homeless and undernourished local men, either sitting or lying on tiled or dirt floors in a semiconscious state. Eventually the 
maze of cement leaves off at a doorway in front of the main dirt road. Often I found Danny, Christian, Barry, and Cisco standing beside the main doorway or leaning on a wooden railing to the left of their building. There the four keep busy watching over the parade of people and calling out to men moving further into Kiku.

That is the very place where I was working - Rico

Figure 5.2 - Picture of inside Mr. Z's brothel

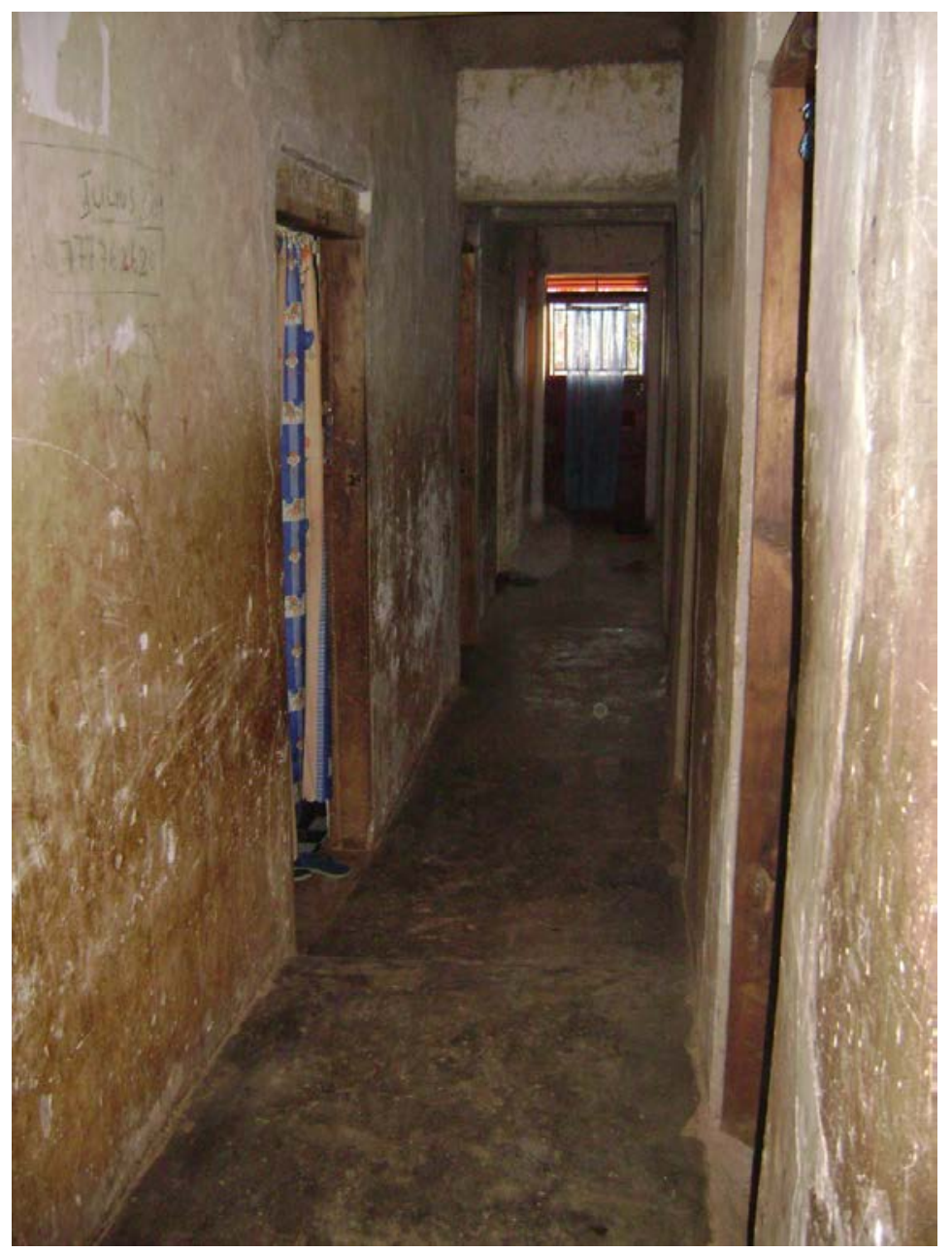

As my ties with Nakato deepened, so did my connections in Kiku. I began engaging more and more with particular men in the community. Over time, these individuals became personally entwined with my social network. In the beginning these 
relationships served the research project well. When Nakato and I started collecting data, we relied heavily on these brothel managers during the first several weeks of the data collection. Through our connections we were able to hold several group discussions between September and November 2012. While the method failed to cull much information from women, our connections with the men in the business made it possible for Nakato and me to use Mr. Z's brothel as a site for our interviews.

Overall Mr. Z's brothel is a far more substantial structure than Danny's establishment. Mr. Z employs staff to clean and tend to the interior, which is a sturdy cement structure, with finished walls and floors made from either tile or cement. There are two sections of the building, and the front half looks older than the back. A heavy metal door and gate secures this front area, which is also the main entrance to the brothel. Inside this entryway there are two rooms with curtains for doors. Opposite these rooms is a long wall framed by several wooden benches. This is where Nakato and I spent the majority of our time conducting interviews. And it is also where Mr. Z's brothel managers and "askaris" ${ }^{46}$ sit during nightly working hours.

To reach the newer section of Mr. Z's brothel requires walking down a hallway that straddles several rooms and the only toilet in the building. Rooms contain a bedframe with a mattress, usually with fitted and flat sheets on top, and a plastic bucket for men and women to clean themselves after sex and/or dispose of used condoms. Light bulbs hang from the ceiling from thin wires. Beyond these rooms the hallway eventually comes to a second door. This exit leads to an area behind the brothel. Although my ability to

\footnotetext{
46. Local term meaning a person involved in security, policing, and/or protection. The origins of the term are hard to find, but web research showed the roots of the term coming from Arabic and Swahili.
} 
directly engage women was stunted, on one particular occasion I did find several women gathered behind Mr. Z's brothel. On that day, Nakato and I had approached the back of Mr. Z's brothel in the late afternoon. There the women were hand-washing clothes in plastic tubs while minding toddlers or wearing babies in cotton wraps around their backs; and/or sitting next to each other braiding hair and chatting. When I noticed these women my hope was to connect with them straight away about the research. But that is not what happened. Instead, as men increasingly dominated the data collection process it became more difficult to cultivate the same kinds of relationships with women as I had done in Babito. With men overpopulating my inner circle of informants, Nakato and I attempted to develop a pattern of sociability that would increase our chances of meeting women.

\section{The others leave their concerns to us - Landlord ${ }^{47}$}

Figure 5.3 - Picture of the entrance to Landlord's bar and brothel

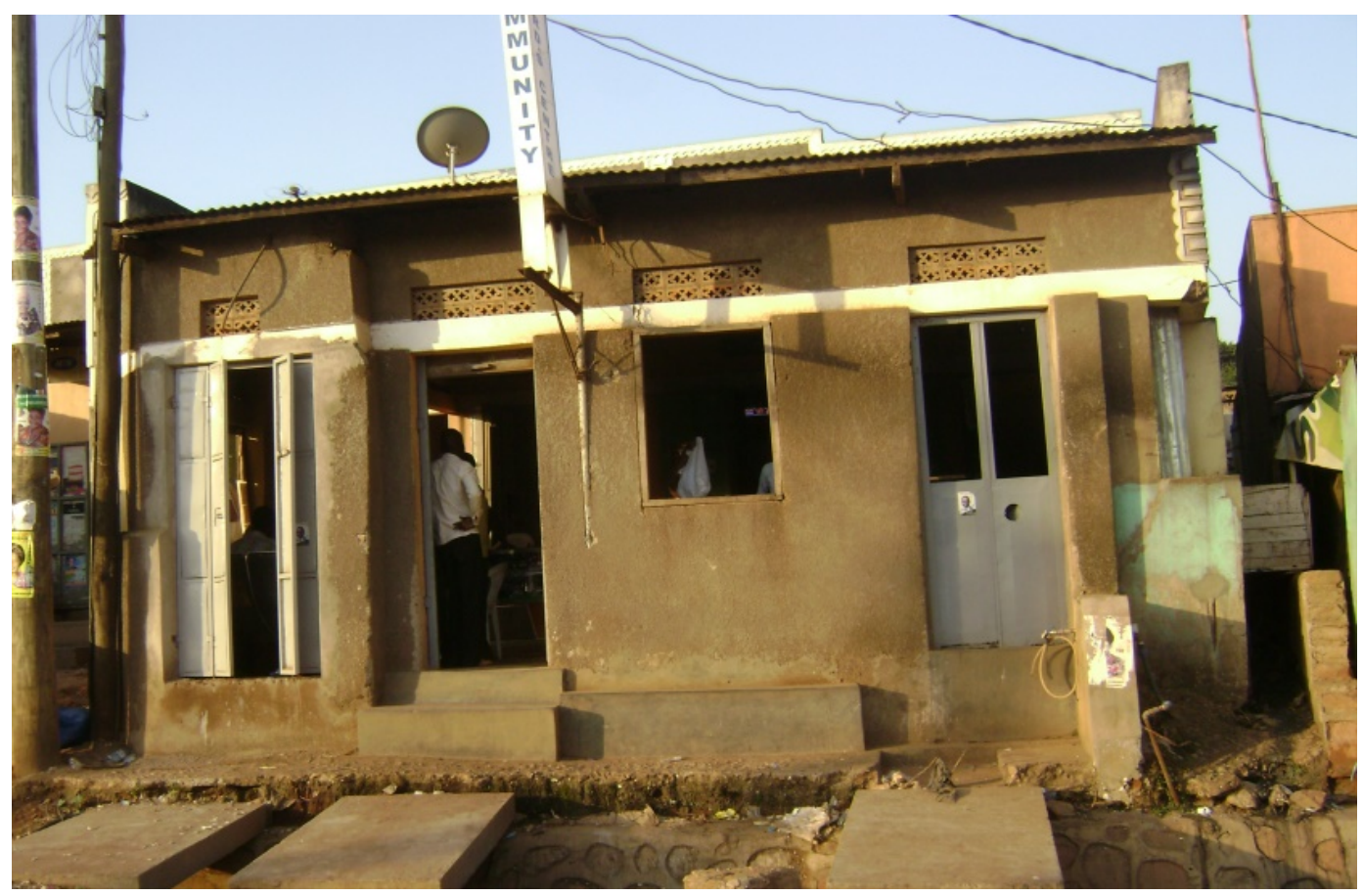

47. Landlord is the only name I heard this person called and I was unable to learn his family name. 
Once Nakato and I grew accustomed to the setting, we sought to collect data in the most uniform way possible. We would begin our workday by walking past Danny's and Mr. Z’s brothels. If Christian, Danny, Barry, Cisco, Rico, and/or Mr. Z were about, and seemed friendly, we would stop and chat. Mostly Nakato would talk and I would listen to her translations. Eventually these exchanges flowed quite easily, and there were even times when I held side conversations with Danny and Mr. Z, who both also spoke English. Beyond these interactions Nakato and I would then move towards the entrance of the third brothel in the area, which was owned by Landlord. To reach his place required passing Mr. Z’s business, two bar/discos, and then eventually ascending a small incline. Once we arrived, Nakato and I would wait for one of our contacts, whom we believed would be able to connect us with women willing to sit for interviews. Waiting at the start of Landlord's compound meant often being surrounded by many men. These individuals would either be sitting or standing near two kiosks to the left of the brothel's entryway or moving in and out of a bar to the right. Besides a few tours around the compound, I rarely spent time in Landlord’s domain.

What I did observe showed an establishment with many sections. The very front of the compound is a carport. The structure is a simple cement ramp, where men park their "boda bodas" (motorbikes). Beyond the parked bodas is the opening for Landlord's inner sanctum, which is where he often sits gambling and drinking local beer or gin. The area resembles a courtyard, one overrun by neglect and strife. Here men sit around a large game board rolling dice, placing cash bets, smoking cigarettes and/or marijuana, and drinking alcohol. Rows of rooms surround the area, which has been expanding for some 
time according to Rico: “Landlord had like seven lodges [in 2003] but now [2012-2013] he has like 40 or 30 something”.

The rooms varied in size and habitability. And depending on the availability of natural light, the outer walls in this part of the compound appear gray or fading white. Inside, rooms are cramped with fabric-encased mattresses lying on cracked tile floors, which seem to be losing their battle to the rising dirt beneath. The few rooms I visited often appeared to have multiple occupants-mostly women with babies and/or toddlers. These children rarely wear clothes and their little faces peak out of doorways. Sometimes their cries spill out into the courtyard, mingled with men and women arguing or having sex.

In Landlord's brothel few boundaries seem to exist between personal and professional space, wholly unlike the other businesses in the area or Babito. Time in Landlord's compound revealed to me the stark differences between sex work networks dominated by women and networks run by men. While the women of Babito have their own interpersonal dilemmas to attend to, which I have shown to have serious implications for their HIV risk management, nothing in their daily life seems as violent and oppressive as it does for the individuals connected with Kiku's sex trade. Whereas Babito is first and foremost a business - a place women come to rent rooms in order to earn cash through sex work. Kiku is a community. Comingled with the dealings of brothel owners and managers and pimps, sex workers, and drug dealers are children, the elderly, and small-time shopkeepers. Although these residents may indirectly benefit from the sex trade, something I discuss further down, their lives are also punctuated by 
the brutal and coercive side of sex work - the side that men's networks in Kiku rely upon in order to gain respect from their peers.

In this way, of all the potential sites for my data collection, both in Kiku and in comparison to Babito, Landlord's seemed the most difficult. For starters, when he finally learned that I was "not paying” he made it clear to Nakato that unless I was prepared to give him something, no one in his employ, and especially him, would participate in my research. Landlord's rent seeking tactics are unsurprising. His approach reflects the pragmatics of survival in Kiku, particularly when income generation is fraught with hierarchy and maintaining control over fleeting assets (women, less influential men, condoms, drugs, alcohol, cash, etc.). Yet Landlord's response is also deeply gendered. My presence and interests in the lives of women, who happen to sell sex, could easily undermine his authority. And this potentiality seems to have incurred his hostility. As a result, Landlord's position towards the research made it impossible for me to connect with the men, and therefore women, in his sphere of influence. Indeed his resistance foreshadowed what was to become of my data collection process in the coming months.

By October, just as Nakato and I were deepening our ties in Kiku, my social network underwent a drastic change. In a matter of a few weeks my social ties in the community intensified. This happened after my roommate Mandy began dating a local pimp, James, who had loose ties to Landlord. ${ }^{48}$ Once this relationship between Mandy and James developed, my personal and professional networks suddenly overlapped. At first, this allowed me to expand my connections in Kiku rapidly. But the situation was

\footnotetext{
${ }^{48 .}$ Further down I discuss James in more detail.
} 
rife with risk to the research process. While their intimate relationship flourished, Landlord's hostility grew and my personal space became fused with the lives of my informants in the community. As a result the trust that I had gained while working with Nakato slowly began to slip away. Eventually there was little left. And only time, distance, and a new approach allowed me to circumvent these challenges.

\section{My coming is because I always see you here - Sebastian}

By January 2013 my data collection in Kiku had been severely undermined. As a result I had to tread carefully when I chose to return, since my presence in the community was barely tolerated. This is partly because Nakato, for personal reasons, no longer cared to work on the project. Her exodus from the research undercut what social capital I accumulated, therefore crippling the interpersonal connections I developed among residents in the sex trade. But along with Nakato's flight, Landlord’s networks were sabotaging my access to women working in the brothels. After two months of trying to reconnect, it seemed my social marginalization within Kiku was complete. Yet simultaneously the community was undergoing change. New investment was underway and there was an influx of new entrepreneurs. Hailing originally from Ethiopia these investors were interested in buying property in the community. To the relief of my data collection their acquisitions included Guest Lodge, the fourth and best-kept brothel in the community.

Guest Lodge is built away from the main dirt road, with a small incline separating the primary entrance from the flow of traffic. Soon after new management purchased the business, I found it safer to return to the community. When I began to visit Kiku again I was working with a new research assistant, Roz. Unlike Nakato, Roz had no affiliations 
with the community. Her role in the research was to provide translation and transcription, as well as help broker relationships with women who seemed willing to engage with us directly. But soon after we started working together we both realized how unlikely it would be to meet with women in Kiku. Thus, meeting the new management for Guest Lodge was a boon. Here Roz and I could speak with these men about our interests, while being welcomed to remain in their company. This opportunity was simply a matter of being in the right place at the right time.

Meeting George, and then eventually Eddy, gave Roz and I a chance to learn more about the inner workings of the sex trade in Kiku. Eddy would openly share information about the recent changes in management, as well as his ties to the Ethiopian diaspora in Uganda. He also underscored the importance of making strategic investments in the community, such as paying into the local Security Committee. This informal governing body is comprised of local politicians and business owners, as well as trusted men loyal to the different brothels. Membership for Guest Lodge required paying approximately US\$40 for registration and then US\$40 each month. In return, local police leave the business alone. Often Eddy, Roz, and I would sit around a large plastic table, with four chairs, and shaded by one very large rainbow colored umbrella. From that perch Roz and I found our refuge — the plastic table — and this round covered space became our point of observation for the remainder of the data collection.

Prior to finding myself under the umbrella, there were times when I had previously toured Guest House in Nakato's company. The lodge is a large, two-story, white building, which functions as a brothel in similar ways to Babito. Women can rent rooms either upstairs, downstairs, or around the patio in the back and I was told the rate is 
US\$5. Compared with Babito there are fewer rooms and women on the premise. The times I moved about the compound my observations were confined to ground level. There I could see a diverse set of activities. For starters, Guest Lodge boasts a small bar and eatery in the front area on the first floor, where some patrons gather. Yet most events seem to take place beyond this front space. A hallway starts just past the bar and leads through a doorway to the heart of the compound. Here, in the very middle of the patio, is a freestanding pool table. The table is covered by a wall-less wooden tent-like structure, with sheets of tin for a roof. Lodge rooms and plastic chairs line the walls of this outdoor space, but during daytime few rooms are open. Regardless, the patio is quite lively. Men play pool or keep seated drinking local beer and/or gin and chatting with small groups of women, who move in and out of the compound. In this self-contained space the management profits from pool games, the sale of alcohol, food sales, and of course sex. And all the while a large metal gate controls the flow of people, bodas, and cars, so few individuals enter without notice.

\section{Community Business}

"You see in this area, the society and the businessmen get money from these sex workers. Even the other guys came [pimps and brokers] because of these ladies. That is why it was difficult to chase them away. Even me in my business [video rental kiosk], I am supported by these ladies. Yes. Even those shops, the bars, they all depend on these ladies.” (Rico, 5 March 2013).

The sale of sex is the most prominent business practice in Kiku. Its importance cannot be denied nor should it be reimagined without the financial prospecting, dramatic posturing, and social vying exhibited by men who want nothing more than to be respected by their peers in the sex trade. I came to learn about the presence and power of 
men's networks, first by way of social inclusion, but also exclusion, thanks to Nakato and my roommate Mandy. Yet, ultimately I came to understand the practices of men's social networks through long-term observation.

Roz and I eventually settled into our own routine for collecting data. Our afternoons and nights were spent seated under the umbrella at the plastic table out front of Guest Lodge. There we observed the spectacle of male attention seeking. We found that while the greatest frequency of exchanges passes between women calling for male clients, the most significant interactions involve those between the differing men in the sex trade and the women in their employ. Motivating these encounters is a strong desire for men in the business to assert control over resources, specifically, the social capital that emerges from gendered mutual obligations. Although I have no direct data for female commercial sex workers in Kiku, what I came to understand about the way men vie for power and position within their networks leaves me to believe there are serious implications for women’s HIV risk management.

In Kiku, men's social networks involve the practice of "mutual obligation". Essentially men’s obligations involve providing “favors" which men hope will further their ties within the community. ${ }^{49}$ With sex work forming the basis of Kiku's economy, most favors involve running errands, transmitting information, and/or escorting people (usually women) to and from engagements. I learned about this process from several men in the community. The first person I noticed engaging in these practices was Teddy. Teddy went to great lengths to maintain, if not extend, his filiations with more influential

\footnotetext{
49. See Whyte, (1993).
} 
men in the community. When we met in the fall of 2012, Teddy claimed to "belong" to Landlord, whose rooms he was managing. Teddy described his relationship with Landlord as being close, as though he was one of Landlord's own sons. At first his position, and even clout, afforded Nakato and me access to the brothels, as well as the chance to meet women in Landlord's employ. Yet, over time Teddy seemed less and less willing and then eventually incapable of doing much to foster these connections. Just as his social ties seemed to be loosening, his position via Landlord was shifting.

\section{Figure 5.4 - Picture of Teddy}

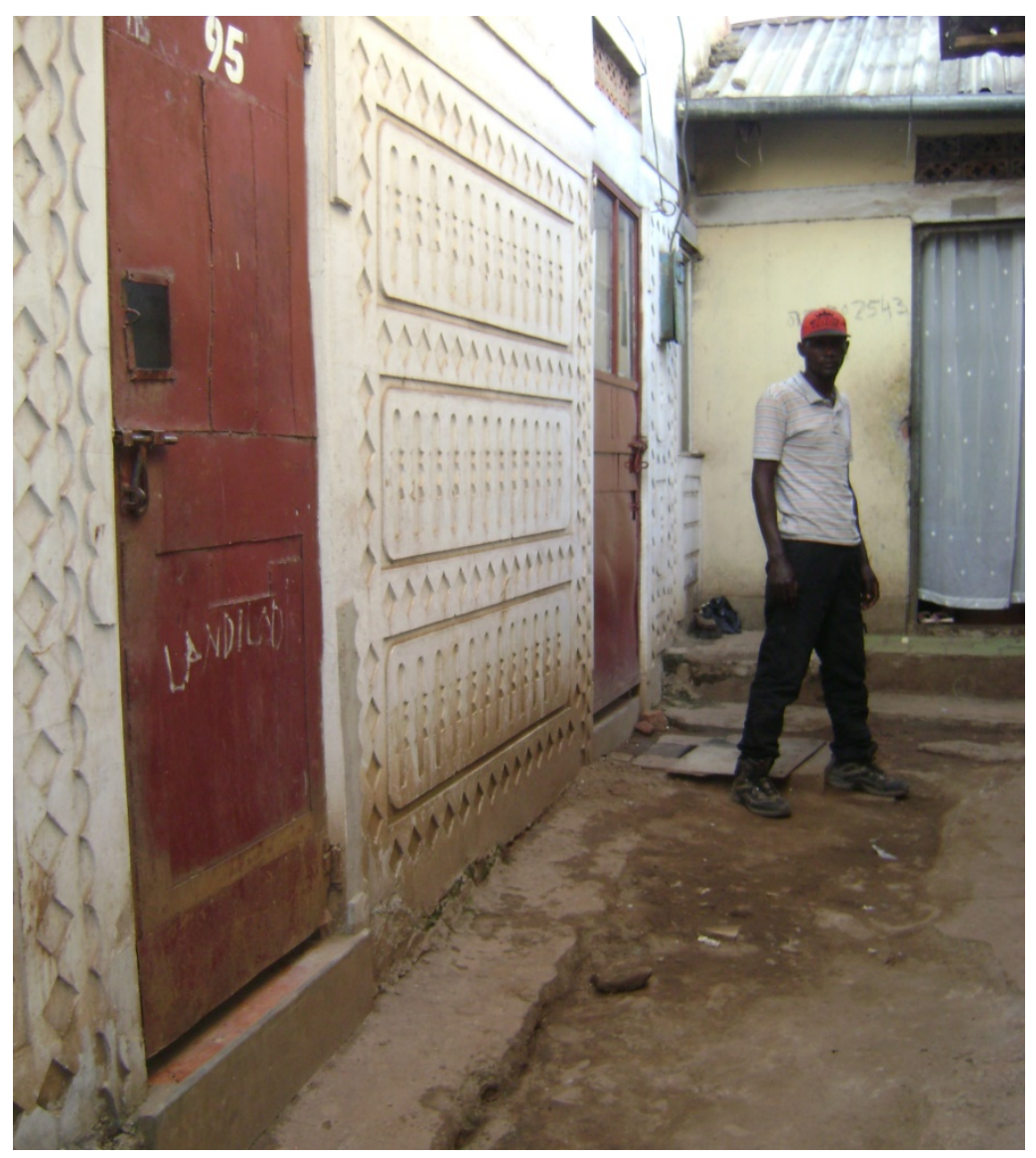

By Spring 2013 Teddy would only arrive in Kiku after nighttime. He no longer engaged in brothel business for Landlord. Instead he was driving his own boda, running 
errands (delivering women, condoms, cash, phones, etc.) on behalf of an elusive Muzeeyi (Sir/Boss). While Teddy moved out from under Landlord's control, he did so only when obligations and protections could be assured. But eventually Teddy was rarely seen in the area. Teddy's disappearance signified an important transition in the community. At one time he was a trusted subordinate in Landlord's cadre. Yet Teddy's efforts, which involved spreading-out from sex work by driving a boda, left an opening in the social organization underpinning Landlord's business. But this was not the case for long. With so many men willing to enter into Kiku's sex trade, openings soon fill. Interestingly, as Teddy slowly withdrew from Landlord's business, James (Mandy's boyfriend) came to take Teddy's place.

I first enrolled James as an informant for the research in fall 2012. At that time he was struggling desperately to find his place in the business hierarchy of Kiku's sex trade. At 22 James was addicted to alcohol, drugs, and gambling. Often he could be seen hustling for cash, “weed” (marijuana), or alcohol, when he wasn’t bent over Landlord's gaming table rolling dice. He had few prospects in terms of building income from pimping, but he seemed enthralled with the lifestyle of Kiku. At night he groped for women he could pimp to random customers, as well as sought the company of other men only slightly better positioned in the network than him. But James had ambitions. He aspired to making "Kiku money", which residents identify as wealth from being a “nannyini kifo” (Landlord) or “omuunyazi” (gangster). Yet James’ life was already fraught with high stakes. In early October he visited Mulago Hospital to address the issue of constant blood in his urine. Fortunately for him he went with Mandy, who happened to be volunteering with a local HIV outreach effort in Kiku. 
James' life changed dramatically once he began his intimate relationship with Mandy. For starters her income provided a steady supply of cash for his interests (new clothes and shoes, drugs, alcohol, gambling, and new business ideas). And with his new access to Mandy's money, James' ties to the community, particularly his networks, realigned themselves. No longer was he struggling to pimp women at night or beg for attention from other men in the business; instead he liaised with Landlord, Mr. Z, and even the local Security Committee. In this way James' new found social position also gave him access to local NGO efforts seeking to bring condoms and HIV prevention and treatment resources into Kiku. Yet these outside ties are what gave James the greatest return on his social investments. As condoms flowed into Kiku, his largess, specific only to other men in the business, captured the loyalty of less fortunate residents in the community. With an ability to generate his own system of mutual obligations, James now had a vested interest in controlling more of the social ties and capital in Kiku.

The change in James' fortune had ripple effects. The most impactful extended outward to other young men, who held few influential connections within Kiku's male dominated networks. Through James, these less-connected younger men could reposition themselves. Of those who tried, the most successful was Kit. I came to think of Kit as James' shadow since I rarely saw them far apart. If so, Kit was usually in constant contact with James and easily knew of his whereabouts. When James began accruing resources, and therefore the respect and capacity to exact obligations from his peers, Kit's own fortunes soon improved. It seemed when Kit was not managing one of the rooms built into the side of Mr. Z's brothel, he was moving around with James' entourage. This meant James’ penchant for large meals, alcohol, “weed”, meera (a green plant chewed for 
its stimulant properties), and opiate-based chews (typically sucked when wedged between the lower front teeth and bottom lip), were all shared with Kit. That is except gambling. James only seemed to keep this practice for himself, even while the money he spent came from Mandy. In return for food, drugs, alcohol, and at times, a place to sleep and bathe (at Mandy’s), Kit was expected to protect James' interests. And it seems the most valuable of James' interests' concerned information.

Kit safeguarded James' information. He kept secrets about James' relationship with Mandy and his ties to local NGOs. But he also spread gossip about individuals who threatened James' position. In case of the latter, Kit maintained a steady flow of chatter about the research. Although I knew Kit spoke unfavorably about me, he willingly enrolled in the study. Once he joined, I made sure to continuously remind him of my observations and note taking. With little regard for his audience, Kit continued to visit the plastic table. On some occasions he was in high spirits. Money had come to him easily, James had shared drugs and alcohol with him, and/or he was fed and rested. Yet other times Kit appeared troubled, acting belligerent or petulant. During these evenings he was fond of wishing for his "own muzungu", one who could make him wealthy and powerful like James. For Kit, James had "struck it rich" and could do anything he pleased, mostly because he had found respect in Kiku. Whereas Kit, even with the money he made from Mr. Z and the benefaction he earned from being loyal to James, ultimately, he still lacked the capacity to become his own boss.

Just as James emerged as a viable "Maneja” (manager/young boss) in Kiku, one of the communities longest term residents, Rico, had been displaced. Of all the men I spoke with, Rico was the most forthcoming. It was with Rico I first toured the 
geographical boundaries of Kiku. His fluency in English allowed for us to talk one-toone. But while Rico was running Mr. Z's brothel when we met in 2010, by 2013 he was simply trying to keep his small video-rental kiosk afloat. Rico’s story is perhaps the most revealing narrative in terms of how residents of Kiku live by way of a gendered system of interdependency and patronage.

At 27 Rico had already given 16 years of his life towards trying to build his fortune in Kiku. As a small boy he lived near the area, which is how he knew the history and meaning of its name ("place of muddy water"). Back then he remembers when Kiku began to change: "There was a playground around where we used to play football. They chased away all the business makers who were there. They told them to leave the place because the rich man was starting to build. And the rich man came and told the people who were around that he wanted to put in those buildings. So they chased us away". As the community began to develop Rico remembers when the women came to sell sex. And soon after Mr. Z followed: “he started building. Here [inside Mr. Z's brothel] was a small house, like four rooms by then. There was a pork joint and a restaurant. And there was a small bar and two rooms for renting to sleep" [pointing to different spots in the brothel compound].

By age 17 Rico was fully immersed in the sex trade. Although he had almost no control over resources (e.g., condoms, women, cash, drugs, other men, etc.) when he began, Rico's life eventually changed. He fondly recalls coming to "the business" by way of Nakato: "By then even Nakato was here and she was the first lady to talk to me. It was Christmas of 2003. Nakato had a guy who was working in the rooms of her sister. During that Christmas period the guy didn't pay money to Nakato. Nakato then asked Ali to ask 
me if I can help her for two weeks until she gets another one to help her. I refused at first but I made up my mind and knew that I was able to do that [work with prostitutes] and I started working with Nakato". In nine years Rico went from brokering sex for Nakato, with almost no authority, to managing Mr. Z's brothel, where he oversaw a large compound, its staff, and the women who came to sell sex.

As Mr. Z's brothel manager Rico was entrusted with Mr. Z's earnings from the business: "He used to see how I was working my job and he used to trust me to even keep his money". But Mr. Z's trust proved fickle, and in 2011 he chose to believe Rico had "thieved". Although Rico admits to quitting instead of being fired, he found being suspended intolerable: "Unfortunately I talked to Mr. Z, but he could not listen to me. As a human being I got annoyed. From there he told me 'go back home for one week'. It was a suspension of one week. I thought many things. I am a family man. I have got kids; what will I feed my family? Remember I had my business already but I wasn't the one working there, I had someone helping me. I went home as he told me, but after some two days I said, 'No, I will not go back to that place. Let me concentrate on my own business.' And with that Rico returned to his small venture of selling videos.

Rico's displacement in Kiku's sex trade did not preclude him from cultivating social ties. Indeed, Rico remained a regular figure about the community. During my "controlled" observations under the rainbow umbrella, Rico was frequently walking around Kiku. He usually arrived in the late afternoon, coming down the incline just behind Mr. Z's brothel. There he often stopped to greet other men, mostly those still in the sex trade. Then he would move on to the cigarette counter built into the wall to the left of Mr. Z's building. At the counter he would catch-up with some of the women, who 
staffed the small shop during the day before shifting to sex work on the street. Some days Rico came around the plastic table, where he would greet Roz in Luganda and me in English. Most of his short visits involved small chatter about the area, his struggles earning money from his business, and his ambitions to become a security officer in the area.

Security officers in Kiku are men who work for the Security Committee, patrolling the area on behalf of the brothel landlords. The role is prestigious among some of the lower-level men in the sex trade hierarchy. Their responsibilities involve keeping order to minimize police interventions. Yet interestingly, order is most often described in terms of controlling women's behaviors. Rico's most important example of the serious work done by security officers involves detailing the ways women "misbehave": "When these ladies see that the guy [client] has money, they inform the other guy, who is a boyfriend, to her and they plan. When the other guy (the customer) wants to quit after having what he has come to do [paid sex], the guy [boyfriend] can inspire the guy [client] to sleep for the whole night. At the moment of sleeping there, the lady can leave the door open and the boyfriend comes and takes the money. That is why they use to get problems sometimes. They used to steal customers' money". Yet the discourse of disorder caused by women, and their lovers, is symbolic of a deeper and gendered social order in the community. Eventually I came to understand that this gendered order had implications not only for my research, but also for women's sociability. Yet, in thinking about the sociability of women's risk management, as I have done in Babito, one must consider that not only is it different in Kiku, but perhaps it is even far less impactful. I cannot discuss this definitively as a result of my limited access to the women in Kiku. Further on in the 
dissertation I draw out the theoretically importance of men's social networks in relation to risk, both for them and for women in the community.

\section{Kept Women}

Figure 5.5 - Picture of room 95 in Landlord's brothel

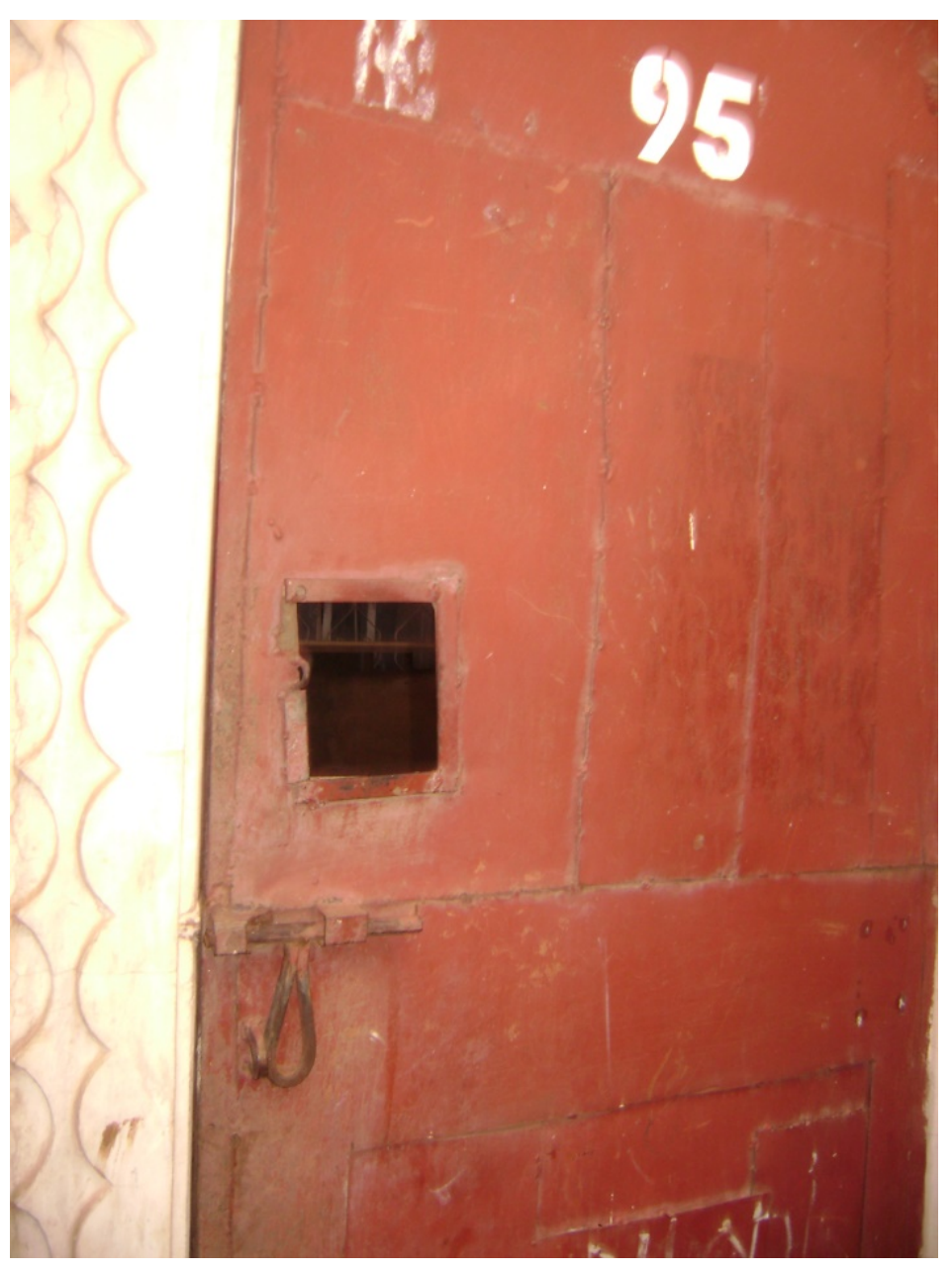

In fourteen months of primary data collection I had few chances to truly connect with women in Kiku. At first I believed it a matter of when women were most often moving about. So it seemed important I arrive during the afternoon or early evening and stay late into night. But my timing made little difference. From there I believed perhaps if I stood on the street, with Nakato ready to strike-up conversations, more women would 
engage with the project. Yet, very few of our interactions generated consistent information. Then finally, I believed if we attempted to spend as much time as possible seated near women's rooms, we would surely find success as we had in Babito. Yet once again women stayed away from the data collection. It would take Nakato’s departure and the development of Mandy and James' relationship to surface, before I began understanding the ties between my failures and a larger pattern of gendered sociability at work in the community.

The first indication came by way of Rico. During one of our longer recorded conversations, he reflected at length on how important it was for women to be managed. Rico’s language seemed innocuous, at first. But there were clues laced into his tale. At times Rico extolled women for cooperating with the interests of the male establishment: "The good thing was that they [women selling sex] became good people to cooperate with because they had no bad manners. Yet simultaneously Rico patronizes women for their conduct and insists on their need for instruction: “They [local leaders and business men] tried to consult them, to show them how a person must be behaving in the area...that is how we tried to keep them". Yet "for these ladies" restraint seemed to be a problem. Rico’s position, like many of his peers in Kiku, was that if women could not be “trusted” to restrain themselves from loud, drunken, and/or indecent behavior, then the men needed to manage them: "That is why we started to cooperate with them, to show them the right thing to do and how not to behave”. Throughout his musings Rico maintained the importance of women's conduct and its relationship to the greater security of the community. This point is particularly crucial, for it signifies the gendered nature of interdependency between the male managers and female commercial sex workers in 
Kiku. Men and women's interdependency stems from the paradoxical nature of the sex trade in Kiku. While women are crucial for the business, so is men's involvement. Men control the resources related to the sex trade—-the places, the condoms, and the security and bribes to the police. Yet this symbiotic relationship can be parasitic at times, especially when it comes to women's personal freedom.

Each night Roz and I sat beneath the umbrella whence we observed women and men engaging in Kiku's most vital business ritual. A man would approach a woman, coming up beside her, as she stood along the dirt road nearby one of the brothels. At first it would seem as though she didn't notice him. Then eventually she would respond to whatever comments he leaned-in to share in her ear. At some point negotiations would appear to have either failed or succeeded. Failed attempts were indicated when he simply walked away. Yet for those encounters ending successfully, we would observe the man and woman walking away together. Yet all the while management keeps close watch on these encounters, with avid attention particularly for how women behave. This is because women's behavior is understood as a "necessary problem".

The men involved in Kiku's sex trade believe they can do no better, financially, than from the income they earn selling women's bodies. Their gambling, drinking, drug habits, and ultimately their property ownership result from money coming through sex work. Many men understand that to continue to do so successfully requires women's cooperation. This results in women's behavior being monitored and managed as needed. An important way to ensure women’s cooperation involves security.

Leaders of the male establishment collude with police and local elected officials in order to maintain "business as usual". This can mean allowing for police sweeps to 
take away women deemed indecent, unruly, and/or disrespectful in the eyes of management. Indeed this was made especially clear to me on a rare occasion, when I spoke with Mr. Z and Landlord. As I sat near the entrance to Landlord's compound, he and Mr. Z proceeded to lament the trouble with "these girls": "skirts are too short; they resist working with pimps; they stand in the path of local community people; they are shouting at men and giving police reasons to come". And their solution to these woes was to keep in place their Security Committee: "we started in 2003 to maintain local order". Yet the notion of "order" is misleading. The order these men seek is a subservient practice of loyalty, not only from younger men in their employ, but for a passive obedience from local women.

Over time these demands become entwined with the very notion of security within Kiku. That is, so long as women cooperate with the male establishment, community life continues uninterrupted by policing. Yet the lives benefitting most from this system of obligatory reciprocity are those at the top-Mr. Z, Landlord, Danny, Eddie from Guest Lodge, and even James to some degree. Indeed the social order in place strips women of any real means of practicing sex work under different conditions. And in this way Kiku's social capital, networks, and very maintenance of the community are a contradiction in survival. Without women engaging in commercial sex work, these men's lives, as well as most businesses keeping Kiku afloat, would falter. Yet, the privilege of this important position is denied women in the community. One can infer the implications of this arrangement on women's HIV risk management practices; especially, when women are likely to retreat in the face of male displeasure if their deeds usurp the interests and/or directives of management. 
I learned this directly in an attempt to engage one of Mr. Z's brothel servants, Mary. In my first memory of Mary she is on her knees using a towel to mop one of the rooms in Mr. Z's brothel. That day she quietly moved the towel back and forth over the floor, eventually standing to remove a plastic bucket filled with human fluids, condoms, and empty condom wrappers. However, our first verbal exchange, by way of Roz, came several months later, when I was already stationed out front of Guest Lodge making observations. Mary slowly and shyly made attempts to connect with me. At first it was a simple smile. Then waves. And eventually greetings: "Osiibye otya Nnyabo" (good afternoon Madam). As Mary warmed to us, I became curious about her experiences working inside the brothels. So I invited her to sit for an interview.

On that occasion, Roz began by first simply explaining to Mary what we required (consent formed signed, audio recording, note-taking, etc.). As their conversation took place I began noticing several men slowly moving towards the plastic table. Initially they stood or sat on wooden benches lining the front wall of Guest Lodge. But their body language appeared defensive, with arms crossed and legs wide apart. When Mary had signed the consent form I took out the audio recorder and placed it in the center of the table. Early into the conversation the men became very loud—laughing, yelling, and shouting out to others across the road from Guest Lodge. We proceeded, but the longer we conversed the more aggressive the men became in their attempts to disrupt the interview. The moment came to a head when, first a few of the men began pushing one another jokingly, while the most bold of the crew came up to the table, surrounded us, and put their hands on the table while proceeding to talk over Mary. 
The entire moment was deeply unsettling. Mary quickly got up from the table and fled across the dirt road, back to Mr. Z's. And for the remainder of the research she refused to issue anything more than an occasional greeting. Mary's response reveals the incredible authority men have in the community, authority, which comes by way of silencing women. This is because while men in the sex trade hold varying management positions, in relation to their peers and elders, they can almost always assert control over

women. And this control comes in differing forms. Whether it is from men watching through a peephole, stymying the flow of condoms, or finally preventing outsiders from engaging with the women in their employ, the women in Kiku are left to work under these conditions. All the while men in Kiku continue to have the capacity to command women's resources—time, privacy, safety, and ultimately their bodies.

In terms of women's bodies, the control men have over women most likely has implications for how they manage risks in general, and HIV in particular. This is because the activities men undertake in order to solidify their place in Kiku's social networks could directly impede women's access to information as well as resources. While the social needs of men remain a barrier to women's safety, it will continue to push women into hiding as well as keep them silent. In this way, women's silence signals an alarm, one that serves as a wake-up call for HIV interventions in Uganda.

\section{What We Want}

While I failed to gain direct evidence specific to how women in Kiku manage daily risks, I came to understand the underlying dynamics of their peril. The hazards shaping life in Kiku extend outward from an ancillary system of gendered survival. At the systems core are a series of symbolic practices shaping social life in the community, 
which have varied implications for the residents involved. For those at the top, Mr. Z and Landlord, it may seem, at first, profit is ultimately the root of their actions. And indeed the motive to gain financially is definitively part of this process. But, I believe more important to wealth is the need for members of Kiku's sex trade to gain respect from others in the community. In this way, the actions of Teddy, James, Kit, and Rico reveal differing manifestations of Kiku's deference based social capital and a system of patronage, which cultivates both loyalty and obedience among those in the sex trade. Yet as the social networks of these men shifted, so did their acceptance or dejection within the community. In turn, this resulted in greater or fewer means of accessing and controlling resources, and especially the most important—women.

Women's risks in Kiku must be considered in light of the men who oversee the community's sex trade. Otherwise any attempt to address women's conditions, without considering the implications of how men seek respect, is futile. This belief is at the heart of my research, which attests to the ongoing ways women search for safety and men unwaveringly negotiate risk. It is these gendered and interpersonal patterns of survival that must be considered in future HIV/AIDS policies. Anything less becomes a malignant form of neglect. And the results, at the policy and programmatic levels, therefore leave the most at-risk of Kampala's society perpetually sick and infectious, while the general population remains susceptible to a long-standing practice of purchasing sex.

Just as ending sex work will not bring an end to HIV, nor will it work to only deal with the virus through a technocratic, case-by-case, individualized system. Rather HIV/AIDS in Kampala must be understood through the patterns of sociability and deference shaping the everyday practices of both men and women in the slums. To do 
this more effectively requires understanding the complexity and network-based ways people survive in their communities. For many, sex work is vitally necessary for their survival. Accepting the necessity of sex work, as well as the differing ways women and men manage the trade is perhaps a first step. But more is needed. Policies and programs can do better by valuing the networks and social capital at the heart of sex work communities. By doing so, interventions have a greater chance of being essential, deliberate, and overwhelmingly place-based. But more importantly, efforts can begin to find greater success, which is urgently needed. Because where it stands, one out of three female commercial sex workers in Kampala is infected with HIV, making the stakes too high and time too short for anything less. 


\section{CHAPTER VI}

\section{CONCLUSIONS ${ }^{50}$}

\section{Reflections on Managing Each Day}

Throughout my research and the writing of this dissertation I have explored and described differing events and interactions reflecting the complexity of women's relationships. I have done this in an effort to answer the central question of this research project, which asks how women manage daily risks associated with sex work, criminalization, and HIV/AIDS. Here, I arrive at an overarching conclusion about the importance of social networks, in this case, the way social networks express the interpersonal ties among people that develop out of mutual obligations and that help to create the basis for communities. My use of the term "social networks", as discussed in my third chapter, invokes a "common sense" understanding of the concept that was similarly adopted by some of the earliest studies (Barnes 1954). In applying the term social networks this way, I believe my research answers how the "give and take" of relationships in both Babito and Kiku provide a compelling way to extend the ongoing development and application of social network theory.

By branching out from the more quantitative attempts to understand the relationship between risk and social networks, my research was capable of going far deeper into a realm of the human condition that is marked by suffering as much as sharing. Thus, in the cases of Babito, where women's interpersonal ties proved an important means of helping them manage daily risk, and in Kiku, where men's efforts to

\footnotetext{
50. In this final chapter I use the terms "sex work communities" and "sex trade communities" interchangeably.
} 
dominate the sex trade offered little evidence that women can effectively avoid harm, I found the presence of two distinct social networks. I also gained critical insights about the sociability of risk. Considering Babito, of all the strategies women have to keep them safe, the most useful is their capacity for social cohesion-networks, capital, and community. Yet the data also reveals the ways women's interaction is rife with risk itself. This is because women's cooperation is uneven, disruptive, penalizing, and precarious. For those women who manage to band together, their unity proves the most durable and reliable form of security. This fact remains central to my findings, as does the knowledge that, as of 2012, 37\% of female commercial sex workers in Kampala, Uganda were HIV positive. ${ }^{51}$

Despite these high rates of infection and the risks of contagion, women continue to sell sex. In Kiku's sex trade community the male social network relies heavily on women's sex work to sustain not only their livelihoods, but also the respect of their peers, and their position in the social network. For men this means striving to attain the most important positions in the sex trade. These range from brothel owners down through managers, attendants, and finally the least influential men in the network, the pimps. Yet, while men in Kiku vie for respect and authority, sex work remains a women's "task". Women take up this work, in both communities, in hopes that the sex trade can provide them with greater social and financial security than the alternative-small-scale informal economic practices (selling vegetables and/or cooked food on the side of the road, sewing

51. See Baral et al. (2012). 
clothes, brewing alcohol, etc.), which women describe is far harder to earn income consistently and with as little preparation as commercial sex work. ${ }^{52}$

For many women engaging in commercial sex work in Babito, their success means earning money and keeping safe, even as they undergo difficult, life-threatening, and often punitive experiences. Yet women there learn to manage the risks of their livelihood in order to survive. I learned this by observing how each day women in the brothel make decisions hoping to enhance their resources (cash, savings, food, personal safety, etc.) in order to strengthen their social networks, expand their social capital, and protect their community. Conversely, in Kiku, men also hope to extend their resources by way of consolidating their social connections and interpersonal favors, relying largely on the income they earn from women. In both settings, the sociability of risk management is revealed as the most important means of how women and men survive daily life in the sex trade.

Virtue, Decency, and Domesticity: The Necessary Trinity for Women in Kampala's Sex Trade

As residents of Babito brothel struggle to balance personal ambition and individual needs, they must do so with the values and norms of the community in mind. Herein lays a difficult challenge for many women in the brothel. The social norms in Babito reflect specific ideas about women's virtue and decency. Indeed, many residents must successfully decode an intricate and shifting set of beliefs concerning their character in order to generate and perpetuate social capital. This is because women's interpersonal

52. Group discussion 18 October 2012 in Babito Brothel. 
reciprocity is a lifeline. Residents rely on small gestures and unplanned interactions for their survival. These practices keep women connected to one another and therefore socially relevant, as well as physically safe. Yet shaping women's reciprocity is a larger cultural script concerned with respectability. The roots of this script are linked with the history of the region.

\section{Figure 6.1 - Map of Uganda}

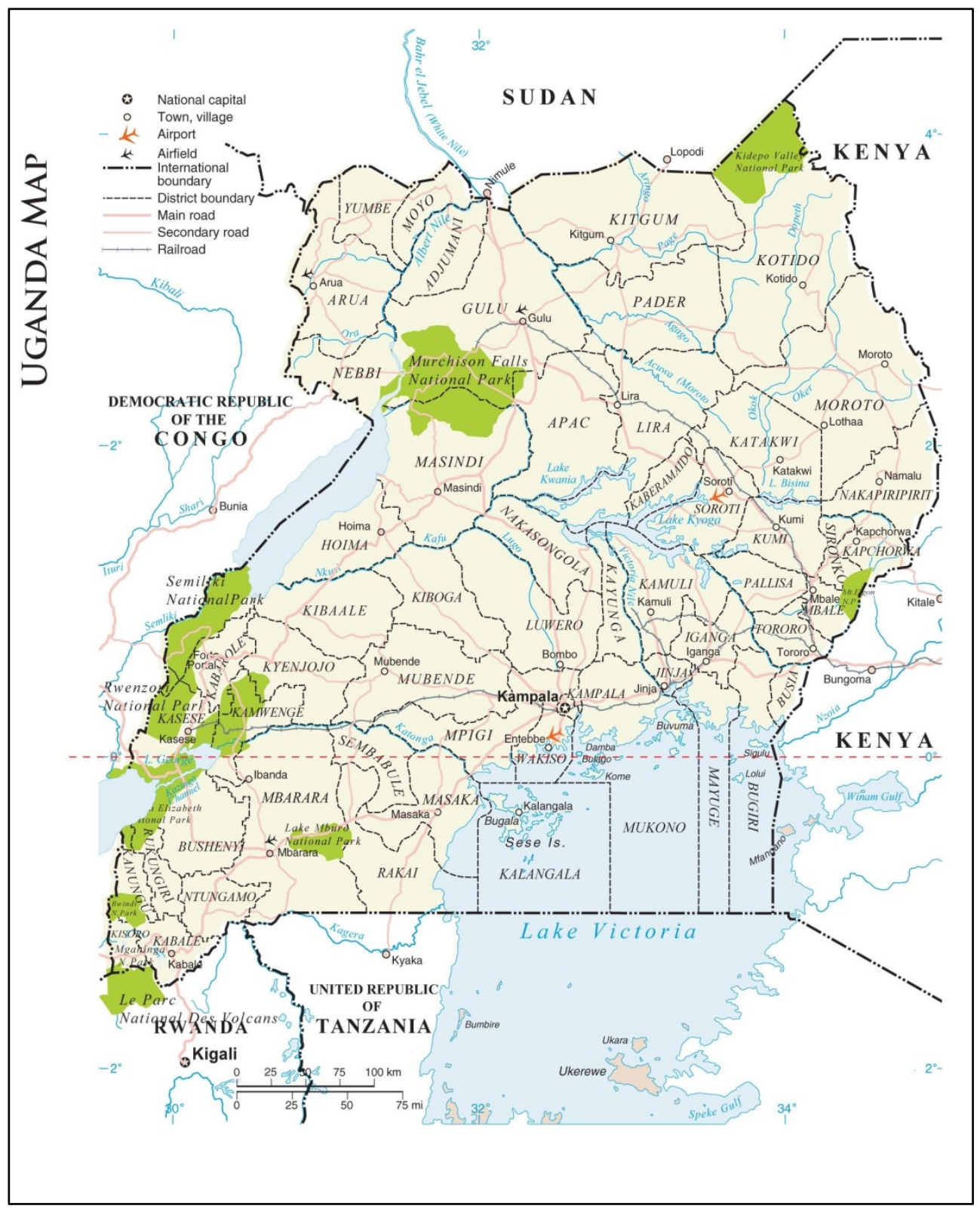


Kampala rests in Uganda's central plateau, which is an area of the country dominated by the Buganda kingdom (see figure 6.1). Historically, women from this culture learn to perform specific hetero-normative sexual practices in marriage, where they are expected to adhere to particular behaviors concerning sexual availability. ${ }^{53}$ At the most basic level these practices assert that women must be consistently sexually willing, and at times even lascivious in bed. ${ }^{54}$ Yet, simultaneously, women must also balance these "appetites" by appearing chaste and demure outside the bedroom. ${ }^{55}$

Compounding these expected qualities is a basic expectation that women be demure, obedient, and willfully subordinate to men. ${ }^{56}$ What results is a discourse concerning women's overall domesticity, which defines their behaviors and actions. ${ }^{57}$ "Good women" understand their role in the home and with men. In turn, for their virtue and decency, these women can earn the respect of both men and other women. ${ }^{58}$ While the practice of sex work in Babito undermines the overt domestic control of men, the cultural predilection for women to maintain their domesticity, by way of virtue and decency, remains. For women in Babito, it becomes imperative for them to maintain these attributes among their female peers. Yet, the opposite proves to be the case in Kiku,

\footnotetext{
53. See Musisi, Nakanyike B. (2001).

54. Ibid.

55. See Bantebya Kyomuhendo and Keniston McIntosh (2006) page 79.

56. Ibid.

57. Ibid.

58. Ibid.
} 
where men continue to assert their prerogative over women's practices and use the excuse of women's indecent behavior as a reason to “manage” them.

In Babito women's social acceptance brings benefits, but also incurs costs. This is because acceptance requires approval from the brothel's social hierarchy. The sociability shaping women's interpersonal relations invokes the power of women's domesticity. Albeit within the brothel setting, the "normal" domesticity of Ugandan women is still expected, though certainly redefined and reconditioned. In the absence of husbands, or rather male residents in general, women's virtue and decency is reoriented, whereas it remains steadfast in Kiku. Women in Babito no longer submit and defer to men, but many still must do so with their colleagues. This is especially true for women who are new and/or who reside in "Hell”. In Kiku younger and/or less established men in the sex trade engage in similar practices, but the goals of respect and social acceptance involve activities that induce risks. In this way, social acceptance reflects the unevenness of community belonging. Without recognizable social capital, specifically the material means to express their respectability, women languish outside the protection of their peers and younger men redouble their efforts to earn the acceptance of their colleagues.

\section{Volatile Circumstances and Compromising Social Networks}

Reciprocity is essential to the social networks of both Babito and Kiku's sex trade communities. While Kiku's male dominated network is an oppressive environment for women, Babito's women-centered network can be divisive. While women in both communities most likely internalize larger cultural scripts concerning heterosexuality, residents of Babito compound these ideas by striving to embody these values through an 
aesthetic that signifies their social relevance among their colleagues. ${ }^{59}$ Women respond to these norms by trying to navigate competing expectations about the way they should look, talk, act, and ultimately be. Meeting social expectations in these areas either affords women entrée into the brothel's hierarchy or arouses derision, slander, and dejection from brothel leaders. ${ }^{60}$ My research shows that for many residents daily life involves accommodating what are ultimately shifting class aesthetics indicative of respectability. ${ }^{61}$ Although fickle, this ongoing process of class formation reflects an important component of community durability, something, that also shapes how men establish and maintain their networks in Kiku.

Men in Kiku have demonstrated a predilection for spending their cash on clothes, jewelry, and shoes in order to appear professional and therefore deserving of respect from their peers. Women in Babito, lacking a similar means of appropriating the class aesthetics of their more socially connected colleagues, struggle to find a recognizable way of belonging to the brothel's inner circle. I found that part of what constitutes women's belonging in Babito is their ability to recognize the social and physical boundaries of the community. Women's residency and their ability to adhere to a particular class aesthetic create social boundaries in the brothel. I found that women capable of emulating what they believed were middle class Ugandan styles and mannerism were also the same residents likely to have more social ties and better ways of keeping secure. Interestingly, residents accept and participate in these hierarchal

\footnotetext{
59. See Bourdieu (1984) page 170.

60. Ibid.

61. Ibid.
} 
divisions, because doing so still affords most women some semblance of protection. In this way, if paradoxically, Babito's discriminatory social hierarchy provides a crucial facet of women's risk management. Essentially, the way women use their social networks reflects this fragile balance. I found this to be true in the ways less influential women deferred to older and/or longer-term residents. The goal of maintaining respectful boundaries with these more powerful women in the brothel reflects the ways social positioning in Babito is a means of minimizing internal and external threats.

Women endure the strictures of the brothel social hierarchy because it affords them a modicum of security. Yet, women's conformity is not blind. Many women understand the failures of communal risk management. Residents acknowledge the predicament and risks associated with depending on their peers, especially as they grapple each day with threats of violence. In light of the few resources women have to escape harm, so much of daily life requires that they resort to informal means (bartering, bribery, sexual favors, etc.) of keeping safe. Unfortunately, I discovered the benefits of solidarity only extend to a handful of well-connected residents. This is unsurprising given the political and social contexts of sex work. The illegality of the practice leaves women in the sex trade susceptible to a myriad of violations. While my experiences in Kiku, among the male dominated social network, leave me with a deep belief that women there are far more insecure in terms of the abilities to manage risks associated with HIV/AIDS, it seems they are just as vulnerable to police intervention as women in Babito, albeit in different ways. I believe this could be a reflection of the fragility and weakness of women's social networks in Kiku, which seemed less durable in terms of helping women fend off threats from the men in the community. 
For many women in Babito the most menacing and persistent form of violence stems from police interference. ${ }^{62}$ In the face of this relentless threat, women attempt to rally one another for protection. But their efforts mirror other aspects of women's social networks. Many residents languish between isolation and incarceration, while their peers remain safe. I found that women with proper "channels" (favorable social connections) more consistently avoid arrest. The same could be true in Kiku, however, there, brothel owners and managers conspire with police to "curb” women’s “disobedience” in an effort to bring them under control. The complexity of men's social networks in Kiku is mirrored by the expectations of Babito's social hierarchy.

Residents in Babito with the greatest resources directly engage Babito's owner and/or local police and are willing to pay bribes. Other times these women rely on the assistance of brothel leaders to avoid police raids. Combined, these strategies, which reflect the power of social networks, illustrate the ways privileged residents manage to keep safe from police brutality. Whether it is a powerful select group of their peers, the brothel landlord, and/or security forces within the local police force, these women enact one of the few remaining defenses left to them. For women in Babito there is little solace outside the walls of the brothel. In Kiku, I could find few instances of how women stayed safe from the pressures of the larger social network dominated by men. In this way, the women of Babito and most likely the women connected to Kiku's sex trade can find no legal refuge from police-sponsored terror, the harm committed by client-boyfriends, and/or the impoverishment caused by theft.

62. Often women described the threat of police violence "as living under terrorism”. 
As a result women in Babito have no recourse other than building their social networks. Conversely, in Kiku, it seemed women could do little else other than cooperate with the male hierarchy. In both instances these connections make women vulnerable. Residents of Babito, who go without a means of political and/or social support, can easily lose social capital and, therefore, relevance with their peers. While men in Kiku willingly sacrifice women in order to maintain control over resources pertinent to the local sex trade. Being vulnerable in these ways illustrates the volatile nature of social networks in both contexts. Women in Babito and men in Kiku both benefit from their connections, yet they must also endure the fragility and judgments of belonging. In this way, women and men in both communities will risk being spurned rather than truly neglect developing and maintaining important ties with their peers. The lucky few in both communities that manage to develop strong social networks ultimately rely on these connections to help keep them alive at the margins of Uganda's society.

\section{A Haven for Hopes}

On the few occasions I spoke about condoms with brothel managers in Kiku or when women in Babito lamented about having little money or no condoms, I found social isolation and/or renunciation to be their greatest sources of pain. This is because at the heart of what it means to be human is a deep desire for connection. The women of Babito and the men in Kiku's sex trade understand this need and as a result, residents of both communities spend each day striving towards a greater sense of belonging. They do this in different ways, but out of the same effort to connect with their peers. Yet how one understands the practice of sociability in each context demands having a realistic positioning of the tactics being deployed in relation to the risks at hand. This means 
recognizing the way subterfuge, gossip, and even theft become incorporated into the ethos of social networks just as giving, sharing, and consoling, help to maintain the reciprocity that is needed for each network to thrive. It took me a while to understand how hardship for some can be an opportunity for others. I found this especially true in the aftermath of police raids in Babito. As women disperse and residents fail to return to the brothel, their absence becomes an important boon for others.

In terms of the brothel itself, vacant rooms become filled with new residents that would otherwise likely risk practicing sex work in far riskier areas of the city, such as Kiku. Essentially, a private room becomes a space that allows women to store their sex work-related resources (clothes, shoes, condoms, hair pieces, nail polish, etc.). Hiding their professional belongings in turn helps women to minimize suspicion from their relatives, lovers, and/or authorities, who may suspect their ties to sex work based on what they wear, the possession of condoms, and/or the hours they keep away from home. Women without rooms are at greater risk of sex work related violence and disease, especially because of their working hours.

In chapters four and five I noted that women working in both Babito and Kiku come from all over Kampala each night in order to practice sex work. The benefits of earning fast cash drive women to risk traveling through Kampala at times when most people choose to remain indoors. Those women who manage to reach Babito must depend on the mercy of residents willing to share their rooms or otherwise resort to selling sex outside. In this way, the highly competitive environment around Babito increases the chances "street-nekos” (women without rooms in Babito) will sell sex in the 
field adjacent to the brothel, against the outer walls of the building, and/or in the corridors of nearby pubs and discos.

In Kiku, women must make similar choices in the face of scare options. In actuality, these women only have two choices - they or their client can either agree to pay an entry fee to gain access to a brothel, which comes with a "free" condom, or they can take their chances engaging in commercial sex somewhat publicly. ${ }^{63}$ In both cases, the women out front of Babito or the women who fail to gain entry to a brothel in Kiku have fewer chances of negotiating condom use by practicing sex work outside the confines of a brothel. Yet lacking condoms, while being an important risk in relation to what drives HIV, is symbolic of how these women also have weaker social standing and interpersonal connections, which can protect them from having to resort to "street sex". The same is true inversely; a woman's ability to access a room signifies her ties with primary residents in the brothel, and therefore, the means of finding support with Babito’s social network in order to minimize her risk.

In terms of Kiku, where it was more difficult to determine the importance of women's networks in relation to their risks, it is very likely that the control men have over the area's social networks incurs more risks for women seeking condoms. This is because men in Kiku's sex trade engage in a pattern of promiscuity that is premised on women's sexual availability. Men in Kiku openly discussed their strategies of coercing women in their employ to have "free sex"—unpaid sex without condoms—when called upon to help women in need of cash, shelter, condoms, transport, etc. Men believe they

63. Brothels in Kiku usually charge the equivalent of US\$ 0.30-0.50. 
are entitled to these "spoils" and viewed the use of women as the most obvious way to exhibit their position in the community. Yet without direct evidence from women about the implications of these exploitative and abusive practices, I am left with only an impression that women's risks in Kiku are far more complicated by the needs of the social network in that community.

Unlike Kiku’s sex work community, Babito brothel seemed to be a haven for women practicing sex work. Residents of Babito belong to a community that offers a modicum of security, which in turn gives women a chance to hope and plan. Residents dream of owning land for retirement, sending children to secondary school, opening businesses, and/or giving up “this life” (sex work) to settle down. Women’s goals evoke understanding among each other as well as instances of compassion. Being compassionate and/or being able to receive empathy is an important aspect of how individuals cope with difficulties. Yet empathy is also serendipitous, as it is about "connecting with the right person at the right time about the right issue". ${ }^{64}$

Tragically, the one issue that seems to go without much compassion is HIV/AIDS. In Kiku, the few conversations about HIV I held with men in the sex trade revealed their deep fear of the virus. Most men do not want to know their status, so they refuse testing. Women in Babito, on the other hand, were willing to disclose being HIV positive during private interviews. Yet these women were skeptical of how their peers would receive the news and would sooner believe their colleagues of being unable to demonstrate any kindness or connection to their personal struggle. Believing they were

\footnotetext{
64. See Brown (2010) page 11.
} 
alone, HIV positive residents experience an additional trauma, one far more devastating, because it leaves them alone and afraid about their social standing in the brothel. In this way, women in Babito choosing to privately manage their HIV, and men in Kiku choosing to ignore the disease, underscore the importance of social networks. This is because in an effort to maintain their interpersonal connections among their peers, individuals will adhere to an isolating and individualizing medical protocol, which fundamentally contradicts the essential life-extending mechanisms of their social networks - the reciprocity that forms the basis of their communities.

\section{The Making of New AIDS Policies: Prescriptions for Intervention}

Uganda's HIV and AIDS policies currently promote healthcare practices that undermine the ways women and men in slum-based sex trades maintain their social networks. As a result, unlike other hazards associated with commercial sex work, sex trade communities have fewer ways of collectively grappling with the risks associated with the virus. I learned this up close through Anna's experiences, where, as her medication companion, I silently observed how her efforts to control the virus resulted in her physical suffering and social isolation. Anna, like others in the sex trade, must choose between revealing their work to AIDS clinic staff or openly "living positive" in their respective communities. ${ }^{65}$ Yet, this dilemma is not solely for women. In the case of Kiku, men fear risking their standing within the social network, which is predicated on their ability to dominate women, earn money, and raise favors from among their peers. As a

65. "Living Positive" is a common term for people living with HIV/AIDS. It refers to a cadre of healthy lifestyle choices and ways of integrating the medical needs associated with HIV/AIDS into an individual's daily life. "Pos Living" is another way to reference personal choices associated with the term (e.g., dating, "coming out” positive to family and friends, keeping medical appointments, etc.). 
result “coming out” to their peers as HIV positive could potentially undermine the important ways men generate social capital and therefore develop their social networks in the community.

Similarly, women in Babito must contend with the pressures of the brothel's social hierarchy. In this way, Anna's story reveals the most impactful risk in sex trade communities - the inability to maintain the necessary ties to one's social networks by having to forgo the social capital developed out of mutual obligations. Anna's efforts to address her HIV-positive status illustrate important gaps in the current system of AIDS interventions in Uganda. First, women engaging in commercial sex work endure a series of obstacles in order to receive care that include transportation to appointments, costs associated with care, and dealing with sometimes unfriendly if not hostile medical staff. While these vexing realities complicate women's abilities to access HIV treatment, women must also balance the norms and expectations put upon them in these clinical settings. As described in chapter four, the contentious environment in the AIDS treatment center contributed to why Anna kept silent about her profession and the physical and social needs that arise from practicing commercial sex work. Compounding Anna's silence is the confusing and individual-focused behavioral messaging being promoted by clinic staff, which clashes with the interpersonal commitments and demands of the social networks that arise in the sex trade. Just as Anna found herself with little recourse, women engaging in sex work become wedged between two demanding contexts that are neither wholly beneficial. This is because HIV-positive women practicing sex work cannot survive long without their social networks or medical support. Finally, while 
women may fear being ostracized by their peers for being HIV positive, contempt and stigma from colleagues still leaves them beyond the reach of the law.

The same cannot be said should women and men inadvertently or intentionally share their involvement with "prostitution" while being treated for HIV. In the instance one were to reveal to clinic staff ties to sex work practices, she or he risks criminal sanctions. This is because the law of the land, as I have discussed in chapter three, is clear-prostitution is illegal in Uganda. So long as this remains so, members of the sex trade will fear to divulge their practices, and as a result, their medical care will be compromised as it was for Anna. Based on Anna's experiences, as well as the evidence provided in this dissertation, which illustrates the importance of social networks and social capital within sex work communities, I hold that Uganda's current system for addressing HIV is wholly ill equipped to handle the needs of female commercial sex workers.

Fortunately, I am not alone in my conclusion. The notion that sex trade communities need different policies to address their HIV is gaining traction. ${ }^{66}$ While other studies look closely at individual women's choices, I explore and document their needs through the social networks in which they are embedded. While my time in Kiku left me with only an impression of women's vulnerability to the demands of men's social networks in the community, thankfully the women of Babito proved amenable to my research. As a result I am able to assert that future policy provisions must consider the sociability of risk in relation to HIV care and the importance of social networks in

66. See Baral et al. (2012) and Vandepitte et al. (2011). 
mitigating these risks. If not, women such as Anna will continue to weaken and die, while a residual stream of infection emanating from these communities will increasingly endanger the general population of Uganda.

\section{Meeting the Needs of Sex Work Communities}

As I come to the end of this study, I no longer believe only technocratic solutions can improve the HIV risk circumstances of female commercial sex workers in Uganda's slums. Rather, I now find their future rests with looking beyond individual responses to the virus and seriously considering policy and programmatic solutions that start with the interpersonal needs shaping sex work communities—-the social networks that depend upon the ongoing reciprocity between and among individuals. Programs intending to serve communities like Kiku must incorporate the pragmatics of income-generation and the practices of respect seeking maintained by the male hierarchies that drive the community’s social network. In Babito, programs must consider women’s social positioning within the greater hierarchy, so that even women lacking strong social ties can still benefit from interpersonal connections among their peers.

These programmatic efforts can be achieved in different ways by introducing changes in policy at multiple levels. One important policy response is the decriminalization of sex work. Although advocates of this approach invoke a wide variety of reasons often stemming from a larger human rights framework ${ }^{67}$ the position in this dissertation is based on the identified needs of the women and men I engaged in Babito and Kiku. The issue of criminalization is something these individuals deeply

\footnotetext{
67. For example see the NSWP: the Global Network of Sex Work Projects (http://www.nswp.org/)
} 
understand. Although their experiences, which I have shared in this dissertation, invite discussion about the issue, I found the problem of criminalization, as it is framed by human rights discourse ${ }^{68}$, is not something being strongly advocated and/or pursued by residents of Babito or men in Kiku's sex trade. Instead, women and men atop the social hierarchies in both communities seem to accept the role police play in their daily lives. In this way, for them interventions intending to deal with the problem of police violence must be more localized if they are to have any impact. This means solutions should be more willing to accommodate the political and economic interests that underpin sex work, which involve the social capital and interpersonal ties members of these communities have with police forces. In an effort to keep these local and interpersonal contexts central to policy changes, I offer a series of ideas that reflect the "matter of fact" nature of sex work, while also recognizing and incorporating the sociability of risks shaping daily life in the sex trade. By doing so, I believe programs have a greater chance of empowering individuals in the sex trade about their HIV health.

\section{Engage Business Leaders}

The importance of brothels must not be understated. I have shown the key role they play in offering women shelter and privacy, as in the case of Babito. But I have also described the pivotal role owners and managers play in controlling resources in sex work communities, like Kiku. In this way, it is important for future HIV interventions to consider developing strategies that incorporate a visible and essential role for brothel

\footnotetext{
${ }^{68}$ In August 2015 Amnesty International put forth a global policy recommendation to decriminalize sex work: "We have chosen to advocate for the decriminalization of all aspects of consensual adult sex - sex work that does not involve coercion, exploitation or abuse. This is based on evidence and the real-life experience of sex workers themselves that criminalization makes them less safe" (found at https://www.amnesty.org/en/latest/news/2015/08/sex-workers-rights-are-human-rights/).
} 
leaders in helping to redistribute HIV related information and in accommodating on-site HIV prevention and treatment protocols. Current networks of international and local organizations dedicated to working with "most-at-risk-populations” ${ }^{69}$ can play a role in helping to identify sex work locations and brothel owners willing to engage in cooperative endeavor.

Some examples of incorporating brothels, and their leaders, could mean establishing formal trade cooperatives between AIDS treatment programs and brothel owners. Business plans could include ways to raise capital for new building designs, which incentivize brothel management to remodel their businesses. Remodeling sections, such as "Hell" in Babito, would directly benefit women's abilities to protect property. Brothel designs could offer private spaces for women to keep their sex work related belongings (condoms, medications, clothes, shoes, hair and beauty supplies, recreational drugs and alcohol, pipe smoking paraphernalia, etc.), which are safe from environmental hazards and theft; well lit; clean from vermin, trash, air pollution; and, somewhat climate controlled to protect condom supplies (screened windows, building materials better suited for warmer climates, elevated rooms to minimize flooding, etc.).

Not only could programs help improve the safety of sex work facilities, but they could also encourage brothel owners to expand existing places where women, like those in Babito, can comfortably and safely hang-out, smoke-pipes, cook and eat, do laundry, and leisurely socialize — talking and sharing information. With newer sections offering places for women to gather it becomes possible to organize training programs for women

\footnotetext{
69. For an example see the MARPs network of Uganda (http://www.marps.net/index.htm)
} 
to attend, free of charge. Trainings can address many complex, overlapping, and simultaneous needs women have on a daily basis. In this way trainings can, and should, address: literacy in both Luganda and English; financial savings, investment, and theft protection; negotiating with clients, landlords, managers, and colleagues about rent, condoms, sex fees, privacy, and personal property; developing “permissible” aesthetics that can help women minimize scrutiny and suspicion from how they dress, the way they speak, and how they comport themselves outside the brothel; strategies to maintain HIV body care and hygiene, such as best practices to address skin rashes and lesions as well as properly disposing of condoms likely to contain infected human fluids (blood and puss) from the vagina and rectum; and finally, the use of social networks as a means of raising support for AIDS.

\section{Incorporate the Police}

My data reveals a pattern of cooperation between commercial sex work communities and police forces. The women in Babito brothel enlist the aid of undercover female police officers to manage their security problems and the brothel owners of Kiku collude with the local police to "discipline” women who fail to uphold the interests of the owners. In both instances, the police and commercial sex workers have put aside the law in order to work together. The same interests could be harnessed to address a variety of needs women and men in sex work communities have in response to the criminalization of sex work. For starters, policies can support women's access to emergency contraception and safe abortions, especially, in cases where police knowingly support and/or commit sexual violence against commercial sex workers. Programs can involve supportive police to give trainings on how sex worker communities can manage police 
sweeps and the ensuing violence that comes with these raids. Trainings can also include information about human rights doctrines and Ugandan laws against "prostitution” (what constitutes the crime, evidence, arrest, sentencing, bail, etc.). While there are communities, such as Kiku, that have their own semi-official spokespeople to broker relations and information with police, it would behoove all sex worker communities to establish these norms and roles. Additionally, programs should support communities to institute widespread savings for police bribery, bail, and prison similarly to the ways programs can build-upon indigenous strategies like the women's savings circles in Babito.

Communities should also be encouraged to develop and/or expand locally developed early warning systems that focus on protecting members from police violence. Finally, and perhaps most importantly, communities need ways heal from the violence perpetuated upon them by police. On the way to recovery it is important for policies to recognize that communities can develop localized strategies of protection. In the instance of police violence, women and men's social networks can harness the practices that generate reciprocity by developing something akin to a "police raiding wellness kit". Commercial sex workers can hide these kits, which include condoms, medications, cash, and important phone numbers, for when they need to access them in the event of a police raid. Moreover, the supplies for these kits can be sourced similarly to how women in Babito consolidate condoms.

\section{Community Approaches to Preventing and Treating HIV/AIDS}

Given that brothels and their owners and managers must be incorporated into programs that seek to reduce the HIV risks of commercial sex workers, so should all 
clinical and medical staff associated with preventing and treating HIV/AIDS. During my data collection I was asked to participate in the "roll out" of a large-scale HIV intervention for commercial sex workers by a large non-governmental organization based in Muyenga. ${ }^{70}$ Over the course of three months I consulted with this organization to help develop the project as well as identify, train, and supervise the staff they hired to engage in community health outreaches. To prepare for the community level health work, the NGO hired six community health workers and one project manager and purchased three "tuk-tuks" ${ }^{71}$ for transportation. All of this was done before the NGO had ever visited a single sex worker community in Kampala. Senior management of the NGO believed the basis of the project—-if we show up with it, they will want it”-was enough to make the endeavor a success. Yet, there was little interest to adjust the project to fit the needs of the communities, which would have meant revising gaps in their successful multi-million pound sterling proposal for funding.

What ensued was a project that stood little chance of gaining any traction in the communities where I pursued my research despite the fact that the NGO team had been introduced to over 100 women and men from both Babito and Kiku. This was done through the support of Helen, an important informant I introduced in chapter one. Helen was one of the few key relationships I developed in Kiku. ${ }^{72}$ Through Helen, the NGO

\footnotetext{
${ }^{70}$ Muyenga is an area of Makindye Division, in Kampala, that houses a lot of expatriates and large-scale international/national NGO operations and headquarters.

71. A "tuk-tuk" is a common name for a small truck-like vehicle most often used in Asia.

72. My first meeting with Helen was 5 November 2012. On that occasion she initially sat for a group discussion with two other women, but eventually, the discussion changed and became an interpersonal interview. Although Helen remained friendly after this initial meeting she made it clear to me that she did not want to participate in the data collection any further. I speculate this is because of the changing dynamics in the community in relation to my research (see chapter five), but also her burgeoning
} 
staff connected to women and men in four different sex work communities. Given Helen's interest in the project and willingness to vouch for the team, it was unfortunate to find little effort on the part of the NGO staff to develop deep ties with the leaders in either Babito's hierarchy, or to consider the financial gains men in Kiku would want to reap from the project. Instead, by the time I left Kampala, it was clear the project was simply focused on "counting heads" and monitoring and evaluating the distribution of their supplies - recording the number of women that received treatment during the health outreaches (e.g., HIV tests, injectable hormonal birth control, pregnancy tests, and antibiotics for gonorrhea, vaginitis, and chlamydia).

As a result of this experience, and in response to my research findings, I now firmly believe programs must be seriously overhauled. To do this will mean changing the priorities of mainstream HIV policies. No longer is it enough to want to "end AIDS" or “stop the spread of HIV”. To achieve such goals, what sex work communities need is a sincere recognition of their humanity. That acceptance only begins when programs become comprehensive and community-centered in their efforts to provide HIV care. It also begins with reconsidering the orthodoxy of clinical and medical responses. This means moving providers away from the technocratic dogma of optimization, individualization, and commodification of programs-processes that seek market driven solutions and theories of change to address public health issues. ${ }^{73}$ Instead of these

relationship with Nakato. However, when the opportunity was presented for Helen to assist me with the NGO project she agreed and since that time we have remained in contact through Facebook and she has even come to visit me in Amsterdam.

73. Examples of market driven interventions can be found in a wide variety of NGO literature and one of the best comes from PSI: "Yes, we're a nonprofit, but don't think of us as a charity. Like a Fortune 500 company, we take a business approach to saving lives. We provide real solutions to complex health 
business cogent approaches that emphasize individual responses, the goal of future policies must be to move providers and strategies towards incorporating the complex and interpersonal strategies of women and men in the sex trade. Complexities that necessitate commercial sex workers, and the men involved in the business, still be able to rely on their social capital and social networks for daily survival.

Future HIV interventions must find ways of being flexible and portable in order to meet commercial sex workers where they work and live. By entering brothels to provide services means program staff must no longer deny or refute the important role these businesses play in the overall economic security of sex work communities. Therefore it behooves programs to find ways of operating nearby if not inside brothels. This can be done by either renting space onsite (“the HIV room”); enlisting brothel attendants to help set-up information services, and assist in the distribution of information and materials; and/or holding on-site services on a bi-weekly basis. Yet before these kinds of plans can be put into place, clinic and medical staff, as well as community health workers must be sensitized to both the environments where sex work takes place and the sensibilities of the people involved in the trade.

Open communication between sex work communities and HIV project teams can mean co-developing a "community wellness checklist". The list could be spearheaded by a group of "experts” comprised of women and men from the sex work community and HIV prevention and treatment project staff. Working together they would become a sort of “Doctors within Brothels” taskforce. Such a team would meet with members of the sex

problems. And, we measure our results” (http://www.psi.org/work-impact/). The theory of change driving these interventions is linked with notions of expanding markets and providing business solutions to address social crises. 
trade community to engage in open discussions about the problems within the brothel (e.g., conditions, environment, staff, management, and/or other women); address issues involving localized violence related to sex work (police, clients, boyfriends, peers); and find ways to collectively resolve social and financial pressures in the community (external threats, interpersonal tensions, disease outbreaks related to living conditions in the slum, the presence of small children, etc.).

Along with exploring the wellbeing of brothel residents and staff, as well as women who commute to work at these locations, programs should develop a recognizable, but removable and portable, medication identification system (e.g., epileptic bracelets). The goal of this device is to be both helpful and reflective of the aesthetics valued in the community. In terms of the needs of medical staff, the device should be able to track the HIV prevalence and incidence in the sex work community. Yet for women and men in the sex trade, the accessory must incorporate the aesthetics valued by leaders and elite members of the dominant social hierarchy, while also being completely innocuous in order to minimize stigma —unlike the current supplies I discussed in chapter four. Examples of these kinds of community-sensitive devices can be found in the literature concerned with gender-based sexual violence and conflict. ${ }^{74}$

Finally, HIV interventions must consider the variance in knowledge between the scientific information that underpins what we know about HIV, and the localized strategies women and men deploy to keep themselves safe in the sex trade. To bridge this gap, programs must institute opportunities to engage in a two-way dialogue about their

74. See Smits and Cruz (2011). 
science and the localized survival strategies of the intended beneficiaries. This can be done in the same vein as "fire-side chats" or "brown bag lunches", whereby project teams and members of sex work communities discuss what to expect from medical appointments, how to speak with each other productively and respectfully in clinic settings, and how to cope with stigma in a hostile medical setting. The last point could mean working with project staff to co-develop “cover stories” for women. These can be plausible professional identities that allow women to maximize their HIV care by believably hiding the fact they sell sex. ${ }^{75}$

Along with a need for open and sensitive communication strategies between clinic and medical teams and slum-based commercial sex workers, programs must find more affordable ways for women and men in the sex trade to access healthcare that cannot be brought to the brothel (blood draws and/or transfusions, x-rays, IV delivered medications, etc.). This means enlisting local transportation methods. In Babito and Kiku, women and men rely on taxis and bodas (motorbikes) for transportation. In the case of the latter, boda drivers have their own social networks, which may overlap with commercial sex work communities. Working with these drivers presents an important opportunity to enlist the help of small-scale entrepreneurs, while bolstering community-wide support for HIV interventions. The goal for projects can be to incentivize boda drivers to reliably and safely transport patients, who are likely to be the same women they either drive at night

\footnotetext{
75. Understandably activists in the sex work movement believe sex workers should not have to hide what they do. While this is an important aspect of the fight to decriminalize "prostitution", there are still too many places where women and men in the sex trade cannot or will not disclose what they do. In their efforts to hide their profession, these women and men find themselves unable to present a credible reason for why they should not receive certain medications and/or why they need their appointments at certain times of the day and/or month.
} 
or pay for sexual services. Essentially, boda drivers, like commercial sex workers, operate as "cash only" businesses. Theft, accidents, and violence mark their lives in similar ways as they do for women and men in sex work communities. In this way, by enlisting boda drivers to join a slum-based HIV intervention, programs demonstrate a willingness to cast a wider net within an intricate social network of mutual interdependence.

Ultimately, the successes of any project that engages sex work communities directly can only be reaped after first accepting the paradoxes of life in the slums, where many brothels are located. Recognition of important survival tactics, like social networks and social capital that mitigate risk for women engaging in sex work, is key. Projects that keep this in mind will manage to strategize interventions that keep the complexities of sex workers' social networks at the forefront of their designs. Doing so not only challenges the orthodoxy of healthy system processes, but also HIV policies long held in place at the national and international level. These policies, which I discussed in chapter two, entail a penchant for solutions that can be measured and materialized. ${ }^{76}$ Yet, the predilection by HIV scientists, policy-makers, and program coordinators to identify patients and then treat them, on a case-by-case basis, has been on a collision course with HIV for quite some time. As a result, it finally seems the "point of no return" is being reached. As noted in chapter two, with HIV rates on the rise again among Uganda's general population and a viral prevalence rate as high as one out of three for female

\footnotetext{
76. Since 2010 HIV prevention has become synonymous with the term "treatment as prevention”, whereby antiretroviral treatment (ART) is being used as a prevention protocol to decrease the risk of HIV infection. This is because ART has been shown to lower the viral load in bodily fluids known for carrying the virus (blood, semen, vaginal and anal fluids, and breast milk).
} 
commercial sex workers in Kampala, time is running out. Solutions can no longer afford to ignore the sociability of risks shaping the lives of women and men engaged in the sex trade.

The women and men discussed in my dissertation teach us about collective survival. Their community-based experiences help us to better understand how individuals mitigate risk through interpersonal connection. These connections also teach us that even when women and men in the sex trade develop ways of depending on each other, there are no guarantees with reciprocity. Yet because women and men understand the uncertainty of these connections they strategize, daily, for ways of maintaining and extending these relationships in order to help them buffer the hazards of each day. In this way, the stories I have shared in this dissertation illustrate how individuals directly benefitting from the sex trade can manage their destitution and degradation by adhering to a larger process of community formation. What I found is that as this process extends outward from interpersonal commitments, it keeps in place important aspects of these individuals' social networks and the necessary social capital sustaining that sustains their communities. In turn, these social ties help individuals gain access to resources, which offer women and men a means of cultivating a shared sense of belonging together in the face of their daily risks.

It is with belonging in mind that I have offered a series of policy considerations for intervention in the pages above. These ideas reflect upon the underlying practice of interconnectivity shaping the daily lives of women in Babito and men in Kiku, which come about from the normative give-and-take between individuals. New policy considerations must take account of these interpersonal dimensions at the root of risks 
associated with sex work, criminalization, and HIV/AIDS in the slums of Kampala. Moreover, these policy recommendations call upon Ugandan authorities, donors, UN Agencies, NGOs, and others who can influence the decision-making processes related to sex work and HIV in Uganda to bring about a more grounded and bottom-up approach to preventing and treating the spread of AIDS in Uganda.

\section{Second Chances and Further Research}

Once when I was struggling to see my way through some of the more difficult periods of the data collection, a friend said to me, "Sometimes we need a second chance because we're not quite ready for the first". Her comment stayed with me until the end of my fieldwork. It has given me much to consider in terms of what I think is important for further research. Thinking about second chances also means recognizing the limitations of my own work, which I addressed in chapter five’s “A Cautionary Tale”. I consider my research in both Babito and Kiku's sex work communities as two important but limited attempts to find answers about a dynamic system of risk management. More research is surely needed. New research must go deeper and continue for longer periods of time in order to document the mutability of daily risk and the practices individuals use to ensure their survival.

Sex work communities, much like an ecosystem, are comprised of multiple competing individuals living together in a state of impermanence tending towards continuous change. ${ }^{77}$ As a result of these proclivities, researchers and policy-makers should expect dynamism rather than equilibrium in the daily lives of men and women in

77. See Worster (1994). 
the sex trade. Thus, new research should strive to accept and appreciate the flux of these challenging environments and the implications this change has on the individual and communal levels of analysis. Looking to the future, it is necessary for studies to simultaneously consider the values of both the interpersonal processes of risk management—social networks, social capital, and community formation—and the individuals living at the center of these processes. The data I gathered by spending time with Anna, as her medication companion, is a first start. Yet more is needed to understand the implications of an individual's illness within the complex social system of a sex work community. This means pushing methodological boundaries wherein designs convey humility and patience, as well as skepticism, about the status quo of AIDS research. In this way the work in my dissertation is an "early round" at endeavoring to pursue "hard-to-reach" subjects working in two difficult settings and with several mercurial individuals.

My research only went so far as to reveal the sociability of risk shaping the lives of women and men in two sex work communities. Studies to come should strive to go deeper, get closer, and give greater time for being at the center of these communities and individuals' lives. The women in Babito and the men I incidentally studied in Kiku are just the beginning. New projects could dedicate their efforts to understanding the role of male social networks in the sex trade and how these networks have implications for a variety of risks—gender based violence, community security, the interplay of state and non-state actors—and their implications for the risk of HIV.

Along with looking at different networks, studies can also explore different sex work communities based on the locations and the types of individuals engaging in the sex 
trade. Here I offer some important first steps towards these kinds of projects, but this is not an exhaustive list. First, further research could explore the interpersonal practices of risk management in relation to different sex work locations, such as urban locations (universities, villages, high-end hotels, bars, government ministries, offices of elected officials) and border locations (Kenya, Rwanda, South Sudan, Tanzania), as well as the social ties sustaining the migration practices of sex workers (trucking routes and sex work abroad). In terms of the "who sells sex", future research could explore the manifestation of sex work within different groups (e.g., Muslims, transgender, gay, lesbian, queer, inter-sexed) and the social networks that protect these more vulnerable sex work actors. Specifically, new research looking into the interpersonal risk management strategies of "sexual minorities" is especially necessary. With the rise of antihomosexuality legislation in Africa, transgender, gay, and lesbian commercial sex workers are especially vulnerable to risks associated with sex work, criminalization, and HIV/AIDS and perhaps even farther removed from traditional interpersonal coping mechanisms as a result of their sexual identity in these highly hetero-normative and patriarchal contexts. Finally, I also believe future queries into the sex trade should strive to hold space for the nuanced minutiae of each day for the participants, which cannot be explained by perpetuating an unfounded and unsuitable dichotomy between "the whole" and "the parts". In this way, it behooves researchers to ask new questions and create new designs that both complicate and simplify the data collection.

Thinking about further research has led me to reflect on the importance of additional factors in risk management. I now believe it is crucial for future researchers to consider the implications of men's social networks and 'sites of sex' in relation to how 
women manage daily risks associated with sex work, criminalization, and HIV/AIDS. In terms of men's networks, research designs could engage these individuals into the data collection process from the outset of the study. But they should also configure ways of letting men's daily practices, specifically those connected to the pragmatics of their income generation and their efforts to achieve the esteem and respect of their peers, be a source of information about what affects women's efforts to mitigate risk through social networks, reciprocity, and community formation. Moreover, with the addition of men's interpersonal dynamics comes an opportunity to include the way in which environments shape risk and risk management practices. I do this somewhat with my discussion of Babito and women’s residency in the brothel ("Clinic”, "Bus”, and "Hell”), but future studies could pursue the notion of "place" in relation to the sociability of risk and its mitigation. In this way it would benefit researchers to consider the implications of onsite gambling, pool tables, bars, and eateries within brothels. The combination of these businesses, which I found in Kiku, may likely dominate sex work sites and complicate the nature of social networks formed in sex worker sites.

The potential for Babito brothel to be an anomaly, in terms of its design but also the homogeneity and dominance of its female population, is pivotal for future research. This is because the findings I documented and discuss in this dissertation concerning the ways women in the brothel manage risk are difficult to generalize. Rather the phenomenon of women's savings circles and the security precautions they take in Babito illustrates the resourcefulness of female commercial sex workers. New research could consider ways of looking for similar efforts. Doing so gives future researchers the chance to expand their approaches for gathering information about the daily lives of women and 
men in the sex trade. In turn, the results of this evidence could embolden subsequent researchers, policy-makers, and AIDS programs to take steps to value and incorporate indigenous solutions that reflect the primacy of social networks and social capital in sex work communities.

\section{Endings and Beginnings}

Here at the end of my dissertation I am still curious about the social problems I attempted to understand at the outset of this study. The benefits of being curious include not giving in to any regrets about what I managed to find (or not find) this time around, but also curiosity, in combination with what I know now, has inspired my imagination. As a result I am beginning to develop new questions and new research designs that I would like to pursue in the aftermath of this study. Should such an opportunity arise, I would use it to push further ahead into researching human conditions that are contentious, fragile, and scarce, but also rife with resourceful individuals. As it stands, I am eager to undertake another study that once again tries to document daily risk. Yet this time, my investigation will have a more "holistic" community focus, which I believe can only be understood through its membership - the individual women and men whose efforts to survive constitute the social networks of their community. Instead of solely looking at how female commercial sex workers manage daily risks, I would rather explore the ways risk shapes daily practices associated with community formation among women and men engaging in slum-based sex trades.

When I begin to imagine another research project I find myself drawn to the possibility of arranging ways to "test" what it would mean to study a brothel specifically designed to provide for what both men and women seek from sex work. First this would 
mean providing for the different ways in which women and men experience leisure. I found in Babito, women’s “down time” involved pipe smoking, beautifying, sitting and talking with each other, as well as doing laundry and eating. With men in Kiku, time away from managing the brothel involved playing pool and gambling. Taking these social practices into consideration, I would want to find ways of hosting these divergent activities while at the same time attending to the ways men and women's social networks operate.

Second, alongside considering how to accommodate for women and men's leisure, it would be important for my next study to consider the implications of a brothel environment that would allow me to explore women and men's risks management techniques. The research design would need to preserve the sanctity of women's authority and independence that underpins the basis of their social hierarchy, as I found in Babito. Yet the study would take up the challenge posed by how men's social networks appropriate women's resources as I observed in Kiku. Thinking through these networkbased needs would involve pursuing a methodological design that manipulates a brothel setting. While I realize doing so may move my research slightly away from its ethnographic roots, it does not preclude observation and participation in the design. From the outset of the research I would remain aware of how manipulations complicate the ethics of data collection, which is why it would be important to consider the implications of having onsite HIV assistance. 
The presence of an HIV "outpost" would be a third way of "testing" how a brothel could meet the needs of women and men in the sex trade. ${ }^{78}$ Having onsite facilities would deepen the study in two ways. First, the presence of clinical staff would necessitate a "sensitization approach" for all those involved in the research design. This would mean incorporating evidence about how well clinic teams could "learn-from" as well as "treat-with" the knowledge women and men have about their daily survival working and living in the brothel. Second, the information gathered from inside the brothel would provide an additional data set that could serve as a baseline measurement of HIV prevalence and incidence. ${ }^{79}$ This last point is perhaps the most compelling aspect of this new research project, because it would allow me to get at the statistic that started it all—Vandepitte et al. (2011)—claiming, as of 2011, that 37\% of women engaging in 'high risk' sex in Kampala test positive for HIV.

Essentially, new research should combine three important findings from this dissertation: (1) the implications of the environment in which sex work takes place; (2) the divergent ways women and men develop and maintain their social networks; and (3) the importance of having sensitive and supportive HIV healthcare facilities to address the HIV health needs of women and men engaging in commercial sex work. All together these insights provide a foundation for pursuing what I believe is a continuation of the same line of analysis. Yet, through the process of completing this dissertation, my

\footnotetext{
78. This clinic would first and foremost be available to the women and men living and working in the brothel. However, should it be determined that a level of interest for HIV testing, prevention messaging, and treatment is coming from clients and/or individuals related to the brothel residents and staff, it would be ideal to find ways of meeting these secondary patient's needs as soon as possible.

79. Incidence means the number of new infections, which is important for studies that seek to estimate overall rates of infection.
} 
concepts for research design have been refined. As a result I believe it is important to consider the implications of a second chance to study the complexities of risks associated with sex work, criminalization, and HIV/AIDS. But this time to do my research from within the confines of a brothel; to recognize the important roles both women and men play in the development of social networks and reciprocity; and, to document these interpersonal practices as integral means of community formation and resilience in the slum.

Finally, throughout this second study it would be crucial to retain the insights I gained from "doing” the research for this dissertation. Meaning I would endeavor to hold space for the unexpected, the difficult, and the terribly sad, as well as venturing forth with even greater appreciation for the commingling of struggle and resources that constitute life in a brothel. Moreover, my next study would invite collaboration from other areas of science, such as health systems research, criminology, social work, and virology. In doing so, I would attempt to create a model for interdisciplinary studies that value these additional streams of research and analysis and reflect the complementarity of work that I believe is essential for researching "hard-to-reach" populations. Ultimately, in pursuing a second study about sex work related risks it is important that my research design be flexible, accountable, and wholly ready to capture the constellation of pain and joy that is part of life in the slums for the men and women engaging in the sex trade. Anything less would dishonor the words in this text. 


\section{BIBLIOGRAPHY}

Abu-Lughod, Lila (1990). “Can There Be a Feminist Ethnography?” in Women \& Performance: A Journal of Feminist Theory, Vol., 5, Issue 1, Pp. 7-27.

Ackerly, Brooke A. (2000). Political Theory and Feminist Social Criticism. Cambridge: Cambridge University Press.

Ackerly, Brooke A., Stern, Maria, and True, Jacqui. (2006). Feminist Methodologies for International Relations. Cambridge: Cambridge University Press.

Agol, Dorice, Bukenya, Dominic, Seeley, Janet, Kabunga, Elizabeth, and Katahoire, Anne. (2014). "Marriage, Intimacy, and Risk of HIV Infection in South West Uganda” in African Journal of Reproductive Health, Vol., 18, No., 4, Pp. 86-94.

Ailio, Jaako. (2011). “Governing Sub-Saharan HIV/AIDS through Gender” in Alternatives: Global, Local, Political, Vol., 36, No., 4, Pp. 345-358.

Altman, Dennis. (1998). “Globalization and the 'AIDS industry"” in Contemporary Politics, Vol., 4, No., 3, Pp. 233-245.

Altman, Dennis. (2001). Global Sex. Chicago: University of Chicago Press.

Amon, Joe. (2010). "Uganda AIDS Policy: From Exemplary to Ineffective” in The Observer found at http://www.hrw.org/print/news/2010/06/24/uganda-aids-policyexemplary-ineffective

Atwiine, S. Kabarira E., Kityo, C., Mugyenyi P., Nakityo, R. (2000). "Prostitution and HIV/AIDS in Uganda: A study of commercial sex workers in Kampala with emphasis on the economic gains vis-a-vis the health risks” for abstract no. WePeD4816, presented at the International Conference on AIDS.

Babbie, Earl. (2008). The Basics of Social Research. Belmont: Chapman University.

Baral, Stefan, Beyrer, Chris, Muessig, Kathryn, Poteat, Tonia, Wirtz, Andrea L., Decker, Michele R., Sherman, Susan G., Deanna Kerrigan. (2012). "Burden of HIV among female sex workers in low-income and middle-income countries: a systematic review and meta-analysis” in Lancet Infections Disease, Vol., 12, Pp. 538-49.

Barnes, J.A. (1958). "Class and Committees in a Norwegian Island Parish” in the Journal of Human Relations, Vol., 7, No., 1, Pp. 39-58.

Barnett, Tony and Whiteside, Alan. (2006). AIDS in the Twenty-First Century: Disease and Globalization. Palgrame Macmillan. 
Basset, Lytta, Fassin, Eric, and Radcliffe, Timothy. (eds). (2007). Christians and Sexuality in the Time of AIDS. New York: Continuum.

Behar, Ruth. (2003). Translated Woman: Crossing the Border with Esperanza's Story, Tenth Anniversary Edition. Boston: Beacon Press.

Bekker, Linda-Gail and Wood, Robin. (2010). "The Changing Natural History of Tuberculosis and HIV Coinfection in an Urban Area of Hyperendemicity” in Clinical Infectious Diseases, No. 50 (S3), Pp. S208-S211.

Berg, Bruce L. and Howard Lune. (eds). (2012). Qualitative Research Methods for the Social Sciences. Eight Edition. Boston: Pearson.

Bernstein, Elizabeth. (2007).“Buying and Selling the 'Girlfriend Experience': The Social and Subjective Contours of Market Intimacy” Pp. 186-202 in Padilla, Mark B., Hirsch, Jennifer S., Munoz-Laboy, Miguel, Sember, Robert E., and Parker, Richard G. (eds). Love and Globalization. Nashville: Vanderbilt University Press.

Biakolo, Emevwo, Mathangwane, Joyce, and Odallo, Dan. (2003). The Discourse of HIV/AIDS in Africa. Gabarone: University of Botswana.

Biggar, Robert J. (1986). “The AIDS Problem in Africa” in The Lancet, Vol. 327, No. 8472, Pp. 79-83.

Bikaako, Winnie. (2007). "The Female and the Prostitute: Historical Perspectives on Prostitution in Kampala City, Uganda: A working paper”. Kampala: Center for Basic Research

Bocast, Brooke. (2014). Doctoral Dissertation “If Books Fail, Try Beauty: Gender, Consumption, and Higher Education in Uganda” Temple University.

Bodenheimer, Thomas S. and Grumbach, Kevin. (2005). Understanding Health Policy: A Clinical Approach, Fifth Edition. New York: MGraw Hill.

Boone, Catherine and Batsell, Jake. (2001). "Politics and AIDS in Africa: Research Agendas in Political Science and International Relations” in Africa Today, Vol., 48, No., 2, Pp. 3-33.

Bor, Jacob. (2007). “The Political Economy of AIDS Leadership in Developing Countries: An Exploratory Analysis” in Social Science and Medicine, Vol., 64, Pp. 1585-1599.

Borne, Francine van den. (2005). Trying to Survive in Times of Poverty and AIDS. Amsterdam: Het Spinhuis. 
Bourdieu, Pierre. (1984). Distinction: A Social Critique of the Judgment of Taste. Cambridge: Harvard University Press.

Bourgois, Phillipe, Lettiere, Mark, and Quesada, James. (1997). "Social Misery and the Sanctions of Substance Abuse: Confronting HIV/RISK Among Homeless Heroin Addicts in San Francisco" in Social Problems, Vol. 44, No. 2 Pp. 155-173.

Bourgois, Philippe. (1998). “The Moral Economies of Homeless Heroin Addicts: Confronting Ethnography, HIV Risk, and Everyday Violence in San Francisco Shooting Encampments” in Substance Use \& Misuse, Vol. 33, No. 11, Pp. 23232351.

Bourgois, Philippe. (2003). In Search of Respect: Selling Crack in El Bario. Second Edition. San Francisco: University of California Press.

Brennan, Denise. (2007). "Love Work in a Tourist Town: Dominican Sex Workers and Resort Workers Perform at Love” Pp. 203-225 in Padilla, Mark B., Hirsch, Jennifer S., Munoz-Laboy, Miguel, Sember, Robert E., and Parker, Richard G. (eds). Love and Globalization. Nashville: Vanderbilt University Press.

Brown, Brene. (2008). I thought it was just me (but it isn't): making the journey from "What will people think?" To "I am enough". New York: Gotham Books.

Brown, Brene. (2010). The Gifts of Imperfection: Let Go of Who You Think You're Supposed to Be and Embrace Who You Are. Central City: Hazelnut.

Brown, Brene. (2012). Daring Greatly: How the Courage to be Vulnerable Transforms the Way We Live, Love, Parent, and Lead. New York: Gotham Books.

Brown, Karen McCarthy. (2001). Mama Lola: A Vodou Priestess in Brooklyn. Berkeley: University of California Press.

Bryant, A. and Charmaz, K. (2007). Grounded Theory in Historical Perspective: An Epistemological Account. Pp. 31-57 in Bryant, A. and Charmaz, K. (eds). The Sage Handbook of Grounded Theory. Los Angeles: Sage.

Bukenya, Justine, Vandepiite, Judith, Kwikiriza, Maureen, Weiss, Helen A., Hayes, Richard, and Grosskurth, Heiner. (2013). "Condom use among female sex workers in Uganda" in AIDS Care: Psychological and Socio-medical Aspects of AIDS, Vol., 25, No., 6, Pp. 767-774.

Callaway, Helen. (1992). "Ethnography and experience: Gender implications in fieldwork and texts”. Pp. 29-49 in Okely, Judith and Callaway, Helen (eds). Anthropology \& Autobiography. London: Routledge. 
Campbell, Catherine. (2000). "Selling Sex in the time of AIDS: the psycho-social context of condom use by sex workers on a Southern African mine" in Social Science \& Medicine, Vol. 50, Pp. 479-494.

Campbell, Catherine. (2003). 'Letting Them Die': Why HIV/AIDS Prevention Programs Fail. Bloomington: Indiana University Press.

Center for Health and Gender Equity. (2004). Debunking the Myths in the U.S. Global AIDS Strategy: An Evidence Based Analysis. Tacoma Park, Maryland

Center for Health and Gender Equity. (2008). Implications of U.S. Policy Restrictions for HIV Programs Aimed at Commercial Sex Workers. Policy Brief for Gender Health.

Charmaz, Kathy. 2014. Constructing Grounded Theory. Second Edition. Los Angeles: Sage.

Cheney, Kristen E. (2007). Pillars of the Nation: Child Citizens and Ugandan National Development. Chicago: Chicago University Press.

Cheney, Kristen E. (2012). “Locating Neocolonialism, “Tradition,” and Human Rights in Uganda’s “Gay Death Penalty”” in the African Studies Review, Vol. 55, No. 2, Pp. 77-95.

Cheng, Sealing. (2007). "Romancing the Club: Love Dynamics between Filipina Entertainers and GIs in U.S. Military Camp Towns in South Korea” Pp. 226-251 in Padilla, Mark B., Hirsch, Jennifer S., Munoz-Laboy, Miguel, Sember, Robert E., and Parker, Richard G. (eds). Love and Globalization. Nashville: Vanderbilt University Press.

Cheng, Sealing. (2012). "Paradoxes of Neoliberalism" a video recording for the Barnard Center for Research on Women found at http://sfonline.barnard.edu/gender-justiceand-neoliberal-transformations/paradoxes-of-neoliberalism/

Clifford, James and Marcus, George E. (eds). (1986). Writing Culture: The Poetics and Politics of Ethnography: Experiments in Contemporary Anthropology A School of American Research Advanced Seminar. Berkeley: University of California Press.

Cohen, Clara, Orza, Michele, and Patel, Deepali. (2008). Design Considerations for Evaluating the Impact of PEPFAR: Workshop Summary. Washington: National Academic Press.

Cole, Jennifer. (2010). Sex and Salvation: Imagining the Future in Madagascar. Chicago: Chicago University Press. 
Comaroff, Jean. (2007). "Beyond Bare Life: AIDS, (Bio)Politics, and the Neoliberal Order” in Public Culture, Vol. 19, No. 1, Pp. 197-219.

Condon, Bradly J. and Sinha, Tapen. (2008). Global Lessons from the AIDS Pandemic: Economic, Financial, Legal and Political Implications. Berlin: Springer.

Cooper, Melinda. (2013). "Double Exposure—Sex Workers, Biomedical Prevention Trials and the Dual Logic of Global Public Health” in S\&F Online Issue 11, No. 3 , found at http://sfonline.barnard.edu/life-un-ltd-feminism-bioscience-race/doubleexposure-sex-workers-biomedical-prevention-trials-and-the-dual-logic-of-globalpublic-health/

Craddock, Susan. (2000). "Disease, social identity, and risk: rethinking the geography of AIDS” in Transactions of the Institute of British Geographers, Vol. 25, No. 2, Pp. 153-168.

Craddock, Susan. (2003). "AIDS and Ethics: Clinical Trials, Pharmaceuticals, and Global Scientific Practice” Chapter 18 in Kalipeni, E., Craddock, S., Oppong, J., Ghosh, J. (eds). AIDS in Africa: Beyond Epidemiology. London: Blackwell.

Crane Survery Report. (2010). "High Risk Group Surveys Conducted in 2008/9” Kampala, Uganda. Makerere University, PEPFAR, United States Centers for Disease Control and Prevention, and Republic of Uganda Ministry of Health.

Crang, Mike and Cook, Ian. (2007). Doing Ethnographies. London: Sage.

Cusick, Linda. (2006). "Widening the harm reduction agenda: From drug use to sex work" in The International Journal on Drug Policy, Vol. 17, Pp. 3-11.

Das, Pamela and Horton, Richard. (2014). "Bringing sex workers to the centre of the HIV response" in The Lancet, published online at http://dx.doi.org/10.1016/S01406736(14)61064-3

Davis, Kathy. (1997). Embodied Practices: Feminist Perspectives on the Body. Thousand Oaks: Sage Publications.

Dekker, Mareleen and Wilms, Annegien. (2009). "Can health insurance be the magic bullet? The case of Microcare Ltd in Uganda" in African Studies Centre, info. Sheet 7, Pp. 1-4.

Dietrich, John W. (2007). “The Politics of PEPFAR: The President's Emergency Plan for AIDS Relief” in Ethics \& International Affairs, Vol., 21, No., 3, Pp. 277-292. 
Doherty, Jacob. (2016). "Infrastructures of Disposability: Waste, Responsibility and the Politics of a Clean Kampala” doctoral dissertation for Stanford University, Department of Anthropology, forthcoming.

Dowset, Gary W. (1993). "I'll Show You Mine if You'll Show Me Yours” in Reproductive Health Matters, No. 7, Pp. 19-24.

Dowset, Gary W. (2003). "Some Considerations on Sexuality and Gender in the Context of AIDS” in Reproductive Health Matters, Vol. 11, No. 22, Pp. 21-29.

Doyal, Lesley, Naidoo, Jennie, and Wilton, Tamsin. (1994). AIDS: Setting a Feminist Agenda. London: Taylor \& Francis.

Dworkin, Shari L. (2005). "Who is epidemiologically fathomable in the HIV/AIDS epidemic? Gender, sexuality, and intersectionality in public health" in Culture, Health \& Sexuality, Vol. 7, No. 6, Pp. 615-623.

Duncan, Nancy. (1996). Body Space. New York: Routledge.

Eboko, Fred. (2005). "Law against morality? Access to anti-AIDS drugs in Africa" produced by UNESCO. Oxford: Blackwell.

Elbe, Stefan. (2006). "Should HIV/AIDS Be Securitized? The Ethical Dilemmas of Linking HIV/AIDS and Security” in International Studies Quarterly, Vol. 50, No. 1, Pp. 119-144.

Ellis, Amanda, Manuel, Claire, and Blackden, C. Mark (eds.). (2006). Gender and Economic Growth in Uganda: Unleashing the Power of Women. Washington: World Bank.

Ellis, Carolyn. (2004). The Ethnographic I: A Methodological Novel About Autoethnography. New York: AltaMira.

Emerson, Robert M., Fretz, Rachel I., Shaw, Linda L. (1995). Writing Ethnographic Fieldnotes. Chicago: University of Chicago Press.

Enloe, Cynthia. (1983). Does Khaki Become You: The Militarization of Women's Lives. London: South End Press.

Enloe, Cynthia. (2000). Bananas, Beaches, and Bases: Making Feminist Sense of International Politics, Second Edition. Berkeley: University of California Press.

Enloe, Cynthia. (2000). Maneuvers: The International Politics of Militarizing Women's Lives. Berkeley: University of California Press. 
Enloe, Cynthia. (2004). The Curious Feminist: Searching for Women in a New Age of Empire. Berkeley: University of California Press.

Epstein, Helen. (2007). The Invisible Cure: Why We Are Losing the Fight Against AIDS in Africa. New York: Picador.

Epstein, Helen. (2010). "The Mathematics of Concurrent Partnerships and HIV: A Commentary on Lurie Rosenthal, 2009” in AIDS Behavior, Vol., 14, Pp. 29-30.

Epstein, Helen and Morris, Martina. (2011). "Concurrent partnerships and HIV: an inconvenient truth” in Journal of the International AIDS Society, Vol. 14, No. 13, Pp. $1-11$.

Ezeonu, Ifeanyi. (2008). “Crimes of Globalization: Health Care, HIV, and the Poverty of Neoliberalism in Sub-Saharan Africa" in International Journal of Social Inquiry Vol. 1, No. 2, Pp. 113-134.

Family Health International. (2004). Behavior Change: A Summary of Four Major Theories, found at http://ww2.fhi.org/en/aids/aidscap/aidspubs/behrcs/ber4thco.html.

Farmer, Paul. (2006). AIDS and Accusation: Haiti and the Geography of Blame. Berkeley: University of California Press.

Farmer, Paul. (2009). "On Suffering and Structural Violence: A View from Below” in Race/Ethnicity: Multidisciplinary Global Perspectives, Vol. 3, No. 1, Autumn, Pp. 11-28.

Forbes, Anne. (2010). "Sex Work, Criminalization, and HIV: Lessons from Advocacy History” in BETA, Vol. 22, No. 4, Summer/Fall, Pp. 21-28.

Foucault, Michel. (1978). The History of Sexuality: An Introduction, Volume 1. New York: Vintage Books.

Foucault, Michel. (1994). Power. New York: The New Press.

Foucault, Michel. (1995). Discipline \& Punish: The Birth of the Prison. New York: Vintage Books.

Foucault, Michel. (2004). Security, Territory, Population: Lectures at the College De France 1977-1978. New York: Palgrave.

Foucault, Michel. (2005). Society Must Be Defended: Lectures at the College De France 1975-1976. New York: Picador. 
Fredby, Jenny Appelblad and Nilsson, David. (2013). “From 'All for Some' to 'Some for All'? A historical geography of pro-poor water provision in Kampala" in Journal of Eastern African Studies, Vol. 7., No. 1, Pp. 40-57.

Gable, Lance, Gamharter, Katharina, Gostin, Lawrence, O., Hodge, James G. Jr., and Puymbroeck, Rudolf V. Van. (eds). (2007). Legal Aspects of HIV/AIDS: A Guide for Policy and Law Reform. Washington: The World Bank.

Geertz, Clifford. (1973). The Interpretation of Cultures. 2000 Edition. New York: Basic Books.

Government of Uganda. (2010). UNGASS Country Progress Report: Uganda. Kampala.

Glaser, B. G. and Strauss, A. L. 2012. The Discovery of Grounded Theory: Strategies for Qualitative Research. Fourth edition. London: Aldine Transaction.

Grmek, Mirko D. (1990). History of AIDS: Emergence and Origin of a Modern Pandemic. Princeton: Princeton University Press.

Grosz, Elizabeth. (1994). Volatile Bodies: Toward a Corporeal Feminism. Indianapolis: Indiana University Press.

Gysels, M., Pool, R., Nnalusiba, B. (2002). "Women who sell sex in a Ugandan trading town: life histories, survival strategies, and risk” in Social Science \& Medicine, Vol. 54, Pp. 17-192.

Hancock, Graham and Carim, Enver. (1986). AIDS: The Deadly Epidemic. London: Victor Gollancz LTD.

Hansen, Holger Bernt and Twaddle, Michael. (1998). (eds.) Developing Uganda. Oxford: James Currey.

Hansen, Holger Bernt and Twaddle, Michael. (1998). (eds.) Changing Uganda. Oxford: James Currey.

Harcourt, C. and Donovan, B. (2005). "The Many Faces of Sex Work” in Sexually Transmitted Infections, Vol. 81, Issue 3, Pp. 201-206.

Harcourt, Wendy. (2009). Body Politics in Development: Critical debates in gender and development. New York: Zed Books.

Hardee, Karen, Gribble, Jay, Weber, Stephanie, Manchester, Tim, and Wood, Martha. (2008). Reclaiming the ABCS: The Creation and Evolution of the ABC Approach. Washington: Population Action International. 
Harding, Sandra. (1987). Feminism and Methodology. Bloomington: Indiana University Press.

Harding, Sandra. (1991). Whose Science? Whose Knowledge? Thinking from Women's Lives. Ithaca: Cornell University Press.

Harris, Paul G. and Siplon, Patricia. (eds). (2007). The Global Politics of AIDS. Boulder: Lynne Rienner.

Haward, Patricia. (2009). Looking Back: Tragedies of Uganda Women and Children 1970-2000. Kampala: Fountain Publishers.

Heckathorn, Douglas D., Broadhead, Robert S., Anthony, Denise L., Weakliem, David L. (1999). "AIDS and Social Networks: HIV Prevention through Network Mobilization" in Sociological Focus, Vol. 32, No. 2, Pp. 159-177.

Hunter, Mark. (2010). Love in the Time of AIDS: Inequality, Gender, and Rights in South Africa. Bloomington: Indiana University Press.

Lutnick, Alexandra and Cohan, Deborah. (2009). "Criminalization, legalization, or decriminalization of sex work: what female sex workers say in San Francisco, USA" in Reproductive Health Matters, Vol. 17, No. 31, Pp. 38-46.

Jewkes, Rachel K., Levin, Jonathan B., Loveday, A. Penn-Kekana. (2003). “Gender inequalities, intimate partner violence and HIV preventative practices: findings of a South African cross-sectional study" in Social Science \& Medicine, Vol. 56, Pp. 125134.

Kane, Stephanie and Mason, Theresa. (2001). "AIDS and Criminal Justice” in Annual Review of Anthropology, Vol. 30, Pp. 457-479.

Kamali, A., Carpenter, L. M., Whitworth, J. A. (2000). "Seven-year trends in HIV-1 infection rates and changes in sexual behaviour among adults in rural Uganda" in AIDS Vol., 14, Pp. 427-434.

Karim, Quarraisha A., Abdool-Karim, S., Soldan, K., Zondi, M. (1995). "Reducing the Risk of HIV Infection among South African Sex Workers: Socioeconomic and Gender Barriers” in American Journal of Public Health, Vol. 85, No. 11, Pp. 15211525.

Kohler, Hans-Peter, Behrman, Jere R., and Watkins, Susan. C. (2007). "Social Networks and HIV/AIDS Risk Perceptions” in Demography, Vol. 44, Issue 1, Pp. 1-33. 
Koster, Winny and Neema, Stella. (2009) “Addressing HIV and AIDS in Uganda CSO’s (Community Service Organizations): Applied Research, End Report” for Stop AIDS Now!

Kruks, Sonia. (2001). Retrieving Experience: Subjectivity and Recognition in Feminist Politics. Ithaca: Cornell University Press.

Kuhanen, Jan. (2008). “The Historiography of HIV and AIDS in Uganda” in History in Africa, Vol., 35, Pp. 301-325.

Kyomuhendo, Grace Bantebya and McIntosh, Marjorie Keniston. (2006). Women, Work, \& Domestic Virtue in Uganda 1900-2003. Oxford: James Currey.

Kyonkunzire, Betty. (2006). Is Criminalization of Commercial Sex Work in Uganda an Answer? A Case Study of Commercial Sex Workers in Kampala District. University of Zimbabwe: Harare.

Laquer, Thomas. (1990). Making Sex: Body and Gender from the Greeks to Freud. Cambridge: Harvard University Press.

Longhurst, Robyn. (2001). Bodies: Exploring fluid boundaries. New York: Routledge.

Lucas, Adetokunbo O. and Gilles, Herbert M. (2003). Short Textbook of Public Health Medicine for the Tropics Fourth Edition. London: Hodder Arnold.

Madison, D. Soyini. (2005). Critical Ethnography: Method, Ethics, and Performance. Thousand Oaks: Sage.

Maguire, Lambert. (1985). Understanding Social Networks. Beverly Hills: Sage Publications.

Maguire, Steve, Hardy, Cynthia, and Lawrence, Thomas B. (2004). "Institutional Entrepreneurship in Emerging Fields: HIV/AIDS Treatment Advocacy in Canada" in The Academy of Management Journal, Vol. 47, No. 5, Pp. 657-679.

Makgoba, M.W. (2000). "Ethics of AIDS research in a developing country: balancing power in disguise" from speech given at the plenary session of AIDS 2000, archives from International AIDS Society.

Mamdani, Mahmood. (1976). Politics and Class Formation in Uganda. New York: Monthly Review Press.

Marlow, Heather M., Shellenber, Kristen, and Yegon, Erick. (2014). “Abortion services for sex workers in Uganda: successful strategies in an urban clinic" in Culture, Health, and Sexuality, Vol. 16, No. 8, Pp. 931-943. 
Marmot, Michael. (2005). "Social determinants of health inequalities” in the Lancet, Vol. 365, Pp. 1099-1104.

Marshall, Wende Elizabeth. (2005). “Aids, race and the limits of science” in Social Science \& Medicine, Vol. 60, Pp. 2515-2525.

Mayaud, P. and Mabey, D. (2003). “Approaches to the control of sexually transmitted infections in developing countries: old problems and modern challenges” in Sexually Transmitted Infections, Vol. 80, Pp. 174-182.

Mbonye, Martin, Nakamanya, Sarah, Nalukenge, Winifred, King, Rachel, Vandepitte, Judith, and Seeley, Janet. (2012). "Gender inequity in the lives of women involved in sex work in Kampala, Uganda” in Journal of the International AIDS Society Vol., 15, Supplement 1, Pp. 1-9.

Mbonye, Martin, Nakamanya, Sarah, Nalukenge, Winifred, King, Rachel, Vandepitte, Judith, and Seeley, Janet. (2013). "It is like a tomato stall where someone can pick what he likes: structure and practices of female sex work in Kampala, Uganda” in BMC Public Health, Vol., 13, Pp. 1-9.

Mbulaiteye, S. M., Mahe, C., Whitworth, J. A. (2002). “Declining HIV-1 incidence and associated prevalence over 10 years in a rural population in south-west Uganda: A cohort study” in The Lancet, Vol., 360, Pp. 41- 46.

McClintock, Anne. (1995). Imperial Leather: Race, Gender, and Sexuality in the Colonial Conquest. New York: Routledge.

McDermott, Elizabeth. (2011). “The World some have won: Sexuality, class, and inequality” in Sexualities, Vol. 14, No. 1, Pp. 63-78.

McLeroy, Kenneth R., Norton, Barbara L., Kegler, Michelle C., Burdine, James N., and Sumaya, Ciro V. (2003). “Community-Based Interventions” in American Journal of Public Health, Vol. 93, No. 4, Pp. 529-533.

Migdal, Joel S. (1988). Strong Societies and Weak States: State-Society Relations and State Capabilities in the Third World. Princeton: Princeton University Press.

Mikell, Gwendolyn. (1997). African Feminism: The Politics of Survival in Sub-Saharan Africa. Philadelphia: University of Pennsylvania Press.

Mintz, Sidney. (1985). Sweetness and Power: The Place of Sugar in Modern History. New York: Penguin Books. 
Mitchell, J. Clyde. (1969). Social Networks in Urban Situations: Analyses of Personal Relationships in Central African Towns. Manchester: Manchester University Press.

Monforte, Antonella d'Arminio, Gonzalez, Lorena, Haberl, Annette, Sherr, Lorraine, Ssanyu-Sseruma, Winnie, Walmsley, and Sharon L. (2010). "Better mind the gap: addressing the shortage of HIV-positive women in clinical trials" in AIDS, Vol. 24, Pp. 1091-1094.

Moon, Katharine H.S. (1997). Sex Among Allies: Military Prostitution in US-Korean Relations. New York: Columbia University Press.

Moore, Erin V. (2014). "The Miniskirt Bill and the Scandal of Young Women in Urban Uganda" for the $113^{\text {th }}$ Annual Meeting of the American Anthropological Association.

Morris, M., Serwadda, D., Kretzschmar, M., Sewankambo, N., and Wawer, M. (1996). "Concurrent Partnerships and HIV Transmission in Uganda" during the International Conference of AIDS, 11:261 (Abstract no. Tu.D.473).

Morris, Martina and Kretzschmar. (1997). "Concurrent Partnerships and the spread of HIV” in AIDS, Vol. 11, No. 5, Pp. 641-648.

Morrison, J. Stephen and Summers, Todd. (2003). "United to Fight HIV/AIDS?” in The Washington Quarterly, Vol. 26, No. 4, Pp. 177-193.

Mosse, David. (2005). "Global Governance and the Ethnography of International Aid" Pp. 1-36 in Mosse, David and Lewis, David (eds). The Aid Effect: Giving and Governing in International Development. New York: Pluto Books.

Msimang, Sisonke. (2003). “HIV/AIDS, globalization and the international women's movement” in Gender and Development, Vol. 11, No. 1, Pp. 109-113.

Mugewa, Yasiin. (2011). "US Faults Uganda as HIV/Aids increases” in the Daily Monitor on Saturday, June 25, 2011.

Mulder, D. W., Nunn, A. J., Wagner, H. U., Kamali, A., Kengeya-Kayondo, J. F. (1994). "HIV-1 incidence and HIV-1-associated mortality in a rural Ugandan population cohort” in AIDS, Vol., 8, No., 1, Pp. 87-92.

Mulder D, Nunn A, Kamali. (1995).“Decreasing HIV-1 Sero- prevalence in young adults in a rural Ugandan cohort” in British Medical Journal, Vol., 311, Pp. 833- 836.

Mulumba, Deborah. (2010). Women Refugees in Uganda: Gender Relations, Livelihood Security, and Reproductive Health. Kampala: Fountain Publishers. 
Mugewa, Yasiin. (2011). “US faults Uganda as HIV/AIDS increases” from Daily Monitor posted on Saturday, 25 June 2011.

Mugyenyi, Peter. (2009). "Flat-line funding for PEPAR: a recipe for chaos" in The Lancet, Vol. 374, Pp. 292.

Munoz, J., Adedimeji, A., Alawode, O. (2010). “'They bring AIDS to us and say we give it to them': Socio-structual context of female sex workers' vulnerability to HIV infection in Ibadan Nigeria" in Journal of Social Aspects of HIV/AIDS, Vol. 7, No. 2, Pp. 52-61.

Murphy, Catherine. (2015). “Sex Workers' Rights are Human Rights” policy position from Amnesty International found at https://www.amnesty.org/en/latest/news/2015/08/sex-workers-rights-are-humanrights/ on 10 December 2015.

Musisi, Nakanyike B. (2001). “Gender and the Cultural Construction of 'Bad Women', in Wicked Women and the Reconfiguration of Gender in Africa. Ed. D. L. Hodgson and S. A. McCurdy. Portsmouth: Heinemann, Pp. 171-187

Nagot, N., Ouangre, A., Ouedraogo, A., Cartoux, M., Huygens, P., Defer, M. C., Zekiba, T., Meda, N., Van de Perre, P. (2002). "Spectrum of Commercial Sex Activity in Burkina Faso: Classification Model and Risk Exposure to HIV" in Journal of Acquired Immune Deficiency Syndrome, Vol. 29, Pp. 517-521.

Naples, Nancy. (2003). Feminism and Method: Ethnography, Discourse Analysis, and Activist Research. New York: Routledge.

Narayan, Kirin. (1993). "How Native is a "Native” Anthropologist” in American Anthropologist, Vol. 95, No. 3, Pp. 671-686.

Nattrass, Nicoli. (2004). The Moral Economy of AIDS in South Africa. Cambridge: Cambridge University Press.

Nattrass, Nicoli. (2006). "What Determines Cross-Country Access to Antiretroviral Treatment?” in Development Policy Review, Vol. 24, No. 3, Pp. 321-337.

Nencel, Lorraine. (2005). "Feeling Gender Speak: Intersubjectivity and Fieldwork Practice with Women Who Prostitute in Lima, Peru" in European Journal of Women's Studies, Vol. 12, No. 3, Pp. 345-361.

Nguyen, Vinh-Kim, Klot, Jennifer, Phillips, Alton, and Pirkle, Catherine. (2006). "Culture, HIV \& AIDS an annotated bibliography" prepared for the United Nations Educational, Scientific, and Cultural Organization (UNESCO). New York: Social Science Research Council. 
Norton, Barbara L., McLeroy, Kenneth R., Burdine, James N., Felix, Michael R., and Dorsey, Alicia, M. (2002). "Community Capacity: Concept, Theory, and Methods" in DiClemente, Ralph J., Crosby, Richard A., and Kegler, Michelle C. (eds). Emerging Theories in Health Promotion Practice and Research: Strategies for Improving Public Health. San Francisco: Jossey-Bass.

Ochs, Elinor and Capps, Lisa. (1996). "Narrating the Self” in Annual Review of Anthropology, Vol. 25, Pp. 19-43.

Ofcansky, Thomas P. (1996). Uganda: Tarnished Pearl of Africa. Boulder: Westview Press.

Oinas, Elina and Jungar, Katarina. (2008). “A luta continua! - South African HIV activism, embodiment and state politics” in Development Dialogue, Pp. 239-258.

Okanya, Andante. (2013). “Government Sued over Bad Condoms” in the New Vision from Tuesday, May 7, 2013.

O’Manique, Collen. (2004). “Global Neoliberalism and AIDS Policy: International Responses to Sub-Saharan Africa's Pandemic” in Studies in Political Economy, Vol. 73, Spring/Summer, Pp. 47-68.

Ortner, Sherry B. (1995). "Resistance and the Problem of Ethnographic Refusal” in Society for Comparative Study of Society and History, Vol. 37, No. 1, Pp. 173-193.

O’Sullivan. (1990). "Mapping: Lesbians, AIDS and Sexuality: An Interview with Cindy Patton” in Feminist Review, No. 34, Spring, Pp. 120-133.

Oyewumi, Oyronke. (1997). The Invention of Women: Making An African Sense of Western Gender Discourses. Minneapolis: University of Minnesota Press.

Padilla, Mark B. (2007). “Tourism and Tigueraje: The Structures of Love and Silence among Dominican Male Sex Workers” Pp. 38-69 in Padilla, Mark B., Hirsch, Jennifer S., Munoz-Laboy, Miguel, Sember, Robert E., and Parker, Richard G. (eds). Love and Globalization. Nashville: Vanderbilt University Press.

Panchanadeswaran, S., Johnson, S.C., Sivaram, S., Srikrishnan, A.K., Latkin, C., Bentley, M.E., $\quad$ Solomon, S., Go, V.F., Celentano, D. (2008). "Intimate Partner Violenceis as important as client violence in increasing street-based female sex workers' vulnerability to HIV in India” in The International Journal of Drug Policy, Vol. 19, Pp. 106-112.

Panter-Brick, Catherine. (2014). "Health, Risk, and Resilience: Interdisciplinary Concepts and Applications” in Annual Review of Anthropology Issue 43, Pp. 431-448 
Parker, Richard, Easton, Delia, Klein, Charles H. (2000). "Structural barriers and facilitators in HIV prevention: a review of international research" in AIDS, Vol. 14, Suppl. 1, Pp. S22-S32.

Parikh, Shanti. (2013). "Sex, lies and love letters: rethinking condoms and female agency in Uganda” in Agenda, Vol. 62, Pp. 12-20.

Parker, Richard. (2000). "Structural barriers and facilitators in HIV prevention: a review of international research” in AIDS, Vol. 14, (Suppl 1), Pp. S22-S32.

Parker, Richard. (2001). "Sexuality, Culture, and Power in HIV/AIDS Research” in Annual Review of Anthropology, Vol. 30, Pp. 163-179.

Parker, Richard. (2009). "Unintended consequences: evaluating the impact of HIV and AIDS on sexuality research and policy debates” in Artigo, Vol. 25, Suppl 2, Pp. S251-S258.

Parkhurst, Justin O. (2002). "The Ugandan success story? Evidence and claims of HIV-1 prevention” in The Lancet, Vol. 360, Pp. 78-80.

Parkhurst, Justin O. (2012). "Framing, ideology and evidence: Uganda's HIV success and the development of PEPFAR's 'ABC' policy for HIV prevention” in Evidence and Policy, Vol. 8, No. 1, Pp. 17-36.

Patterson, Amy. S. (ed.) (2005). The African State and the AIDS Crisis. Burlington: Ashgate.

Patton, Cindy. (1988). “AIDS: Lessons from the Gay Community” in Feminist Review, No. 30, Autumn, Pp. 105-111.

Patton, Cindy. (1990). Inventing AIDS. New York: Routledge.

Patton, Cindy. (2002). Globalizing AIDS. Minneapolis: University of Minnesota Press.

Patton, Cindy. (2007). "Bullets, balance, or both: medicalization in HIV treatment” in The Lancet, Vol. 369, Pp. 706-707.

PEPFAR Watch. (2011). Implications of U.S. Policy Restrictions for HIV Programs Aimed at Commercial Sex Workers. Washington: PEPFAR Watch Global AIDS Relief Monitor.

Pepin, Jacques. (2011). The Origins of AIDS. Cambridge: Cambridge University Press. 
Peters, Pauline E., Kambew, Daimon, and Walker, Peter A. (2010). "Contestations Over “Tradition” and "Culture” in a Time of AIDS” in Medical Anthropology, Vol. 29, No. 3, Pp. 278-302.

Peterson, John L. (1995). “AIDS-Related Risks and Same-Sex Behaviors Among African American Men” Pp. 85-104 in Herek, Gregory M. and Greene, Beverly (eds). AIDS, Identity, and Community: The HIV Epidemic and Lesbians and Gay Men. Thousand Oaks: Sage.

Peterson, V. Spike and Runyan, Anne Sisson. (1999). Global Gender Issues: Dilemmas in World Politics. Boulder: Westview Press

Peterson, V. Spike. (2003). A Critical Rewriting of Global Political Economy: Integrating Reproductive, Productive, and Virtual Economies. New York: Routledge.

Pisani, Elizabeth. (2008). The Wisdom of Whores: Bureaucrats, Brothels, and the Business of AIDS. London: GRANTA.

PlusNews Global. (2011). "Uganda: Desperately seeking condoms in the north” found at http://www.irinnews.org/report/91657/uganda-desperately-seeking-condoms-in-thenorth

PlusNews Global. (2011). “Uganda: Sex Workers pay the price for HIV prevention gaps” found http://www.irinnews.org/report/92664/uganda-sex-workers-pay-the-price-forhiv-prevention-gaps

PlusNews Global. (2012). "Kenya: Many sex workers are married, new report reveals” found at http://www.irinnews.org//report/95173/kenya-many-sex-workers-aremarried-new-report-reveals

Poku, Nana K. (2002). “The Global AIDS Fund: context and opportunity” in Third Quarterly, Vol. 23, No. 2, Pp. 283-298.

Poku, Nana K., Whiteside, Alan, and Sandkjaer, Bjorg. (eds). (2007). AIDS and Governance. Burlington: Ashgate.

Preda, Alex. (2005). AIDS, Rhetoric, and Medical Knowledge. Cambridge: Cambridge University Press.

Putnam, Robert D. (2000). Bowling Alone: The Collapse and Revival of American Community. New York: Simon \& Schuster Paperbacks.

Pyett, P.M. and Warr, D.J. (1997). "Vulnerability on the streets: female sex workers and HIV risk” in AIDS CARE, Vol. 9, No. 5, Pp. 539-547. 
Pyett, P.M. and Warr, D.J. (1999). "Women at risk in sex work: strategies for survival” in Journal of Sociology, Vol. 35, No. 2, Pp. 187-197.

Rabinow, Paul. (ed.). (1984). The Foucault Reader. New York: Pantheon Books.

Reed-Danahay, Deborah E. (ed.) (1997). Auto/Ethnography: Rewriting the Self and the Social. Oxford: Berg.

Rekart, Michael. (2005). “Sex work harm reduction” in The Lancet, Vol. 366, Pp. 21232134.

Relief Web. (2013). "Uganda: Condoms continue to confound Uganda” from IRIN NEWS found at http://www.irinnews.org/report/97573/analysis-condoms-continueto-confound-uganda

Remien, Robert and Rabkin, Judith. (1995). "Long-Term Survival with AIDS and the Role of Community” Pp. 169-186 in Herek, Gregory M. and Greene, Beverly (eds). AIDS, Identity, and Community: The HIV Epidemic and Lesbians and Gay Men. Thousand Oaks: Sage.

Republic of Uganda. (1950). "Chapter 120 of the Penal Code” found at http://opm.go.ug/assets/media/resources/290/PENAL\%20CODE\%20ACT.pdf

Republic of Uganda. (2010). "Health Sector Strategic Investment Plan: Promoting People’s Health to Enhance Socio-economic Development 2010/11-2014/15” for the Ministry of Health.

Republic of Uganda (2010). “National AIDS Policy 2010” for the Ministry of Health.

Republic of Uganda Ministry of Health. (2011). "National Condom Strategy” for the STD/AIDS Control Programme of the Ministry of Health.

Republic of Uganda. (2011). “National HIV Prevention Strategy 2011-2015” for the Uganda AIDS Commission.

Republic of Uganda. (2012). “National Strategic Plan for HIV\&AIDS 2011/12-2012/15 Revised” Report.

The Republic of Uganda. (2012). “Global AIDS Response Progress Report: Country Progress Report” for the Uganda AIDS Commission.

Republic of Uganda. (2013). “HIV/AIDS Country Progress Report” for UNAIDS. 
Rhodes, Tim. (2002). “The 'risk environment': a framework for understanding and reducing drug-related harm” in The International Journal of Drug Policy, Vol. 13, Pp. 85-94.

Rhodes, Tim, Singer, Merrill, Philippe Bourgois, Friedman, Samuel R., Strathdee, Steffanie A. (2005). "The social structural production of HIV risk among injecting drug users” in Social Science and Medicine Vol. 61, Pp. 1026-1044.

Richardson, Laurel. (2000). "Evaluating Ethnography” in Qualitative Inquiry, Vol. 6, No. 2, Pp. 253-255.

Richey, Lisa Ann. (2003). "HIV/AIDS in the Shadows of Reproductive Health Interventions” in Reproductive Health Matters, Vol. 11, No. 22, Pp. 30-35.

Richey, Lisa Ann. (2004). "From the Policies to the Clinics: The Reproductive Health Paradox in Post-Adjustment Health Care” in World Development, Vol. 32, No. 6, Pp. 923-940.

Riessman, Catherine Kohler. (2008). Narrative Methods for the Human Sciences. Boston: Sage.

Robertson, Claire and Berger, Iris. (eds.). (1986). Women and Class in Africa. New York: Africana Publishing Company.

Robinson, Jonathan and Yeh, Ethan. (2007). "Sex Work as a Response to Risk in Western Kenya” for the Department of Economics, Princeton Univesity.

Robinson J and Yeh E. (2011). "Transactional sex as a response to risk in Western Kenya”. American Economic Journal: Applied Econometrics. Vol., 3, No., 1, Pp. 3564.

Round Up. (2007). “HIV/AIDS” in Reproductive Health Matters, Vol. 15, Issue 29, Pp. 197-203.

Sanchez Meertens, Ariel. (2013). Letters from Batticaloa: TMVP's Emergence and the Transmission of Conflict in Eastern Sri Lanka. Utrecht: University of Utrecht.

Sayer, Andrew. (1984). Method in Social Science: A Realist Approach. New York: Routledge.

Scaccabarrozzi, Luis. (2005). "Sex Workers and HIV" in AIDS Community Research Initiative of America, Vol. 15, No. 1, Pp. 2-5. 
Schneider, Carmen Huckel. (2008). "Global public health and international relations: pressing issues - evolving governance” in Australian Journal of International Affairs, Vol. 62, No. 1, Pp. 94-106.

Schoepf, Brooke G. (2001). "International AIDS Research in Anthropology: Taking a Critical Perspective on the Crisis” in Annual Review of Anthropology, Vol. 30, Pp. 335-361.

Schper-Hughes, Nancy. (1987). “The Mindful Body: A Prolegomenon to Future Work in Medical Anthropology” in Medical Anthropology Quarterly, Vol. 1, No. 1, Pp. 6-41.

Scheper-Hughes, Nancy. (1992). Death Without Weeping: The Violence of Everyday Life in Brazil. Berkeley: University of California Press.

Scheper-Hughes, Nancy. (1995). "The Primacy of the Ethical: Propositions for a Militant Anthropology” in Current Anthropology, Vol. 36, No. 3, Pp. 409-440.

Scheper-Hughes, Nancy. (1996). "Small Wars and Invisible Genocides” in Social Science \& Medicine, Vol. 43, No. 5, Pp. 889-900.

Scheper-Hughes, Nancy. (2004). "Parts unknown: Undercover ethnography of the organs-trafficking underworld” in Ethnography, Vol. 5, No. 1, Pp. 29-73.

Scherz, China. (2014). Having People, Having Heart: Charity, Sustainable Development, and Problems of Dependence in Central Uganda. Chicago: Chicago University Press.

Scorgie, Fiona, Nakato, Harper, Eric, Richter, Marlise, Maseko, Sian, Nare, Prince, Smit, Jenni, and Chersich, Matthew. (2013). “We are despised in the hospitals': sex workers' experiences of accessing health care in four African countries” in Culture, Health \& Sexuality, Vol. 15, No. 4, Pp. 450-465.

Scott, John. (1988). “Trend Report: Social Network Analysis” in Sociology, Vol. 22, No. 1, Pp. 109-127.

Scott, John. (1991). Social Network Analysis: A Handbook. London: Sage.

Seckinelgin, Hakan. (2006). "Evidence-based Policy for HIV/AIDS Interventions: Questions of External Validity, or Relevance for Use” in Report on the Global AIDS Epidemic: A UNAIDS 10 th Anniversary Special Edition. Geneva: UNAIDS.

Seeley, Janet. (2014). HIV and East Africa: Thirty Years in the Shadow of an Epidemic. New York: Routledge.

Sentumbwe, Simon. (2010). Correlates of STD and HIV/AIDS Infections Among Sex Workers in Uganda: A Stratified Adjusted Analysis. Berlin: VDM. 
Setel, Philip W., Lewis, Milton, and Lyons, Maryinez. (1999). Histories of Sexually Transmitted Diseases and HIV/AIDS in Sub-Saharan Africa. London: Greenwood Press.

Shaffer, Ellen R., Waitzkin, Howard, Brenner, Joseph, and Jasso-Aguilar, Rebecca. (2005). "Ethics in Public Health Research" in American Journal of Public Health, Vol. 95, No. 1, Pp. 23-34.

Shafer, A. L., Biraro, S., Nakiyingi-Miiro, J., Kamali, A., Ssematimba, D., Ouma, J., Ojwiya, A., Hughes, P., Van der Paal, L., Whitworth, J., Opio, A., Grosskurth, H. (2008). "HIV prevalence and incidence are no longer falling in southwest Uganda: evidence from a rural population cohort 1989-2005” in AIDS, Vol. 22, Pp. 16411649.

Shannon, K., Thomas, K., Shari, A., Chettiar, J., Shovellar, J., Tyndall, M.W. (2007). "Social and structural violence and power relations in mitigating HIV risk of drugusing women in survival sex work” in Social Science \& Medicine, Vol. 66, Pp. 911921.

Shelton, James D. (2011). "Role of Concurrency in Generalized HIV Epidemics” in The Lancet, Vol. 378, Pp. 1843.

Shiripinda, Iris. (2012). Sex, HIV, and AIDS: Practices and ideas of Zimbabwean women on sexuality and prevention of infection. Nijmegen: Radbound University.

Silverman, Jay G. (2011). “Adolescent female sex workers: invisibility, violence, and HIV” in Archives of Disease in Childhood, Vol. 96, Pp. 478-481.

Sindig, Steven W. (2005). “Does 'CNN' (Condoms, Needles, and Negotiation) Work Better Than 'ABC' (Abstinence, Being Faithful and Condom Use) in Attacking the AIDS Epidemic?” in International Family Planning Perspectives, Vol. 31, No. 1, Pp. 38-40.

Singh, S., Darroch, J. E., and Bankole, A. (2002). The Role of Behavior Change in the Decline in HIV Prevalence in Uganda. New York: Alan Guttmacher Institute.

Sjoberg, Laura. (2006). Gender, Justice, and The Wars in Iraq: A Feminist Reformulation of Just War Theory. Lanham: Lexington Books.

Slaymaker, Emma and Zaba, Basia. (2003). "Measurement of Condom Use as a Risk Factor for HIV Infection” in Reproductive Health Matters, Vol. 11, No. 22, Pp. 174184. 
Smith, Daniel Jordan. (2004). "Youth, Sin and Sex in Nigeria: Christianity and HIV/AIDS-Related Beliefs and Behavior among Rural-Urban Migrants” in Culture, Health \& Sexuality, Vol. 6, No. 5, Pp. 425-437.

Smith, Kristen P. and Christakis, Nicholas A. (2008). "Social Networks and Health” in Annual Review of Sociology, Vol. 34, Pp. 405-418.

Smith, Linda Tuhiwai. (1999). Decolonizing Methodologies: Research and Indigenous Peoples. London: Zed Publishers.

Smits, Rosan and Cruz, Serena. (2011). "Increasing Security in DR Congo: GenderResponsive Strategies for Combating Sexual Violence” in Clingendael, Issue 7.

Sontag, Susan. (1990). Illness and Metaphor and AIDS and Its Metaphors. New York: Picador.

Ssemwanga, Deogratius, Ndembi, Nicaise, Lyagoba, Fred, Bukenya, Justine, Seeley, Janet, Vandepitte, Judith, Grosskurth, Heiner, and Kaleebu, Pontiano. (2012). "HIV Type 1 Subtype Distribution, Multiple Infections, Sexual Networks, and Partnership Histories in Female Sex Workers in Kampala, Uganda” in AIDS Research and Human Retroviruses. Vol., 28, No. 4, Pp. 357-365.

Ssemwanga, Deogratius, Ndembi, Nicaise, Lyagoba, Frederick, Magambo, Brian, Kapaata, Anne, Bukenya, Justine, Lubega, George W., Bertagnolio, Silvia, Vandepitte, Judith, Grosskurth, Heiner, and Kaleebu, Pontiano. (2012). "Transmitted Antiretroviral Drug Resistance Among Drug-Naïve Female Sex Workers with Recent Infection in Kampala, Uganda” in Clinical Infections Disease, Vol. 201, No. 54, (Suppl 4), Pp. S339-S342.

Stacey, Judith. (1988). “Can There Be a Feminist Ethnography?” in Women's Studies International Forum, Vol. 11, No. 1, Pp. 21-27.

Steiner, Markus J. and Cates, Willard. (2006). “Condoms and Sexually-Transmitted Infections” in the New England Journal of Medicine, Vol., 354, No., 25, Pp. 26422643.

Steen, Richard and Dallabetta, Gina. (2003). "Sexually Transmitted Infection Control with Sex Workers: Regular Screening and Presumptive Treatment Argument Efforts to Reduce Risk and Vulnerability” in Reproductive Health Matters, Vol. 11, No. 22, Pp. 74-90.

Sylvester, Christine. (1999). "Development Studies and postcolonial studies: disparate tales of the 'Third World'” in Third World Quarterly, Vol., 20, No., 4, Pp. 703-721. 
Szlezak, Nicole A., Bloom, Barry R., Jamison, Dean T., Keusch, Gerald T., Michaud, Catherine M., Moon, Suerie, and Clark, William C. (2010). "The Global Health System: Actors, Norms, and Expectations in Transition” in PLOS Medicine, Vol. 7, Issue 1, Pp. 1-4.

Tamale, Sylvia. (1999). When Hens Begin to Crow: Gender and Parliamentary Politics in Uganda. Boulder: Westview.

Tamale, Sylvia. (2011). "Paradoxes of Sex Work and Sexuality in Modern-Day Uganda” Pp. 145-173 in Tamale, Sylvia, (ed). African Sexualities: A Reader. Nairobi: Pambazuka Press.

Tamale, Sylvia. (2011). "Researching and theorizing sexualities in Africa” Pp. 11-36 in Tamale, Sylvia. (ed). African Sexualities: A Reader. Nairobi: Pambazuka Press.

Tanser, F., Barnighausen, T., Hund, L., Garnett, G.P., McGrath, N., Newell, M.L. (2011). "Effect of concurrent sexual partnerships on rate of new HIV infections in a high prevalence, rural South African population: a cohort study” in The Lancet, Vol. 378, Pp. 247-255.

Tansery, James and O’Riordan, Tim. (1999). “Cultural theory and risk: a review” in Health, Risk, and Society, Vol. 1, No. 1, Pp. 71-88.

Taylor, Julie J. (2007). “Assisting or compromising intervention? The concept of 'culture' in biomedical and social research on HIV/AIDS” in Social Science \& Medicine, Vol. 64, Pp. 965-975.

Thebaud, Annie. (1986). “Aid Games” in Review of African Political Economy, Vol. 13 No. 36, Pp. 43-49.

Thornton, Robert J. (2008). Unimagined Community: Sex, Networks, and AIDS in Uganda and South Africa. Berkeley: University of California Press.

Tickner, J. Ann. (2001). Gendering World Politics: Issues and Approaches in the PostCold War Era. New York: Columbia University Press.

Townsend, Loraine, Mathews, Catherine, and Zembe, Yanga. (2013). “A Systematic Review of Behavioral Interventions to Prevent HIV Infection and Transmission among Heterosexual, Adult Men in Low and Middle-Income Countries” in Prevention Science, Vol. 14, Pp. 88-105.

Treichler, Paula A. (1999). How to Have Theory in An Epidemic: Cultural Chronicles of AIDS. Durham: Duke University Press. 
Tripp, Aili Mari. (2000). Women \& Politics in Uganda. Madison: The University of Wisconsin Press.

Tripp, Aili Mari. (2001). "The Politics of Autonomy and Cooptation in Africa: The Case of the Ugandan Women's Movement" in The Journal of Modern African Studies, Vol. 39, No. 1, Pp. 101-128.

Tripp, Aili Mari. (2004). "The Changing Face of Authoritarianism in Africa: The Case of Uganda” in Africa Today, Vol. 50, No. 3, Pp. 3-25.

Tripp, Aili Mari. (2010). Musseveni’s Uganda: Paradoxes of Power in a Hybrid Regime. London: Lynne Rienner.

Twinomugisha, Ben Kiromba. (2012). Beyond 'Malaya' or Prostitute: Interrogating Sexual and Reproductive Health Rights of Young Female Sex Workers in the Context of HIV/AIDS in Uganda. Kampala: Human Rights Center.

United Nations Joint Program on AIDS (UNAIDS). (2000). Report on the Global AIDS Epidemic. Geneva.

UNAIDS. (2008). “Criminalization of HIV Transmission: Policy Brief”. Geneva.

UNAIDS. (2010). UNAIDS Report on the Global AIDS Epidemic. Geneva.

UNAIDS. (2010). Ugandan HIV Prevention Response and Modes of Transmission Analysis. Geneva.

United States President's Emergency Plan for AIDS Relief. (2007). “The Power of Partnerships”. Third Annual Report to Congress.

United States President's Emergency Plan for AIDS Relief. (2008). “The Power of Partnerships”. Fourth Annual Report to Congress.

Vandepitte, J., Bukenya, J., Weiss, H., Nakubulwa, S., Francis, S., Hughes, P., Hayes, R., Grosskurth, H., (2011). "HIV and Other Sexually Transmitted Infections in a Cohort of Women Involved in High-Risk Sexual Behavior in Kampala, Uganda" in Sexually Transmitted Diseases, Vol. 38, No. 4, Pp. 316-323.

Verheijen, Janneke. (2011). “Complexities of the 'transactional sex’ model: Nonproviding men, self-providing women, and HIV risk in rural Malawi in the Annals of Anthropological Practice, Vol. 35, No. 1, Pp. 116-131.

Verheijen, Janneke. (2013). Balancing men, morals, and money: Women's agency between HIV and security in a Malawi Village. Leiden: African Studies Center University of Leiden. 
Wallis, Daniel. (2005). "Heroin use hits poorest in Ugandan slums" found at http://beta.iol.co.za/news/africa/heroin-use-hits-poorest-in-ugandan-slums-237333

Weber, Cynthia. (1999). Faking It: U.S. Hegemony in a "Post-Phallic" Era. Minneapolis: University of Minnesota Press.

Wechsberg, W.M., Luseno, W.K., Lam, W.K. (2005). "Violence against substance abusing South African sex workers: intersection with culture and HIV risk" in AIDS Care, Vol. 17, Suppl. 1, Pp. S55-S64.

Weeden, Lisa. (2010). "Reflections on Ethnographic Work in Political Science” in Annual Review of Political Science, Vol. 13, Pp. 255-272.

Weitzer, Ronald. (2005). "New directions in research on prostitution" in Crime, Law, \& Social Change, Vol. 43, Pp. 211-235.

Wellman, Barry and Berkowitz, S.D. (1988). Social Structures: A Network Approach. Cambridge: Cambridge University Press.

White, Luise. (1990). The Comforts of Home: Prostitution in Colonial Nairobi. Chicago:University of Chicago Press.

Whitworth, Sandra. (1994). Feminism and International Relations. New York: St. Martin's Press.

Whyte, William Foote. (1993). Street Corner Society: The Social Structure of an Italian Slum. Fourth Edition. Chicago: University of Chicago Press.

Williams, Kate. (2008). "Social Networks and Social Capital: Rethinking Theory in Community Informatics" in The Journal of Community Informatics, Vol. 4, No. 3., Pp. 1-21.

Wiseman, Rosalind. (2009). Queen Bees and Wannabes: Helping Your Daughter Survive Cliques, Gossip, Boyfriends, and the New Realities of Girl World. New York: Three Rivers Press.

Wolf, Diane L. (1996). "Situating Feminist Dilemmas in Fieldwork” Pp. 1-55 in Wolf, Diane L. (ed). Feminist Dilemmas in Fieldwork. Boulder: Westview.

Wolf, Margery. (1992). A Thrice-Told Tale: Feminism, Postmodernism, and Ethnographic Responsibility. Stanford: Stanford University Press. 
Wolfers, I., Alexander, P., Ditmore, M., Cler-Cunningham, L., Christenson, C. (2001). "Violence, repression, and other health threats: sex workers at risk" in Research for Sex Work, Vol. 4, Pp. 1-26.

Wojcicki, Janet Maia and Malala, Josephine. (2001). “Condom use, power, and HIV/AIDS risk: sex-workers bargain for survival in Hillbrow/Joubert Park/Berea, Johannesburg” in Social Science \& Medicine, Vol. 53, Pp. 99-121.

Wood, Katherine and Jewkes, Rachel. (1997). "Violence, Rape, and Sexual Coercion: Everyday Love in a South African Township" in Gender and Development, Vol. 5, No. 2, Pp. 41-46.

World Health Organization (WHO). (2005). Toolkit for targeted HIV/AIDS prevention and care in sex work settings. Geneva: World Health Organization.

World Health Organization. (2009). Global Health Risks: Mortality and burden of disease attributable to selected major risks. Geneva: World Health Organization.

Worster, Donald. (1994). Nature's Economy: A History of Ecological Ideas, Second Edition. Cambridge: Cambridge University Press.

Wu, Grace and Zama, Muhammad H. (2012). "Low-cost tools for diagnosing and monitoring HIV infection in low-resource settings" Geneva: World Health Organization Bulletin found at http://www.who.int/bulletin/volumes/90/12/12102780/en/\#

Young, Iris Marion. (1990). Justice and the Politics of Difference. Princeton: Princeton University Press.

Young, Iris Marion. (1997). Intersecting Voices: Dilemmas of Gender, Political Philosophy, and Policy. Princeton: Princeton University Press.

Young, Rebecca M. and Meyer, Ilan H. (2005). "The Trouble with "MSM" and "WSW": Erasure of the Sexual-Minority Person in Public Health Discourse" in American Journal of Public Health, Vol. 95, No. 7, Pp. 1144-1149.

Zalwango, Flavia, Eriksson, Lina, Seeley, Janet, Nakamanya, Sarah, Vandepitte, Judith, and Grosskurth, Heiner. (2010). "Parenting and money-making: sex work and women’s choices in Urban Uganda” in Wagadu, Vol. 8, Pp. 71-92.

Zwillich, Todd. (2009). "Obama administration may flat-line funding for PEPFAR" in The Lancet, Vol. 373, Pp. 1325. 
VITA

\section{SERENA CRUZ}

2015 - Present

$2007-2015$

$2011-2014$

2013
Research Fellow

The Conflict Research Unit (CRU) of the Netherlands

Institute of International Relations 'Clingendael'

The Hague, Netherlands

Visiting Scholar

IS Academy Education and International Development /

Research Consortium Education and Peace-building

University of Amsterdam, AISSR - Amsterdam Institute for

Social Science Research

Amsterdam, Netherlands

Ph.D. Candidate of International Relations

Department of Politics and International Relations in the School of International and Public Affairs

Florida International University

Miami, Florida

Recipient of the Shepard Broad Foundation Fellowship and the Doctoral Evidence Acquisition Fellowship

University Graduate School, Florida International University

Lecturer - Department of International Relations

Florida International University

Masters of International Studies

Department of International Relations in the School of International and Public Affairs

Florida International University

Graduate Assistant - Department of International Relations

Florida International University

Visiting Researcher

The International Institute of Social Studies (ISS) of Erasmus University

The Hague, Netherlands

Visiting Lecturer - Women and Gender Studies Faculty

Makerere University

Kampala, Uganda 
$2000-2004$

2001
Bachelors of Political Science

Department of Political Science in the College of Liberal Arts Florida Atlantic University

Boca Raton, Florida

Everett Public Service Fellow

Office of Gender-Based-Violence and Hate Crimes

NOW Legal Defense and Education Fund (Legal Momentum)

Washington D.C.

\section{PUBLICATIONS AND PRESENTATIONS}

Co-author of the paper "What Has Sexual Violence got to do with the Economy? The case of the DRC” in the Women, Peace \& Security: Business as Usual published by Women Peacemakers Program.

Co-author of the paper "Violence, Gender and Forced Labor in Eastern DRC: The Consequences of Theorizing” presented September 2014 at the African Studies Association of the United Kingdom annual conference.

Co-author of the paper "Imagining Sustainability in a Context of Sexual Violence and Forced Labor in Eastern DRC” presented 2 July at the Women’s Leadership, Peace and Sustainable Livelihoods in the DRC and Region conference, Galway, Ireland.

Co-author of the book chapter "The Continuities of Violence in Congo: Peace and Justice in light of the Legacies of Hammarskjold and Lumumba”, in Peace Diplomacy, Global Justice and International Agency: Rethinking Human Security and Ethics in the Spirit of Dag Hammarskjold (forthcoming publication: Cambridge University Press)

Co-author of the Policy Brief "Increasing Security in DR Congo: Gender-Responsive Strategies for Combating Sexual Violence” (2011) published by the Conflict Research Unit (CRU), 'Clingendael'

Author of the working paper "The Added-Value of the interplay between state and nonstate actors in the DRC and the Netherlands" for the Peace, Security, and Development Network (PSDN)

Contributing author to the article "Men, Masculinities and the Security-Development Nexus” published by the Clingendael Conflict Research Unit (CRU)

Paper presentation “'The Hard to Reach' in International Relations: Challenges of Ethnographically Inspired Policy Relevant Research” University of Paris conference Uganda and the World, May 2013. 